\title{
The merit of ipsative measurement : second thoughts and minute doubts
}

Citation for published version (APA):

de Vries, A. L. M. (2006). The merit of ipsative measurement : second thoughts and minute doubts.

[Doctoral Thesis, Maastricht University]. PrintPartners Ipsikamp. https://doi.org/10.26481/dis.20061201av

Document status and date:

Published: 01/01/2006

DOI:

10.26481/dis.20061201av

Document Version:

Publisher's PDF, also known as Version of record

\section{Please check the document version of this publication:}

- A submitted manuscript is the version of the article upon submission and before peer-review. There can be important differences between the submitted version and the official published version of record.

People interested in the research are advised to contact the author for the final version of the publication, or visit the DOI to the publisher's website.

- The final author version and the galley proof are versions of the publication after peer review.

- The final published version features the final layout of the paper including the volume, issue and page numbers.

Link to publication

\footnotetext{
General rights rights.

- You may freely distribute the URL identifying the publication in the public portal. please follow below link for the End User Agreement:

www.umlib.nl/taverne-license

Take down policy

If you believe that this document breaches copyright please contact us at:

repository@maastrichtuniversity.nl

providing details and we will investigate your claim.
}

Copyright and moral rights for the publications made accessible in the public portal are retained by the authors and/or other copyright owners and it is a condition of accessing publications that users recognise and abide by the legal requirements associated with these

- Users may download and print one copy of any publication from the public portal for the purpose of private study or research.

- You may not further distribute the material or use it for any profit-making activity or commercial gain

If the publication is distributed under the terms of Article $25 \mathrm{fa}$ of the Dutch Copyright Act, indicated by the "Taverne" license above, 


\title{
The merit of ipsative measurement
}

Second thoughts and minute doubts

\author{
Anton L.M. de Vries
}


The merit of ipsative measurement: Second thoughts and minute doubts

/ Anton L.M. de Vries

pp. xviii-238, $24 \mathrm{~cm}$.

PhD Thesis, Maastricht University

Includes bibliographical references and propositions on a separate flyleaf.

ISBN-10: $\quad 90-9021250-7$

ISBN-13: $978-90-9021250-0$

1. Forced choice, testing method. 2. Test standardization. 3. Response bias.

4. Social desirability. 5. Profiles, measurement. 6. Preference measures.

7. Edwards Personal Preference Schedule.

Title in Dutch: De waarde van ipsatief meten: Afwegingen en reserves

Printed by PrintPartners Ipskamp, Enschede

Copyright (C) 2006 by Anton L.M. de Vries, Amsterdam

All rights reserved. No part of this publication may be reproduced or transmitted in any form or by any means, electronic or mechanical, including photocopying, recording, or by any information storage and retrieval system, without permission in writing from the author.

Cover design by Peter Gerritsen (http://www.plasticpeter.com). 


\title{
The merit of ipsative measurement Second thoughts and minute doubts
}

\author{
PROEFSCHRIFT \\ ter verkrijging van de graad van doctor aan de Universiteit Maastricht, \\ op gezag van de Rector Magnificus, prof. mr. G.P.M.F. Mols, \\ volgens het besluit van het College van Decanen, \\ in het openbaar te verdedigen op
}

vrijdag 1 december 2006 om 12.00 uur

door

Anton Leonard Monte de Vries 
Promotores:

Prof. dr. J. van Heerden

Prof. dr. G.J. Mellenbergh Universiteit van Ansterdam

Beoordelingscommissie:

Prof. dr. G.J. Kok voorzitter

Dr. A. Evers Universiteit van Amsterdam

Prof. dr. W.K.B. Hofstec Rijksuniversiteit Groningen

Prof. dr. R..A. Roe

The data used in the research reported in chapters 4 to 8 inclusive were collected by participating in the Test Week, organized by drs. H.C.M. Vorst at the Methodology Division of the Department of Psychology, Faculty of Social and Behavioural Sciences, University of Amsterdam. 


\section{Dankwoord}

Harrie Vorst heeft me geleerd dat het ontwikkelen van een psychologisch meetinstrument één van de laatste ambachten is. Om een goed meetinstrument te maken moet iemand thuis zijn in zowel de psychologische meettheorie, als de theoretische onderbouwing van het te meten begrip. Psychologische meetinstrumenten bestaan er dan ook in grofweg twee soorten. De bedenker is ofwel een praktisch ingesteld methodoloog, die zich in de theorie van het meetonderwerp heeft verdiept. Ofwel de samensteller is een inhoudsdeskundige die zich op meettheoretisch vlak verder heeft ontwikkeld. Nergens gaapt de kloof wijder tussen deze twee stamoudsten dan op het gebied van de ipsatieve meetmethode voor het meten van interesses. Volgens de methodologen is deze meetmethode, die de proefpersoon vraagt om een keuze te maken tussen interessegebieden, overduidelijk inferieur. Inhoudsexperts daarentegen omhelzen de methode als de enig juiste. Zij verfoeien de vrijblijvendheid van de benadering om de respondent per interessegebied apart te laten aangeven in welke mate die van toepassing is.

Vanaf ongeveer 1970 heeft de ipsatieve meetmethode voor de methodologen afgedaan. Er kleefden te veel meettechnische bezwaren aan de methode, zonder dat er ooit een voordeel van gebleken was. Ze vonden het sop de kool niet waard en zwegen de methode vervolgens dood. De inhoudsexperts bleven echter volharden in het toepassen van de ipsatieve meetmethode, vaak zonder rekening te houden met de impliciet strenge aannames waarop deze benadering berust. Als zodanig geraakte ipsatief meten in steeds verdere staat van ontbinding, zonder echt te overlijden. Het lijk bonkte derhalve harder en harder op zijn kastdeur. Een geluid dat ook in het onderwijs, door een gebrek aan eenduidige literatuur, met elke klop luider werd.

De enig juiste benadering voor een dergelijke verzameling botten is in mijn ogen dan ook het soort methodologische archeologie dat in dit proefschrift bedreven wordt. Nu heb ik niet de illusie dat de gevonden resultaten een definitief antwoord geven op de geschiktheid van de ipsatieve meetmethode. Wel hoop ik dat het een en ander scherper voor het voetlicht is komen te staan, waardoor een beter geïnformeerde keuze om wel of niet ipsatief te meten mogelijk is geworden. 
Daarbij heb ik de hulp gehad van velen die ik op deze plek gratg wil bedanken. En dan richt ik me op de eerste plaats tot mijn drie bogeleiders: Jajp) van Heerden. Don Mellenbergh en Harrie Vorst. Mijn productiviteit hedt altijel achter gelegen op jullie leshonger. die zich in het laatste jaar manifesteerde in vrijwel wekelijkse bijecnkonsten. Maar jullie zijn nict alleen verantwoordelijk geweest voor de begeleiding van mij tijkens mijn promotic onder\%oek. Jullie hebben alledrie cen beslissende rol gespeeld in mijn academische vorning.

Voor het derde studiejarr psychologie moest ik een afstudecrichting kiczen. maar ik was besluiteloos. Ik zal nooit de awond in de kroog vergeten. Harrie, toen jij als mijn begeleider van het Onderzoekspracticnu me crop wees dat je geen studierichting moet kiezen warvan je de kennis ook wol op eigen houtje kan verwerven. Een voorwarde die methodenleer in ieder geval nict nitshit. Ik blik met veel plezier terng op alle hoe-gaat-het gesprekjes, watrin je me trakteerde op cen kopje koffic en de stand wan zaken doomam, zonder ooit een socialal wenselijk antwoord te verlangen. Jij was het ook die de vruchtbare suggestie deed om ipsatief meten als promotie onderwerp te kiezen. En ik kan slechts gissen naar alle dingen die je geruisloos voor me hebt geregeld om alle data voor dit onderzocksproject te verzamelen.

Naast resultaten van empirische aard. bevat dit proefschrift ook de resultaten van een meer argumentaticve benadering. De benodigde mentale wendbaarheid heb ik voor een belangrijk deel an jon. Jaap, te danken. De cursus Grondslagen van de Psychologie tegen de achtergrond van het geest-lichaam debat tussen Demnett en Searle, heeft mijn wetenschappelijk denkkader doorslaggevend verruind. Met veel plezier schreef ik onder jouw begeleiding mijn afstudecrscriptie over de betekenis van het neurofysiologische onderzoek van Libet voor het interactionisme. Ik prijs me gelukkig dat jij me achterna gereisd bent naar Maastricht. Een toevallige onstandigheid, die zich in de relatic meester gezel meestal omgekeerd voordoet. Maar ja, jij hebt je nooit laten voorstaan op je status als meerdere op grond van de professionele hiërarchie. Wars als jij bent van een argumentatio ad hominem of ex cathedra. De onverwachte uitnodiging om mee te eten met je gezin, koester ik als een warme herimnering.

Don, jij bent voor mij het boegbeeld van de psychometrie in Nederland. Het centrale thema in jouw werk is voor mij je aandacht voor de relatie tussen het theoretische model en de praktijk. Een thema waarvan de elegantie me voor het eerst duidelijk werd tijdens jouw cursus Psychometrie. En die signatum is ook in dit proefschrift terug te vinden. Onder jouw begeleiding deed ik mijn afstudeeronderzoek naar de detectie van vraagonzuiverheid met het graded item response model van Samejima. Destijds cn ook nu had jouw analytische blik altijd oog voor mijn methodologische veronachtzaamheden. Je hebt me behoed voor vele misstappen, die je altijd introduceerde met: 'Klopt dat wel?' of. vaak nog verwoestender: 'Dat snap ik niet...' Waarna ik tijdens mijn uitleg, verstrikt raakte in mijn eigen misvattingen. Ik heb veel te danken aan jouw erudiete kemnis van het vakgebied en je aandacht voor mijn zoektocht.

Ook heb ik veel te danken aan mijn twee paranimfen Paul Oosterveld en 
Andra Waagmeester. Jullie beider vriendschap is voor mij heel belangrijk. Paul, jij bent voor mij cen geestverwant op het gebied van de psychometrie. Ik heb me valk aan jon kumnen spiegelen en je hebt me altijd weer kunnen motiveren voor het onderzocksproject, vooral op momenten dat het tegen zat. Jij hebt me ook gewezen op de mogelijkheid om me in Maastricht verder te ontplooien. Andra, ondanks mijn neiging tot wereldvreemdheid, hielpen de door jou georganiseerde nitstapjes me een open oog te houden voor de wereld om mij heen. Jouw interesse voor gadgets voorzag in mijn hardware bchoeften. Zo kreeg ik van jou een laptop en een memory stick, zodat veel van dit procfschrift in de trein tot stand heeft kumnen komen.

De data voor dit onderzoek is verzameld in de testweek. Ooit heb ik zelf als cerstcjaars student psychologic -..- de naïeve proefpersoon bij uitstek - vijftien uur (in vijf sessies van drie uur) besteed aan het invullen van allerlei tests en vragenlijstjes. Destijels stond ik nogal geringschattend tegenover deze in mijn ogen 'idiote' praktijk. Nooit had ik kumnen bevroeden dat ik mijn eigen promotie onderzoek aan deze geolicde machine te danken zon hebben. Daarom mijn oprechte dank aan alle radertjes: de eerstejaars psychologie studenten die met hun inspanningen mij de gegevens geleverd hebben, waarop dit onderzoek gebaseerd is. De olie in de machine word gevormd door drie testweek coördinatoren. Ze hebben me met raad en chad bijgestaan en ver voorbij het passeren van de deadlines nog achter de broek aangezeten. Jelte Wicherts, Suzanne Kats, en Kim de Crom, ook jullie mijn dank voor jullic essentiële bijdrage aan dit onderzock.

Ineke van Osch, jij was voor mij cen belangrijk aanspreekpunt voor de afdeling Methodologie in Amsterdam. In de aanloop naar de data verzameling heb jij op beslissende momenten mijn achterstand om de vragenlijsten digitaal aan te leveren weer goed weten te maken. Ook was het nooit een probleem om de vele versies van de hoofdstukken voor mij uit te printen. Ik dank je voor je warmte en hartelijkheid waarmee je me altijd hielp. Jan Hoogenboom, jij hebt alle cirkels, streepjes en kruisjes op de vele vragenlijsten ingevoerd in voor mij analyseerbare databestanden. Hartelijk dank voor zowel je snelheid als nauwkeurigheid in deze.

Arne Evers, dank voor je hulp bij mijn eerste schreden op het gebied van ipsatief meten en je belangstelling gedurende de voortgang van het project. Wouter Lucassen. jij bedankt voor het belangeloos beschikbaar stellen van de broncode van je scoringsprogramma voor de BIT. Personen die als een klankbord voor me hebben gefungeerd zijn mijn kamergenoten Alex Sack on (iets langer geleden) Hanneke van Mier, mijn 'buren' Vincent van de Ven en Rob de Vries, en op iets meer afstand Andries van der Ark, Hester Breman, Michael Capalbo, Manuela Heins, David Hessen, en Lourens Waldorp. Mijn hartelijke dank voor jullie interesse en stcun.

Gerjo Kok en Bernadette Jansma, jullie dank ik voor het grote vertrouwen in mij dat ik voor mijn promotie onderzoek mijn eigen route mocht kiezen. Annemie Jeukens en Riny Bodifée, ik dank jullie beiden voor jullie hulp bij de vele regelklussen. Petra Hurks, Sven Stapert, Kim Kuypers, en Marleen Wingen: bedankt voor alle steun wammeer door mijn onderzoek mijn onderwijsverplichting 
voor met name het blok Psychodiagnostick onder druk kwan te staan. Robert van Doorn, ik dank je voor het programmeren van de besturing voor het schrijftablet. Dat is gebruikt on de antwoorden op een onderzock met en ipsatieve visual analogue scale (VAS) in te voeren. Helaas is het niet in dit proefschrift opgenomen; het wacht nog op een grondige analyse...

Peter Gerritsen, je artistieke ontwikkeling heb ik altijd met veel belangstelling gevolgd. Jouw creaties vind ik iedere keer opnicuw verrassend expressicf en boeiend. Ik was heel verheugd dat je de omslag van mijn proefschrift wilde ontwerpen. En met welk een schitterend resultant!

Lieve Ans en Frits, tenslotte dank ik jullie voor jullie onvoorwaardelijke liefde, steun, en geloof in mij. Af en toe was het loodzwaar. Maar jullie voorbeeld om niet op te geven was $\mathrm{cn}$ is voor mij een grote bron van inspiratie.

Anton de Vries

Amsterdam, 15 oktober 2006 


\section{Contents}

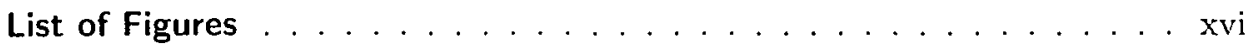

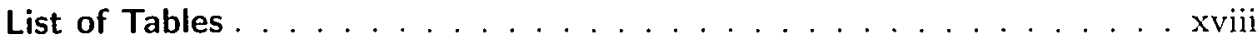

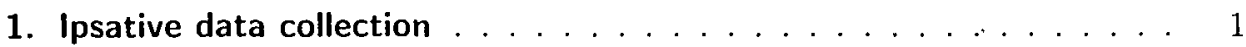

1.1 The early beginnings of the forced-choice item format $\ldots \ldots \ldots 3$

1.1.1 The WD AGO Form $67-1 \ldots \ldots \ldots \ldots$

1.1.2 The Jurgensen Classification Inventory . . . . . . . . . . 6

1.2 The three flavours of the forced-choice item format $\ldots \ldots \ldots$

1.2.1 The matched unidimensional compound item . . . . . . 9

1.2.2 The matched indeterminate compound item . . . . . . . 10

1.2.3 The matched multidimensional compound item . . . . . . 11

1.2 .4 Conclusion . . . . . . . . . . . . . . . 12

1.3 The vector nature of a compound item response . . . . . . . 12

1.3.1 The vector nature of the $\mathrm{MCI}$ response $\ldots \ldots \ldots \ldots 12$

1.3.2 The vector nature of the UCI response . . . . . . . . 14

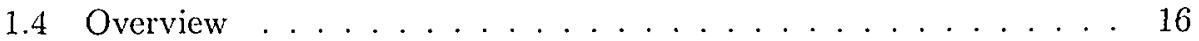

2. Methods to derive a unit of measurement . . . . . . . . . . 19

2.1 The levels of measurement . . . . . . . . . . . . . . . 19

2.2 Measuring up to a standard . . . . . . . . . . . 22

2.2 .1 Instrument-referenced standardization . . . . . . . . . 23

2.2.2 Measurement-referenced standardization . . . . . . . . . 24

2.3 Procedures of standardization . . . . . . . . . . . 24

2.3.1 Standardization at the nominal measurement level . . . . 25

2.3.2 Standardization at the ordinal measurement level . . . . . 25

2.3.3 Standardization at the interval measurement level . . . . 26

2.3.4 Standardization at the ratio measurement level . . . . . . 29

2.4 Defining the set of reference measurements . . . . . . . 29 
2.4.1 Normative standardization ............. 30

2.4 .2 Ipsative standardization . . . . . . . . . . . . . . . . . . . . . . . . . . . .

2.4 .3 Iterative standardization . . . . . . . . . . . . . 40 40

2.4 .4 Combinations of standardization . . . . . . . . . . . 40 40

2.4.5 Sclf-inclusiveness in standarclization . . . . . . . . . . 42

2.5 The choice of a measurement unit . . . . . . . . . . . . . . . 43

2.5.1 Selection decision . . . . . . . . . . . . . . . . 44

2.5.2 Classification decision ................ . . 44

2.5.3 Placement decision ................ . . . 45

2.5.4 Mastery decision ................. . 45

3. A new typology of response tendencies . . . . . . . . . . . . . . . . . . 47

3.1 A typology of response tendencies . . . . . . . . . . . . . 47

3.1.1 Response consistency . . . . . . . . . . . . . . . . . 48

3.1 .2 Response style . . . . . . . . . . . . . . . . . . 49

3.1 .3 Response habit . . . . . . . . . . . . . . . . 53

3.1 .4 Response set . . . . . . . . . . . . . . . . 55

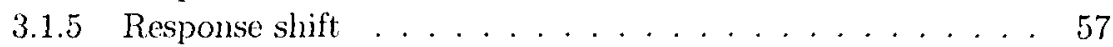

3.1.6 Response fashion ................... 58

3.1 .7 Response drift ..................... 59

3.1.8 Response whim ................... 61

3.2 Strategies to control for the diverse response tendencies . . . . . 62

3.2 .1 Response style .................. 62

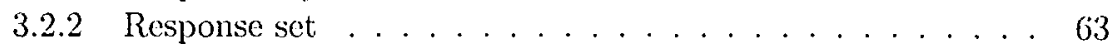

3.2.3 Response shift .................. . 65

3.3 Circumventing response tendencies by standardization . . . . . . 66

3.3.1 Comparative overview ............... 68

4. The benefit of the $\mathrm{MCl}$ for individual profile assessment . . . . . . . 69

4.1 The three between-formats comparative designs . . . . . . . . . . 69

4.1.1 Between-formats comparative reliability design . . . . . . 71

4.1.2 Between-formats comparative validity design . . . . . . 75

4.1.3 Between-formats comparative profile similarity design . . . 77

4.1.4 Overall conclusions of the literature review . . . . . . . 78

4.2 Hypotheses ........................... 79

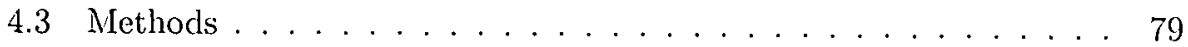

4.3.1 Instruments . . . . . . . . . . . . . . . . . 79

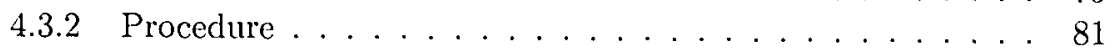

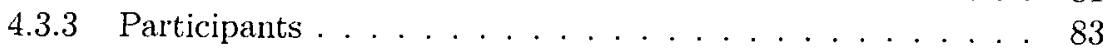

4.4 Results.......................... 83

4.4 .1 Consistency in the SOV-PC . . . . . . . . . . . . . 83

4.4.2 Between-formats comparative reliability design ...... . 84

4.4.3 Between-formats comparative profile similarity design . . . 87

4.5 Discussion . . . . . . . . . . . . . . . . . 89 
4.5.1 Consistency in the SOV-PC ............. 89

4.5.2 Between-formats comparative reliability design . . . . . 89

4.5.3 Between-formats comparative profile similarity design . . . 90

4.5 .4 Overview .......................... 91

5. The benefit of the $\mathrm{MCl}$ in feedback reports . . . . . . . . . . . . 93

5.1 Introduction . . . . . . . . . . . . . . . . . 93

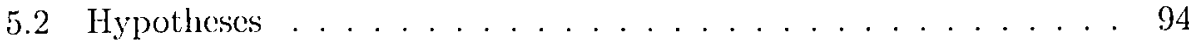

5.2 .1 Design ..................... 94

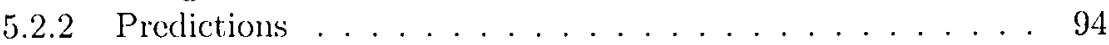

5.3 Methods ....................... . . . 95

5.3 .1 Materials .................... 95

5.3 .2 Score transformations . . . . . . . . . . . . . 96

5.3 .3 Procedure . . . . . . . . . . . . . . . . . . 100

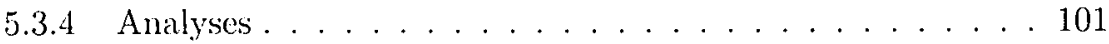

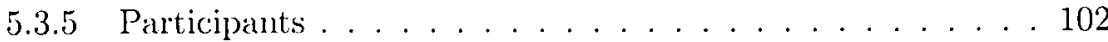

5.4 Results. . . . . . . . . . . . . . . . . . 102

5.4.1 Descriptive statistics of the VIT-MCI and VIT-SI . . . . . 102

5.4.2 Group differences in the within-subjects statistics . . . . . . 103

5.4 .3 Between formats profile comparison . . . . . . . . . . 105

5.4 Between formats reliability comparison . . . . . . . . . 106

5.4 .5 Recapitulation ..................... 107

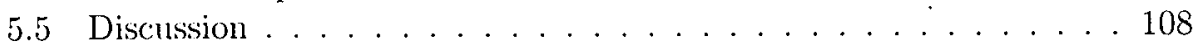

5.5.1 Descriptive statistics of the VIT-MCI and VIT-SI . . . . 108

5.5.2 Group differences in the within-subjects statistics . . . . . . 108

5.5.3 Between formats profile comparison .......... . 109

5.5.4 Between formats reliability comparison . . . . . . . . . . 111

5.5 .5 Final overview .................. 112

6. A new kind of ipsative measurement . . . . . . . . . . . . . 113

6.1 Ipsative data collection free from ipsative standardization . . . . . 113

6.1.1 Scoring the aligned MCI . . . . . . . . . . . . . . . . 114

6.1 .2 Scoring the opposed MCI . . . . . . . . . . . . 116

6.1.3 Combining the aligned with the opposed MCI . . . . . . 116

6.2 The control of response biases . . . . . . . . . . . . . 118

6.2.1 Response styles . . . . . . . . . . . . . . 119

6.2 .2 Stimulus order effects . . . . . . . . . . . . 120

6.3 Hypotheses . . . . . . . . . . . . . . . . 120

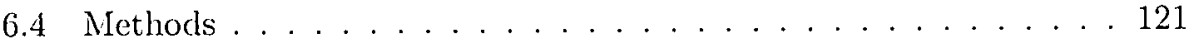

6.4 .1 Instruments . . . . . . . . . . . . . . . . . 121

6.4 .2 Participants . . . . . . . . . . . . . . 123

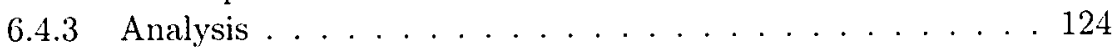

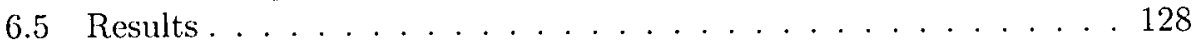

6.5.1 Ipsativity of the raw response scores . . . . . . . . . . 128 
6.5.2 Multitrait-multimethod analysis . . . . . . . . . . . . 129

6.5.3 Comparative susceptibility to response styles . . . . . . . . 131

6.6 Discussion . . . . . . . . . . . . . . . . . 132

6.6.1 Ipsativity of the raw response scores . . . . . . . . . . 132

6.6.2 Multitrait-multimethod analysis ............ 133

6.6.3 Comparative susceptibility to response styles . . . . . . . 133

6.6.4 Concluding remark . . . . . . . . . . . . . . . . 134

7. Matching stimuli to control for social desirability . . . . . . . . . 137

7.1 The problem of individual differences in social desirability . . . . . 138

7.1.1 The multidimensional interpretation of social desirability . 139

7.1.2 Individual differences in the stimulus desirability ratings . . 140

7.1.3 Individual differences in the achieved matching accuracy . . 142

7.1 .4 Conclusions ................... 145

7.2 Hypotheses ........................... 145

7.2.1 Research approach ................. 145

7.2 .2 Predictions ................... 147

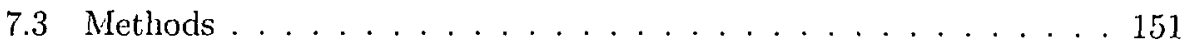

7.3 .1 Instruments . . . . . . . . . . . . . . 151

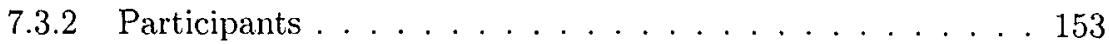

7.3 .3 Analysis ..................... 154

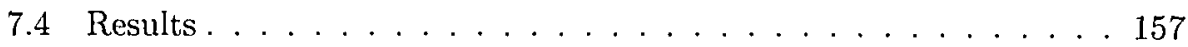

7.4.1 Order effects .................... 157

7.4.2 The longitudinal stability of social desirability . . . . . . 157

7.4.3 The multidimensional interpretation of social desirability . 158

7.4.4 Individual differences in the stimulus desirability ratings . . 161

7.4.5 Individual differences in the achieved matching accuracy . . 162

7.5 Discussion . . . . . . . . . . . . . . . . 166

7.5.1 Order effects . . . . . . . . . . . . . . . . 166

7.5.2 The effect of longitudinal changes in social desirability . . . 166

7.5.3 The multidimensional interpretation of social desirability . 167

7.5.4 Individual differences in the stimulus desirability ratings . . 168

7.5.5 Individual differences in the achieved matching accuracy . . 169

7.5 .6 Overview ...................... 171

8. The failure to control for social desirability with the matched $\mathrm{MCI} \quad .173$

8.1 The stability of stimulus desirability across item formats . . . . . . 174

8.2 Hofstee's investigations . . . . . . . . . . . . . . . . 175

8.2.1 Hypothesis ..................... 175

8.2.2 Favourableness judgements of singular stimuli . . . . . . 175

8.2.3 Favourableness choices of matched stimulus pairs . . . . . . 176

8.3 Supplementary analysis with the Hofstee (1967) stimuli . . . . . . 178

8.3.1 Hypothesis .................... 179

8.3 .2 Methods...................... 180 
8.3 .3 Results ...................... 180

8.3 .4 Conclusions . . . . . . . . . . . . . . . . 180

8.4 The invalidity of the additive scoring model . . . . . . . . . . . . 181

8.4.1 The additive scoring of MCIs matched for difficulty . . . . . 182

8.4.2 The additive scoring of MCIs matched for desirability . . . 184

8.4.3 The thickening of the plot . . . . . . . . . . . . 185

8.5 Discussion ...................... 187

Epilogue . . . . . . . . . . . . . . . . . . . 191

English summary . . . . . . . . . . . . . . . . . . 195

Nederlandse samenvatting . . . . . . . . . . . . . . . . . 199

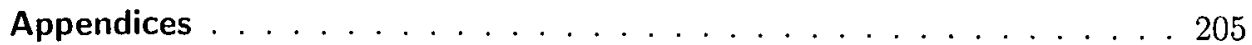

A.4 Appendices to Chapter 4 . . . . . . . . . . . . . . . 206

A.4.1 Supplementary results of the SOV-SI and SOV-MCI . . . 206

A.4.2 Dichotomising the item in the SOV Part I . . . . . . . . . . 207

A.4.3 Frequency polygons of the profile similarity coefficients . . . 208

A.5 Appendices to Chapter 5 . . . . . . . . . . . . . . . 210

A.5.1 The domain-referenced score transformation . . . . . . . . 210

A.5.2 The Vocational Interests Test-Feedback form (VIT-FB) . . 211

A.5.3 Example of a personal report shect of the VIT results . . . 212

A.5.4 Supplementary results of the VIT-MCI and VIT-SI . . . . . 213

A.5.5 Scatterplots of domain-referenced scores on VIT halves . . 214

A.5.6 Subject counts of preference on VIT-FB items 1 to 11 . . 218

A.6 Appendices to Chapter 6 . . . . . . . . . . . . . . . 219

A.6.1 Split-half correlation matrix . . . . . . . . . . . . . 219

A.6.2 Fitted MTMM structure models . . . . . . . . . . . 220

A.6.3 Scoring only opposed multidimensional compound items . . 224

A.7 Appendices to Chapter 7 . . . . . . . . . . . . . . . . 225

A.7.1 Order effects in the EPPS-SPD . . . . . . . . . . . 225

A.7.2 Differences in the within-subjects correlations . . . . . . 226

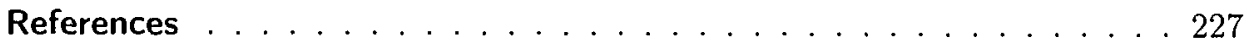




\section{List of Figures}

1.1 A typical item used for ipsative data collection . . . . . . . . 1

1.2 Percent less than excellent Army Captains on WD AGO Form 67 . 4

1.3 An item of Section IV. Job Proficiency of WD AGO Form 67-1 . . 5

1.4 Some items of the Jurgensen Classification Inventory . . . . . . 7

1.5 A typical singular item . . . . . . . . . . . . . 8

1.6 An item of the Edwards Personal Preference Schedule . . . . . . . 11

1.7 A two-dimensional compound item with a response matrix . . . . 13

1.8 The same compound item with the represented response vectors . . 13

1.9 An ipsative version of the same compound item . . . . . . . . 14

1.10 Item of the Beck Depression Inventory . . . . . . . . . . . . 15

1.11 Implied rating scale points of the Beck Depression Inventory item . 16

2.1 Overview of standardization methods . . . . . . . . 23

2.2 The default orientation of a data matrix . . . . . . . . . . 31

3.1 Decision tree for determining the type of response tendency . . . . 49

3.2 The effect of response styles on the response distribution . . . . . 51

4.1 Hypothetical response patterns of three subjects on three MCIs . 73

4.2 Example item of the Study of Values Part I . . . . . . . . . . 80

4.3 Instructions of the Study of Values Part I . . . . . . . . . . . 80

4.4 Example item of the Study of Values Part II . . . . . . . . . 81

5.1 Example item of the VIT-MCI . . . . . . . . . . . . 95

5.2 Example item of the VIT-SI . . . . . . . . . . . . . 96

5.3 VIT-MCI domain-referenced score transformation curve . . . . . . . 98

6.1 A schematic view of two aligned MCIs . . . . . . . . . . 115

6.2 A schematic view of two opposed MCIs . . . . . . . . . . . 117

6.3 A schematic view of two aligned and two opposed MCIs . . . . . . 119 
6.4 Example items of the BVAQ-SI . . . . . . . . . . . . . 122

6.5 Example items of the BVAQ-MCI . . . . . . . . . . . . 123

6.6 Frequency histogram of the score subtotal of the opposed MCIs . . 129

7.1 Two conditions of a stimulus pair matched for social desirability . . 143

7.2 Correlations of within-subjects correlations with $\mathrm{D} 2 \mathrm{Q}$ variables . . . 165

8.1 Two traits with their stimuli matched for difficulty in five MCIs . . 183

8.2 Two traits with their stimuli matched for desirability in four MCIs . 185

8.3 Five matched MCIs of two traits differently related to desirability . 187

8.4 Ceiling effect due to faking in the raw score profile of one subject . 188

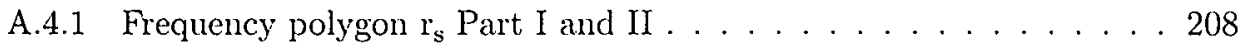

A.4.2 Frequency polygon $r_{s}$ Part I . . . . . . . . . . . . . . . . 209

A.4.3 Frequency polygon $r_{s}$ Part II . . . . . . . . . . . . . . . . 209 


\section{List of Tables}

1.1 Example deviation ipsative scores of Mr. Brown on the Big Five . . 3

2.1 Levels of measurement . . . . . . . . . . . . . . . . 21

2.2 The NSK 2004 results with normative standard scores . . . . . . . . 34

2.3 The NSK 2004 results with ipsative standard scores . . . . . . . . 39

3.1 Strengths and weaknesses of the various standardization methods . 68

4.1 Split-half reliability of the SOV-MCI and SOV-SI ipsative scores . . 84

4.2 Split-half reliability of the SOV-MCI and SOV-SI raw scores . . . . 85

4.3 Cronbach's $\alpha$ of the SOV-MCI and SOV-SI raw scores . . . . . . . . 86

4.4 Distribution of the rank correlations with profiles of the SOV-PC . 87

4.5 Profile similarity comparisons with Wilcoxon $\mathrm{Z}$ coefficients . . . . 89

5.1 Donine scale classes with associated labels and score ranges . . . . . 99

5.2 Ipsine classes with associated labels and score ranges . . . . . . . . 99

5.3 Research sample distribution over the conditions . . . . . . . . . . 103

5.4 Crosstables of overall profile preference vs. majority of preferences . 104

6.1 The derivation of the deviation ipsative scores of subjects A and B . 118

6.2 The differences between the paired stimuli in the BVAQ-MCI . . . . 122

6.3 Sample statistics of the variables . . . . . . . . . . . . . . 128

6.4 Split-half reliability coefficients . . . . . . . . . . . . . . . . . 129

$6.5 \quad$ Fit indices of the MTMM structure models . . . . . . . . . . . . 130

6.6 Comparisons between the hierarchically nested models . . . . . . . 131

6.7 Correlations between the ADRS indices and PRRB indices . . . . 132

7.1 Stimulus counts by mean social desirability mismatch ES . . . . . 158

7.2 Correlations of the D2Q and the within-subjects correlations . . . 158

7.3 The distribution of the stimulus standardized regression weights . . 159

7.4 Correlations of endorsements, desirability ratings, and beta weights 160 
7.5 Sample statistics of the within-subjects correlations . . . . . . . 163

7.6 Polychoric correlations between endorsement and desirability . . . . 163

8.1 Expected choices and variable scores on the items of Figure 8.1 . . 182

8.2 Expected choices and variable scores on the items of Figure 8.2 . . 184

8.3 Expected choices and variable scores on the items of Figure 8.3 . . 186

A.4.1 Descriptive statistics of the SOV-SI and the SOV-MCI . . . . . 206

A.4.2 Congruent correlations between the SOV-SI and the SOV-MCI . . 206

A.4.3 Distribution of the rank correlations with profiles of the SOV-PC . 207

A.4.4 Profile similarity comparisons with Wilcoxon Z coefficients . . . . 207

A.5.1 Split-half reliability coefficients of the VIT-MCI and VIT-SI . . . 213

A.5.2 Descriptive statistics of the domain-referenced VIT scores . . . . . 213

A.5.3 Student's t-tests of differences in within-subjects statistics . . . . 213

A.6.1 Correlated Traits-Correlated Methods model . . . . . . . . . . . . 220

A.6.2 Correlated Traits-Uncorrelated Methods model . . . . . . . . . . . . 221

A.6.3 Correlated Traits-Joint Methods model . . . . . . . . . . . . 222

A.6.4 Correlated Traits-No Methods model . . . . . . . . . . . . . . . 223

A.7.1 Two Hotelling's $T^{2}$ tests of order effects per EPPS-SPD version . . 225

A.7.2 Non-parametric tests of differences in within-subjects correlations . 226

A.7.3 Effect sizes of the differences in within-subjects correlations . . . . 226 


\title{
Ipsative data collection
}

\author{
What one "finds out" from one's data is a function of two things: \\ the information in the data and how this information is extracted. \\ What information the data contain depends on how it is collected. [...] \\ The method of analysis, then, defines what the information is and \\ may or may not endow this information with certain properties.
}

(Coombs, 1953, p. 471)

Ipsative measurement either refers to a data collection method or a data standardization method. Ipsative data collection requires a subject to compare stimuli that represent different traits. Figure 1.1 depicts a typical item used for ipsative data collection. Suppose the item is part of a questionnaire aimed at measuring personality according to the Big Five personality theory. Stimulus $\mathrm{A}$ is a sentence that represents the trait Extraversion. stimulus B is a sentence that represents the trait Conscientiousness, and stimulus $C$ is a sentence that represents the trait Openness. If a Mr. Brown selects stimulus A, then one point is added to his Extraversion variable score and none to his Conscientiousness variable score or Openness variable score. ${ }^{1}$ Should Mr. Brown choose stimulus B instead, then one point is awarded to his Conscientiousness variable score and none to his Ex-

\footnotetext{
${ }^{1}$ In psychology the value of a variable that represents a trait is commonly called a scale score. But a scale also refers to an instrument measuring a single trait. With ipsative measurement a trait cannot be quantified in isolation. Therefore the term 'variable score' is adopted here to indicate the measurement result that expresses the estimated amount of a single trait.
}

Figure 1.1: A typical item used for ipsative data collection

You are doing some pressing paperwork when friends call you to join them at the local pub. What do you do?
A I postpone my paperwork and meet my friends at the pub.
B I decline my friends' invitation and finish my paperwork.
C I suggest to go to the movies instead.

Note. Stimulus A represents the trait Extraversion, stimulus B the trait Conscientiousness, and stimulus $\mathrm{C}$ the trait Openness. 
traversion variable score or Opemness variable score. Finally, in case Mr. Brown opts for stimulus $\mathrm{C}$, one point is accredited to his Opcmness variable score and none to his Extraversion variable score or Conscicntionsness variable score. In effect, the item score is divided among the represented variables, depending upon the response. The term ipsative data collection thus informs the reader about the type of item format, the kind of required response behaviour, and the way in which the item responses are translated into variable scores.

On the other hand, ipsative standardization applies to variable scores after all item scores have been incorporated. Standardization is a score transformation procedure that aims to improve the interpretability of the variable scores. Generally a raw variable score ${ }^{2}$ in itself does not convey much information. It is not very informative to know that $\mathrm{Mr}$. Brown obtained a raw score of 12 representing the trait Extraversion. This figure lacks a unit of measurement. Standardization actually provides for such a measurement unit. If this unit is derived by comparing Mr. Brown's raw score on Extraversion with the raw scores that he himself obtained on other variables, it is called ipsative standardization. This is illustrated by the Big Five scores of Mr. Brown as depicted in Table 1.1. The first column lists the trait names. The second column shows his inaginary raw scores $X_{j}$. Mr. Brown's mean raw score $\bar{X}$ equals 15 . So, the deviation scores $x_{j}$ in the third column are obtained by subtracting his own mean score from his raw scores. The fourth column includes the squared deviation scores $x_{j}^{2}$, of which the mean represents his score variance. The last column displays his deviation ipsative scores. These are obtained by dividing his deviation scores from column three by his standard deviation, i.e. the square root of his score variance: $\sqrt{20 / 5}=\sqrt{4}=2$. Mr. Brown's deviation ipsative scores reveal that his personality profile agrees with the following variable order, running from most to least present: Emotional stability, Agreeableness, Openness, Conscientiousness, and Extraversion. Ipsative standardization thus indicates the relative contribution of each trait within a subject.

In ordinary psychometric parlance ipsative data collection and ipsative standardization are barely discriminated. This negligence may be rooted in the fact that both methods are closely related. So far, ipsative data collection has simply resulted in variable scores that are automatically standardized in an ipsative sense. The converse, however, is not true. Ipsative standardization is not fundamentally restricted to data that is collected ipsatively. In practice though, ipsative standardization is hardly applied voluntarily. Mainly, because ipsative standardization results in variable scores that are mutually related. This imparts the data with unfavourable statistical properties. So, in effect, it is never applied, unless it is already imposed by an ipsative data collection method. Still, for an accurate understanding of this thesis, it is imperative to separate both aspects. The current chapter will therefore focus on ipsative data collection methods. The next chapter will address the diverse standardization methods.

\footnotetext{
2 If a score is not standardized it will from now on be designated as a raw score.
} 
Table 1.1: Example deviation ipsative scores of Mr. Brown on the Big Five

\begin{tabular}{lcccc}
\hline Variable $j$ & Raw score & Deviation score & $\begin{array}{c}\text { Squared } \\
\text { deviation score }\end{array}$ & $\begin{array}{c}\text { Deviation } \\
\text { ipsative score }\end{array}$ \\
\hline & $X_{j}$ & $x_{j}=\left(X_{j}-\bar{X}\right)$ & $x_{j}^{2}$ & $\frac{x_{j}}{\sqrt{\left(\sum x_{j}^{2}\right) / 5}}$ \\
\hline Extraversion & 12 & -3 & 9 & -1.5 \\
Agreeableness & 16 & 1 & 1 & 0.5 \\
Conscientiousness & 14 & -1 & 1 & -0.5 \\
Emotional stability & 18 & 3 & 9 & 1.5 \\
Openness & 15 & 0 & 0 & 0.0 \\
\hline Sum & 75 & 0 & 20 & 0.0 \\
Mean & 15 & 0 & 4 & 0.0 \\
\hline
\end{tabular}

\subsection{The early beginnings of the forced-choice item format}

Ipsative data collection uses the forced-choice item format, of which a typical example was already shown in Figure 1.1. Today a forced-choice item is regarded an item that contains several stimuli. The respondent is required to select or order the presented stimuli. Originally, however, the term 'forced-choice' was reserved for items of which the stimuli had been matched for their social desirability. The social desirability of a stimulus is determined by a subject's tendency to endorse the stimulus in order to depict oneself more favourably. It is relatively unknown that the early instruments that used the forced-choice item format actually did not result in ipsative data. It was not until Edwards (1954) implemented the item format in his Personal Preference Schedule that the forced-choice approach resulted in ipsative data. His instrument provided the major impetus by which ipsative forced-choice measurement caught on. But first the early beginnings of the forced-choice item format are outlined in somewhat more detail.

Two separate developmental pathways mark the beginning of the forcedchoice item format. The item format owes its name and recognition to its implementation in WD AGO Form 67-1 of the U.S. Army Officer Efficiency Reporting System (Staff, 1946), which is in fact a rating scale. ${ }^{3}$ But, unknown to the responsible Personnel Research Section until after World War II, it was Jurgensen (1944) who reported about this item format first. He used it in a personality questionnaire: the Classification Inventory. Other early applications of the forced-choice item format are: 1) the Personal Inventory (Shipley, Gray, \& Newbert, 1946), a psychiatric screening questionnaire intended for navy recruits; 2) the Self-Description Blank (Newkirk, Brogden, \& Loeffler, 1950), aimed at predicting leadership qualities in cadets of the Reserve Officers' Training Corps; and

${ }^{3}$ The acronym WD AGO stands for War Department Adjutant's General Office. 
Figure 1.2: Percent less than excellent Army Captains on WD AGO Form 67

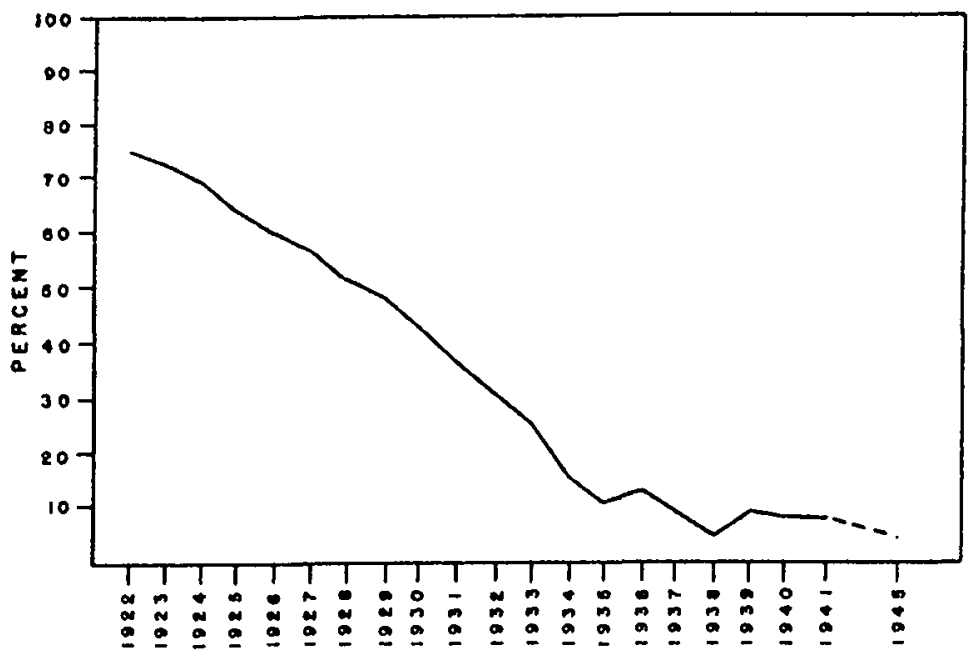

Note. No ratings for War Years 1942-1944; derived from Baier (1951, p. 430).

3) the Biographical Information Blank (in Baier, 1951). But these appear a direct corollary of the development of WD AGO Form 67-1. Consequently, only the first two instruments will be outlined in the next two sections.

\subsubsection{The WD AGO Form 67-1}

In part the forced-choice item format belongs to the legacy psychology owes to World War II. Already before the war the U.S. Army had recognized the importance of a valid and regular efficiency reporting system. This evaluation system made use of several rating scales, of which the information was collected with WD AGO Form 67. However, as Sisson (1948) explained:

"[W] hen the clouds of war rolled up in 1940 and it became evident that the Army needed to promote a rather large number of top-ranking offcers immediately to serve as generals of the rapidly mobilizing forces, it was suddenly discovered that the years of regular efficiency reporting had provided no basis for the important decisions that had to be made." (pp. 366-367)

What had gone wrong? Well, the rating scale utilized a 5-point rating scale using the labels: 'superior', 'excellent', 'very satisfactory', 'satisfactory', and 'unsatisfactory'. And what might be feared had happened. WD AGO Form 67 largely suffered from a ceiling effect in its response scale. During the interbellum 
period, as Sisson (1948) expressed it so eloquently: "[W]hat was supposed to be outstanding became typical; and to be labelled "satisfactory" was to be called intolerable inefficient" (p. 368). This devaluation of the original scale point labels is exemplified by the drastic decline in the percentage of all regular Army Captains receiving less than excellent ratings on WD AGO Form 67. Over the years from 1922 to 1945 this percentage had dropped from about $75 \%$ to less than $10 \%$ (Baier, 1951, see also Figure 1.2).

To counteract this degeneration of the response scale labels the forcedchoice method was applied. Although Paul Horst himself does not remember the occasion (Horst \& Wright, 1959), he is credited for being the true originator of the so-called 'forced-choice' item format, as he suggested to match the stimuli for social desirability during an APA meeting (Baier, 1951, Footnote 10). Robert J. Wherry, then present, picked up the idca and first developed the scaling procedure while working for the Civil Aeronautics Authority. When he changed position and became engaged in the Persomel Research Section he was responsible for its adoption in the Army Officer Efficiency Reporting System.

The sequel to WD AGO Form 67 was imaginatively called WD AGO Form 67-1. It contained two sections with forced-choice items. These items were presented as tetrads that consisted of two favourable stimuli and two unfavourable stimuli (see Figure 1.3). The accompanying instruction was "that the rater indicates which of the four is most characteristic, and which is least characteristic" (Sisson, 1948, p. 369). The strongest indicative of the two favourable stimuli adds credit, if checked as most characteristic. The strongest contra-indicative of the two unfavourable stimuli also adds credit, if it is selected as least characteristic instcad. As a result one item can yield zero to two points.

Sisson (1948) reported that at the semi-ammual efficiency report in June 1946 for all officers both Form 67 and Form 67-1 were used. For fifteen thousand of this same group additional criterion information was collected. The results demonstrated that the ratings produced by the new form were less biased by the rank of the rated officer. The distribution of scores obtained with Form 67-1 was less skewed than with Form 67. Form 67-1 had previously only been administered experimentally, without any consequences for the efficiency evaluation. In June 1946 however, Form 67-1 was administered as part of the actual evaluation. A comparison with the previous experimental administrations revealed that the average score had in fact increased. This leniency effect in the 'for keeps' setting

Figure 1.3: An item of Section IV. Job Proficiency of WD AGO Form 67-1
A.
Becomes dogmatic about his authority.
B.
Careless \& slipshod in attention to duty.
C. No one ever doubts his ability.
D. Well-grounded in all phases of Army life.

Note. The item is derived from Figure 1 of Sisson (1948), p. 371; the key is unknown. 
was nevertheless more marked with the old form than with the new (E. K. Taylor \& Wherry, 1951).

Still, the army did away with the forced-choice approach of Form 67-1. Bernardin and Beatty (1985) mentioned as reason for its demise the story "that West Point officers were not scoring any higher than the "six month wonders" from Officer Candidate School" (p. 97). But Cronbach's account seems closer to the truth. According to him the use of Form 67-1 was discontinued due to the resistance of the rating officers. They wanted to know how thcir reports would be interpreted and to have the freedom to give an entirely favourable impression of the man rated (Cronbach, 1970, p. 588). In other words, it appears that Form 67-1 invaded the rating authority of the senior officers.

\subsubsection{The Jurgensen Classification Inventory}

Earlier than the previous group Jurgensen (1944) applied a similar procedure in the Jurgensen Classification Inventory. This personality questionnaire was aimed for industrial purposes. Jurgensen therefore adopted the following four principles:

1. The questionnaire should be hard to "fake".

2. The items must allow every applicant to select an answer, without using a "don't know" response alternative.

3. The test should be scored and validated on specific jobs rather than traits.

4. The scoring and validation sample should be representative for the target population.

The first two principles made him decide to develop items that require the respondent to compare two or three stimuli. His original list included 559 stimuli. So he first asked the respondent to rank order 170 groups of five stimuli. From each group of rankings he inferred the individual response preferences on the ten dyads and the ten triads that can be derived from these five ranked stimuli. ${ }^{4}$ Only those items were eligible for inclusion, if the between-subjects average preference was roughly the same; combinations in which one stimulus was preferred by more than $75 \%$ of the subjects were excluded. Jurgensen also computed the difference between the original rank numbers of the stimuli within each subject. The average of this within-subjects difference should be large. Items with stimuli that were close in rank number were excluded.

The first selection criterion was regarded to warrant the equality in social desirability between the included stimuli. The second selection criterion was thought to secure the discriminative power of the included stimuli. Otherwise, an item would merely contain near synonyms. The resulting item pool thus contained stimuli that were roughly equally preferred within a group, but distinctly

$$
\left(\begin{array}{l}
5 \\
2
\end{array}\right)=\left(\begin{array}{l}
5 \\
3
\end{array}\right)=\frac{5 !}{2 ! 3 !}=\frac{5 \times 4}{2 \times 1}=10
$$


Figure 1.4: Some items of the Jurgensen Classification Inventory

\begin{tabular}{lll} 
B N W & Acquire tuberculosis. \\
B N W & Acquire heart trouble. \\
B N W & Lose your eyesight. \\
B N W & Be calm. \\
B N W & Be alert. \\
B N W & Be friendly. \\
B & Persons who always interrupt when you are talking. \\
B & Persons who pick their teeth. \\
B & Considered pleasant. \\
B & Considered punctual. \\
\hline
\end{tabular}

Note. The items are derived from Jurgensen (1944, p. 452).

preferred by different subjects. Using another sample the preliminary version was further reduced in length selecting the most consistent and discriminating items. The final form contained 45 triads, of which a best $(\mathrm{B})$, a neutral $(\mathrm{N})$, and a worst (W) stimulus had to be selected, and 55 dyads, of which only a best (B) stimulus had to be chosen by circling the applicable character. Figure 1.4 shows some examples.

So far, the construction steps had not resulted in the definition of variables. How were the item responses to be scored and added? The third construction principle actually prescribed that the variables should be developed by criterion keying. It required the selection of two groups of subjects: one group of subjects who were good at the job to be predicted, and one group of subjects who performed badly. Items with the strongest correlations between stimulus preference and criterion group membership had to be combined to form a variable. Jurgensen (1944) did in fact develop two scoring keys, one for graduate students and one for salesmen. Its validity appeared rather promising.

Even so, he intended to make the questionnaire available without any scoring key. He regarded the inventory as a stack of potentially discriminative items, of which the 'right' answer would be hard to predict. In accordance with his construction principles 3 and 4 Jurgensen expected that a company adopting his questionnaire would develop its own scoring keys. Then the external validity of the generated keys would be maximally guaranteed. Almost by definition the company would use the proper job criteria and collect the data in a representative sample. Because of this do-it-yourself approach the questionnaire can be considered the true psychological equivalent of the IKEA kit. Jurgensen (1944) promised to write an elaborate manual informing how to develop new scoring keys, in case its robustness against the social desirability response set would be replicated with other jobs. 
Mais (1951) developed a scoring key for measuring self-confidence. Remarkably this is a trait and thus deviates from. Jurgensen's third principle. Mais' study raised, however, a more serious objection as he did not confirm the robustness of the inventory against faking. In 1953 Jurgensen hinself abandoned his brainchild. He frankly concluded the forced-choice item format to be inadequate for controlling malingering (Longstaff of Jurgensen, 1953). The derived scales have never been published. In addition, Jurgensen himself gave up on the item format as early as 1953. Both aspects help explain the little impact the scale had in the acceptance and recognition of the forced choice item format.

Actually, Gordon (1951) did not regard the Jurgensen Classification Inventory as employing the forced-choice item format in the proper sense. He restricted the term 'forcecl-choice' to imply "measurement situations in which the stimuli have been matched for equality of preference value and also have differential discriminating ability in a specified situation" (p. 407). It is true that this differential discriminating ability was not empirically validated for each job in question, as this was not Jurgensen's intention. Nevertheless, he did solect the items that were most discriminatory. That Jurgensen developed a method that might succeed without specifying the situation, adds to his credit.

\subsection{The three flavours of the forced-choice item format}

The two presented forced-choice item formats do not result in data that is antomatically ipsative in the raw item responses. That requires the included stimuli in one item to represent different traits. The example item in Figure 1.1 presents such a forced-choice item, at least if the stimuli had been matched for social desirability. After all, that was originally the defining characteristic. The item was named 'forced-choice', because "[t]he essence of the forced choice technique [...] is to force the rater to choose between descriptive phrases which appear of equal value (have the same preference index, in our terminology) but are different in validity (d[i]scriminative index)" (Staff, 1946, p. 267). So, the naming was considered self-explanatory since it forces the respondent to choose. Baier (1951) rephrased this definition that alternatives "are paired so as to give each alternative equal face validity and differing true validity" (p. 424).

But Baier (1951) actually regretted the name 'forced choice'. He preferred to consider it a scaled multiple-choice item. The latter name more accurately describes the structure of the item. The name 'forced choice' is also inconvenient

Figure 1.5: A typical singular item

\begin{tabular}{lcccc}
\hline On the whole, I am satisfied with myself. & $\square$ & $\square$ & $\square$ & $\square$ \\
\hline
\end{tabular}

Note. Item derived from Rosenberg's Self-Esteem Scale (SES) (Rosenberg, 1965, p. 307). 
since it suggests that a choice is essential to the format. However, the main feature is that the included stimuli are matched. Whether a choice is forced or not is actnally irrelevant. Instead of a clear-cut choice it is feasible to ask the respondent to indicate one's preference on a graded scale. In that respect the chroice needs not to be forced whatsoever. The functional term 'forced-choice' will thercfore be abandoned.

Cronbach (1990) made a distinction between endorsement and comparison items. Endorsement items require the subject to rate one stimulus. Comparison items on the other hand demand the respondent to compare several stimuli. But with a graded response scale the required comparison may actually involve a rather elaborate relative endorsement. It is also preferred to adopt a more structural terminology, instead of the functional one that Cronbach (1990) advanced. Hence, if an item just consists of one stimulus it will from now on be called a singular item (see also Figure 1.5). An item containing more than one stimulus is referred to as a compound item. The previously presented items in Figures 1.1, 1.3, and 1.4 all constitute compound items. If the stimuli are matched for social desirability these items will be more specifically referred to as matched compound items.

With this redefinition the forced-choice item format actually exists in three flavours: the matched unidinensional compound item, the matched indeterminate compound item, and the matched multidimensional compound item. The matched unidimensional compound item (matched UCI) is represented by the WD AGO Form 67-1 (see also Figure 1.3). The matched indeterminate compound item (matched ICI) is characterized by the items of the Jurgensen Classification Inventory (see Figure 1.4). The matched multidimensional compound item (matched MCI) has not been presented yet, although it resembles the item of Figure 1.1. The stimuli need to be matched for social desirability, however. It was introduced by Edwards (1954) with his Personal Preference Schedule.

\subsubsection{The matched unidimensional compound item}

Theoretically, a matched UCI includes stimuli that all aim to represent the same trait, but differ in 'difficulty' or 'attractiveness'. The stimuli are matched for their social desirability, i.e. they are equally fit to make a favourable impression. To obtain the matching the stimuli are usually judged for their social desirability status. The 'difficulty' or 'attractiveness' parameter of a stimulus is not obtained by judgements. Instead, it is more typically derived from the actual stimulus endorsement frequencies. The item response cannot be guided by the stimulus desirability, because these are equalized. Any preference is regarded only to depend upon the difference in stimulus 'difficulty' or 'attractiveness'. As a result this approach appears to isolate the influence of social desirability from the influence of the represented trait on the item response. The tetrad item that was used in the WD AGO Form 67-1 was the first specimen of this item format. Following the early army instruments the method seems to have been applied only sparingly (Appel, 1956; Buxton, 1966; D. N. Jackson \& Minton, 1963). Recently, the robust- 
ness of this item format against social desirability has been re-established (D. N. Jackson. Wroblewski. \& Ashton, 2000), although it remained unclear whether this study in fact employed the matched UCI.

\subsubsection{The matched indeterminate compound item}

The matched ICI also includes stimuli that do not differ in desirability. But, whether the stimuli represent the same or different traits is considered immaterial. The defining characteristic is that the item response correlates with the criterion behaviour that is to be predicted. This is the hallmark of variable construction by criterion-keying. The dimensionality of the stimuli within the item remains essentially unknown, hence the term indeterminate compound item format. It is the item format that Jurgensen (1944) advocated. The method to select items for the prediction of a variable is rigorously empirical. It may, for example, be found that good salesmen prefer 'persons who pick their teeth' above 'persons who always interrupt when you are talking' (see Figure 1.4). Yet, the link between this preference and a good performance as a salesman may stay a mystery. Consequently, the criterion-keyed method of questionnaire construction is not concerned with stimulus content (Oosterveld, 1996).

As the relation between the stimulus content and the criterion behaviour remains obscure, it is actually quite inconsequential to fear response distortion by the social desirability response set. A respondent that aims to present himself as a good salesman, is then expected to anticipate that good salesmen prefer 'persons who pick their teeth' above 'persons who always interrupt when you are talking'. This relation is not very straightforward. Anyone who fears that a respondent might anticipate such a response, attributes the subject with clairvoyant powers. From a theoretical measurement perspective it is therefore illogical to view such a questionnaire construction method as vulnerable to the social desirability response bias. The lack of a transparent relation between stimulus content and criterion might in itself sufficiently obfuscate any strategy to depict oneself favourably.

The predictive efficiency of the instrument could, of course, be harmed by social desirable responding. But only if the pressure to respond in a social desirable way during common instrument use deviates from the urge to depict oneself favourably in the research by which the item-criterion correlations were obtained. If the criterion groups suffer the same pressure to respond favourably as any future group for which the instrument is intended, this influence is attenuated for by the item-criterion correlations. Items with an obviously preferable stimulus content, for instance: "I can persuade people easily" in the context of salesmen selection, will then not discriminate. Both good and bad salesmen will select this stimulus, either out of true endorsement, or due to anticipated desirability. As a result the item-criterion correlation will equal zero and the stimulus will not be incorporated in the variable.

If the social desirability response pressure in the research that establishes the item-criterion correlations deviates from the pressure in the settings for which 
Figure 1.6: An item of the Edwards Personal Preference Schedule

$\begin{array}{cl}\text { A } & \text { I like to help my friends when they are in trouble. } \\ \text { B } & \text { I like to do my very best in whatever I undertake. }\end{array}$

Note. Item derived from Edwards (1954).

the questionnaire is aimed, it lacks the necessary external validity (Waters, 1965). The maintenance of external validity in the criterion keying research should be tremendously beneficial in the prevention of a social desirability response bias. In that case it appears redundant to match stimuli for social desirability. Nevertheless, the matched ICI scems currently the most popular type of forced-choice item format (Bernardin, 1987; Christiansen, Burns, \& Montgomery, 2005; Villanova, Bernardin, Johnson, \& Dahmus, 1994). The item format evidences a hybrid approach that confuses two questionnaire construction principles that are to some extent at odds: optimising criterion validity versus optimising construct validity. This item format is therefore omitted from further consideration.

\subsubsection{The matched multidimensional compound item}

The matched MCI was first applied in the Edwards Personal Preference Schedule (EPPS) (Edwards, 1954). As he explains: "In this inventory, an attempt is made to minimize the operation of the social desirability variable by pairing statements representing different personality variables on the basis of their social desirability scale values in such a way that the social desirability scale values of the two statements are comparable" (Edwards, 1959, p. 115). The difference with the previous two forced-choice formats is that the stimuli explicitly represent two or more different variables. So, the method that Edwards advocates requires the comparison between at least two variables. Contrary to the previous two forcedchoice item formats, it is therefore not directed at eliminating the influence of social desirability from the judgements of a single variable. It aims instead to correct for any disparity in social desirability between the variables that these stimuli represent.

The EPPS covers 15 personality variables. It is a subset of the manifest needs originally listed by Murray (1938). A specimen of its item format is depicted in Figure 1.6. The item presents the respondent with two stimuli marked A and $\mathrm{B}$. The selection of stimulus $\mathrm{A}$ adds one point to the Nurturance variable. The preference for stimulus B contributes one point to the Achievement variable. Edwards (1954) matched the stimuli on social desirability. Someone earns about equal social approval whether the person claims "I like to help my friends when they are in trouble", or "I like to do my very best in whatever I undertake". The item is thus regarded to impose the respondent to reveal one's true nature. The selection of either stimulus does not make the subject look more favourable.

Due to its format this item generally produces ipsative standard scores. 
The item response does not affect the total item score. It only deternines how the item score is distributed over the included stimmli that represent the different variables. The total item score summed over the incorporated stimuli remains constant, in this case 1 . The variable scores are gencrally obtained by smmming the scores of their representing stimuli over all items. If all variable scores within a subject are subsequently added, the total sum of all variable scores then equals the total item score multiplied by the number of items. Consecuently, the withinsubjects mean variable score across all variables will be the same for each subject. Notice that the deviation ipsative score mean of Mr. Brown in Table 1.1 will be the same for every other subject as well. In Table 1.1 this mean equals 0.0. But the actual value is immaterial. What matters is that the procedure causes all subjects to have the same mean variable score. This is a key feature of ipsative standard scores. It will be outlined further in Chapter 2.

\subsubsection{Conclusion}

Of the three carly compound item formats, i.e. the matched UCI, the matched ICI, and the matched MCI, only the matched $\mathrm{MCl}$ yields direct ipsative standard scores. So, the compound item format as a structure appears not to be reciprocally associated with ipsative standardization. The matched MCI alone results in direct ipsative standard scores, whereas the other formats do not. What sets the matched MCI apart from the other compound items is that the various stimuli within an item represent different variables of which each may acquire a score. The issue whether the stimuli are matched or not is actually of no importance. The adopted item scoring method is what makes the difference. The item scoring method determines whether the compound item is multidimensional or not. And the item scoring method also determines whether the resulting data is ipsative or not.

\subsection{The vector nature of a compound item response}

The previous section outlined that the item scoring method establishes whether the item is unidimensional or multidimensional. Irrespective of the scoring, the response to either compound item format should be recognized to make up a vector. The vector coordinates simply reflect the ratings of each of the separate stimuli. It will elucidate the relationship between the UCI and the MCI. As it is the more straightforward in the MCI, this item format will be discussed first.

\subsubsection{The vector nature of the $\mathrm{MCl}$ response}

The response to a MCI is usually recorded as separate scalar units at the stimulus level. The MCI response, however, should be properly regarded to reflect a single profile, i.e. a vector. The response to one MCI has a bearing on multiple stimuli. As a result these separate stimulus responses cannot be considered independent 
Figure 1.7: A two-dimensional compound item with a response matrix

\begin{tabular}{|c|c|c|c|c|c|c|}
\hline & & \multicolumn{5}{|c|}{$\leftarrow$ the meaning of life. $\rightarrow$} \\
\hline & & $\begin{array}{c}\text { completely } \\
\text { disagree }\end{array}$ & disagree & neutral & agree & $\begin{array}{c}\text { completely } \\
\text { agree }\end{array}$ \\
\hline$\uparrow$ & completely disagree & $\square$ & $\square$ & $\square$ & $\square$ & $\square$ \\
\hline developments & disagree & $\square$ & $\square$ & $\square$ & $\square$ & $\square$ \\
\hline in & neutral & $\square$ & $\square$ & $\square$ & $\square$ & $\square$ \\
\hline science. & agree & $\square$ & $\square$ & $\square$ & $\square$ & $\square$ \\
\hline$\downarrow$ & completely agree & $\square$ & $\square$ & 凶 & $\square$ & $\square$ \\
\hline
\end{tabular}

data points. If the separate stimulus responses are considered to form a vector, the independent data point remains identified. The response vector itself simply constitutes the independent data point.

Figure 1.7 illustrates the argument. It shows a non-ipsative multidimensional compound item with a complete response matrix, i.e. the $5 \times 5$ set of checkboxes. The stimulus 'the meaning of life' represents the interest variable Religious; the stimulus 'developments in scicnce' the variable Theoretical. Both are paired and associated with a response matrix. The respondent is instructed to mark one checkbox.

The interdependency of the responses to the stimuli of such an item is demonstrated by considering the marked checkbox in the figure. It implies that the subject is neutral towards discussing the meaning of life, but agrees completely with regard to discussing developments in science. As a result one might consider to record the associated three points and five points separately. Suppose, however, that the subject used the response matrix in the wrong way. He actually intended to indicate that he agreed completely with discussing the meaning of life and was neutral about developments in science. It shows that the response is erroneous to both stimuli. Hence, the responses should not be recorded as if they were

Figure 1.8: The same compound item with the represented response vectors

\begin{tabular}{|c|c|c|c|c|c|c|}
\hline \multicolumn{7}{|c|}{ I am keenly interested in discussions about } \\
\hline & & $\begin{array}{c}\text { completely } \\
\text { disagree }\end{array}$ & disagree & neutral & agree & $\begin{array}{c}\text { completely } \\
\text { agree }\end{array}$ \\
\hline$\uparrow$ & completely disagree & {$\left[\begin{array}{ll}1 & 1\end{array}\right]$} & {$\left[\begin{array}{ll}1 & 2\end{array}\right]$} & {$\left[\begin{array}{ll}1 & 3\end{array}\right]$} & {$\left[\begin{array}{ll}1 & 4\end{array}\right]$} & {$\left[\begin{array}{ll}1 & 5\end{array}\right]$} \\
\hline developments & disagree & {$\left[\begin{array}{ll}2 & 1\end{array}\right]$} & {$\left[\begin{array}{ll}2 & 2\end{array}\right]$} & {$\left[\begin{array}{ll}2 & 3\end{array}\right]$} & {$\left[\begin{array}{ll}2 & 4\end{array}\right]$} & {$\left[\begin{array}{ll}2 & 5\end{array}\right]$} \\
\hline in & neutral & {$\left[\begin{array}{ll}3 & 1\end{array}\right]$} & {$\left[\begin{array}{ll}3 & 2\end{array}\right]$} & {$\left[\begin{array}{ll}3 & 3\end{array}\right]$} & {$\left[\begin{array}{ll}3 & 4\end{array}\right]$} & {$\left[\begin{array}{ll}3 & 5\end{array}\right]$} \\
\hline science. & agree & {$\left[\begin{array}{ll}4 & 1\end{array}\right]$} & {$\left[\begin{array}{ll}4 & 2\end{array}\right]$} & {$\left[\begin{array}{ll}4 & 3\end{array}\right]$} & {$\left[\begin{array}{ll}4 & 4\end{array}\right]$} & {$\left[\begin{array}{ll}4 & 5\end{array}\right]$} \\
\hline$\downarrow$ & completely agree & {$\left[\begin{array}{ll}5 & 1\end{array}\right]$} & {$\left[\begin{array}{ll}5 & 2\end{array}\right]$} & {$\left[\begin{array}{ll}5 & 3\end{array}\right]$} & {$\left[\begin{array}{ll}5 & 4\end{array}\right]$} & {$\left[\begin{array}{ll}5 & 5\end{array}\right]$} \\
\hline
\end{tabular}


Figure 1.9: An ipsative version of the same compound item

\begin{tabular}{|c|c|c|c|c|c|c|}
\hline \multicolumn{7}{|c|}{ am keenly interested in discussions about } \\
\hline & & $\begin{array}{c}\text { completely } \\
\text { disagree }\end{array}$ & disagree & neutral & agree & $\begin{array}{l}\text { completely } \\
\text { agree }\end{array}$ \\
\hline$\uparrow$ & completely disagree & & & & & $\square$ \\
\hline developments & disagree & & & & $\square$ & \\
\hline in & neutral & & & $\square$ & & \\
\hline science. & agree & & $\square$ & & & \\
\hline$\downarrow$ & completely agree & $\square$ & & & & \\
\hline
\end{tabular}

Note. See for the associated response vectors the inverse diagonal of Figure 1.8.

independent. The error in the two separate response readings must be considered related.

With the item in Figure 1.7 a single behavioural response has a bearing on two stimuli. Each checkbox must therefore be considered to represent a response vector with two coordinates. Figure 1.8 shows how each checkbox is associated with a single response vector. These response vectors are the genuine independent data points.

It is obvious that the example compound item in Figure 1.7 becomes ipsative by limiting the response matrix to the inverse diagonal: the boxes on the diagonal from the bottom left to the top right (see Figure 1.9). With this response format the responses to both stimuli are even more closely related. The subject who opted for the response vector [ 53 ] in the item of Figure 1.7 has now to decide whether he chooses [ 33 3], [ $\left.\begin{array}{ll}4 & 2\end{array}\right]$, or [ $\left[\begin{array}{ll}5 & 1\end{array}\right]$. Notice that in this case the sum of the vector coordinates equals six. If this sum is taken to represent the total item score, it will be invariant again between the subjects.

\subsubsection{The vector nature of the $\mathrm{UCl}$ response}

The vector nature of the UCI response could be as straightforward as with the MCI. More commonly however the vector nature of the UCI is even more implicit. That is, because the UCI often makes use of sorted stimuli. The selection of one stimulus out of a set of sorted stimuli actually reflects an incomplete sort itself. This incomplete sort of the stimuli then forms the proper UCI response vector.

Figure 1.10 presents such a UCI with sorted stimuli from the Beck Depression Inventory (BDI) (Beck, Ward, Mendelson, Mock, \& Erbaugh, 1961). The item proposition indicates the key content "(Indecisiveness)". Its sentences are stimuli that represent this same aspect. This is actually revealed by how the item response is converted into an item score. The respondent is required to circle the number of the applicable stimulus. These numbers in fact specify the scoring weights of the stimuli. Selecting the first stimulus adds zero points to the depression variable. Preferring the last stimulus adds three points to the depression 
Figure 1.10: Item of the Beck Depression Inventory

\begin{tabular}{ll}
\hline$M$ & (Indecisiveness) \\
0. I make decisions about as well as ever \\
1. I am less sure of myself now and try to put off making decisions \\
2. I can't make decisions any more without help \\
3. I can't make any decisions at all any more \\
\hline
\end{tabular}

Note. Item derived from Beck et al. (1961, p. 571).

variable. The response thus determines the score that the item contributes to the represented trait, because the stimuli stand for different quantities of the same quality. That is the hallmark of the UCI. Such an item produces plain raw data suitable for any kind of standardization.

But the scoring weights are actually the silent witnesses of a response vector. A UCI essentially allows a comparison between quantities. This comparison might be captured in a response vector. With the BDI the instruction is "to select the statement that seemed to fit him the best at the present time" (Beck et al., 1961, p. 562). This suggests to respond according to a proximity relation. The probability to select a stimulus is then assumed to increase as the subject position on the underlying trait approaches the stimulus position. With this instruction the stimulus is chosen that is closest to the trait position of the subject.

Fortunately, the stimuli are ordered according to their 'attractiveness' or 'difficulty', i.e. their relative position on the underlying trait continuum. So, the chosen stimulus reveals the relative trait position of the subject to the other stimuli. This relative position allows the deduction of the dominance relations between the subject and the other stimuli. If the subject selects the first stimulus, the trait position of the respondent is closest to this stimulus. So it follows that the other stimuli are not mastered. In case the second stimulus is selected, the respondent is located nearest to this stimulus. Then the first stimulus must be mastered and the other stimuli are not mastered. Selection of the third stimulus implies that the first and second stimulus are mastered and the fourth stimulus is not mastered. Finally, in case the fourth stimulus is chosen, all other stimuli are mastered. The issue whether the preferred stimulus is mastered itself, remains in effect unknown. Assuming that the chosen stimulus is not mastered, the dominance score vectors should be coded as $\left[\begin{array}{llll}0 & 0 & 0 & 0\end{array}\right],\left[\begin{array}{llll}1 & 0 & 0 & 0\end{array}\right],\left[\begin{array}{llll}1 & 1 & 0 & 0\end{array}\right]$, and $\left[\begin{array}{llll}1 & 1 & 1 & 0\end{array}\right]$, respectively. The first coordinate of these dominance score vectors represents the score to the first stimulus, and so forth. As the stimuli all contribute to the same variable, the vector coordinates may be summed. This yields the scores that are in agreement with the original stimulus weights (see Figure 1.10).

Keep in mind, however, that the derivation of these dominance score vectors is contingent upon the assumption that the stimuli represent the same trait and are adequately ordered. If these assumptions are not met, the derived dominance 
Figure 1.11: Implied rating scale points of the Beck Depression Inventory item

\begin{tabular}{|c|c|c|c|c|c|}
\hline M & (Indecisiveness) & 1 & 2 & 3 & 4 \\
\hline 0. & I make decisions about as well as ever & $\square$ & $\square$ & $\otimes$ & $\square$ \\
\hline 1. & I am less sure of myself now and try to put off making decisions & $\otimes$ & $\square$ & $\square$ & $\square$ \\
\hline 2. & I can't make decisions any more without help & $\square$ & $\otimes$ & $\square$ & $\square$ \\
\hline 3. & I can't make any decisions at all any more & $\square$ & $\square$ & $\square$ & $凶$ \\
\hline
\end{tabular}

Note. Item derived from Beck et al. (1961, p. 571).

score vectors are inappropriate. Also note that if these assumptions are justified, the respondent orders the stimuli by selecting one stimulus. This ordering may be incomplete. The selection of the second stimulus, for instance, does not indicate whether the first stimulus is preferred over the third or fourth stimulus. The back translation from the selection of a stimulus into a preference order implies that each stimulus sentence can be thought of as associated with a separate 4-point rating scale. Selection of the second stimulus could have resulted from the preference order that is indicated in Figure 1.11. Note that this response is represented by the proximity response vector $\left[\begin{array}{llll}3 & 1 & 2 & 4\end{array}\right]$. But an observed preference for the second stimulus could equally have resulted from the implied proximity response vectors [ [ $\left.\begin{array}{llll}2 & 1 & 3 & 4\end{array}\right]$ and $\left[\begin{array}{llll}4 & 1 & 2 & 3\end{array}\right]$. An implied proximity response vector of $\left[\begin{array}{llll}2 & 1 & 4 & 3\end{array}\right]$ is inadmissible, because that would be in conflict with the assumed unidimensional order of the stimuli. Nevertheless, the implied proximity response vector is beyond retrieval. This is of no concern to the derived dominance score vectors.

\subsection{Overview}

The current chapter outlined the beginnings of the forced-choice item format. Originally, this item format did not yield ipsative data. It was mainly characterized by matching stimuli for social desirability within an item. With the advent of the EPPS the forced-choice item did result in ipsative data. It was not the matching, but the fact that the stimuli represented diverse traits, which was essential to the ipsative nature of the data. This item format was named the multidimensional compound item. The MCI format was argued to yield data that can be best considered to represent vector scores, or in other words profile scores. All ipsative data collection methods use a kind of MCI. It is the MCI that will be the focus of the empirical investigations.

The opening motto by Coombs (1953) adequately captures the empirical orientation of the present thesis. Does ipsative data collection result in data containing information that is not retrieved by other data collection methods? A positive answer would allow an educated decision when to adopt this method for practical measurement purposes. But, to answer that question properly, the research methods should allow that information to be extracted in principle. Con- 
sequently, one needs to have an explicit idea what this information is.

As a result, the next two chapters first aim to deepen the theoretical knowledge of ipsative measurcment. Chapter 2 explains the nature of ipsative standardization. It is presented along with other types of standardization. A proper understanding of ipsative standardization facilitates the notion of what defines ipsative data collection, and in what circumstances it might prove beneficial. Chapter 3 provides a typology of response tendencies. The idea that data collection methods may diverge in their susceptibility to measurement inaccuracies, in particular response tendencies, played a major role in the development of the ipsative data collection methods. So, this typology of response tendencies will allow any alleged benefit of ipsative measurement to be put in proper perspective.

The present chapter argued that the MCI produces vector scores. Chapters 4 and 5 therefore investigate whether ipsative data collection may be better suited at profile measurements in the individual. In Chapter 4 the same trait domain is assessed by an ipsative data collection method, a more general data collection method, and a criterion measure. Both data collection methods are then compared with respect to their within-subjects profile agreement with this external criterion. Chapter 5 addresses the same question. But, instead of using an independent criterion measure, the respondent himself is consulted to indicate which data collection method renders the more accurate score profile.

Note that Figure 1.7 presented a MCI, which did not result in ipsative data. It only became ipsative after restricting the possible response alternatives to the inverse diagonal (see Figure 1.9). Elaborating on this notion Chapter 6 will provide a new way of constructing and scoring the MCI. This new approach yields data that is not automatically standardized in an ipsative sense. Its correspondence with the more general data collection methods is investigated according to a multitrait-multimethod design. In addition, the new method is evaluated for its resistance against acquiescence, i.e. the response tendency to endorse a stimulus irrespective of its content.

Chapters 7 and 8 focus on the efficacy of the matched MCI to control for the social desirability response set. The utility of matching stimuli on the basis of their population average social desirability levels has been questioned. It might not secure the equality in social desirability at the individual level. If subjects diverge widely in what they conceive of as socially desirable, it would render the matching inadequate. Chapter 7 investigates whether this criticism is justified.

Previous studies of the robustness of the matched MCI against the social desirability response bias instructed respondents to select the more desirable stimulus. If adequately matched the selection frequency distribution should be uniform. Chapter 8 tests whether the frequency distributions deviate from uniformity, because respondents tend to select the stimulus that is to them the more applicable instead of the more desirable. It also scrutinizes what consequences the matching of stimuli fosters for the additive scoring of the matched MCI. 



\title{
Methods to derive a unit of measurement
}

\author{
[I]t is more valuable to know that Shakespeare at nine \\ had a recognition vocabulary of thirty-eight thousand words \\ than that he stood at the ninety-second percentile in the \\ County of Warwick Vocabulary Test of that day.
} (Cattell, 1944, pp. 299-300)

The present chapter aims to present a general framework of standardization methods that puts ipsative standardization in proper perspective. Standardization is directed at defining a unit of measurement. It is applied to all kinds of measurement outcomes. The use of standardization relates to the measurement level. Celsius standardized the measurement of temperature by identifying two reference points: the temperatures at which water boils and freezes. He created a unit of measurement by dividing the obtained temperature interval in 100 equidistant sections. A point of zero degrees, the starting point of the scale, was simply assigned to one of the reference points. ${ }^{1}$ The standardization of a measure of length however never needed the allocation of a zero point. A length of zero was already available. In the measurement of temperature an absolute zero point only became available after thermodynamics had inferred this point by using the expansion ratio of gases for the extrapolation. The level of measurement thus determines the extent of standardization that is required. To elucidate these differences the various levels of measurement are outlined first.

\subsection{The levels of measurement}

The representational theory of measurement defines measurement as "the assignment of numerals to objects or events according to rules" (Stevens, 1946, p. 677; 1951, p. 1 and 22). The rules are intended to assign the numerals in such a way that the empirical relationships between the observations are properly represented by the numerical relationships in a selected mathematical model. Suppose for ex-

\footnotetext{
${ }^{1}$ Celsius originally assigned the degree of zero to the temperature at which water boils. It is cxemplified by the scale on his thermometer that is exhibited at the University of Uppsala.
} 
ample a subject ranks three Scotch single-malt whiskies' according to preference in the order:

$$
\text { Talisker } \prec \text { Oban } \prec \text { Highland Park. }
$$

where the symbol $\prec$ indicates is preferred to". To translate this empirical result in a proper mathematical model the order of the assigned numerals should maintain the order of preference. One might code his response by assigning Talisker the numeral 1. Oban the numeral 2, and Highland Park the numeral 3, because:

model 1: $1<2<3$.

So the preference relation $\prec$ is represented by the mathematical relation <. i.e. 'less than'. But it could also be assigned $3,5,7$. because:

model 2: $3<5<7$.

preserves the preference order equally well. One might argue that the series 3,2 . 1 represents the rank order equally well:

model 3: $3>2>1$.

However, it is important to note that by this series the preference relation $\prec$ is represented by the opposite mathematical relation $>$. 'greater than'. Logically the assignment of 2,1,3, is not acceptable, because neither:

model 4a: $2>1>3$.

nor:

model 4b: $2<1<3$

is true. With this assignment the numerical order is in conflict with the empirical order. So only the first three assigmments establish a measurement scale that adequately represents the empirical result.

The example evidences that there is not one unique solution. The first scale in the example can simply be transformed in the second scale by the function: $f(x)=2 x+1$, or in the third scale by the function: $f^{\prime}(x)=-x+4$. Nevertheless, the more empirical relations are represented by the mathematical model, the less arbitrary the choice of the numerals becomes. Hence, a more elaborate model limits the permissible scale transformations, as these may alter the numerical relations that are deemed relevant for the representation. The transformation of model 1 into model 3 by $f^{\prime}(x)=-x+4$ is actually not permissible, since the rank order is reversed. The transformation changes the relation between preference and order. The relation $\prec$ becomes associated with 'greater than' instead of 'less than'. The positive flip side however is that statistical operations are meaningful insofar they remain invariant under these permissible scale transformations. So, the

\footnotetext{
${ }^{2}$ F.-J. Lapointe and Legendre (1994) provided a complete classification of single-malt Scotch whiskies.
} 
Table 2.1: Levels of measurement

\begin{tabular}{|c|c|c|c|c|}
\hline Level & Defining relationships & $\begin{array}{l}\text { Admissible scale } \\
\text { transformations }\end{array}$ & $\begin{array}{r}\text { Meaningful } \\
\text { statistics }\end{array}$ & Examples \\
\hline Nominal & equality or inequality & $\begin{array}{l}\text { permutation group } \\
x^{\prime}=f(x) \\
f(x): \text { any one-to-one } \\
\quad \text { substitution }\end{array}$ & $\begin{array}{l}\text { Number of cases } \\
\text { Mode } \\
\text { Contingency } \\
\quad \text { correlation }\end{array}$ & $\begin{array}{l}\text { shirt number in sports } \\
\text { social security number } \\
\text { ZIP code } \\
\text { ISBN code }\end{array}$ \\
\hline Ordinal & $\begin{array}{l}\text { equality or inequality } \\
\text { greater or less }\end{array}$ & $\begin{array}{l}\text { isotonic group } \\
x^{\prime}=f(x) \\
f(x): \text { any monotonic } \\
\quad \text { increasing function }\end{array}$ & $\begin{array}{l}\text { Median } \\
\text { Percentiles } \\
\text { Rank-order correlation }\end{array}$ & $\begin{array}{l}\text { Mohs' scale of hardness } \\
\text { of minerals } \\
\text { Beaufort scale of wind- } \\
\text { force }\end{array}$ \\
\hline Interval & $\begin{array}{l}\text { equality or inequality } \\
\text { greater or less } \\
\text { equality of intervals or } \\
\text { differences }\end{array}$ & $\begin{array}{l}\text { general linear group } \\
x^{\prime}=a x+b\end{array}$ & $\begin{array}{l}\text { Mean } \\
\text { Standard deviation } \\
\text { Product-moment } \\
\quad \text { correlation }\end{array}$ & $\begin{array}{l}\text { temperature in: } \\
\text { - centigrade, or } \\
\text { - Fahrenheit } \\
\text { calendar time }\end{array}$ \\
\hline Ratio & $\begin{array}{l}\text { equality or inequality } \\
\text { greater or less } \\
\text { equality of intervals or } \\
\text { differences } \\
\text { equality of ratios }\end{array}$ & $\begin{array}{l}\text { similarity group } \\
x^{\prime}=a x\end{array}$ & $\begin{array}{l}\text { Geometric mean } \\
\text { Coefficient of variation }\end{array}$ & $\begin{array}{l}\text { temperature in Kelvin } \\
\text { length } \\
\text { weight } \\
\text { electrical resistance }\end{array}$ \\
\hline Absolute & $\begin{array}{l}\text { equality or inequality } \\
\text { greater or less } \\
\text { equality of intervals or } \\
\text { differences } \\
\text { equality of ratios } \\
\text { equality of number }\end{array}$ & $\begin{array}{l}\text { identity group } \\
x^{\prime}=x\end{array}$ & counting & \\
\hline
\end{tabular}

reduction in permissible scale transformations increases the number of statistical operations that are meaningful.

Stevens (1946) originally classified four different types of empirical relationships. He identified the permissible transformations along with the statistical operations that are meaningful to each class. These classes are listed in Table 2.1 and are known as the levels of measurement. Notice for instance that the whisky preference example represents an ordinal measurement level. At this level only monotonic increasing scale transformations are allowed. According to this schema the function $f^{\prime}(x)=-x+4$ is prohibited indeed as it is a decreasing scale transformation. Stevens (1946) in fact only identified the nominal, ordinal, interval, and ratio level.

The nominal measurement level is defined by the equality relationship. Measurement at this level uses the numerals simply as symbols to demarcate classes of objects. It permits any one-to-one substitution. The ordinal measurement level extends the nominal measurement level. It uses numerals not only to convey the class identity but also the rank order of the objects on the attribute. This measurement level permits any monotonic increasing function. A measurement scale representing an interval measurement level has all the characteristics of an ordinal scale. But equal differences between measurements now represent equal quantities as well. Any positive linear scale transformation is permitted. In addition to the properties of an interval measurement level, the ratio measurement level is characterized by an absolute zero point. At this level ratios of 
measurements have become interpretable. The only admissible transformation is the definition of a positive rescaling factor.

Nevertheless, Stevens (1951) already noticed that Von Nemmann and Morgenstern (1947. p. 23) added a fifth class: the absolute level, which does not allow any transformation at all. This is the only measurement levol with one mique representation model. They failed to mention the required relationship however. In Table 2.1 it is only added tentatively. ${ }^{3}$ At an absolute measurement level even the unit of measurement ceases to be arbitrary. The unit then equals one. Counting is associated with this measurement level. The number of pages of this thesis can for instance be measured at an absolute measurement level.

\subsection{Measuring up to a standard}

With the levels of measurement in mind standardization is actually nothing more but a consensus strategy to express a measurement result mequivocally. If a variable is regarded to be measured at a particular measurement level, the measurement level simply fixes the scale up to the system of admissible scale transformations. So a length of 12 does not convey any information, until it is indicated if the number represents light-years, nanometres, or any other unit. Length is assumed to be measured at a ratio level. Consequently its unit of measurement determines the a parameter of the admissible scale transformation $f(x)=$ a $x$. Comparably with temperature the measurement unit centigrade both defines the $a$ and $b$ parameters of the admissible scale transformation $f(x)=a x+b$. As a direct corollary the absolute measurement level does not need (nor allow) standardization. For the only admissible transformation is the identity relation: $f(x)=x$.

The two examples differ, however, in their approach to establish a unit. The unit of length had for a long period been identified by a standard measurement instrument itself. At least, if one is willing to accept that the bar of platimum iridium alloy, which defined the standard metre, constituted a ruler in itself. Or, if one agrees that the standard kilogram represents a weight to be used with a pair of scales for that matter. After all, the length of the standard metre is since October 20, 1983 defined as the distance that light travels in 1/299,792,458 second in vacumn. Like the old standard metre, however, psychology may derive a measurement unit by referring to a standard instrument as well.

In contrast, the unit of temperature has been defined in relation to reference measurements. Celsius circumscribed the exact conditions of the two calibrating measurements, i.e. boiling and freezing water. For a large part, however, psychology aims to measure aspects of the living animal, humans included. As a result psychology cannot exploit the measurements of two standard subjects, simply because organisms change and expire. Einstein is no longer among us to provide us with a reference point for the standardization of intelligence. Still, Celsius: stan-

\footnotetext{
${ }^{3}$ Other measurement levels have been identified as well. These are nevertheless omitted as they are not regarded relevant for the subsequent discussion on types of standardization.
} 
Figure 2.1: Overview of standardization methods

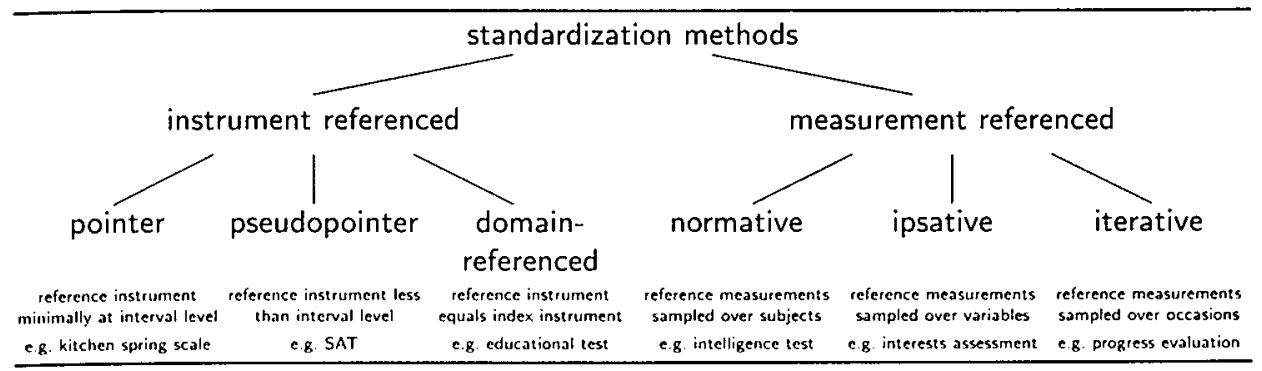

dardization procedure of temperature measurement can actually be viewed as the assessment of the average velocity of a huge collection of water molecules. And the exact same set of water molecules that Celsius used is unavailable today as well. Yet, the defining characteristics of water have remained constant, although the molecules did vaporize and disperse. Analogously, psychology aims to use a large set of reference measurements. The larger the sample the more precise the descriptive statistics will be estimated. Both routes of standardization will now be discussed.

\subsubsection{Instrument-referenced standardization}

With instrument-referenced standardization an instrument is either equated to another instrument that is considered to be a standard or the instrument is elevated to a standard itself. Suppes and Zimnes (1963) called an instrument that is equated to another standard instrument a pointer instrument. The strict condition was that the standard had to give evidence of measuring at an interval level at least. Otherwise, they referred to it as a pseudopointer instrument. A kitchen spring scale of which the spring is calibrated using standard weights can be considered a pointer instrument. The author is not familiar with any pointer instrument in psychology. The example that comes closest is the Scholastic Aptitude Test (SAT). The SAT is intended to assess a student's aptitude for college work. But considering the Suppes and Zinnes (1963) definition this should be properly regarded a pseudopointer instrument. Every year various new versions of the SAT are developed. To maintain constancy of the scale and therefore crosssectional comparability of the test scores over time, each version is equated to its predecessor forms. The origin of the standard can be traced back to April 1941 for the verbal section and April 1942 for the mathematical section (Angoff \& Donlon, 1971).

In psychology an instrument is more frequently stipulated to constitute a standard itself. It is then considered a domain-referenced instrument. This type of standardization is often accredited to Glaser (1963), who referred to it as criterionreferenced standardization. Others have, however, advanced this standardization 
method already before him (Ebel. 1962: Flanagan. 1939: Tucker, 1953). The term content-referenced standardization is also employed. This type of standardization uses the range of the possible raw variable scores of the instrument self to derive a standard score. The approach is rather common in educational measurement. because it yields a score that is relative to the maximum score. As stuch it is particularly relevant to indicate the extent in which the represented domain is mastered and thus for pass-fail decisions (Van der Linden, 1994).

\subsubsection{Measurement-referenced standardization}

In contrast to instrument-referenced standardization other standardization methods use a set of reference measurements to define a unit of measurement. These reference measurements may either be collected over subjects. variables. or measurement occasions. If the set of measurements is collected over subjects, it is addressed as normative standardization. Normative standardization is, for instance, applied to intelligence measurement, using the population mean to indicate an IQ of 100 and the standard deviation covering 15 or 16 IQ points. In case the reference measurements are collected over different variables within a subject, it is referred to as ipsative standardization. Ipsative standardization is generally adopted for the assessment of interests. Finally, if the measurements are collected over different measurement occasions within a subject it will be called iterative standardization. For a progress evaluation one could make use of some sort of iterative standardization to monitor development. Together these standardization approaches are regarded to constitute the class of measurement-referenced standardization methods. Regardless how the set of reforonce measurements is collected its descriptive statistics is used to derive a mit of measurement. In psychology measurement-referenced standardization implements in particular the mean and standard deviation to derive a unit of measurement.

\subsection{Procedures of standardization}

Figure 2.1 presents an overview of the standardization methods discussed so far. First the procedures of standardization will be ontlined. The procedures are ordered according to the applicable measurement level as well as the main standardization approach: domain-referenced standardization versus measurementreferenced standardization. The two other instrument-referenced standardization methods, pointer and pseudopointer measurement, are omitted from the next presentation. These procedures aim to equate the measurement results to other instruments and are not deemed relevant for the current discussion. Also, no distinction is yet made between normative, ipsative, and iterative standardization methods. How the set of reference measurements is collected, bears little relevance to the procedure of standardization. The differences between normative, ipsative, and iterative standardization are elaborated on later. 


\subsubsection{Standardization at the nominal measurement level}

At the nominal measurement level no uniform standardization strategy can be offered. It depends on the mature of the classification. Historically, the goalkeeper of a soccer team receives the number 1 . And the first digits of a ZIP code are deternined by the larger region in which a particular address is located. Nevertheless in a first order classification, i.e. without a hicrarchical subdivision that characterizes the ZIP code, one gencrally starts with number 1 and counts up to the number of classes. The highest possible number occupying all reserved digit positions is assigned to the class of objects that camot be classified clue to missing data. So a subject whose sex is unknown is simply attributed a 9 as this classification requires only one digit.

\subsubsection{Standardization at the ordinal measurement level}

By convention a score of 1 is nsually assigned to the lowest measurement class, a score of 2 to the next measurement class and so forth up to the highest class. Both Mohs" scale of hardness of mincrals as well as the Beaufort scale of wind-force follows this suit. The interpretation of such a score, however, night be cnhanced by knowing the maximm score, i.e. the number of classes. The achicvement of someone finishing third in a race is valued differently whether it was among four contestants or four hundred. To correct for the implication of the maximum score a standard maximum might be chosen. Of course this approach is only useful if the original scale differentiates a large number of measurement classes. These classes may then be combined to constitute a predeternined number of scores. The gain in denotation is however bought at a loss of information. For the process of combining consecutive measurement classes is in conflict with the permissible scale transformation. It entails, after all, a monotonic non-decreasing transformation proper. Where the classes are combined the graph that represents the transformation is horizontal, i.e. non-increasing.

\section{Domain-referenced standardization at the ordinal measurement level}

Standardization that takes the measurement scale of the instrument as point of departure clusters all attainable measurement classes to have each cluster contain an equal number of scale points. If the total number of possible classes is not a multiple of the number that are grouped together the lower or upper score category will represent less measurement classes than the others (see also Van den Brink \& Kocle, 2000, pp. 27-28). Irrespective of this deviation each score roughly represents an equal number of the original measurement classes. As a result a distribution of the thus standardized scores closely resembles the distribution of the original measurement results. The scoring of an educational essay test might follow this strategy. If the attainable measurement classes run from 0 to 50 the aim is to reduce these 51 classes into 11 grades ruming from 0 to 10 . Measurement classes 0 to 2 will then be combined into a grade of 0 , classes 3 to 7 into a grade 
of 1 . ..., classes 23 to 27 into a grade of 5 . classes 28 to 32 into a grade of $6, \ldots$. classes 43 to 47 into a grade of 9 , and classes 48 to 50 into a grade of 10 . If a student attains a grade of 6 it indicates that he has earned roughly $60 \%$ of the total credits of the test.

\section{Measurement-referenced standardization at the ordinal measurement level}

Standardization that utilizes a set of reference measurements clusters these measurements in such a way that each cluster contains an equal number of measurement results. Each class may be clustered to contain for instance $1 / 100^{\text {th }}$ of the total number of reference measurements. This will result in 100 scores ranging from 1 to 100. Suppose a standard scorc of 9 is assigned to a measurement result on a thus standardized achievement test. This then indicates that $8 \%$ of the reference measurements are below the obtained measurement and $91 \%$ of the reference measurements are above that measurement. The remaining $1 \%$ share that same score by definition. Consequently, it reflects a poor performance. Other fractions that are commonly used are $1 / 10^{\text {th }}$ and $1 / 25^{\text {th }}$ (see also Van den Brink \& Koele, 2000, pp. 29-31). By definition this transformation will result in a uniform distribution of the scores in the collection of reference measurements. Hence, it is referred to as a homogenizing transformation.

\subsubsection{Standardization at the interval measurement level}

In an interval scale the zero point and unit of measurement are arbitrary. Standardization thus consists of two steps: the choice of a zero point and the development of a unit of measurement. Again two routes can be followed: standardization based on the limits in the possible range of raw scores of the instrument or standardization based on the descriptive statistics of the raw scores in a set of reference measurements.

\section{Domain-referenced standardization at the interval measurement level}

If standardization uses the limits of the possible score range, the minimum possible raw score is frequently chosen as zero point. This is achieved by subtracting the minimum possible raw score $(\min (X))$ from the observed raw score $\left(X_{i}\right)$ of any given measurement $i$. The actual unit of measurement is usually based on the range. This range is given by the maximum possible raw score minus the minimum possible raw score. The ratio renders a standard score that runs from 0 to 1 . This may be multiplied by any factor to increase the range of the standard score, e.g. 100:

$$
s_{i}=\frac{X_{i}-\min (X)}{\max (X)-\min (X)} \times 100 \quad \text { for } i=1,2, \ldots, n,
$$

where $s_{i}$ represents the standard score of any given measurement $i$. Compare this procedure also with the example of the educational test from the previous 
subsection. It was considered ordinal. Nevertheless, application of the current procedure using a scaling factor of 10 yields the same standardized scores after rounding off. Yet the interpretation is different. Within ordinal measurement the differences between scale points are not considered to represent a quantity. At an interval measurement level it does, which makes the actual rescaling by division and multiplication appropriate.

The difference with the procedure that Celsius adopted is by the way that Celsius defined the minimum and maximum by mcasurements. The above procedure is applicable to any manometric thermometer in principle by assigning 0 to the bottom and 100 to the top irrespective whether the thermometer is aimed for outdoor, refrigerator, or bodily use. It illustrates that the measurement unit is now dependent upon the used instrument. The merit of Celsius" approach is that nobody actually had to travel to Uppsala to use his thermometer.

\section{Measurement-referenced standardization at the interval measurement level}

Standardization based on a collection of reference measurements generally makes use of the descriptive statistics of these raw scores. Again two procedures are required: one to allocate a zero point and one to develop a unit of measurement. In psychology the zero point is commonly allocated to the average of the reference measurements. This is achieved by subtracting the average raw score $(\bar{X})$ from all $n$ collected raw scores $\left(X_{i}\right)$ :

$$
x_{i}=X_{i}-\bar{X} \quad \text { for } i=1,2, \ldots, n .
$$

Mostly the average is taken to be the arithmetic mean of the measurements. But it could equally well be the median. The subtraction establishes a simple linear translation of all the scores along the scale continum. This is the centralization step, as it centres the score distribution on zero. After centralization the set of measurements represents deviation scores: positive scores are above average and negative scores below average. But a way to express the amount of deviation has not yet been established. A unit of measurement is still lacking. Often, the standard deviation is chosen as unit of measurement. Now, if the set of reference measurements is considered to constitute a sample that represents a larger universe of measurements, the standard deviation in the universe of reference measurements is estimated by:

$$
\begin{aligned}
S & =\sqrt{\frac{\sum_{i=1}^{n}\left(X_{i}-\bar{X}\right)^{2}}{n-1}} \\
& =\frac{\sqrt{x_{1}^{2}+x_{2}^{2}+\cdots+x_{n}^{2}}}{\sqrt{n-1}} \quad \text { for } i=1,2, \ldots, n
\end{aligned}
$$

where $n$ represents the number of reference measurements. On the other hand the set of reference measurements may in itself already make up the complete 
universe of measurements. For instance, if one aims to relate each performance on an educational test to the results of the total student group. i.e. 'grading to the curve", the particular group makes up the complete miverse of measurenents. Or. to give an ipsative example. if the reference measurements assess all the existing variables according to a particular theory in the same subject this set can be considered a complete universe as well. In either case the standard deviation in the universe of reference measurements does not need to be estimated but is simply established by:

$$
\begin{aligned}
\sigma & =\sqrt{\frac{\sum_{i=1}^{n}\left(X_{i}-\bar{X}\right)^{2}}{n}} \\
& =\frac{\sqrt{x_{1}^{2}+x_{2}^{2}+\cdots+x_{n}^{2}}}{\sqrt{n}} \quad \text { for } i=1,2 \ldots n .
\end{aligned}
$$

To express a score in units of standard deviation. the deviation score is divided by the standard deviation. The standard score $s_{i}$ of measurement $i$ is therefore obtained by:

$$
s_{i}=\frac{X_{i}-\bar{X}}{S} \quad \text { for } i=1.2 \ldots n .
$$

or:

$$
s_{i}=\frac{X_{i}-\bar{X}}{\sigma} \quad \text { for } i=1.2 \ldots n .
$$

In which one may recognize the score transformation to obtain z-scores. But z-scores are specifically linked to a particular set of reference measurements, i.e. collected over subjects. That issue. however, will be discussed in the section considering the selection of a set of reference measurements. This second step. the division by the standard deviation is commonly called the normalization step. ${ }^{4}$

4 This term stems from matrix algebra as the set of deviation scores can be regarded the coordinates of a vector $\mathrm{x}$ in real space of $n$ dimensions $\left(\mathcal{R}^{n}\right)$. The length of such a vector is represented by the norm and defined by the square root of the inner product:

$$
\|\mathbf{x}\|=\left(\mathbf{x}^{\prime} \mathbf{x}\right)^{\frac{1}{2}}=\sqrt{x_{1}^{2}+x_{2}^{2}+\cdots+x_{n}^{2}} \quad \text { for } \mathbf{x} \in \mathcal{R}^{n} .
$$

That the norm corresponds to the length of the vector can be made plausible by realizing that with two dimensions $(n=2)$ the equation reflects the Pythagorean theorem. Note that the norm equals the numerator of either the sample standard deviation (Formula 2.3a) or the population standard deviation (Formula 2.3b). Hence, if the set of reference measurements constitutes a sample, the standard score in vector notation is defined as:

$$
\mathrm{s}=\frac{\mathbf{x}}{\|\mathbf{x}\|} \sqrt{n-1} \quad \text { for } \mathrm{x} \in \mathcal{R}^{n} .
$$

If the set of reference measurements makes up the complete universe, it is given by:

$$
\mathrm{s}=\frac{\mathbf{x}}{\|\mathbf{x}\|} \sqrt{n} \quad \text { for } \mathrm{x} \in \mathcal{R}^{n} .
$$




\subsubsection{Standardization at the ratio measurement level}

At the ratio measurement level the absolute zero point not just discards the requirement to identify a zero point. Such an operation actually evidences malpractice, for it would reduce the measurement level to an interval level. After all, the admissible transformation only allows the definition of a rescaling factor, i.e. a unit of neasurement.

\section{Domain-referenced standardization at the ratio measurement level}

Domain-referenced standardization at the ratio measurement level does not need nor allow subtraction of the minimum of the response scale. The standardization thus becomes:

$$
s_{i}=\frac{X_{i}}{\max X} \times 100 \quad \text { for } i=1,2, \ldots, n .
$$

\section{Measurement-referenced standardization at the ratio measurement level}

With measurement-referenced standardization the unit of measurement may simply be defined in the same way as at the interval level without attributing the zero point to the raw scale score mean. In that case it amounts to dividing the scores by the sample standard deviation:

$$
s_{i}=\frac{X_{i}}{S} \quad \text { for } i=1,2, \ldots, n
$$

or the population standard deviation:

$$
s_{i}=\frac{X_{i}}{\sigma} \quad \text { for } i=1,2, \ldots, n .
$$

But in fact any unit, how arbitrarily chosen, will do. Somewhat comparably the discovery of the absolute zero point in the measurement of temperature did not result in the identification of a new unit of measurement. The new scale is expressed in Kelvin (K). It kept the unit defined by Celsius and only relocated the zero point. So the difference between the temperature of freezing and boiling water remains $100 \mathrm{~K}$.

\subsection{Defining the set of reference measurements}

Already in 1939 Flanagan outlined the three ways in which reference mcasurements may be collected for standardization purposes. The raw variable score of a respondent may be standardized by comparing it with: (a) the raw scores of other respondents on the same variable (either at the same or a previous administration occasion), (b) the respondent's own raw scores on other variables obtained at the same administration occasion, or (c) the respondent's own raw scores on the same 
variable obtained at previous measurement occasions. In other words the reference measurements are either collected as (a) a between-subjects within-variables within-occasions sample, or (b) a within-subjects between-variables within-occasions sample, or (c) a within-subjects within-variables between-occasions sample.

Standardization type (a), the comparison with the raw scores of other respondents on the same variable, is called normative standardization. Cattell (1944) originally labelled both standardization procedures (b) and (c) ipsative. Because in that case standardization is obtained by comparison with the respondent's own scores. Currently however the term 'ipsative standardization' is reserved only to indicate standardization type (b): comparison with the respondent's own raw scores on other variables obtained at the same measurement occasion. The other standardization type (c) will be referred to as iterative standardization: comparison with the respondent's own raw scores on the same variable obtained at previous measurement occasions. After all, it requires submitting the respondent to the measurement repeatedly.

\subsubsection{Normative standardization}

\section{Definition}

Normative standardization is the predominant standardization procedurc. It entails that a variable is expressed in units that are related to the distribution of scores on that variable obtained by other subjects. The term norm-referenced is also used. But this choice must be considered unfortunate. As explained in footnote 4 the term 'norm' has a circumscribed mathematical meaning. Measurementreferenced standardization of an interval scale uses this norm irrespective of how the collection of reference measurements is defined. So, group-referenced or population-referenced standardization would be a more accurate descriptive term. Nevertheless this thesis adopts the more current term 'normative standarclization'.

\section{Units}

Normative standardization at an ordinal measurement level yields percentile, decile, or other quantile scores. ${ }^{5}$ At an interval level normative standardization results in z-scores. The unit of measurement is the population standard deviation with zero indicating the population mean. This procedure is also referred to as vertical standardizing, because the default orientation of a data matrix puts the subjects into rows and the variables into columns (see Figure 2.2).$^{6}$ The reference measurements are thus collected within a column.

\footnotetext{
${ }^{5}$ Galton (1885) introduced the term percentile in reporting some results of his anthropometric laboratory.

6 The use of the orientation in the data matrix to indicate the standardization approach can be traced back to Stern (1911, pp. 17-18). However, he put the subjects in the columns and the variables in the rows.
} 
Figure 2.2: The default orientation of a data matrix

\begin{tabular}{lccccccc}
\hline & Variable 1 & Variable 2 & Variable 3 & Variable 4 & Variable 5 & Variable 6 & Variable 7 \\
\hline Subject 1 & 1 & 5 & 2 & 5 & 3 & 3 & 4 \\
Subject 2 & 2 & 2 & 2 & 5 & 3 & 4 & 4 \\
Subject 3 & 3 & 3 & 5 & 4 & 5 & 4 & 4 \\
Subject 4 & 4 & 4 & 2 & 4 & 4 & 2 & 5 \\
Subject 5 & 5 & 4 & 3 & 5 & 4 & 2 & 4 \\
Subject 6 & 6 & 3 & 5 & 2 & 3 & 2 & 5 \\
Subject 7 & 7 & 4 & 3 & 4 & 2 & 2 & 4 \\
\hline
\end{tabular}

\section{Goal}

The normative standardization method aims to define a unit of measurement that is specific to the variable in question, but generic across subjects. Thus, normative standardization only produces an accurate measurement unit if the subjects of the reference sample have an equal understanding about the utilization of the instrument. Subjects need to agree on the interpretation of the content domain of the variable. They also have to apply the rating scale equally; they should have the same interpretation about how much applicable a scale point labelled 'moderately applicable' indicates. On the other hand, an accurate normative measurement unit hinges on the between-subjects variability within the trait that the variable aims to represent. The more the reference subjects have an unequivocal conception of the variable content domain and agree in the use of the response scale, the less error variance resides in the raw between-subjects score variance. The more the reference subjects diverge on the trait, the more true score variance makes up the raw between-subjects score variance. At the interval measurement level the standard deviation in the reference subjects is used as unit of measurement. So, from this perspective, it seems advisable to include in the reference sample subjects that diverge as widely as possible on the trait to be measured, but agree as much as possible in the conception of the content domain of the variable and the use of the response scale. The developed measurement unit is then applicable to all subjects that belong to the same population that the reference sample represents.

\section{Limitations}

The normative standardization procedure presupposes that all subjects are judged using the same scale. In achievement tests this is generally the case, due to the rigorous scoring rules. Observation schemas to the contrary are notorious for the finding of differences between judges. Consequently, if two subjects receive the same score from two different judges they still could be far from exhibiting the same trait amount. One judge may simply be rigid whereas the other is charitable. This is generally prevented by thorough and regular training of the judges, or by 
averaging over several judges. In self-report questionnaires to the contrary there is just one single judge available: the respondent himself. Compared to observation methods a questionnaire severely limits the possible variety in response behaviont. The questionnaire approach therefore relatively reduces the scoring difficultics. Nevertheless. it remains important to realize that the normative standard scores of different respondents in self-report questionnaires may be biased by a differential use of the response scale. This response bias is called a response style and will be addressed in the next chapter.

This standardization procechure only allows direct conparison with the scores on the same variable of other subjects that belong to the same reference population. After all. the normative standardization procedure defines the mit of measurement. The comparison of scores obtained from different reference groups is like comparing two temperatures, one expressed in contigrade. i.e. Celsius, and the other in Falnenheit. The original Groninger Intelligence Test (GIT), for instance, allowed the user to compute three standard scores by tabular comparison: an age score. a gender score, and an achievement score (Lutcijn \& Van der Ploeg, 1983). The age score is derived by comparing the raw score with the standard scores of the group representing the sanc age gronp. The gender score adopts the same age groups as the age score but in addition distinguishes between males and females. The achievement score is obtained by evaluating the raw score against the standard scores of the total reference sample. Now, it is important to realize that a difference between the age scores of two subjects that belong to different age groups only allow the inference that subject $A$ performs better for his age than subject $B$ does for her age. ${ }^{7}$ Any verdict that subject $A$ performs better than subject $B$ on the basis of these age scores is unfounded. It rests on the hidden assumption that both reference groups have the same mean and standard deviation. Surely this is not the case. Otherwise the entire distinction between agc and gender groups in the reference sample would have been a gratuitous exercisc. Fortunately, the availability of achievement scores precludes such a far-fetched assumption for this kind of evaluation. The same argument applies mutatis mutandis to the comparison of the gender scores. In the second edition of the GIT the possibility to derive an achievement score is regrettably omitted (Luteijn \& Barelds, 2004).

The above limitation in the comparability of standard scores between subjects is generally acknowledged. What is less well realized is that the same proviso can be made for the comparison between variable scores, even within a subject. To elucidate this point the reader is familiarized with a piece of Dutch folklore: the Dutch National Championships Ice Speed-skating (NSK). Table 2.2 presents the results of all men participating in the 2004 edition. These championships took place in Heerenveen from October 31 to November 2, 2003. ${ }^{8}$ Each skater

\footnotetext{
' Strictly this interpretation assumes that in both reference groups the content domain of the variable is the same. Cross-cultural psychology teaches that this assumption cannot be taken for granted.

${ }^{8}$ This is not a clerical error; the 2004 edition of the NSK did take place at the end of 2003.
} 
only participated in a subset of the major tracks. The left sicle of the table lists the results in seconds, the right side shows the same results but now expressed in z-values. Of course this reduces the measurement level from a ratio level to an interval level. Yet, it illustrates that absolute comparisons between the tracks expressed in z-values needs the assimption that the units are commensurable.

The upper contestant. Henk Angenent is a famons marathon skater. ${ }^{9}$ According to the table he finished the $5.000 \mathrm{~m}$ in 415.74 seconds and the $10,000 \mathrm{~m}$ in 839.21 seconds. Because these finish times are commonly expressed in minutes and seconds, it is not immediately clear how well he performed. His z-values reveal however that this was not his championship. Both his finish times are above average. which indicate slower than average. The z-values show that he performed somewhat better on the $10.000 \mathrm{~m}$. This agrees with his prestige as a marathon authority. But the conclusion rests upon what a good or bad performance actually is. Normally good and bad are defined comparative to the achievements of others. Nevertheless the crux of the example is to demonstrate that with only his $\%$-values there is strictly no telling what distance he completed faster: the $5,000 \mathrm{~m}$ or the $10,000 \mathrm{~m}$. The lower $z$-value of the latter distance does not imply that he completed the $10,000 \mathrm{~m}$ quicker than the $5,000 \mathrm{~m}$. This inference would require the availability of both the associated zero points and standard deviations. Then it follows that he finished the $5,000 \mathrm{~m}$ faster:

$\begin{array}{cccl}\text { Track } & \text { z-value } & & \text { Seconds } \\ 5,000 \mathrm{~m} & 1.05 & \Rightarrow & 10.91 \times 1.05+404.25=415.71 \mathrm{~s} \\ 10,000 \mathrm{~m} & 0.38 & \Rightarrow & 14.31 \times 0.38+833.83=839.27 \mathrm{~s}\end{array}$

Of course this sounds a bit silly. Logically, twice the distance is completed in about twice the time of completing the single distance. But suppose instead of comparing the 5,000 $\mathrm{m}$ and $10,000 \mathrm{~m}$ the discussion is reverted back to ordinary psychological constructs, for instance comparing extraversion with conscientiousness. Now, likewise, it remains undecided whether a Mr. Brown is more extravert than he is conscientious. The original units that the population mean and standard deviation of both traits represent, to make both traits commensurable are simply lacking. Yet masses of psychologists fill their days with drawing normative standard score profiles and mutter about whether or not the profile should be regarded disharmonic. Is it wrong then to make such comparisons? A forceful "No!". should be the answer. But one needs to bear in mind that these scores only allow relative comparisons. Mr. Brown is relatively more extravert than he is relatively conscientious. With personality constructs this explication does not seem to import much of a benefit, particularly because a common unit of measurement

\footnotetext{
${ }^{9}$ In 1997 Henk Angenent won the ultimate skate cvent, the so-called Friese Elfstedentocht. It is a classic race around all eleven Frisian cities over about $200 \mathrm{~km}$, of which the first official edition was held in 1909. He beat Erik Hulzebosch in a nerve-racking final sprint on the Bonkervaart, an aqueous variant of the Champs Elysées. He also won the $10,000 \mathrm{~m}$ of the NSK the year before.
}

${ }^{10}$ The minor deviations from the factual results are due to rounding errors. 
Table 2.2: The NSK 2004 results with normative standard scores

\begin{tabular}{|c|c|c|c|c|c|c|c|c|c|c|c|c|}
\hline \multirow[b]{2}{*}{ Name } & \multicolumn{6}{|c|}{ seconds } & \multicolumn{6}{|c|}{ z-scores } \\
\hline & $500 \mathrm{ml}$ & $500 \mathrm{~m}$ & $1,000 \mathrm{~m}$ & $1.500 \mathrm{~m}$ & $5.000 \mathrm{~m}$ & $10.000 \mathrm{~m}$ & $500 \mathrm{~m}$ & $500 \mathrm{~m}$ & $1.000 \mathrm{~m}$ & $1.500 \mathrm{~m}$ & $5.000 \mathrm{~m}$ & $10.000 \mathrm{~m}$ \\
\hline Henk Angenent & & & & & 415.74 & 839.21 & & & & & 105 & 0.38 \\
\hline Eelco Bakermans & & & & & 40423 & 837.39 & & & & & 0.00 & 0.25 \\
\hline Jan Bos & 35.91 & 35.72 & 71.74 & & & & -117 & -1.34 & .072 & & & \\
\hline Helmuth van den Brink & & & & 113.57 & & & & & & 1.44 & & \\
\hline Bas Brusche & 36.52 & 36.56 & 72.39 & & & & -0.28 & -0.33 & .0 .21 & & & \\
\hline Lars Elgersma & 36.78 & 37.55 & 73.76 & 115.35 & & & 0.10 & 0.87 & 0.86 & 2.38 & & \\
\hline Rutger Elsinga & & & & 111.52 & 402.54 & 862.24 & & & & 0.35 & -0.16 & 1.99 \\
\hline Arjen R. Folkerts & 37.60 & 37.65 & 74.12 & & & & 1.29 & 0.99 & 1.14 & & & \\
\hline Michiel van Goor & & & & & 414.46 & & & & & & 0.94 & \\
\hline Arne de Groote & 37.15 & 36.83 & 73.70 & & & & 0.63 & 0.00 & 0.81 & & & \\
\hline Stefon Groothuis & 36.43 & 36.56 & 72.22 & 112.86 & & & -0.41 & -0.33 & .0 .35 & 1.06 & & \\
\hline Jeroen Mainwassers & 37.01 & 36.77 & 72.77 & 111.46 & & & 0.43 & -0.07 & 0.08 & 0.32 & & \\
\hline Ronald van den Ing & 37.40 & 37.22 & 74.34 & & & & 1.00 & 0.47 & 131 & & & \\
\hline Sicco Janmast & & & & 11188 & 408.54 & & & & & 0.54 & 0.39 & \\
\hline Bob de Jong & & & & 11070 & 388.16 & 821.13 & & & & .008 & -1.48 & .0 .89 \\
\hline Dennis Kalker & 37.45 & 37.27 & & & & & 1.07 & 0.53 & & & & \\
\hline Daan Kegel & & & 73.18 & & & & & & 0.40 & & & \\
\hline Rhian Ket & & & 72.91 & 111.05 & 430.76 & & & & 0.19 & 0.10 & 2.43 & \\
\hline Sander Sijbrand Kingma & & & & 112.76 & 408.99 & & & & & 1.01 & 0.43 & \\
\hline Jacques de Koning & 36.03 & 36.10 & 72.21 & & & & -0.99 & -0.88 & .0 .35 & & & \\
\hline Simon Kuipers & 36.50 & 36.52 & 71.10 & 110.11 & & & .0 .31 & .0 .38 & -1.22 & -0.39 & & \\
\hline Dave Lensen & 37.27 & 37.33 & 73.68 & & & & 0.81 & 0.60 & 0.80 & & & \\
\hline Jarno Meijer & & & & 111.78 & 408.74 & & & & & 0.49 & 0.41 & \\
\hline Beorn Nijenhuis & 36.00 & 35.79 & 70.60 & 109.26 & & & -1.03 & -1.26 & .1 .61 & -0.84 & & \\
\hline Remco Olde Heuvel & 37.18 & 37.34 & 73.76 & 11109 & & & 0.68 & 0.62 & 0.86 & 0.12 & & \\
\hline Alexander Oltrop & 35.88 & 36.31 & 70.42 & & & & -1.21 & -0.63 & .1 .75 & & & \\
\hline Mark Ooijevaar & & & & & 420.63 & & & & & & 1.50 & \\
\hline Otto van de Pol & & & 73.23 & 111.46 & & & & & 0.44 & 0.32 & & \\
\hline Ids Postma & & & & 10809 & 400.20 & 826.65 & & & & $-1,46$ & .0 .37 & -0.50 \\
\hline Tom Prinsen & & & & 109.81 & 400.13 & 835.78 & & & & -0.55 & .0 .38 & 0.14 \\
\hline Rolf van der Rijst" & & & & DQ & 400.17 & 854.28 & & & & $\mathrm{DQ}$ & -0.37 & 1.43 \\
\hline Rintje Ritsma & & & & & 407.57 & & & & & & 0.30 & \\
\hline Gianni Romme & & & & 109.29 & 393.39 & 836.53 & & & & -0.83 & .1 .00 & 0.19 \\
\hline Miel Rozendaal & & & & & 400.20 & 822.83 & & & & & -0.37 & -0.77 \\
\hline Bjarne Rykkje & & & 74.22 & & & & & & 1.22 & & & \\
\hline Brigt Rykkje & & & & & 404.16 & 837.04 & & & & & -0.01 & 0.22 \\
\hline Apjan Samplonius & 82.47 & 39.07 & & & & & - & 2.71 & & & & \\
\hline Yuri Solinger & 36.88 & 36.78 & 72.64 & 110.72 & & & 0.24 & .0 .06 & -0.02 & .0 .07 & & \\
\hline Jurre Trouw & 37.32 & 37.32 & 73.95 & & & & 0.88 & 0.59 & 1.01 & & & \\
\hline Mark Juitert & & & 71.21 & 107.78 & 392.68 & & & & -1.13 & -1.63 & -1.06 & \\
\hline Jochem Uytdehaage & & & & 108.41 & 387.55 & 812.96 & & & & -1.29 & -1.53 & .1 .46 \\
\hline Gerard van Velde & 35.40 & 35.47 & 70.42 & & & & .1 .91 & -1.65 & -1.75 & & & \\
\hline Carl Verheijen & & & & 109.01 & 386.56 & 819.87 & & & & -0.98 & -1.62 & -0.98 \\
\hline Stefan Verlaan & 37.49 & 37.31 & & & & & 1.13 & 0.58 & & & & \\
\hline Doume de Vries & & & & 409.53 & & & & & & & 0.48 & \\
\hline Erben Wennemars & 35.53 & 35.62 & & & & & .1 .72 & -1.47 & & & & \\
\hline Andreas Wierda & & & & 408.60 & & & & & & & 0.40 & \\
\hline Mark Wouda & 37.24 & 37.18 & & & & & 0.77 & 0.42 & & & & \\
\hline Mean & 36.71 & 36.83 & 72.66 & 110.86 & 404.25 & 833.83 & 0.00 & 0.00 & 0.00 & 0.00 & 0.00 & 0.00 \\
\hline SD & 0.69 & 0.83 & 1.28 & 1.89 & 10.91 & 14.31 & 1.00 & 1.00 & 1.00 & 1.00 & 1.00 & 1.00 \\
\hline
\end{tabular}

${ }^{a}$ Ralf van der Rijst was disqualified on the $1,500 \mathrm{~m}$ track, because he hindered and even touched his direct opponent Beorn Nijenhuis during the first change of lanes. Miraculously they both kept their feet.

${ }^{b}$ The result of Arjan Samplonius in the first heat of the $500 \mathrm{~m}$ track is regarded an outlier. He fell during the race. His result is therefore excluded from the computation of the $z$-scores.

for both constructs is not easily conceived. With interest measurement a common unit of measurement is generally available: the subject's preference. In predicting his choice of a dessert it is of no concern whatsoever whether Mr. Brown likes 
pudding above the population mean and ice cream below the population mean. If the reference population prefers ice cream above pudding, Mr. Brown remains perfectly consistent should he choose ice cream in resolving this consuming dilemma. It is therefore not surprising that in the realm of interest measurement -- and in particular as applied to job counselling -..- ipsative standardization is employed and still catches on.

\subsubsection{Ipsative standardization}

\section{Definition}

Ipsative standardization is much less frequently applied than normative standardization. With this standardization method a variable is expressed in units that are related to the distribution of scores to other variables obtained by the same subject at the same occasion. Cattell (1944) derived the term 'ipsative' from the Latin word ipse meaning 'self'. Due to the distinction with iterative standardization the term 'ipsative' has become over inclusive. It is true that iterative standardization uses scores obtained by the same subject as well. As a result a better label would be: 'variable-referenced standardization'. Nevertheless, the term 'ipsative' is hardly ever used to indicate within-subjects standardization over repeated measurements. This thesis will therefore maintain the expression 'ipsative standardization' in this restricted sense.

\section{Units}

The resulting score units of ipsative standardization have no separate names as with normative standardization (e.g. percentiles or z-scores). At an ordinal measurement level ipsative standardization results in scores expressing a relative rank. Division by the number of variables does not occur, because their amount rarely exceeds 10 . Ipsative standardization at an interval level requires the subtraction of the within-subjects mean and the division by the within-subjects standard deviation over all variables. This will be called ipsative deviation scores. The following derivation shows that these standard scores are invariant for all score transformations $X_{i}^{\prime}=a X_{i}+b$ :

$$
\begin{aligned}
s_{i}^{\prime} & =\frac{X_{i}^{\prime}-\overline{X^{\prime}}}{\sigma^{\prime}}=\frac{a X_{i}+b-\frac{\sum_{i=1}^{n}\left(a X_{i}+b\right)}{n}}{\sqrt{\frac{\sum_{i=1}^{n}\left[a X_{i}+b-\frac{\sum_{i=1}^{n}\left(a X_{i}+b\right)}{n}\right]^{2}}{n}}} \\
& =\frac{a X_{i}+b-a \bar{X}-b}{\sqrt{\frac{\sum_{i=1}^{n}\left(a X_{i}+b-a \bar{X}-b\right)^{2}}{n}}}=\frac{a\left(X_{i}-\bar{X}\right)}{\sqrt{a^{2} \frac{\sum_{i=1}^{n}\left(X_{i}-\bar{X}\right)^{2}}{n}}}=\frac{X_{i}-\bar{X}}{\sigma}=s_{i}
\end{aligned}
$$

Sometimes the results are divided by the total sum score over all variables. Consequently for each subject the ipsative standard scores add up to one; they are 
said to be sum constrained. Each variable score expresses the anount of the represented trait as the part of the overall trait domain of the subject. These scores will be called ipsative partition scores. The next derivation shows however that this standardization procedure is not invariant over all linear transformations:

$$
\begin{aligned}
s_{i}^{\prime} & =\frac{X_{i}^{\prime}}{\sum_{i=1}^{n} X_{i}^{\prime}} \\
& =\frac{a X_{i}+b}{\sum_{i=1}^{n}\left(a X_{i}+b\right)} \\
& =\frac{a X_{i}+b}{a \sum_{i=1}^{n} X_{i}+n b} \\
& =\frac{X_{i}+\frac{b}{a}}{\sum_{i=1}^{n} X_{i}+\frac{n b}{a}}
\end{aligned}
$$

Only for $b=0$ is this procedure invariant. i.e. over all similarity transformations $X_{i}^{\prime}=a X_{i}$. So it implies that this standardization procedure requires a ratio moasurement level. In contrast to nomative standardization the reference measurements are now taken from the rows of the default data matrix (see Figure 2.2). It is therefore also called horizontal standardizing.

\section{Goal}

The ipsative standardization method aims to define a unit of measurement that is specific to the subject in question, but generic across variables. Consequently, the precision of the unit on the one hand depends on the similarity in which the reference variables cover the trait content domain and the constancy by which the particular respondent applies the rating scale to all variables. On the other hand. it hinges on the within-subjects variability between the traits that the reference variables aim to represent. The more the reference variables agree in content coverage and the more consistent the respondent applies the response scale to the reference variables; the less error variance is contained within the raw betweenvariables score variance. The more the subject varies between the traits; the more true score variance makes up the raw between-variables score variance. At the interval measurement level the standard deviation in the reference variables is used as unit of measurement. So, from this perspective, it seems advisable to include in the reference sample variables that represent traits on which the respondent diverges as widely as possible. The included variables should, however, have a similar content coverage and advance a constant use of the response scale by the subject. Nevertheless, generally all variables are included. The derived unit of measurement is applicable to all variables that are part of the reference variables. 


\section{Limitations}

The ipsative standardization procedure assumes that all stimuli are judged using the same response scale. Any subject thus has to use the response scale in an equal way to all stimuli that relate to the diverse variables. Failure to attend to this principle affects the precision of the ipsative measurement unit. The differential use of the response scale between different variables that is the same across subjects is a type of bias that has not yet been identified. It is referred to as the response habit, and will be outlined further in Chapter 3 .

The reference measurements are all collected within the subject. As a consequence, the resulting mit of measurement is only defined within that same subject. So, in contrast to normative standardization, the ipsative standardization procedure cnables direct comparison of all the scores on variables that belong to the same set of reference variables within one subject. But now conversely comparing the scores on the same variable between two subjects is like comparing temperatures in centigrade with that in Fahrenheit. In this case it remains undefined whether Mr. Brown is more extravert than Mr. Grey. Again only relative comparisons are possible. Mr. Brown can be more extravert relative to his other traits than Mr. Grey is. As a result this approach is particularly aimed at deriving an individual profile consisting of diverse variables.

Ipsative standardization is sometimes judged the equivalent of normative standardization applied to the transposed data matrix. After all, instead of collecting measurements over subjects, i.e. vertically; the measurements are collected over variables, i.e. horizontally (see Figure 2.2). But this should be considered a misrepresentation. Normative standardization expresses the scores of a subject relative to the results of other subjects. In test theory the actual group of reference subjects is regarded a random sample of a larger. mainly infinite, reference population. Within a subject ipsative standardization expresses the scores on a variable relative to the results on other variables. But the group of reference variables is not considered a random sample of a larger universe of variables. Variables are most commonly derived from a theoretical model. The Big Five personality variables, for example, are thought to have exhausted the complete universe of personality variables. There is no domain in the universe left to represent. So, ipsative standardization does not equal normative standardization applied to the transposed data matrix.

By regarding ipsative standardization equal to normative standardization of the transposed data matrix, the variables in ipsative standardization are equated to subjects in normative standardization. But, instead of equating the variables to subjects, the stimuli in ipsative standardization should be properly likened to the subjects in normative standardization. The stimuli may well be regarded a random sample of a larger, possibly infinite, universe of stimuli. Such a sample of stimuli, however, is believed to cover the same variable. Parallel, in normative standardization the subject sample is viewed to represent the same population. Still, ipsative standardization requires a collection of measurements over variables, 
not stimuli. Then it follows that the various variables in ipsative standardization can be thought of as different populations in normative standardization. Ipsative standardization is thus the equivalent of a between-populations standardization over the transposed data matrix. As this standardization method is rarely if ever implemented, it is not helpful to relate ipsative standardization to a transposed data matrix approach.

A major drawback of ipsative standardization is that in most questionnaires the number of variables is rather limited. The use of a limited number of reference variables makes the variable scores to become interdependent after ipsative standardization. Suppose there is a questionnaire with two scales. The partition approach then dictates that the total sum score is in fact split over the two variables. If variable $A$ is 0.99 , variable $B$ is 0.01 and vice versa. Hence the variables correlate by exactly -1 . Assuming that the reference variables in nonipsative form are either orthogonal or correlate with each other to some constant degree, it has been mathematically shown that the off-diagonal elements in the correlation matrix of the reference variables after ipsative standardization will on average correlate by:

$$
r=-\frac{1}{m-1}
$$

where $m$ is the number of variables (Clemans, 1966, see Property 6.1 and 6.2; Radcliffe, 1963, Formula 11). So six independent variables would on average correlate by $-1 /(6-1)=-0.20$. just because of the ipsative standardization procedure. Only if $m$ approaches 30 this correlation appears sufficiently diluted to become negligible. This presents a major problem.

As a result ipsative standardization causes the variables to be interdependent due to the use of a limited set of reference variables. It invalidates the application of parametric statistical techniques, since these methods require independent data points. Validity research, for instance, often makes use of factor analysis. As this technique is then applied to biased correlations it has been advised against. Altogether this is why ipsative standardization has never celebrated a profound interest by psychometricians. However, recently new statistical techniques have become available that deal with the artificial interdependency arising from the use of a limited set of reference variables (Aitchison, 1986; Chan, 2003; Van der Ark, 1999). These tools may therefore come to the rescue of ipsative standardization.

As a final remark the standardization method should be reviewed in light of the preservation of information in a data matrix. One of the fundamental properties of a matrix that reflects this information is its rank. In algebra any scalar quantity (for instance 10) can be expressed as the product of two quantities in an infinite number of ways $\left(2 \times 5,4 \times 2 \frac{1}{2}, 6 \frac{2}{3} \times 1 \frac{1}{2}\right.$, et cetera). A matrix can likewise be expressed as a product of two matrices in an infinite number of ways. The rank of a matrix is defined by the minimum number of rows or columns that the two matrices require in order to reproduce the exact original matrix. 
Table 2.3: The NSK 2004 results with ipsative standard scores

\begin{tabular}{|c|c|c|c|c|c|c|c|c|c|c|c|c|c|}
\hline \multirow[b]{2}{*}{ Name } & \multicolumn{6}{|c|}{ seconds } & \multirow[b]{2}{*}{ Sum } & \multicolumn{6}{|c|}{ ipsative partition scores } \\
\hline & $500 \mathrm{~m}$ & $500 \mathrm{~m}$ & $1,000 \mathrm{~m}$ & $1,500 \mathrm{~m}$ & $5,000 \mathrm{~m}$ & $10.000 \mathrm{~m}$ & & $500 \mathrm{~m}$ & $500 \mathrm{~m}$ & $1,000 \mathrm{~m}$ & $1.500 \mathrm{~m}$ & $5.000 \mathrm{~m}$ & $10.000 \mathrm{~m}$ \\
\hline Henk Angenent & & & & & 415.74 & 839.21 & 1254.95 & & & & & 0.33 & 0.67 \\
\hline Eelco Bakermans & & & & & 404.23 & 837.39 & 1241.62 & & & & & 0.33 & 0.67 \\
\hline Jan Bos & 35.91 & 35.72 & 71.74 & & & & 143.37 & 0.25 & 0.25 & 0.50 & & & \\
\hline Heimuth van den Brink & & & & 113.57 & & & 113.57 & & & & 1.00 & & \\
\hline Bas Brusche & 36.52 & 36.56 & 72.39 & & & & 145.47 & 0.25 & 0.25 & 0.50 & & & \\
\hline Lars Elgersmo & 36.78 & 37.55 & 73.76 & 115.35 & & & 263.44 & 0.14 & 0.14 & 0.28 & 0.44 & & \\
\hline Rutger Elsinga & & & & 111.52 & 402.54 & 862.24 & 1376.30 & & & & 0.08 & 0.29 & 0.63 \\
\hline Arjen R. Folkerts & 37.60 & 37.65 & 74.12 & & & & 149.37 & 0.25 & 0.25 & 0.50 & & & \\
\hline Michie! van Goor & & & & & 414.46 & & 414.46 & & & & & 1.00 & \\
\hline Arne de Groote & 37.15 & 36.83 & 73.70 & & & & 147.68 & 0.25 & 0.25 & 0.50 & & & \\
\hline Stefan Groothuis & 36.43 & 36.56 & 72.22 & 112.86 & & & 258.07 & 0.14 & 0.14 & 0.28 & 0.44 & & \\
\hline Jeroen Hairwassers & 37.01 & 36.77 & 72.77 & 111.46 & & & 258.01 & 0.14 & 0.14 & 0.28 & 0.43 & & \\
\hline Ronald van den Ing & 37.40 & 37.22 & 74.34 & & & & 148.96 & 0.25 & 0.25 & 0.50 & & & \\
\hline Sicco Janmast & & & & 111.88 & 408.54 & & 520.42 & & & & 0.21 & 0.79 & \\
\hline Bob de Jong & & & & 110.70 & 388.16 & 821.13 & 1319.99 & & & & 0.08 & 0.29 & 0.62 \\
\hline Dennis Kalker & 37.45 & 37.27 & & & & & 74.72 & 0.50 & 0.50 & & & & \\
\hline Daan Kegel & & & 73.18 & & & & 73.18 & & & 1.00 & & & \\
\hline Rhian Ket & & & 72.91 & 111.05 & 430.76 & & 614.72 & & & 0.12 & 0.18 & 0.70 & \\
\hline Sander Sijbrand Kingma & & & & 112.76 & 408.99 & & 521.75 & & & & 0.22 & 0.78 & \\
\hline Jacques de Koning & 36.03 & 36.10 & 72.21 & & & & 144.34 & 0.25 & 0.25 & 0.50 & & & \\
\hline Simon Kuipers & 36.50 & 36.52 & 71.10 & 110.11 & & & 254.23 & 0.14 & 0.14 & 0.28 & 0.43 & & \\
\hline Dave Lensen & 37.27 & 37.33 & 73.68 & & & & 148.28 & 0.25 & 0.25 & 0.50 & & & \\
\hline Jarno Meijer & & & & 111.78 & 408.74 & & 520.52 & & & & 0.21 & 0.79 & \\
\hline Beorn Nijenhuis & 36.00 & 35.79 & 70.60 & 109.26 & & & 251.65 & 0.14 & 0.14 & 0.28 & 0.43 & & \\
\hline Remco Olde Heuvel & 37.18 & 37.34 & 73.76 & 111.09 & & & 259.37 & 0.14 & 0.14 & 0.28 & 0.43 & & \\
\hline Alexander Oltrop & 35.88 & 36.31 & 70.42 & & & & 142.61 & 0.25 & 0.25 & 0.49 & & & \\
\hline Mark Ooijevaar & & & & & 420.63 & & 420.63 & & & & & 1.00 & \\
\hline Otto van de Pol & & & 73.23 & 111.46 & & & 184.69 & & & 0.40 & 0.60 & & \\
\hline Ids Postma & & & & 108.09 & 400.20 & 826.65 & 1334.94 & & & & 0.08 & 0.30 & 0.62 \\
\hline Tom Prinsen & & & & 109.81 & 400.13 & 835.78 & 1345.72 & & & & 0.08 & 0.30 & 0.62 \\
\hline Ralf van der Rijst & & & & DQ & 400.17 & 854.28 & 1254.45 & & & & $D Q$ & 0.32 & 0.68 \\
\hline Rintje Ritsma & & & & & 407.57 & & 407.57 & & & & & 1.00 & \\
\hline Gianni Romme & & & & 109.29 & 393.39 & 836.53 & 1339.21 & & & & 0.08 & 0.29 & 0.62 \\
\hline Miel Rozendaal & & & & & 400.20 & 822.83 & 1223.03 & & & & & 0.33 & 0.67 \\
\hline Bjarne Rykkje & & & 74.22 & & & & 74.22 & & & 100 & & & \\
\hline Brigt Rykkje & & & & & 404.16 & 837.04 & 124120 & & & & & 0.33 & 0.67 \\
\hline Arjan Samplonius ${ }^{a}$ & 82.47 & 39.07 & & & & & 121.54 & 0.68 & 0.32 & & & & \\
\hline Yuri Solinger & 36.88 & 36.78 & 72.64 & 110.72 & & & 257.02 & 0.14 & 0.14 & 0.28 & 0.43 & & \\
\hline Jurre Troum & 37.32 & 37.32 & 73.95 & & & & 148.59 & 0.25 & 0.25 & 0.50 & & & \\
\hline Mark Tuitert & & & 71.21 & 107.78 & 392.68 & & 571.67 & & & 0.12 & 0.19 & 0.69 & \\
\hline Jochem Uytdehaage & & & & 108.41 & 387.55 & 812.96 & 1308.92 & & & & 0.08 & 0.30 & 0.62 \\
\hline Gerard van Velde & 35.40 & 35.47 & 70.42 & & & & 141.29 & 0.25 & 0.25 & 0.50 & & & \\
\hline Carl Verheijen & & & & 109.01 & 386.56 & 819.87 & 1315.44 & & & & 0.08 & 0.29 & 0.62 \\
\hline Stefan Verlaan & 37.49 & 37.31 & & & & & 74.80 & 0.50 & 0.50 & & & & \\
\hline Douwe de Vries & & & & & 409.53 & & 409.53 & & & & & 1.00 & \\
\hline Erben Wennemars & 35.53 & 35.62 & & & & & 71.15 & 0.50 & 0.50 & & & & \\
\hline Andreas Wierda & & & & & 408.60 & & 408.60 & & & & & 1.00 & \\
\hline Mark Wouda & 37.24 & 37.18 & & & & & 74.42 & 0.50 & 0.50 & & & & \\
\hline
\end{tabular}

${ }^{a}$ Now the result of Arjan Samplonius in the first heat of the $500 \mathrm{~m}$ track is retained. It cannot be regarded an outlier since we lack sufficient observations to make this inference. If we ignore the context the data might equally well fit somebody who falls every race. Then the result of the second heat would be considered an outlier.

The rank of a matrix is maximally equal to the minimum of its own number of rows or columns. So the rank of a data matrix containing more subjects than variables is bounded by the number of variables. If such a data matrix is ipsatized the last variable becomes a linear transformation of the scores on the other variables. In effect the rank of the resulting matrix is reduced by 1 . Hence, the preservation of information would best be served by preferring ipsative 
measurement over normative measurement if the number of variables exceds the number of subjects.

Usually the number of subjects exceeds the number of variables. However, there is a different consicleration that might urge one to opt for an ipsative measurement unit. It helps to reconsider the ice spect-skating example again. Table 2.3 presents the same results as Table 2.2, only the right part now consists of ipsative partition scores. Now it is immediately clear that Henk Angenent finished the $5,000 \mathrm{~m}$ faster than the $10,000 \mathrm{~m}$. He spent 0.33 of his total skating time to finishing the $5,000 \mathrm{~m}$ and 0.67 of his total skating time to finishing the $10,000 \mathrm{~m}$. In this case it is safe to conclude that he finished the $5,000 \mathrm{~m}$ twice as fast, because the partition scores of the finish times reflect a ratio measurement level. With psychological constructs this will not be the case. Nevertheless, the argued benefit of ipsative measurement above normative measurement is that an ipsative measurement unit better serves the within-subjects commensurability of traits. If Mr. Brown likes pudding above his within-subjects average and ice cream below his within-subjects average it allows the prediction that he chooses pudding. Of course this prediction could be off, but in that case it would at least be justified to question his consistency. Fortunately, the championships did not make use of ipsatized scores. It would have become impossible indeed to appoint the winner of each track.

\subsubsection{Iterative standardization}

In psychology iterative standardization is rarely applied. It makes use of repeated measurements of the same variables within a subject. Still, it could be of particular interest in the assessment of developmental processes and change. For instance, in the measurement of moods or temperaments this type of standardization could be applied. It allows the inference how a subject's current mood relates to previous measurements of his mood. The repeated measurement of the same subjects and the same variables results in a data matrix for every replication (see Figure 2.2). One may envision the total data matrix to become a three-dimensional cube if the repeated measurement results are appended from front to back. Then this standardization procedure could also be regarded transversal standardization. This procedure will not be elaborated on any further. It is just mentioned to be complete and to stress the difference with ipsative standardization in the restricted sense.

\subsubsection{Combinations of standardization}

The three types of measurement-referenced standardization may be applied to scores that are first domain-referenced standardized. This is even advisable if the possible score range of the instrument differs over the dimension that defines the set of reference measurements: subjects, variables, or administration occasions. Suppose the subjects complete either a short version or the complete version of an 
instrument. Then domain-referenced standardization should be applied before the normative standardization procedure is started. Otherwise the between-subjects differences in raw variable scores are partly due to which version is completed. Then the number of stimulus responses differs between subjects. With ipsative standardization, the scores deserve to be standardized in a domain-referenced fashion first if the various variables are each covered by a different number of stimuli. And finally, iterative standardization should follow domain-referenced standardization, if the number of stimuli representing a variable has changed over the measurement occasions. In all three examples domain-referenced standardization is essential to correct for the differential content coverage within the collection of reference measurements.

The three main types of measurement-referenced standardization may also be combined with each other. A matrix that is standardized in two directions is called a doubly centred data matrix. A triply centred data matrix has never been suggested. Cattell (1944) already realized that the order in which these operations are performed makes a difference. Reversing the order does not yield the same results. The results of the ice-skaters for instance may first be standardized iteratively. How well did they skate on the $500 \mathrm{~m}$ of the championship compared to their previous training results? Hopefully all performed better than their own average, because of the generally outstanding skating conditions during a championship. Suppose an iterative standardization on a ratio level is employed in the form of division by the average, instead of the standard deviation as was applied in Formulas 2.8a and 2.8b. Then the championship results for all in standard scores should lie between zero and one. Subsequent normative standardization of these scores then reveals who improved himself on the championship most, who moderately, and who least. Conversely, first normative standardization of all training and championship results indicates for each training moment and the championship who performed best, who average, and who worst. Subsequent iterative standardization now shows the change in these normative results on the championship. Some improved, some remained the same, and some deteriorated, all relatively to the other competitors.

It has been questioned whether normative standardization of already ipsative standardized results is informative or even admissible (Fedorak \& Coles, 1979; Katz, 1962; Van Geffen, 1980). The argument against such an operation is that ipsative standardization expresses the results in a measurement unit that is respondent specific. Ipsative standard scores reveal the relative importance of the scales for the subject. Consequently, Allport, Vernon, and Lindzey (1960, p. 8) warn against the misinterpretation of their ipsative Study of Values (SOV): "It is quite possible for the highest value of a generally apathetic person to be less intense and effective than the lowest value of a person in whom all values are prominent and dynamic." Absolute comparisons are only warranted if one assumes each respondent to be endowed with the same total amount of traits (Caminada, Evers, \& Brouwer, 1981).

Nevertheless, without this assumption relative comparisons can still be 
made. The issue whether such a comparison is informative depends on what the actual question is. Fedorak and Coles $(1979$, p. 920) formulated the kind of inference that the comparison between two normative standardized ipsative scores grant: "Person $\mathrm{A}$ is higher on variable $\mathrm{X}$ in relation to his other attributes than person $\mathrm{B}$ is on variable $\mathrm{X}$ in relation to his other attributes." The normative standardization of ordinary raw scores needs to assume that the different respondents use the response scale equally. The assumption is not crucial, however, if the raw scores are ipsatized first. In that case the transformation removes this kind of variance from the ipsative standard scores.

\subsubsection{Self-inclusiveness in standardization}

In instrument and measurement-referenced standardization the reference instrument or reference measurement itself could either be included in the reference set or not. This is referred to as the self-inclusiveness of the standardization method. The instrument-referenced standardization method makes use of one instrument only. Hence the distinction is quite straight-forward. In case the instrumentreferenced standardization method is self-inclusive, measurements will refer to the instrument itself; and this is domain-referenced measurement. If not, the measurements will refer to another measurement, which indicates pointer or pseudopointer measurement. So, in instrument-referenced measurement the self-inclusiveness of the standardization method is clearly distinguished.

With measurement-referenced standardization this division is more implicit. Measurement-referenced standardization makes use of a set of reference measurements. The measurement that is to be standardized, i.e. the index measurement, is either part of the set of reference measurements or not. But all three kinds of measurement-referenced standardization: normative, ipsative, and iterative can either be self-inclusive or not. In a self-inclusive measurement-referenced standardization method the set of reference measurements usually make up the whole population. As the standard deviation is differently defined for a population or a sample, the distinction is of practical importance.

The normative standardization of an educational test is usually performed over all students that completed the test. That is because most educational tests are just used once. There is simply no other representative sample available that may provide for an independently estimated mean and standard deviation. As the mean and standard deviation are estimated using the exact same sample as the sample to which the standardization is applied, students are competing among themselves for the highest grades. This is what 'grading to the curve' is all about. It is referred to as self-inclusive normative standardization.

To the contrary many psychological tests are standardized using a representative sample of subjects. The Wechsler Adult Intelligence Scale-III, for instance, presents norm tables in the manual. These allow the results of a subject to be compared with the mean and standard deviation of a representative sample. Then the results of the subject are independent of the other subjects that the psychol- 
ogist assessed. This is considered self-exclusive normative standardization.

In ipsative standardization the index measurement is usually a part of the set of reference measurements. Ipsative standardization collects the set of reference measurements within the same subject over other variables. These other variables also yield scores that are incorporated in the final score profile. As a consequence the variables are competing within the subject for the highest scores. This is the critical characteristic of the multidimensional compound item (MCI). Analogously, this is regarded self-inclusive ipsative standardization.

However, it is conceivable to express a variable score relative to the scores of a group of reference variables, without the index variable score being part of it. The group of reference variables may be considered irrelevant for the measurement at hand to be assessed on their own. Essentially, the matched indeterminate compound item (ICI), presented in Chapter 1, makes reference to such a group of dummy variables. It was the type of forced-choice item that originally was presented by Jurgensen (1944). Such an item consists of multiple stimuli of which one is keyed to the relevant variable, whereas the remaining stimuli do not contribute to a variable (see also Figure 1.4). These other stimuli do represent other variables, but are not scored. Hence, they are considered dummy stimuli and dummy variables. This approach results in one variable score. This variable score, therefore, does not suffer from correlated errors.

Nevertheless, it is a mistake to consider the scores of the matched ICI not essentially as ipsative standard scores. Suppose, for instance, that Subject $\mathrm{A}$ is endowed with traits $\mathrm{X}, \mathrm{Y}$, and $\mathrm{Z}$ on an absolute level of 25, 15, and 10, respectively. Subject $B$ commands traits $X, Y$, and $Z$ on an absolute level of 25 , 35 , and 40 , respectively. The index variable covers trait $X$, whereas the dummy variables represent traits $Y$ and $Z$. In that case it can be expected that Subject $A$ mostly chooses the stimulus that represents trait X. Subject B will mostly prefer the stimuli that represent traits $Y$ and $Z$. On the basis of these responses it may seem that Subject $A$ masters trait $X$ in a larger extent than Subject B. But the only inference allowed is that Subject A masters trait $\mathrm{X}$ more as compared to his levels of the dummy traits than Subject B. Because, as was given at the outset, both subjects agree in their absolute levels on trait X. Hence, the matched ICI must be considered to result in self-exclusive ipsative standard scores.

\subsection{The choice of a measurement unit}

It is hoped that the ice skating example made it clear that the foremost reason to opt for a particular standardization approach is the kind of decision that the measurement is aimed for. Van der Linden (1994) offered a classification of four types of measurement based treatment decisions. A treatment is broadly defined here; it not necessarily implies a therapy, but may well signify an educational method or the assignment to a job. He distinguished the selection, classification, placement, and mastery decision. These decisions resolve different questions. And 
each decision hinges on another sort of information.

All these decisions are frequently based on raw scores. Simply, because in raw data all information is retained. The standardization methods are acceptable insofar they do not remove the information that the decision requires. As a result these decisions are only weakly associated with the varions standardization approaches. The suggested relation between the type of decision and the method of standardization is not mandatory. Still, the proposed association will now be outlined.

\subsubsection{Selection decision}

A selection decision involves the measurement of subjects before they are admitted to a treatment. Success of the potential treatment will be established by a criterion measurement. The decision measurement aims to predict which subjects will most likely succeed in the treatment. Examples of selection decisions are auditions for a role in a musical, or student admission examinations for a master program. Clearly, success in the musical will just be evaluated by the observed performance at rehearsals, whereas a master program consists of all kinds of examinations. Mammography as a population screening measurement for breast cancer, for instance, also constitutes a selection decision. The ensuing treatment is further testing, i.e. biopsy, which is considered 'successful', i.e. a correct diagnosis, if the collected tissue reveals cancer. Selection thus addresses the question: "Will the subject meet the criterion?"

Two different kinds of selection decisions exist. In case the capacity of the treatment is fixed, it is called quota-fixed selection. With the musical audition, for instance, they just need so many subjects as there are roles. As a result only the most promising subjects are accepted. The remaining subjects may still be good, but are nevertheless rejected. A quota-fixed selection decision accepts normative standardization, because these standard scores remain directly informative about someone's relative standing in the sample or population.

If the number of treatments is not limited, it is called quota-free selection. All subjects that are expected to meet the criterion will be admitted. The mammography example is a case of quota-free selection. With a quota-free selection decision normative standardization is acceptable as well, since the rank order of the subjects is maintained.

\subsubsection{Classification decision}

A classification decision aims to assign the subject to the treatment that is expected to be most beneficial to the individual. Contrary to a selection decision, every subject receives a treatment. The treatments to choose from differ in their objectives. The criteria that establish whether the treatment was successful or not are therefore dissimilar. In effect, a classification decision assigns the subject to one of several treatment objectives. The selected treatment objective will then 
result in the associated treatment. The classic example is the measurement of interests for vocational guidance. A classification decision therefore answers the question: "Of which of the treatment objectives will the subject best meet the criterion?", or a bit less cryptic: "Which criterion will the subject meet best?"

If a classification decision relates to a multitude of treatment objectives, as for instance vocations, it is unlikely that the same subject characteristic would be most predictive of all criterion measurements. Matching a subject with the best fitting treatment objective thus requires the collection of multivariate information. It results in multiple variable scores. As the subject should be assigned to the best fitting treatment, the criteria for the diverse treatments need to remain comparable within the subject. Ipsative standardization preserves the comparability of the diverse criteria within the subject. So, a classification decision with many treatment objectives is not hampered by ipsative standardization.

\subsubsection{Placement decision}

Like a classification decision, a placement decision aims to assign the subject to the treatment that is expected to be most beneficial to the individual. Contrary to a classification decision though, the treatments all share the same objective. Hence, the criterion measure is identical. The treatments are distinguished, because it is realized that subjects may diverge in their reaction to a particular treatment. The response to a treatment might be affected by an interaction effect between subject and treatment. So, one subject may profit more from treatment $\mathrm{X}$, whereas another subject would thrive better on treatment $Y$. Examples are the choice between regular or Montessori education, or the assignment of a client to either behavioural or cognitive therapy. The critical question in such a decision is: "How will the subject best meet the criterion?"

A placement decision thus aims to predict the treatment from which the respondent will profit most. Van der Linden (1994) noted that placement decisions have mostly been tackled using linear-regression techniques. This requires the measurement unit to remain comparable among subjects. But an arrested or retarded development, evidenced by repeated measurements within a subject, could evidently also motivate a change of placement. That would demand a unit of measurement that remains constant over measurement occasions. Therefore no clear association between this type of decision and a permissible kind of standardization is found.

\subsubsection{Mastery decision}

With a mastery decision the subject already received a kind of treatment. The objective of a mastery decision is to determine whether a subject has profited sufficiently from the treatment to be released from it. If not, the treatment program is continued or repeated. Hence, the measurement for a mastery decision constitutes the criterion measurement itself. Examples are the evaluation of suicide 
risk to grant discharge from a psychiatric hospital. or a driving test. A mastery decision answers the question: "Did the subject meet the criterion?"

With this type of decision it seems best to relate the score to the objectives of the treatment. Such a measurement should cover the treatment objectives completely, in order to fulfil the requirement of content validity. Domain-referenced standardization is in that case the most apposite method (Glaser, 1963). Its susceptibility to all types of response tendencies notwithstanding, this method indicates best a subject's standing with regard to the treatment objectives. 


\title{
A new typology of response tendencies
}

\author{
Any particular scale $[. .$.$] may be objected to on the grounds of$ \\ bias, low precision, restricted generality, and other factors, \\ but the objector should remember that these are relative and practical matters \\ and that no scale used by mortals is perfectly free of their taint.
}

(Stevens, 1946, p. 680;1951, p. 30)

Every psychological measurement is affected by error. Measurements will always in some extent diverge in the actual quantifications of the traits they cover. This is considered particularly relevant when the measurements are based on judgements. Then a fair share of this error may be attributed to differences in the application of the rating scale. Remember for instance your teachers in high school. Some were more generous in their grading than others. Bias caused by this differential application of a rating scale is referred to as a response tendency.

An important factor in the emergence of response tendencies is the number of scale points that the rating scale includes, i.e. the resolution of the rating scale. Any increase in the resolution of the rating scale enhances the risk of its differential application. Usually, compound items allow a less differentiated judgement of each stimulus than singular items. As a result ipsative data collection may be less susceptible to response tendencies.

In addition, the various approaches to standardize data are each vulnerable to different types of response tendencies. In other words both the data collection methods and the standardization procedures play an important role in the management of response tendencies. Actually, the concern about response tendencies has for a large part contributed to the development and sustenance of both aspects of ipsative measurement. Therefore, in order to do justice to ipsative measurement, the issue of response tendencies deserves proper attention.

\subsection{A typology of response tendencies}

In Chapter 2 the distinction between normative, ipsative, and iterative standardization was based on whether the reference measurements were sampled over 
subjects, variables, or measurement occasions respectively. In self-report questionnaires the subjects judge themselves. So, if it is realized that the subject also constitutes the judge, these same three units provide the basis for a typology of response tendencies. The result provides a revealing insight into the relationship between response tendencies and standardization methods.

As said before, a response tendency is the differential application of a rating scale. But the essential question is: 'Differential over what?' The answer is plain and simple. The rating scale may be applied differentially over judges, over variables, or over measurement occasions. They may be combined freely. So it produces a 2 (differential across judges: yes/no) $\times 2$ (differential across variables: yes/no) $\times 2$ (differential across occasions: yes/no) typology. This combination results in eight possible response tendencies.

Four of them have already been described in the literature before. These will now fall into place: the response style, the response set, the response shift, and no response tendency at all: response consistency. Of the four that may be added one is particularly relevant to ipsative standardization. It is the differential application of the rating scale over variables. This will be addressed as the response habit. The three other newcomers are baptised and christened as well. The differential rating scale use across both judges and measurement occasions is called the response fashion. The differential rating scale use across both variables and measurement occasions is called the response drift. And finally the differential rating scale use across judges, variables and measurement occasions is referred to as the response whin.

Figure 3.1 depicts the typology as a decision tree. The next subsections will outline these distinguished response tendencies in the same order as they are listed. After defining each response tendency, the implication of its occurrence for the diverse standardization methods is discussed.

\subsubsection{Response consistency}

\section{Definition}

Response consistency is actually the absence of any response tendency (see Figure 3.1). It means that different judges utilize the rating scale in the same manner, that the rating scale is applied in the same manner to different variables, and that the rating scale is employed in the same manner across measurement occasions. This is actually the basic assumption of any rating scale that allows the assignment of quantities. The represented quantities are assumed to be the same for any judge, variable, or measurement occasion.

\section{Implications for standardization methods}

Without a response tendency, the test user is free to choose any method of standardization that is available. If judges rate multiple variables, in multiple subjects, at multiple occasions with the same observation schema comparisons be- 
Figure 3.1: Decision tree for determining the type of response tendency

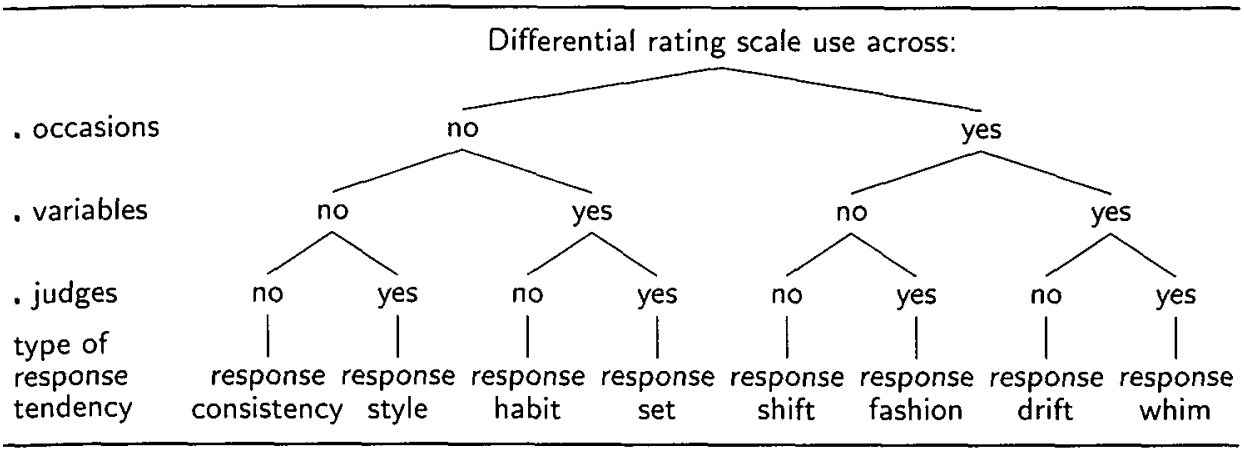

tween judges, subjects, variables, or measurement occasions all remain valid. The method of choice would be domain-referenced standardization. This standardization approach derives a mit that can be applied to compare different judges, different subjects, different variables, and different measurement occasions. Normative standardization only allows direct comparisons between subjects. Ipsative standardization just permits direct comparisons between variables. And iterative standardization, eventually, is limited to direct comparisons between measurement occasions.

\subsubsection{Response style}

\section{Definition}

The most common response tendency is the response style. It is the differential use of a rating scale between judges (see Figure 3.1). The response style is regarded constant over the various variables and measurement occasions. Rorer (1965) was the first to clearly demarcate this type of response tendency. At least six different response styles are known: acquiescence, dissentience, inclusiveness, the midpoint response style, the extremity response style, and the random response style. The best known representative is acquiescence or yea-saying, which is customarily defined as the general tendency to endorse stimuli regardless of their content (Cronbach, 1942; Fritz, 1927; Lentz, 1938; Lorge, 1937). The exact opposite is called dissentience or nay-saying. It is the general tendency to reject stimuli irrespective of their content (Cruse, 1966).

Inclusiveness is limited to the use of checklists and indicates the tendency to check many or few propositions (Cronbach, 1946; D. N. Jackson \& Minton, 1963). The Adjective Check List, for instance, presents the respondents with a list of adjectives. Each adjective is associated with a single checkbox. The respondent is asked to check the adjectives, which he or she considers applicable. Some subjects, however, select many adjectives, whereas others mark only a few. This divergence 
is thought to be partly due to individual differences in the preparedness to consider an adjective applicable, irrespective of its content. An inclination to mark stimuli easily is called inclusiveness. Supplying each adjective with two checkboxes allows the respondent to indicate for each separate adjective whether it is applicable or not. It simply eliminates the inclusiveness response style. Inclusiveness then reduces to either acquiescence or dissentience.

Evasiveness (Cronbach, 1950) or the midpoint response style (Furnham, 1986) is the general tendency to be in doubt or choose the midpoint of the rating scale. The reverse of which is the extremity response style (Frederiksen, 1965; Rundquist, 1950). That is the general tendency to select one of the extreme rating scale points. The final response style is the random response style. Then the judge simply marks scale points at random, without interpreting the associated stimuli.

An easy method to get an impression how a judge applied the rating scale, is to tally the times he used a particular scale point over all his ratings. Acquiescence, dissentience, and inclusiveness all induce a shift in the resulting frequency distribution of selected scale points. The centre of this within-judge response frequency distribution is displaced. Acquiescence relocates the centre of this distribution in the direction of the agreement pole, and dissentience towards the disagreement pole. Inclusiveness displaces the centre of the within-subjects response frequency distribution towards the 'checked' pole of the rating scale.

In geometry such a transformation is called a translation. Hence, acquiescence, dissentience, and inclusiveness are referred to as translating response styles. Conceptually, translating response styles must be considered due to a differential attribution of what point constitutes the centre of the rating scale. So, the scale point anchor labels do not fix the scale points unequivocally to the underlying trait continuum: all anchors equally slip.

Unlike the previous response styles, the midpoint and extremity response style do not displace the centre of the response frequency distribution. Instead, they affect its dispersion. The midpoint response style causes the responses to be concentrated around the midpoint. It induces a leptokurtic, i.e. sharpened, response frequency distribution. The extremity response style distributes the responses away from the midpoint. That results in a platykurtic, i.e. flattened, or even bimodal response distribution. The midpoint of the rating scale remains fixed, but the distances towards the midpoint are differentially interpreted.

In geometry this kind of transformation is called a homothetic transformation. The midpoint and extremity response style are therefore regarded homothetic response styles. From a theoretical viewpoint, these response styles arise from a differential interpretation of the unit of measurement of the rating scale. The scale point anchor labels do not fix the scale points to the underlying trait continuum either. But now the rating scale is considered shrunken or stretched, keeping the centre in place.

These response styles affect the stimulus score depending on the stimulus type. Two different stimuli exist: indicative stimuli and contra-indicative stimuli. Indicative stimuli correlate positively with the trait they represent, whereas 
Figure 3.2: The effect of response styles on the response distribution

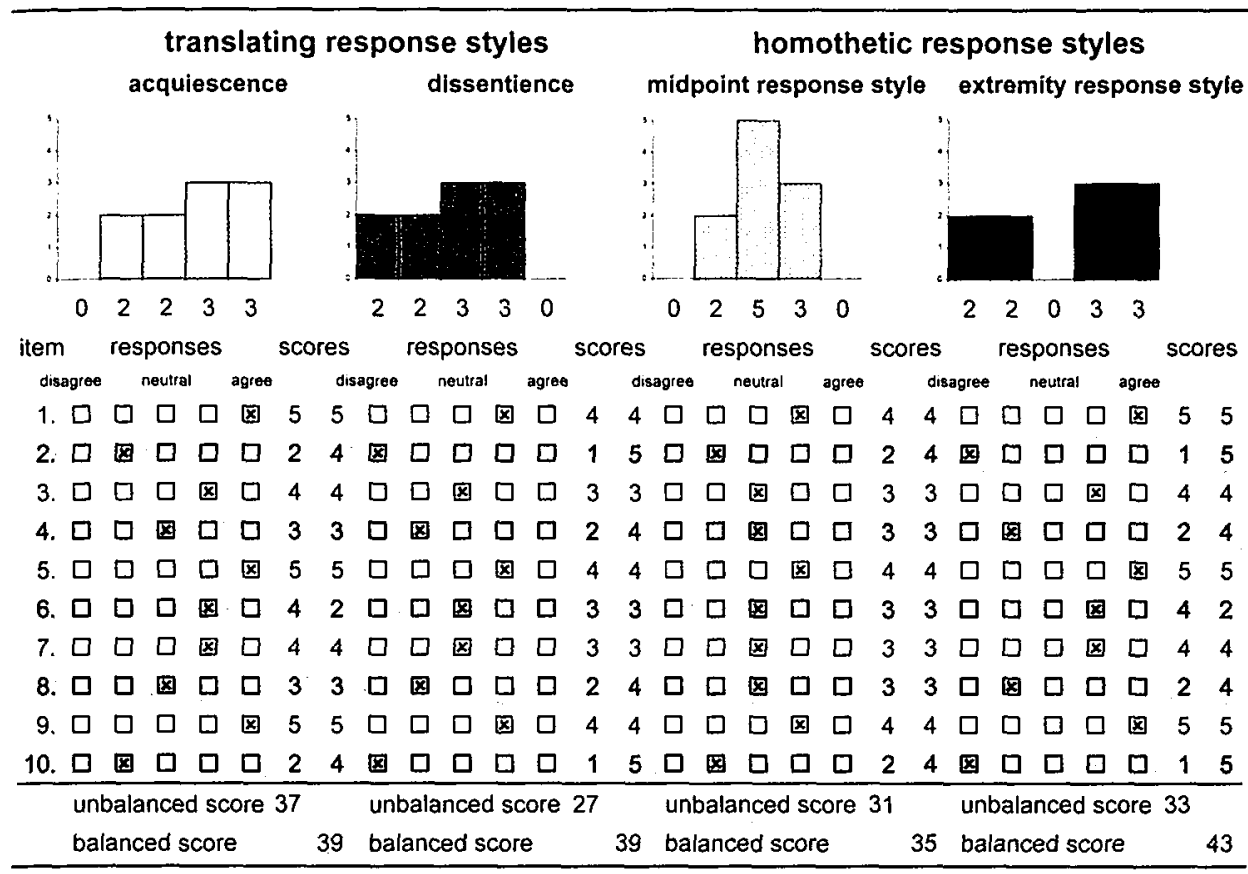

Note. The checkboxes reveal the responses of four different judges rating the same subject with the same stimuli. The histograms indicate the selection frequencies of the scale points. The item scores and total scores relate to two different instruments. If the instrument only consists of indicative stimuli, the unbalanced score is the variable score. If the instrument contains an equal number of indicative stimuli (uneven items) as contra-indicative stimuli (even items), the balanced score is the variable score. Balancing as a strategy to control for response styles is explained in Section 3.2.2

contra-indicative stimuli correlate negatively with it. As a result the higher the rating of an indicative stimulus, the higher the score that is contributed to the variable score. With a contra-indicative stimulus a higher rating adds a lower score to the variable.

In response to indicative stimuli acquiescence and inclusiveness elevate the response scores, whereas dissentience reduces them. The midpoint response style increases response scores that are below the midpoint and reduces them above the midpoint. The extremity response style to the opposite increases response scores above the midpoint and reduces them below the midpoint. In response to contra-indicative stimuli, the influences of all these response styles are reversed.

So far, the random response style has not been incorporated into the subclassification. That is, because the random response style forms a class in itself. It cannot be expected to arise from an alternative interpretation of the rating 
scale. It simply results from ignoring the stimulus content. Hence, it does not transform the response frequency distribution linearly.

Figure 3.2 illustrates the operation of acquiescence, dissentience, the miclpoint response style, and the extremity response style on a 5-point Likert scale. The checkboxes show the ratings of four hypothetical judges who rate the sane subject on the same ten stimuli. The outer left judge evidences acquiescence; his ratings deviate towards the agree pole. The middle left judge displays dissentience; his ratings deviate towards the disagree pole. The niddle right judge demonstrates the midpoint response style; his ratings deviate towards the middle of the rating scale. And finally, the outer right judge exhibits the extremity response style; his ratings deviate towards either end of the rating scale.

The responses are invented, but the system underlying these data is quite straightforward. The responses of the dissentient judge deviate from the acquiescent judge by one scale point towards the disagree pole. The midpoint judge agrees with both judges. He selects, however, the most middle rating of them. The extremity judge also agrees with the acquiescent and dissentient judge, but he chooses the most extreme rating of both. The frequency of selecting each scale point is shown by the counts on the $x$-axis of each histogram. The histograms now explain why acquiescence and dissentience are called translating response styles. These response styles displace the centre of the raw stimulus response distribution towards either the agree or disagree end of the rating scale. The midpoint and extremity response styles are regarded homothetic response styles. The underlying rating scale can be considered shrunken or stretched, for they respectively decrease or increase the dispersion in the raw stimulus response distribution.

\section{Implications for standardization methods}

All kinds of response styles reflect a differential rating scale use between judges. As a result these response styles make comparisons between judges illegitimate. This may bear relevance to the adopted standardization method. Because the standardization methods compare measurements to derive a unit of measurement.

Response styles render domain-referenced measurement units incommensurable across judges. With self-report questionnaires the respondent is the judge. So, by definition the unit then becomes defective for between-subject comparisons. Any difference between two subjects could either be caused by a difference in the trait, the adopted response style, or both. Response styles do not restrict the measurement unit that is obtained by domain-referenced standardization insofar it is used for within-judge comparisons. If judges rate multiple variables, in multiple subjects, at multiple occasions with the same observation schema comparisons between subjects, variables, or measurement occasions rated by the same judge remain equally valid. After all, this judge applies the rating scale in an equal way to all subjects, variables or measurement occasions by definition.

Normative standardization is not invalidated by the response style either, as long as the group of reference subjects, i.e. the norm sample, is rated by the 
same judge. Within a judge all measurements are equally affected by the same response stylc. The transformation of the scores due to the response style is then eliminated by the normative standardization transformation at an interval measurement level (sce Formula 2.9).

If normative standardization is applied to data obtained over different judges the derived measurement unit is invalidated by a response style. The judges will always differ with self-report questionnaires, because the respondent judges only himself. In that case the precision of the normative measurement unit is affected by the response style. Normative standardization rests upon the assumption that the rating scale is applied in the same way to all reference subjects. If the reference subjects are rated by different judges, a response style undermines this assumption. In that case a normative measurement unit will be biased.

Ipsative standardization according to an interval measurement level approach (sce Formula 2.4b) is not susceptible to response styles. With ipsative standardization any raw variable score is interpreted relative to the raw scores of the reference variables within the same subject. The influence of the response style is defined as constant across all variables. The compared variables should therefore be rated using the same rating scale. Then its influence on the derived measurement unit is filtered out (see also Formula 2.9).

At a ratio measurement level ipsative standardization is not equally robust against the response styles. A translating response style influences the resulting variable scores by adding a constant: $x^{\prime}=x+b$. The constant $b$ reflects the shift of the scale midpoint. Ipsative standardization at a ratio level commonly expresses the variable score as a partition of the total sum score: partition ipsative scores. It was demonstrated that partition ipsative scores are not invariant to additive transformations (see Formula 2.10). So, ipsative standardization at a ratio level is vulnerable to translating response styles. Partition ipsative scores are nevertheless robust against homothetic response styles. After all, a homothetic response style affects the resulting variable score by multiplying it by a constant: $x^{\prime}=a x$. In case $b=0$ the partition ipsative score was shown to remain the same (see Formula $2.10)$.

Iterative standardization is likewise insensitive to any of the response styles insofar all stimuli are rated by the same judge on all the reference measurement occasions. Iterative standardization relates a variable score to scores on that same variable by the same subject at other measurement occasions. With the use of self-report measures invariance of the judge is guaranteed.

\subsubsection{Response habit}

\section{Definition}

The response habit is defined as the differential rating scale use across variables (see Figure 3.1). This is a new type of response tendency that has not been identified before. Like the response shift (see Section 3.1.5) it is a differential use 
of the rating scale that is homogeneous across judges. It is therefore suggested here to term this type of response tendency the response habit. The term 'habit' is thought to reflect adequately the commonality of this response tendency.

It might be somewhat difficult to grasp that the response habit thus defined constitutes a genuine response tendency. After all, everybody agrees in the differential application of the rating scale across two variables. If two raw variable population means differ, it just seems to indicate that the two variables are present in different amounts in the population. And, if the population means are assumed to be the same, the divergence in the population means calls the equality in content coverage of both traits into question. One trait may be represented by more attractive or easy stimuli than the other trait. That constitutes the primary rationale for applying normative standardization, which permeates all practical psychological measurement. Still, if the equality in content coverage of both traits is warranted, a response habit could in principle emerge.

The response habit might, for instance, be detected in the construction of a word spelling and vocabulary questionnaire. The words are selected on the basis of their word frequency, the number of meanings, the number of synonyms, but also the word length, the number of syllables, the spelling variants of the sounds (viz. 'f' and 'ph'), and the acoustic salience of the sounds (viz. 'n', with its resemblance to ' $m$ ' and 'ng', versus ' $r$ '). The word selection model aims to create a word sample that is equally difficult to name as well as to spell. The respondents get the words orally presented. They have to indicate separately their degree of confidence that they can name the word accurately and their degree of confidence that they can spell it correctly. The order of these ratings is counterbalanced. Subsequently, the respondent is actually required to name and spell the words. So now the self-ratings can be compared with the test results. In case all respondents overestimate their vocabulary knowledge and underestimate their spelling proficiency it suggests the operation of a response habit. It may simply be a widespread attribution error to overrate one's control of word meanings relative to one's spelling ability. As a result all will in an equal extent raise their self-assessment of lexical knowledge. In effect the rating scale for this variable is devaluated with respect to spelling capacity. A comparison of the self-report scores between the variables then becomes inappropriate, because these scores have no common metric.

\section{Implications for standardization methods}

The response habit does not restrict the measurement unit that is obtained by domain-referenced standardization for within-variable comparisons. If judges rate multiple variables, in multiple subjects, at multiple occasions with the same observation schema comparisons between judges, subjects, or measurement occasions are not biased as long as they are compared on the same variable. After all, response habits do not change between judges, subjects, or measurement occasions by definition. Still, the response habit does make domain-referenced measure- 
ment units incommensurable across the variables. Any difference between two variables could either be the result of a difference between the represented traits, the adopted response habits, or both.

Normative standardization is immune to the operation of a response habit, irrespective whether the group of reference subjects is rated by the same judge or different judges. The response habit is defined as constant across all judges. Normative standardization derives a measurement unit by expressing a variable score relative to the scores of a group of reference subjects on the same variable. This variable score is in an equal extent affected by the response habit in all reference subjects. It will therefore not bias the derived measurement unit (see also Formula 2.9).

To the contrary, ipsative standardization is susceptible to the response habit. Ipsative standardization yields a measurement unit by expressing a variable score relative to the scores of a group of reference variables. It not only assumes the reference variables to be equally represented by the stimuli, i.e. their content coverage must be the same. Ipsative standardization also presupposes that the rating scale is equally used across variables. The response habit exactly compromises this latter assumption. It will affect the score of at least one of the reference variables and therefore influence the average and standard deviation of the set of reference measurements. As a result the ipsative measurement unit is biased.

Like normative standardization, iterative standardization is resistant to the response habit. The response habit is defined to be constant across measurement occasions. Since iterative standardization is obtained by relating a variable score to scores on that same variable by the same subject at other measurement occasions, the derived measurement unit remains the same.

\subsubsection{Response set}

\section{Definition}

Rorer (1965) demarcated the response set from the response style as the response set is a content related response tendency. This view fits its current position in the response tendency typology. The response set is defined as the combined differential use of the rating scale both over variables and judges (see Figure 3.1). It can be considered a response style that also differs across variables, or a response habit that in addition varies between judges. With self-report questionnaires the most cited cause for the occurrence of a response set is a social desirability response bias. On the one hand this bias is due to discrepancies in the social desirability of variables. On the other hand it is caused by differences in the efforts of respondents to give a socially desirable impression. Keep in mind that the respondents are their own judges then. In other words, the social desirability response set is the differential tendency to create a favourable image of oneself by responding in a socially desirable way. Subjects differ in their susceptibility to 
social approval. which affects their response behaviour. As the socially accepted response depends on the variable content, it results in differential rating scale use across subjects as well as variables.

Another cause for the occurrence of a response set is malingering. Contrary to the social desirability response set, which is directed at faking good, a respondent may also aim to give a bad or sick impression. Malingering is simply faking bad. Not so much as to seek social disapproval, but more generally to give an incapacitated impression. It is a common response tendency in a forcnsic measurement setting. In criminal prosecution the view that a mental disorder compelled the offender to break the law may result in a considerable penalty reduction. This poses a formidable incentive to the defendant to simulate a mental condition.

\section{Implications for standardization methods}

A response set severely hampers the usability of the measurement unit that is obtained by domain-referenced standardization. The response set does indicate a differential rating scale use between judges and variables. If judges rate multiple variables, in multiple subjects, at multiple occasions with the same observation schema only comparisons between subjects, or measurement occasions rated by that same judge on the same variable remain equally valid. So, the response set renders the domain-referenced measurement unit only applicable to both withinjudge and within-variables comparisons. In self-report questionnaires the subject constitutes the judge. Hence, domain-referenced standardization of self-report questionnaire data that is affected by a response set will yield a measurement unit that is specific to both the respondent and the variable. Only within-subjects comparisons of the development in a specific variable over time are interpretable without limitations. Any difference in a variable score between two subjects, or between two variable scores within a subject, could either be caused by a difference in the represented traits, the adopted response set, or both.

The response set was circumscribed before as a response style that also differs across variables, or a response habit that in addition differs across judges. It was already argued that normative standardization of self-report questionnaire data is vulnerable to response styles. Ipsative standardization was found to be susceptible to the response habit. As a result neither normative standardization nor ipsative standardization remain unaffected by the response set. Both measurement units are biased by the response set.

The only measurement-referenced standardization approach that is robust against the response set is iterative standardization. The response set is such defined that the differential rating scale use is assumed to remain constant over time. Consequently, only longitudinal developments of one variable within a subject remain interpretable. Should this influence evolve then it must not be considered a response set anymore. It becomes a response whim (see Section 3.1.8). 


\subsubsection{Response shift}

\section{Definition}

The response shift is defined as the differential rating scale use across measurement occasions (see Figure 3.1). The response shift is also referred to as beta change (Golembiewski, Billingsley, \& Yeager, 1976). It originates from evaluation research of training interventions by self-report measures using a two-group pretest-posttest design. The comparison of pretest scores with posttest scores assumes that respondents use the rating scale at both measurement occasions in the same way. But any training intervention aims to change the subjects' knowledge of the target concept. That process commonly alters the perception of one's level of functioning with respect to that concept. After the training a subject has become more modest in the evaluation of the own knowledge about the concept than before. The response shift is responsible for a complete lack or a reduction of the difference between the pretest and the posttest measurement in the experimental group. The shift does not occur in the control group. Only in the experimental group the response shift actually causes both scores to be incommensurable. As a result it attenuates the effect of the manipulation, i.e. the result of the training intervention.

The response shift is the only documented response tendency in which the rating scale is not used differentially across judges. In this aspect it resembles the response habit. One might question whether the response shift, as well as the response habit, should in fact be regarded response tendencies. Oort (1993), for instance, offered a classification of biases in which he assigned the response shift to a different class of bias than the response tendency class. However, the essence of the response shift is a recalibration of the rating scale (Lindell \& Drexler, 1979). It fits therefore the current definition of a response tendency as the differential use of a rating scale. This differential rating scale use is equally justified if it is homogeneous across the judges. In fact, the present classification has still one more type of response tendency to offer that is constant over judges: the response drift (see Section 3.1.7).

\section{Implications for standardization methods}

Domain-referenced standardization is affected by the response shift in that the derived measurement unit cannot be considered invariant over time. If judges rate multiple variables, in multiple subjects, at multiple occasions with the same observation schema, comparisons between judges, subjects, or variables are not biased as long as they are compared on the same measurement occasion. Response shifts, by definition, do not differ between judges, subjects, or variables. However, response shifts do make domain-referenced measurement units incommensurable across various measurement occasions. As a result the domain-referenced measurement unit becomes defective for the assessment of changes in time. Any difference between the measurement outcomes obtained at two occasions could 
either be caused by a change in the trait, a response shift, or both.

Normative standardization is robust against the response shift insofar the measurements in the group of reference subjects are obtained at the same occasion. The same proviso applies to ipsative measurement. Ipsative measurement remains equally unaffected by the response shift, if the set of reference variables are measured at the same occasion.

Still, the response shift does affect the measurement unit that is derived from iterative standardization. The consistent use of the rating scale across measurement occasions is an essential assumption of this standardization method. With a response shift this assumption is not satisfied. As a result the response shift biases an iterative measurement unit.

\subsubsection{Response fashion}

\section{Definition}

The second new response tendency that results from the typology of response tendencies is the differential rating scale use across both judges and measurement occasions. It is proposed to term this response tendency 'response fashion' (see Figure 3.1). 'Fashion' is deemed the proper term to indicate a trend in rating scale use that may be adopted differently across judges, but is homogeneous across variables. As such it can be considered an influence of response style that changes over time, or a response shift that pervades the judges unevenly. The former description implies that over measurement conditions the response styles change. The midpoint responder might become an extremity responder after several measurements, whereas the extremity responder remains an extremity responder. So in this instance the influence of response styles reduces over the measurement occasions. The latter explication suggests that between judges the response shift differs. For instance a sex bias in the amount of response shift in fact constitutes the response fashion if the judges are of either sex.

\section{Implications for standardization methods}

The response fashion imposes a major restriction in the applicability of domainreferenced measurement units. The response fashion reflects a differential rating scale use between judges and measurement occasions. If judges rate multiple variables, in multiple subjects, at multiple occasions with the same observation schema, only comparisons between subjects, or variables rated by that same judge on the same measurement occasion remain equally valid. Subject and judge are one and the same in self-report questionnaires. As a result, domain-referenced standardization of self-report questionnaire data that is affected by a response fashion will yield a measurement unit that is specific to both the respondent and the measurement occasion. Only within-subjects comparisons between variables measured at the same time are interpretable without reservations. Any difference in a variable score between two subjects, or between two measurement occasions 
within a subject could either be caused by a difference in the represented trait, the influence of a response fashion, or both.

The response fashion was circumscribed before as a response style that also differs across measurement occasions. It was already argued that normative standardization is only immune to the response style if the measurements of the group of reference subjects all originate from the same judge. With self-report questionnaire data this will not be the case. So, a normative measurement unit of such data will be affected by the response fashion.

Contrariwise, ipsative measurement is robust against the response fashion. It requires that the set of reference variables is rated by the same judge at the same measurement occasion. Self-report data ensures that the ratings stem from the same judge. With self-report data the measurement unit that is obtained by ipsative standardization will therefore not be biased by the response fashion.

The response fashion could also be viewed as a response shift that in addition differs across judges. Iterative standardization was demonstrated to be vulnerable to response shifts before. As a result iterative standardization yields a measurement unit that is influenced by the response fashion as well.

\subsubsection{Response drift}

\section{Definition}

The response drift is like the response habit and response shift a response tendency that affects all judges equally. The response drift is the differential rating scale use across both variables and measurement occasions (see Figure 3.1). The term 'drift' is believed to indicate best secular trends in rating scale use that affects variables differently, but is homogeneous across judges. It is essentially a response habit that changes in time or a response shift that differs among the variables.

Remember the example of the response habit. Respondents were asked to rate their proficiency in word naming and spelling. They presumably overrated their word knowledge and underrated their spelling capacity. Suppose these subjects receive feedback, and get the same questionnaire administered again, but over a parallel stimulus set. Probably the respondents are better calibrated to rate their naming and spelling proficiency more accurately. Then a differential response shift over both variables has occurred: a response drift.

Golembiewski et al. (1976) identified three factors that may contribute to an effect in longitudinal research. These three factors were called alpha, beta, and gamma change. Beta change was already recognized to correspond to the response shift that was presented in Section 3.1.5. The term alpha change refers to the genuine trait changes in subjects, that most longitudinal experiments aim to establish. Gamma change is a change in the response scores due to an overall reconceptualisation of the measured trait. Then the general perception of its content domain has changed. With the advent of e-mail and the mobile phone the concept of personal accessibility for instance has been redefined. The use of 
an answering machine is not sufficiont anymore to qualify as highly accossible.

It is important to differentiate the response drift from gamma change. Like any response tendency, a response drift pertains to differences in the use of the rating scale alone. It must be considered independent from any change in content, except for a possible change in the meaning of the scale point labels, if present.

The response drift has not been recognized before. Yet, the regular update of norming data is considered good clinical practice (Evers, Van Vliet-Mulder, \& Groot, 2000). This requirement should be regarded to suit the elimination of a response drift. The advocated replication of a normative standardization study essentially constitutes the recalibration of the measurement unit. In case an instrument includes multiple variables, the recalibration may produce different changes in the norming data of each variable. Variable A may exhibit a major change in population mean, whereas variable $B$ only demonstrates a change in dispersion. If the traits are assumed equally distributed in the population, the mean and standard deviation of the variables should be equal. Then the replicated norming corrects for the effect of response drift.

The regular updating of norming data cannot be considered to eliminate the effect of gamma change. For a change in the content coverage of the variables, would in fact demand the repeated establishment of the validity of the instrument. Some variables would require new stimuli to account for the altered content domain.

Whether the revision of norms should be aimed to accommodate alpha changes, i.e. genuine trait changes in the subjects, is a matter of dispute. Opponents warn that it undermines the longitudinal constancy of the measurement unit (Angoff, 1962, 1971; Lindquist, 1953). A z-score of zero using the new mean that reflects a genuine trait change refers to a different trait level than a $z$-score of zero that used the old mean. From this perspective the preservation of longitudinal constancy of the measurement unit may be defendable.

Still, gamma change or differential alpha change across variables is hard if not impossible to distinguish from response drift. If two population mean variable scores have changed relative to each other, one or both content domains may have changed (gamma change), the use of the rating scale may have altered differentially across the variables (response drift), or the subjects in the population differ in their development in both traits (differential alpha change). Of course a combination of effects would also be possible. Without an independent criterion for the content coverage of both traits, there is no telling which effect is responsible for the change in the population mean variable scores.

\section{Implications for standardization methods}

The generality of the domain-referenced measurement unit is considerably restricted by the response drift. A response drift occurs when the rating scale is differently used between both variables and measurement occasions. If judges rate multiple variables, in multiple subjects, at multiple occasions with the same ob- 
servation schema comparisons between judges, or subjects are not biased as long as they are compared on the same variable at the same measurement occasion. If self-report data is influenced by a response drift, domain-referenced standardization will thus yield a measurement unit that is only suitable to compare subjects on the same variable within the same measurement occasion. Any difference in the scores of two variables within the same occasion, or the scores on the same variable at two measurement occasions could either be caused by a difference in the represented traits, an influence by a response drift, or both.

Self-inclusive normative standardization is the only measurement-referenced standardization method that is not affected by the response drift. This normative measurement unit is immune to the response drift, as the group of reference subjects are rated at the same measurement occasion as the subject whose scores are expressed in standard scores. It even does not matter whether the data is obtained from one judge or multiple judges as with self-report data. For the response drift is simply defined not to differ between judges.

Response drift was characterized before as a response habit that changes over measurement occasions or a response shift that differs among variables. It was already explained that ipsative standardization is vulnerable to the response habit. Iterative standardization was found to be susceptible to the response shift. Neither ipsative standardization nor iterative standardization are therefore robust against the response drift. A response drift biases both measurement units.

\subsubsection{Response whim}

\section{Definition}

Finally all three main types of response tendency: the response style, the response shift, and the response habit may combine to form the so-called response whim. The response whim is the differential rating scale use across judges, variables, and measurement occasions (see Figure 3.1). The term 'whim' is chosen to stress the capricious nature in which the rating scale is used. Imaginably the response whim has a devastating influence on any dataset. It implies that the measurements are not comparable across judges, or variables, or measurement occasions. It leaves the researcher at a loss about the interpretation of the response scores as each score is expressed in a unique unit of measurement.

\section{Implications for standardization methods}

One may be inclined to subsume the response whim under random error. But this is not entirely correct. If judges rate multiple variables, in multiple subjects, at multiple occasions with the same observation schema comparisons between subjects are still feasible as long as they are rated by the same judge and compared on the same variable at the same measurement occasion. In self-report data the response whim is still a part of systematic error, as it remains constant within the subject, variable, and measurement occasion. As a result a part of 
Cronbach's $\alpha$ may be considered to reflect the score variance due to this response tendency. Nevertheless all measurement-referenced standardization procedures are useless. Domain-referenced mensurement is technically feasible but must be considered equally obscure. Even an idiographic, i.c. within-subjects interpretation is prohibited as the developed measurement units cannot grant comparisons across variables or measurement occasions.

\subsection{Strategies to control for the diverse response tendencies}

Of the previous typology of response tendencies four are known: the response consistency, the response style, the response set, and the response shift. Response consistency reflects the absence of a response tendency. It is not a response tendency that should be prevented. Instead, it should be sought after. Logically, no strategies to avoid its occurrence have been advanced. The strategies that aim to eliminate any of the other response tendencies, all intend to secure response consistency. In the literature only methods to prevent the remaining three of the known response tendencies have been discussed. These will be presented in the following subsections.

\subsubsection{Response style}

The occurrence of response styles can be limited by the design of the instrument. The careful wording of the anchor labels for the scale points will minimize its effect (Eekhof, Mol, \& Pielage, 1992; Mosteller \& Youtz, 1990; Van den Brink \& Van Schaik, 1995). Another strategy to control for response styles, is to include an equal number of indicative and contra-indicative stimuli, i.e. to balance the instrument (Nederhof, 1985; Paulhus, 1991). The effect of this countermeasure is shown by scoring the responses in Figure 3.2 (see p. 51). First the responses will be scored as if they originate from an unbalanced questionnaire. The items are all considered to be indicative of the same trait. The resulting variable scores are indicated by 'unbalanced score' at the bottom of Figure 3.2. Secondly the responses will be interpreted as if they result from a balanced questionnaire. Now, the variable scores are marked by 'balanced score'.

If all items are indicative of the same trait, a rating of 'disagree' yields one point, 'neutral' three points, and 'agree' five points. The unlabelled scale points in between add two and four points respectively. So, for the acquiescent judge the resulting variable score is obtained by adding from top to bottom the indicated item scores: $5+2+4+3+5+4+4+3+5+2=37$. The dissentient judge achieves a variable score of 27 . That could be expected, since his credit is consistently reduced by one scale point on each of the ten items. Of course, a difference of ten scale points is quite large on a range of $10 \times 5-10 \times 1=40$ points to be assigned. The difference between the judges with a midpoint and extremity response style is far less outspoken. They differ by just two scale points. 
The example suggests that with only indicative items, the variable score is more susceptible to the translating response styles, than to the homothetic response styles. The variable scores of the acquiescent and dissentient judge differ by ten scale points, whereas they almost agree between the midpoint and extremity judge. This is a false impression. The influence of the homothetic response style can be expected to increase with the deviation of the variable score from the fixed midpoint, i.e. 30 . On the other hand the influence of acquiescence reduces as the item responses approach the upper limit of the rating scale. Then a ceiling effect arises: the item scores cannot be increased any further. The influence of dissentience is limited at the lower end of the rating scale, because of a floor effect. In that case the item scores cannot be reduced any further.

Now, the responses will be scored again as if they originate from a balanced questionnaire. In this instrument the variable is covered by both indicative (uneven items) and contra-indicative items (even items). The indicative item responses are scored as explained before. The contra-indicative item responses are reverse scored. In that case 'disagree' awards five points, 'neutral' three points, and 'agree' one point to the variable score. The unlabelled scale points are reversed as well; they now result in four and two points respectively. The right scores are the result of this balanced questionnaire. The addition of the item responses of the acquiescent judge from top to bottom result in a variable score of: $5+4+4+3+5+2+4+3+5+4=39$. The responses of the dissentient judge result in the same variable score. The difference in variable score between the judge with the midpoint response style and the judge with the extremity response style now amounts to 8 scale points. So, the influence of the homothetic response style appears to be inflated. These scores are not directly comparable with the previous results, though. Still, the example effectively shows that balancing accounts for the translating response styles, but not the homothetic response styles.

Another strategy to control for response styles, is to have the same subject rated by different judges on the same stimuli. The found variable scores diverge between the judges. Hence, if only one judge is available the variable score is influenced by the response style of the judge in question. With multiple judges the influence of a response style can be minimized by averaging over the judges. Note, that if the questionnaire in Figure 3.2 is interpreted to consist of indicative stimuli exclusively, the row average variable score over the four judges equals 32. The balanced questionnaire interpretation results in a row average variable score of 39 over the four judges. So, averaging over judges well attenuates for the influence of the different kinds of response styles. With self-report questionnaires the respondent can only act as a judge. As no other judge is available, these measures are particularly susceptible to response styles.

\subsubsection{Response set}

Of all response tendencies, the response set is the one that has been most heavily attacked, in particular the underlying social desirability response bias. Nederhof 
(1985) divided the methods to control for social desirability response bias into two categories: reduction and detection techniques. Reduction techniques aim to reduce either the susceptibility of the instrument. or the demand in the population towards depicting oneself favourably. There are several reduction techniques that aim to strengthen the robustness of the instrmment. One major strategy is to match stimuli of compound items on their social desirability. This specific item format was already presented in Chapter 1 (see for instance Figures 1.3, 1.4, and 1.6). The item is considered to attenuate the infuence of social desirability on the response behaviour, simply because the included stimuli are equally desirable.

The matching of stimuli on social desirability within a compound item was first hailed as the method of choice to control for social desirability response set and faking (Edwards, 1953; Gordon, 1951; Zavala, 1965). Ensuing research, however, suggested that the matching procedure did not live up to its promise of robustness against these response sets (Braun \& Costantini, 1968; Braun \& Seamon, 1969; Braun \& Tinley, 1968; Corah et al., 1958; Feldman \& Corah, 1960). Hicks (1970), therefore, advised against its application. His paper became very influential and the method was no longer current. Nevertheless, recent investigations have suggested that the method might still be beneficial (Christiansen et al., 2005; D. N. Jackson et al., 2000; Martin, Bowen, \& Hunt, 2002; Stanush, 1997). So, if the first aim is to control the social desirability response set, ipsative measurement using a matched compound item format might offer a solution. The merit of this approach will be discussed further in Chapters 7 and 8.

Still other techniques have been advanced to reduce the susceptibility of the instrument: the use of neutral stimuli, the use of content saturated stimuli, the selection of stimuli after principal-factor deletion, or the concealment of the purpose of the instrument. The use of neutral stimuli is self-explaining. It requires stimuli that are relatively neutral with regard to social desirability (Walsh, 1990). The use of content saturated stimuli require an elaborate definition of the construct to include both desirable and undesirable aspects over the full range of the thus defined trait continuum. Then both ends of the trait continuum are equally desirable. Isolated stimuli may appear more or less desirable. But this depends on the particular addressed subsection of a trait domain and is not related to the trait position.

The selection of stimuli after principal-factor deletion (Paulhus, 1981) involves four steps. First, a principal component analysis is applied to the item correlation matrix, selecting the aimed number of factors plus one. The component that represents social desirability is subsequently removed from the component matrix. Then the item communalities are adjusted by subtracting the squared factor loading of the removed component. And finally, the thus reduced component matrix is rotated.

Finally, the purpose of an inquiry may be concealed. The self-report form could have an unrevealing title. For instance, a Dutch questionnaire to measure sensation seeking is headed by the acronym 'SBL'. The respondent is deliberately kept in the dark that it stands for 'Spanningsbehoefte Lijst', i.e. Sensation Need 
List. Instead, the subtitle of the response form suggests that the questionnaire is an interest inventory (Feij \& Van Zuilen, 1984).

The influence of social desirability can also be reduced by targeting the respondent instead of the instrument. Methods that may minimize social desirable responding in the sample are: the assurance of anonymity, the application of the random response technique (Warner, 1965), the warning that the questionnaire detects faking, or - more aggressively - the connection of subjects to a (bogus) lie detector (Jones \& Sigall, 1971).

The previous measures to control the social desirability response set all intended to reduce its influence. Detection techniques, however, merely aim to assess the level of social desirable responding in the individual respondent. This assessment may be used for excluding the respondent, correcting his scores, or registering its impact. From a theoretical perspective, McGuire (1969) recognizes in the exclusion of high scoring subjects a 'logic of desperation'. Social desirability is considered to constitute a continuum instead of a dichotomy. So any critical score that demarcates a cut-off point remains arbitrary as the distinction between contaminated and uncontaminated data is not clear-cut. From an experimental perspective, Nederhof (1985) notes that the exclusion of subjects impairs the representativeness of the sample and thus the external validity of the research. Finally, from a practical perspective, this approach does not seem useful. It leaves a psychodiagnostician empty handed in case the results of an individual client should be rejected.

A correction for social desirability may either be implemented in the data analysis or in the computation of the variable scores. The data analysis could incorporate the social desirability measure as a covariate. The variable scores might also be corrected by partialling out the variance that is due to social desirability. This is achieved by regressing each scale score to the social desirability score. The residuals now represent the corrected scale scores (Lanning, 1989; Norman, 1967). The advantage of the latter technique is that it may offer a method to correct for social desirability in individual diagnostics. One simply needs to make available the regression weights as obtained in a representative sample. Of course, both correction methods presume that social desirability is linearly related to the variable scores. This linear relation between social desirability and the variable scores could be questioned. Subjects might disagree as to which traits they consider socially desirable. Any correction needs to assume that subjects roughly agree on the extent in which the traits are socially desirable.

\subsubsection{Response shift}

The response shift has only been dealt with within a pretest-posttest design. In such a design any difference between the pretest and the posttest might partly be due to a response shift. If the occurrence of a response shift is suspected, it should be anticipated by employing a retrospective pretest, also known as the then-test (Sprangers, 1988). The retrospective pretest is administered after the 
conventional posttest. The subjects are asked to rate their condition at the time they answered the conventional pretest once nore. They are encouraged not to reproduce their ratings of that moment, but to re-evaluate themselves at that time with the rating scale as they use it now. A recalibration of the rating scale is then indicated by a difference between the pretest and the then-test. This recalibration is actually what the response shift constitutes.

\subsection{Circumventing response tendencies by standardization}

After having discussed the implications of the response tendencies for the standardization methods to derive a unit of measurement, a question that logically arises is: 'What method of standardization should be preferred?' In the previous chapter it was already indicated that the type of decision that the measurement is aimed for plays an important role in the choice of measurement unit (see Section 2.5). The various standardization approaches have been argued to differ in their susceptibility to the different response tendencies. Therefore, their relative robustness against a type of response tendency that is considered prevalent may dictate the choice of measurement unit.

The difference between domain-referenced standardization and the three measurement-referenced standardization methods, is that the domain-referenced measurement unit itself remains unbiased. That is, because the maximum possible range of the variable score is used as a reference. This maximum range remains constant with any response tendency. As a result any effect of a response tendency is directly incorporated into the domain-referenced scores. This offers both an advantage and a disadvantage. The advantage is that the unit of measurement remains interpretable in comparisons over the dimensions that did not give evidence of differential rating scale use, i.e. judges, variables, and/or measurement occasions. The disadvantage is that the error produced by any response tendency is included in the score. The domain-referenced score cannot be regarded to relate to the domain anymore.

With the measurement-referenced standardization methods, however, a response tendency equally affects the set of reference measurements. It alters the distribution statistics of the reference measurements. The bias is thus incorporated in the resulting measurement unit. But only if the differential rating scale use occurs over the dimension in which the reference measurements are sampled, i.e. judges, variables, and/or measurement occasions. Again, this has a positive as well as a negative effect. The positive effect is that the influence of a response tendency might be filtered out by using a measurement-referenced standardization method that is immune to the response tendency at hand. However, both the scores and the unit are biased if the measurement-referenced standardization method is adopted that is not immune. It renders the derived standard scores useless. That is the negative effect.

However, the positive effect of measurement-referenced standardization 
methods to correct for a response tendency must in fact be considered deceptive. The reason is that such a correction rests on a hidden assumption. The assumption is that the variance, which is removed by the circumventing standardization method, completely represents error variance due to the circumvented response tendency. Ipsative standardization may, for instance, correct for a response style. But it must assume that all between-subjects differences in their within-subjects averages over the variables within a measurement occasion are due to the response style. Otherwise, the resulting ipsative standard unit must be considered subject specific. In that case no between-subjects comparisons are permissible. Only if the removed variance represents error, the commensurability of the derived measurement unit is maintained.

Unfortunately, such an assumption is usually unwarranted and cannot be checked. So, the assumption must be considered a strong assumption indeed. It is much more plausible that the response tendency is only partly responsible for the differences found. Correcting a response tendency by adopting a different standardization method is in this respect a crude approach. It is quite opportunistic to assume that the variance, which is removed by the circumventing standardization method, represents error variance only. If that assumption is not warranted, the derived measurement units are incomparable. The bias by a response tendency may then simply be traded for a bias due to incommensurable scores.

Remember, for instance, the argued devaluation of the rating scale labels in the U.S. Army Officer Efficiency Reporting System by WD AGO Form 67. Figure 1.2 (see p. 4) illustrated the drop in the percentage of Army Captains, who received less than excellent ratings from about $75 \%$ in 1922 to less than $10 \%$ in 1945 . This decline was taken to evidence a response shift, what incited the development of WD AGO Form 67-1. But this argument is based on the same assumption. If one regards it to constitute a response shift only, the efficiency of the corps must have remained constant. It is likely, though, that the efficiency in the corps improved as well. Particularly, since one would hope that the implementation of a reporting system also promotes the efficiency of the average officer. As a result, an officer with an efficiency score of $z=+1$ in 1925, cannot be regarded equally efficient as an officer with an efficiency score of $z=+1$ in 1935 .

Therefore, the use of another measurement-referenced standardization method to filter out a response tendency is not advocated. The required assumption is quite strong, and cannot be checked. Without that assumption this circumventing standardization method only allows a relative comparison. The previous chapter already explained how Fedorak and Coles (1979, p. 920) formulated such a normative interpretation of ipsative standard scores. 'Person $A$ is higher on variable $\mathrm{X}$ in relation to his other attributes than person $\mathrm{B}$ is on variable $\mathrm{X}$ in relation to his other attributes.' This is the proper interpretation as it incorporates the difference in measurement unit in the formulation. But this relative interpretation was not susceptible to the circumvented response tendency in the first place. Consequently, the utility of selecting a standardization method to control for a response tendency is rather limited. 


\subsubsection{Comparative overview}

Table 3.1 lists the various strengths and weaknesses of each standardization approach. Not surprisingly, it suggests that the criterion of eligible comparisons is inversely related to the robustness against response tendencies. That is, where domain-referenced standardization allows comparisons between all standardization dimensions, i.e. subjects, variables, and measurement occasions, it is also susceptible to all response tendencies.

Normative standardization only allows direct comparisons of isolated variables between subjects. This is paired with a reduced robustness against the response style, at least if not all subjects are rated by the same judge. Ipsative standardization in fact solely permits the direct comparison of variables within a subject. This characteristic goes with an increased vulnerability to the response habit. And iterative standardization just makes it possible to compare the scores of a particular variable within a subject across measurement occasions. That strength is associated with a weakness for the response shift. In addition iterative standardization is the only method that is robust against the response set.

The approach to circumvent a response tendency by applying a robust standardization method is clearly hazardous. For the aimed comparison is not warranted by this circumventing standardization method, unless an extra assumption is made. This additional assumption will in most instances not be fulfilled and cannot be checked by the approach.

Table 3.1: Strengths and weaknesses of the various standardization methods

\begin{tabular}{lccccccc}
\hline & \multicolumn{4}{c}{ eligible comparisons } & \multicolumn{5}{c}{ response tendencies } \\
$\begin{array}{c}\text { Standardization } \\
\text { method }\end{array}$ & $\begin{array}{c}\text { between } \\
\text { subjects }\end{array}$ & $\begin{array}{c}\text { between } \\
\text { variables }\end{array}$ & $\begin{array}{c}\text { between } \\
\text { occasions }\end{array}$ & $\begin{array}{c}\text { response } \\
\text { style }\end{array}$ & $\begin{array}{c}\text { response } \\
\text { habit }\end{array}$ & $\begin{array}{c}\text { response } \\
\text { shift }\end{array}$ & $\begin{array}{c}\text { response } \\
\text { set }\end{array}$ \\
\hline domain-referenced & + & + & + & - & - & - & - \\
normative & + & - & - & - & + & + & - \\
ipsative & - & + & - & + & - & + & - \\
iterative & - & - & + & + & + & - & + \\
\hline
\end{tabular}




\section{The benefit of the multidimensional compound item for individual profile} assessment

It is reasonable to suppose that some particular item form
might be more effective than another in "squeezing out"
such small differences as would be assumed to exist.

(Zuckerman, 1952, p. 79)

In Chapter 1 it was argued that the item responses to a compound item should properly be regarded response vectors. The separate stimulus ratings cannot be considered independent. So, the response vector identifies the independent data point. In the multidimensional compound item (MCI) the coordinates of this response vector are taken to reflect the scores of the stimuli that represent the different variables. Consequently, the error between the separate variable scores within a scale must be considered related. The stimulus scores of the singular item (SI) are independent instead. For they allow to rate one stimulus in isolation. As a consequence the error between the separate variable scores of the SI can be regarded independent. One might, therefore, hypothesize that the SI item format is better designed to minimize error in the measurement of separate traits. To the opposite, the MCI seems better suited to minimize error in estimating the combined distribution of different variables, i.e. a profile. Put differently, the MCI may provide more accurate results than the SI if the data are aimed to be interpreted ipsatively. That is the central thesis of the current investigation.

\subsection{The three between-formats comparative designs}

There is a long line of research contrasting the MCI format to the SI format. During this history the criterion deciding which format to be superior has changed. Correspondence studies that simply correlate the results of both formats with each other will never reveal a relative benefit (Bartlett, Quay, \& Wrightsman, 1960; 
Block, 1957; Kogan \& Fordyce, 1962). The formats have also been compared using three psychometric properties as a criterion: reliability, validity, and profile similarity. Many studies have in the first place aimed to demonstrate a difference in reliability between both item formats. This is considered the between-formats comparative reliability design. A second line of research has contrasted the validity of the data obtained by both item formats. This is referred to as the betweenformats comparative validity design. And, finally, both item formats have been judged for their relative similarity in profile estimation with an external criterion at the level of the respondent. This is regarded the between-formats comparative profile similarity design. The between-formats comparative reliability design and the between-formats comparative validity design evaluate both formats at the level of the isolated variable scores. If it is realized that the crror in the separate variable scores is related, the between-formats comparative profile similarity design seems the only suitable criterion. In that case the effect of the related error scores can be taken into account.

Still, to put the current investigation in proper perspective all three comparative designs will be discussed. The results of such an overview though, remain difficult to interpret. Not just because the research has used different criteria, but also because it suffers various shortcomings. In the first place, the MCI format has been compared to the SI format applying each to different subject samples (Gordon, 1951). Secondly, both item formats have been compared using different stimulus sets (Bartlett et al., 1960, Howe, 1960, 1964; Howe \& Silverstein, 1960). ${ }^{1}$ And, finally, the $\mathrm{MCI}$ format is frequently compared to the SI format after the stimuli have been matched for social desirability in the MCI (Gordon, 1951; Horst \& Wright, 1959; Karr, 1958; Scott, 1963). The first two design characteristics allow a difference between the SI and MCI format to emerge that is actually due to differences between subject samples or stimulus sets. The use of the MCI that contains stimuli matched for social desirability is considered a problem as well. This matching practice disparately corrodes the relative content coverage of the compared traits (see Chapter 8$)^{2}$ These studies will therefore be disregarded in the next discussion.

\footnotetext{
${ }^{1}$ Sometimes a compound item makes use of dummy stimuli, i.e. stimuli not deemed relevant for the measurement domain and thus not linked to a trait (Heineman, 1953). In Chapter 1 this format was referred to as the indeterminate compound item (ICI). Such a scoring practice prevents the item total score from being fixed. Consequently, it reduces the negative correlation that characterizes ipsative variable scores (Hicks, 1970). It nevertheless obfuscates the comparability with the SI format. So, the requirement of identical stimulus samples for both item formats excludes the ICI.

2 The exclusion only regards MCI questionnaires with stimuli that are matched on the basis of quantified social desirability ratings. Kolb's Learning Style Inventory, for instance, is not excluded, because the constructors matched the stimuli at face value. These judgements are considered not precise enough to allow an adequate matching of the stimuli (Beutell \& Kressel, 1984).
} 


\subsubsection{Between-formats comparative reliability design}

The majority of studies with a between-formats comparative reliability design report that the SI format yields more reliable data than the MCI format. This defect in the MCI format however, is not considered conclusive evidence for its inferiority. After all, one minus the reliability indicates the proportion of error score variance in each variable separately. As was pointed out before, the error scores are expected to correlate over the variables. So, at the profile level the MCI may still yield more precise profile scores. Apart from this possible heightened precision at the profile level, the inferiority of the MCI format with respect to the reliability on the variable level appears to be misguided. That is mainly due to the fact that the bulk of studies use Cronbach's $\alpha$ or KR-20 to compare the reliability of both item formats. Both are internal consistency estimators of reliability. But the MCI cannot be expected to produce data that is internally consistent.

Comparing the two item formats using separate versions of Kolb's revised Learning Style Inventory (KLSI-R) Geiger, Boyle, and Pinto (1993) were the only ones who found both resulting datasets to agree in Cronbach's $\alpha$. The other studies all demonstrated a higher Cronbach's $\alpha$ or KR-20 in the SI data. Among the instruments investigated were: Kolb's Learning Style Inventory (KLSSI) (Merritt \& Marshall, 1984b), Canfield's Learning Style Inventory (CLSI) (Merritt \& Marshall, 1984a), the Dutch Vocational Interests Test (VIT) (Evers, Lucassen, \& Meijaard, 1983), the third edition of the Study of Values (SOV-III) and Scott's Values Scales (SVS) (Scott, 1968), the PAL-TOPAS personality questionnaire (Matthews \& Oddy, 1995), the Occupational Personality Questionnaire (OPQ) (Saville \& Willson, 1991), Jackson's Personality Research Form (PRF) (D. N. Jackson, Neill, \& Bevan, 1973), and the Biology Cognitive Preference Test (BCPT) (Tamir \& Lunetta, 1977).

Johnson, Wood, and Blinkhorn (1988) claim that the reliability, i.e. the proportion true score variance, of instruments yielding ipsative data is overestimated. Or, as they phrase it:

"[R]eliabilities of ipsative tests overestimate, sometimes severely, the actual reliability of the scales" (Johnson et al., 1988, p. 154).

To illustrate their argument they correlated the stimuli of three MCIs with the four variables that every MCI covered. Each MCI consisted of four stimuli, so the three MCIs produced a 12 (stimuli) $\times 4$ (variables) correlation matrix (Johnson et al., 1988, Table 3, p. 158). In each MCI the respondent had to indicate which of its four stimuli was liked most and which one was liked least. The stimuli did not only correlate with the target variable they represented, but also with the other variables. This must of course be ascribed to the comparative nature of the response process. Only one stimulus can be selected as "most like" and one as "least like". As a direct result these stimuli will tend to correlate negatively with the other three stimuli (see also Formula 2.11). The particular example questionnaire happens to include four traits in total: Dominance, In- 
ducement, Submission, and Compliance. So the stimuli within the item cover the complete trait domain of the questionnaire. The negative stimulus correlations within the item are therefore almost directly propagated into considerable positive and negative correlations with the variables. It lures Johnson et al. (1988) into the conclusion:

"Any consistency within one scale automatically creates consistency in some or all of the other scales with the net result that all reliability coefficients, particularly those estimating internal consistency, will be inflated." (Johnson et al., 1988, p. 158, italics added)

But this argument cannot substantiate their claim. They are correct in pointing out that any consistency within one scale enhances the consistency in the remaining scales. If in the diverse compound items the stimuli that represent the same variable are assigned the same rank, it forbids the assignment of this rank to one of the other three represented variables. As a corollary it increases the consistency in the other variables. But they mistakenly conclude that this association affects the reliability coefficients only. Johnson and his co-workers do not realize that this must equally influence the reliability itself: the proportion true score variance. That is in effect what their example demonstrates. The required item response behaviour of comparing stimuli that represent different variables causes the observed item scores between the variables to be related. But these observed scores consist of both an error component and a true score component. So, the proportions true score variance of the variables are related as well. In conclusion, the interdependency of the reliability coefficients cannot be taken as an argument for the claim that they overestimate the proportions true score variance, as the proportions true score variance of the variables must be considered interdependent as well.

This refutation may have raised a more alarming problem. For the interrelatedness of error scores seems to strike at the heart of classical test theory. After all, one of its basic assumptions is that the error scores are not related. One should realize, however, that classical test theory is mainly defined within one single unidimensional trait. In that respect classical test theory is not invalidated by the correlation between the error scores of variables. The MCI causes the error scores between variables to be correlated, not within one single variable. Nevertheless contrary to the allegation of Johnson et al. (1988) it will be argued that both KR-20 and Cronbach's $\alpha$ in fact disparately underestimate the proportion true score variance of data obtained by the MCI format as compared to the SI format.

From an analytical viewpoint both KR-20 and Cronbach's $\alpha$ offer a lower bound approximation of reliability. These reliability coefficients only equal the proportion true score variance if the stimuli are essentially $\tau$-equivalent (Lord \& Novick, 1968). It means that the stimulus true scores can only differ by a constant that is the same across all subjects, but the error variance is allowed to differ across the stimuli. This translates into assuming that all subjects agree on the 
Figure 4.1: Hypothetical response patterns of three subjects on three $\mathrm{MCls}$

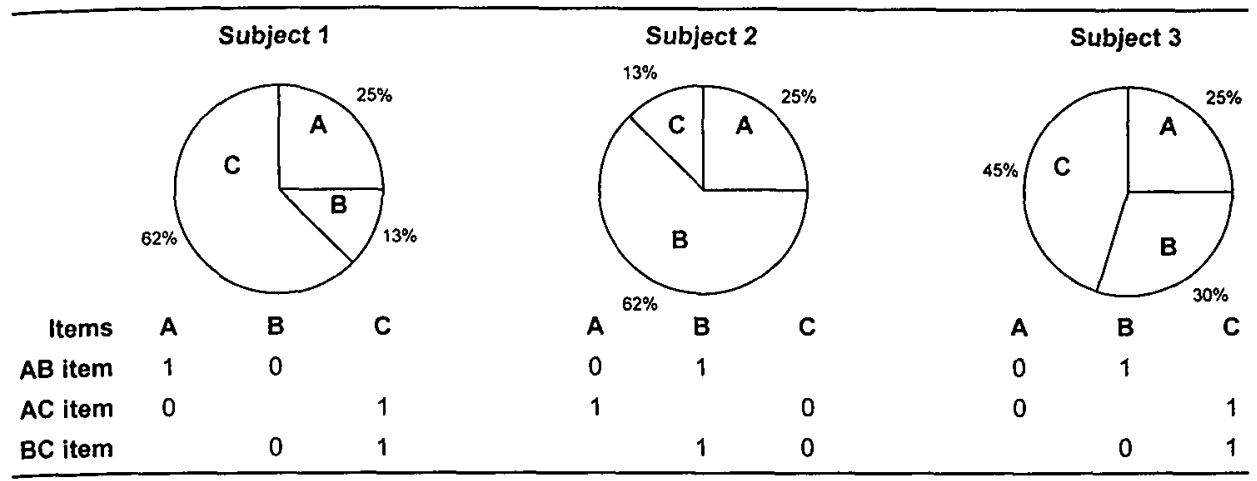

difficulty or attractiveness parameters of the stimuli and the subjective distances between the used response scale points. The essence of internal consistency is that a difficult stimulus is equally difficult to all subjects and an easy stimulus is equally easy to all subjects. As a result individual differences in responses can only be due to individual differences in trait levels. Although the assumption of essential $\tau$-equivalence is not likely to be met in SI data, it will definitely be more seriously violated by the additive scoring of the MCI. This assertion will be substantiated using an example.

Suppose a questionnaire is directed at measuring three traits using paired comparison items. Consequently, there are three possible trait combinations. An item might require the respondent to compare two stimuli representing traits $\mathrm{A}$ and $\mathrm{B}$, two stimuli representing traits $\mathrm{A}$ and $\mathrm{C}$, or two stimuli representing traits $B$ and $C$. The first is called an $A B$ item, the second an $A C$ item, and the third a $\mathrm{BC}$ item. Figure 4.1 depicts the true trait compositions of three hypothetical subjects by three pie charts. Sorted in descending order of magnitude Subject 1 is endowed with trait profile $\mathrm{CAB}$, Subject 2 with trait profile BAC, and Subject 3 with trait profile CBA. Based on the trait distribution of Subject 1 it is quite logical to expect Subject 1 to prefer the stimulus that represents trait $A$ in the majority of $\mathrm{AB}$ items. In $\mathrm{AC}$ items Subject 1 will predominantly prefer the stimulus that represents trait $\mathrm{C}$. And in $\mathrm{BC}$ items Subject 1 will be more inclined to select the stimulus that represents trait $C$. The tabulated ones and zeros below the pie chart of Subject 1 indicate this expected orientation in preference. It is also shown for Subjects 2 and 3.

For each subject the indicated orientation of preference is in perfect agreement with one's trait composition. Now the crux is that the subjects all agree in their proportion of trait A (25\%), yet they differ in their stimulus preferences. Note that the orientation of preference in Subject 1 dictates that the stimuli representing trait $A$ in $A B$ items are far more attractive or less difficult than the stimuli representing trait $\mathrm{A}$ in $\mathrm{AC}$ items. The reverse is however true for 
Subject 2. For this subject the stimuli representing trait $A$ in $A B$ items are far less attractive or more difficult than those in AC items. For Subject 3 the stimuli that represent trait $\mathrm{A}$ are about equally attractive whether presented in $\mathrm{AC}$ items or $\mathrm{AB}$ items. Considering the trait composition of Subject 3 though they might be slightly more attractive in the $\mathrm{AB}$ items. Consequently, the subjects do not agree on the difficulty or attractiveness parameters of the stimuli. But this lack of internal consistency is essentially due to the individual differences in trait compositions.

The same line of reasoning applies to other MCI formats than the paired comparison item. Although the inclusion of more traits in the item will act as a buffer. Note that if the example questionnaire only consisted of $A B C$ items, including for each trait one stimulus that the subject has to rank order, the difference between subject 1 and 2 disappears. Both would then mainly assign stimuli that represent trait $A$ to the second place in the rank order. Only subject 3 would remain deviant. This subject would assign stimuli that represent trait A to the third place. So, representing more traits in the MCI subdues the influence of the differential trait composition on the internal consistency.

Still, the distribution of the other traits, against which the stimuli are contrasted on the item level, affects the difficulty of the stimuli. The MCI format is therefore in direct conflict with the assumption of essential $\tau$-equivalence. The internal consistency estimate is not only dependent upon the consistency in the stimulus parameters, but also on the consistency in the trait compositions in the sample. To alleviate the influence of any differential trait composition, all subjects should have the same trait composition. But then the MCI format would not allow any true score variance to occur. In that case, all observed score variance would equal error variance by definition. So, the two internal consistency approximations to reliability, Cronbach's $\alpha$ and KR-20 are both biased against MCI data as compared to SI data.

The split-half, test-retest, or alternate-form approaches seem more suitable to compare the reliability of both item formats, because these estimates do not make any assumptions on the item level. An evaluation of the reliability of MCI data against SI data also demands the SI data to be ipsatized in advance. Otherwise, the SI data incorporates additional information about the absolute trait amount, whereas the additive scoring of MCIs generally does not. Of course this additional information of the SI data might be biased by response styles, as Evers et al. (1983) also observe. However, this source of bias does not contribute to random error. So even if the differences in amount merely reflect systematic error due to response styles, the added variance will still result in an increase in reliability. SI data simply offers this advantage, one could argue. That is beyond doubt, but the difference in reliability then testifies to this merit of raw SI data. If the aim is to obtain ipsative standard scores, the question whether the SI format is preferable to the $\mathrm{MCI}$ format remains unanswered then.

The split-half approach is only acceptable if the selected halves of the ipsative measure each contain at least an equal number of items for every trait 
combination. Otherwise, the halves cannot be considered parallel. And, in addition, the same kind of argument as put against the internal consistency estimates (see Figure 4.1) could be raised against this approach. For the between-subjects differences in the distribution of the variables will differentially affect the disparity in content coverage of both halves. Logically, the same split must be applied to the SI data, and again each half should first be ipsatized. Zuckerman (1952) computed an odd-even split-half reliability in his comparison of MCI and SI format questionnaires. Remarkably three of the four scales are equal in reliability. The discrepant fourth scale was not reliable at all (MCI: 0.19 versus SI: 0.48) owing to a lack of items. Still, Zuckerman did neither secure that the same trait combinations appeared in both halves of the MCI questionnaire, nor that the same split was applied in both the MCI and SI questionnaire. In addition, he failed to ipsatize the results of the SI questionnaire first. A final drawback was that the stimuli were selected by empirical keying, using criterion groups. This method is also known as the external method of questionnaire construction (Oosterveld, 1996). In an addendum Zuckerman (1953) noted himself that a split-half correlation is not the appropriate reliability estimate, because empirically keyed variables will have low inter-item correlations, due to their heterogeneity. $\mathrm{He}$ therefore concludes:

"To determine whether reliabilities of those L-I-D keys [= SI] are lower than for forced-choice keys [= MCI], the study would require the addition of test-retest reliability information which is not presently available." (Zuckerman, 1953, p. 94)

So, after quite an exhaustive literature review, no clear empirical evidence was found to decide which item format provides the more reliable data at the variable level.

\subsubsection{Between-formats comparative validity design}

Instead of comparing the reliability of both item formats, some studies have been aimed at comparing their validity. Again, superiority of the SI format in the validity of the separate variables cannot invalidate the MCI format conclusively. The MCI format may still come out beneficial at the profile level. Nevertheless, this line of research also deserves some attention. The results of the comparative reliability approach were nullified as the predominant criterion, the reliability coefficients Cronbach's $\alpha$ and KR-20, were shown to be biased against the MCI format. Likewise, the comparative validity approach has for a large part relied on the use of factor analysis to contrast the construct validity of both item formats. However, the constant sum constraint in ipsative data induces a negative correlation between the variables (see Formula 2.11). The rank of the data matrix is reduced by one, at least if the number of variables falls below the number of subjects. Guilford (1952), therefore, justifiably warned against the application of factor analysis. A warning that has been restated time and again (Clemans, 1966; 
Closs, 1976, 1996; Cornwell \& Dunlap, 1994; Davis \& Chisson, 1981; Dunlap \& Cornwell, 1994; Hicks, 1970; Loo, 1999; Radcliffe, 1963). Comparative validity studies that disrespect this warning thereby disqualify thenselves (Geiger et al., 1993; Merritt \& Marshall, 1984a, 1984b; Saville \& Willson, 1991; Wright, 1961).

Admittedly, Cattell and Breman (1994) found in an empirical comparison that the ipsative transformation only resulted in a minor distortion. This finding, however, does not establish that no distortion will occur in other comparisons. Moreover, even their study showed that the use of a factor solution as a criterion to compare both methods will still be biased against the MCI format. And, finally, better ways to factor analyse ipsative data have been suggested (Aitchison, 1983, 1986; Chan, 2003; Chan \& Bentler, 1993, 1996; 1998; D. J. Jackson \& Alwin, 1980; Ten Berge, 1999). So far, however, none of the comparative validity studies have made use of any of these advocated approaches. Hence the investigations that make use of factor analysis will be disregarded in this overview. Only the studies that simply correlate the results of both formats to an external criterion remain worth discussing. Logically, these studies concentrate on criterion validity.

Some of the remaining studies still suffer from other shortcomings in the research design. Zuckerman (1952) obtains the stimulus loadings by criterionkeying, but fails to cross-validate the results altogether. Pcrry (1955) also uses criterion-keying, but limits the cross-validation to one criterion group only, preventing any possibility to compare the item formats in their differential prediction between two groups. Only five studies seem to shed some light on the issue.

Heilbrun (1963) evaluated a SI version against a MCI version of the Achievement and Nurturance need variables of the Adjective Check List (ACL). The correlation of the Achievement variable with the cumulative grade-point average was significantly above zero for the $\mathrm{MCl}$ version only. To obtain a Nurturance criterion respondents were asked to list their charitable donations and voluntary activities within the previous two years. A sex-stratified median split over the list count defines a high and low nurturance group. Now only the mean of the SI scores prove to differ significantly between both criterion groups. So these results remain equivocal.

R. R. Knapp (1964) compared the criterion and construct validity of the standard MCI version of the Survey of Interpersonal Values with a new SI version. A previous study suggested its utility in predicting delinquent tendencies among Navy recruits. Prior offenders deviated significantly from non-offenders on two variables of the SI version only. The scores on the MCI version were not significantly different between both criterion groups. In a second sample the SI version also demonstrated enhanced congruent validity. Its correlations with corresponding variables of the DF Opinion Survey were increased compared to the variable scores of the $\mathrm{MCI}$ format. These results credit the SI version with superior criterion and construct validity.

T. R. Knapp (1966) contrasted the standard SI version of the Career Preference Inventory with a new MCI version. The congruent validity was obtained by correlating the results with corresponding variable scores of the Strong Vo- 
cational Interest Blank. The difference in validity was significant in five out of ten comparisons, three favouring the SI version and two the MCI version. These differences are slightly in favour of the SI format.

Scott (1968) compared a SI with a MCI version of the Study of Values and Scott's Values Scales. In addition, two friends judged each respondent by rating and ranking the trait descriptions. The subject self provided a third criterion by rating one's own behaviour relevant to the traits measured. No format came out superior in validity over the other format. Even an additional discriminant validity analysis failed to reveal any important differences.

Finally, Tamir and Lunetta (1977) contrasted a SI version of the Biology Cognitive Preference Test (BCPT) with a MCI version. The researchers not only employed a factor analysis. They also compared the cognitive preferences of 172 high school students with their prospective major field of study in college. Admittedly, they did not formulate clear hypotheses about their relationship. Nevertheless, the MCI version did not discriminate any groups. The SI version however identified the non-science group from the engineering, biological sciences, and pre-medical group. It also separated the pre-medical group from the physical sciences, engineering, and biological sciences group.

The results of the studies by Heilbrun (1963) and Scott (1968) did not indicate a relative benefit of either item format. The investigations of $R$. $R$. Knapp (1964), T. R. Knapp (1966), and Tamir and Lunetta (1977) are in favour of the SI format. No study has been found that credited the MCI format with an advantage. In conclusion, the SI format should be preferred for the isolated assessment of variables.

\subsubsection{Between-formats comparative profile similarity design}

It is remarkable that ipsative measurement, which is associated with 'correlating people' (Broverman, 1961, 1962; Cattell, 1952; Stephenson, 1952), has so many times been evaluated by 'correlating tests'. As such the issue has primarily been addressed in the wrong direction of the resulting data matrix. The research discussed before has actually been aimed at establishing whether the MCI is at least equally suitable to collect data for between subject comparisons within a variable as the SI. It should, however, be the other way around. The proper question that needs an answer is whether the SI is at least equally suitable to collect data for between variable comparisons within a subject as the MCI.

The between-formats comparative profile similarity design appears to be the right method to resolve that question. The profile similarity is assessed by computing the distance between two profiles of the same set of variables within each subject. Both the profiles obtained by MCI data and SI data need to be compared with a criterion profile. The correct approach is to compute within-subjects correlations between the profiles for both item formats separately. The distribution of these within-subjects correlations need subsequently to be compared between the two item formats. Although Merenda and Clarke (1963) correlated 
the MCI profile with the SI profile they failed to use an independent criterion measure. Mellenbergh and Thio (1966) had not constructed a SI version. They only validated the MCI profiles by within-subjects profile correlations with a criterion. Just one study has adopted the complete between-formats comparative profile similarity approach before.

Evers et al. (1983) administered the original MCI and a new SI version of the Vocational Interests Test (VIT) to a group of secondary-school pupils. In addition, a criterion questionnaire was devised containing descriptions of the nine original VIT variables. The pupils were requested to order these variable descriptions according to preference. The individual profile correlations were averaged after applying Fisher's Z-transformation. The average profile correlation between the MCI data and the criterion exceeded that between the SI data and the criterion, both in boys ( 0.47 and 0.42 , respectively) and girls (0.50 and 0.42 , respectively). It remained unclear, however, whether the difference was statistically significant. Evers et al. (1983) also considered it unfortunate that they had used a 3-point Likert scale in the SI version. They acknowledged that this could have exerted a selective detrimental effect to the SI version: it keeps the variable variances of the SI version down. Hence, they advised to use a 5-point Likert-scale in future replications.

\subsubsection{Overall conclusions of the literature review}

The issue whether SI data or MCI data is the more reliable on the variable level cannot be answered satisfactorily. Cronbach's $\alpha$ and KR-20 only equal the proportion true score variance if the item scores meet the assumption of essential $\tau$-equivalence. The MCI format is in direct conflict with that assumption. Subjects with the same trait level may evaluate the difficulty or attractiveness of a representing stimulus differently. That is, because this stimulus is rated in comparison to other stimuli covering other traits. As a result the difficulty of the stimulus also depends on subject position on the other traits that are represented in the MCI.

Hence, the between-formats comparative reliability design has to utilize the split-half, test-retest, or alternate form reliability coefficient. To allow a proper comparison between the MCI and SI format it was further contended that the SI data should be ipsatized prior to computing the correlations. Otherwise, the SI data profits unevenly from stable score variance due to response tendencies. Exclusion of the studies that are in conflict with these two recommendations did not leave any information allowing a fair comparison between the reliability of both item formats.

The SI format shows evidence of more valid measurement results at the variable level. A lot of studies compared the construct validity between the two item formats by factor analysis. But factor analysis is not directly applicable, because the within-subjects constant sum constraint in the MCI data yields a singular covariance matrix. Such an approach requires the pre-processing of the 
data as was first proposed by Aitchison (1986). No between-formats comparative validity studies have applied factor analysis using these advocated procedures. The remaining studies suggest a slight advantage of the SI format. Evers et al. (1983) were the first to compare both item formats on the basis of their relative within-subjects profile similarity. Their result indicated an advantage of the MCI in the measurement of multiple traits at the respondent level.

\subsection{Hypotheses}

In accordance with the proposed recommendations the MCI and SI will be compared using the split-half reliability coefficient on the ipsatized data. It is hypothesized that both item formats will not differ in reliability. So the study aims to corroborate the first null hypothesis that the item formats have equal ipsatized split-half reliability coefficients. Moreover, the influence of the failure to ipsatize the SI data a priori as well as the habit to use Cronbach's $\alpha$ as the reliability coefficient is investigated empirically. The hypothesis is that the failure to ipsatize the data a priori will result in a selective increase in the raw score split-half reliability coefficients of the SI data as the MCI data is already ipsatized in the raw scores. So the second null hypothesis is that the item formats have equal raw score split-half reliability coefficients. It is aimed to be refuted. The use of Cronbach's $\alpha$ will result in a selective decrease in the reliability approximation of the MCI data, because the MCI format is in direct conflict with the assumption of essential $\tau$-equivalence. As a result the third null hypothesis is that the item formats have equal Cronbach's a. It is intended to be refuted as well.

Secondly, the benefit of the MCI format is expected to come forward in the assessment of individual profiles. The MCI focuses on the actual comparison between the variables by every separate respondent. Consequently, these responses put the relative evaluation of the variables on the same scale within each subject. The MCI format is therefore thought to yield more accurate profile scores than the SI format. The original study of Evers et al. (1983) that adopted a comparative profile similarity approach showed promising results. This study essentially replicates their research design. The hypothesis is in agreement with their results in that the MCI profile is regarded to be more similar to the profile of the criterion measure than the SI profile. The final null hypothesis is that both MCI and SI profile are equally similar to the criterion profile. Again this null hypothesis is expected to be proven false.

\subsection{Methods}

\subsubsection{Instruments}

To compare the MCI format with the SI format the Dutch translation of the Study of Values was used (Wolff-Albers \& Mellenbergh, 1970). It was updated compa- 
Figure 4.2: Example item of the Study of Values Part I

4. Assuming that you have sufficient ability, would you prefer to be:

a. a banker

b. a politician

Note. Item derived from Kopelman et al. (2003, p. 212).

rable to the recent adaptation by Kopelman, Rovenpor, and Guan (2003) of the obsolete third edition (Allport et al., 1960). As was explained in the first chapter the questionnaire aims to assess the six values according to Spranger's taxonomy of fundamental individuality types. Spranger (1928) distinguished six types in total: the Theoretic, Economic, Aesthetic, Social, Political, and Religious type. Like the original questionnaire, the revised version consists of two different types of multidimensional compound items. Part I contains 30 compound items that instruct the respondent to distribute three points over two stimuli representing two different traits (see Figures 4.2 and 4.3). Such an item is referred to as a

Figure 4.3: Instructions of the Study of Values Part I

DIRECTIONS: A number of controversial statements or questions with two alternative answers are given below. Indicate your personal preferences by writing appropriate figures in the boxes to the right of each question. Some of the alternatives may appear equally attractive or unattractive to you. Nevertheless, please attempt to choose the alternative that is relatively more acceptable to you. For each question you have three points that you may distribute in any of the following combinations.

1. If you agree with alternative (a) and disagree with (b), write 3 in the first box and 0 in the second box, thus

2. If you agree with (b); disagree with (a), write

3. If you have a slight preference for (a) over (b), write

4. If you have a slight preference for (b) over (a), write

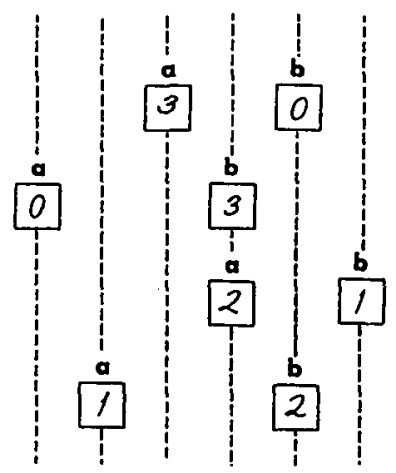

Do not write any combination of numbers except one of these four. There is no time limit, but do not linger over any one question or statement, and do not leave out any of the questions unless you find it really impossible to make a decision.

Note. Instruction derived from Kopelman et al. (2003, pp. 211-212). 
Figure 4.4: Example item of the Study of Values Part II

15. Viewing Leonardo da Vinci's picture, "The Last Supper," would you tend to think of it --

a. as expressing the highest spiritual aspirations and emotions

b. as one of the most priceless and irreplaceable pictures ever painted

c. in relation to Leonardo's versatility and its place in history

d. the quintessence of harmony and design

Note. Item derived from Kopelman et al. (2003, p. 219).

graded comparison item. Two traits out of six can be combined $\left(\begin{array}{l}6 \\ 2\end{array}\right)=15$ times. Each trait combination thus occurs twice. Part II consists of 15 compound items that require the respondent to sort four stimuli representing four different traits (see Figure 4.4). Such an item is called a Q-sort item. Four traits out of six can be combined $\left(\begin{array}{l}6 \\ 4\end{array}\right)=15$ times. So now each trait combination occurs once.

A SI version of the SOV was constructed that contained all 120 stimuli from both Part I and Part II. The SI format sometimes necessitated a slight adaptation of the stimulus. But these changes were kept at a minimum (see also Scott, 1968). As a result the SOV-SI included the same stimuli as the authentic SOV-MCI. Stimuli originating from one dyad or tetrad were maximally separated in the questionnaire and provided with a 7-point Likert scale, following the recommendations by Preston and Colman (2000). The resolution of the Likert scale thus even exceeded the five point scale that was advocated by Evers et al. (1983).

The criterion measure presented the respondent with six scale vignettes based on the original scale descriptions in the manual (Allport et al., 1960; Mellenbergh \& Thio, 1966). The scales were subsequently offered in a paired comparison format. Hence, the criterion instrument is called the SOV-PC version. All 15 possible scale combinations were presented once. This allowed the derivation of a complete rank order conform the theory of comparative judgment. The scale combinations were presented in a random order to account for order effects (Ross, 1934; Wherry, 1938) and printed in two columns. As the 15 paired comparisons would yield the two columns to be uneven, the first comparison was repeated in reverse order merely to align the two columns. The subjects received the instruction to indicate their preferred scale description in each comparison.

\subsubsection{Procedure}

First, the respondents are checked whether they took the administration of the SOV-PC serious. The theory of comparative judgment makes it possible to calculate the number of inconsistent choices. These inconsistent choices violate the transitivity in the individual preference order. A violation of transitivity minimally includes three stimuli. Such a violation is called a circular triad. Subjects with more than one circular triad raise suspicion about the precision in their 
responses. They will be subsequently excluded.

Secondly, the ipsative split-half, raw split-half, and Cronbach's $\alpha$ reliability coefficients of the SOV-MCI and SOV-SI are compared. The ipsative split-half reliability is derived after both scores are expressed as ipsative deviation scores. The variable scores are subtracted by the within-subjects mean and divided by the within-subjects standard deviation, both obtained over the six variable scores within each half (see Formula 2.4b). The scores are fully ipsatized to eliminate the possibility that a response style contributes to the systematic score variance.

Every reliability coefficient is provided with a $95 \%$ confidence interval. The confidence limits of a split-half coefficient is computed using Fisher's Z-transformation on the correlations between the halves (Fan \& Thompson, 2001). The confidence interval for Cronbach's $\alpha$ is based on a random effects model. In addition to the reliability coefficients of the complete instrument the coefficients of Part I and II are also separately shown. Because the advocated balanced split for a fair split-half reliability estimate is only possible in Part I. Part II just includes one item for every scale combination. ${ }^{3}$

The hypotheses regarding the differences in reliability between the SOVMCI and SOV-SI are tested for all three coefficients. The ipsative and raw split-half reliability coefficients are estimated using the Spearman-Brown correction. The uncorrected correlations are, however, utilized to test for any divergence in split-half reliability. The Pearson-Filon statistic is applied to the Fisher Z-transformed correlations, treating them as correlated but non-overlapping correlations (see Raghunathan, Rosenthal, \& Rubin, 1996, Formulas 2 and 3). Feldt (1980) provided a way to test the discrepancy in Cronbach's $\alpha$ of two variables in the same sample. But this test requires the assumption that the stimulus sets of both instruments are random samples of the same universe of stimuli. That requirement is not met with. The stimulus sets of both instruments are equalized as much as possible. So instead, the Cronbach's $\alpha$ coefficients are compared at the instrument level over the six variables by the Sign test and the Wilcoxon signed-ranks test.

Finally, the similarity of the SOV-MCI profile and SOV-SI profile with the SOV-PC profile is computed for every participant by a within-subjects Spearman rank correlation. The SOV-MCI consists of two MCI formats: graded comparison items in Part I and Q-sort items in Part II. The graded comparison items in Part I could be biased by response tendencies. To anticipate such a bias the item scores of Part I are also dichotomised by recoding the response score vectors [ $\left[\begin{array}{ll}3 & 3\end{array}\right.$ and $\left[\begin{array}{ll}1 & 2\end{array}\right]$ into [ $\left[\begin{array}{ll}1\end{array}\right]$ and the opposite vectors vice versa. As a result the SOV-MCI profile is derived in five different ways, based on: Part I, Part I dichotomised,

${ }^{3}$ The items are randomly distributed over the halves. One half of Part I includes the item numbers: $2,3,5,7,8,9,10,12,14,15,19,24,26,28$, and 29. One half of Part II includes item numbers: $2,3,4,5,8,13,14$ and of item 15 the stimuli that represent the scales Theoretical and Religious. In both the SI and $\mathrm{MCI}$ version the same split is applied to each part. The split-half correlations as well as the upper and lower confidence limits are adjusted by the SpearmanBrown formula. 
Part II, Part I + II, and Part I dichotomised + Part II.

The SOV-SI only consists of 7-point Likert scale items. Three meaningful profiles can be derived, based on: the raw scores, the normative standardized scores, and the item ipsative standard scores. It has no use to compute the profile similarity for the variable ipsative standard scores separately. The raw scores and variable ipsative standard scores will yield the same profile similarity. After all, the profile similarity is expressed as a within-subjects rank correlation and ipsative standardization at the variable level does not change the order of the variable scores within the subject. Hence, they are referred to as SOV-SI raw/ipsative. The normative scores are computed as z-scores using the sample as the set of reference measurements. These scores will be indicated as SOV-SI normative.

As a third comparison the obtained SI scores can be compared conform the stimulus combinations in the MCI. In fact this yields an ipsative score as well but now at the item level. In Part I differences of one Likert point between the compared stimuli are translated into a [1 2 ] or [2 1 1] vector score; differences more than one Likert point are converted into a $\left[\begin{array}{ll}0 & 3\end{array}\right]$ or $\left[\begin{array}{ll}3 & 0\end{array}\right]$ vector score. Ties are averaged. So in Part $I$ a tie results in [1.5 1.5]; in Part II it depends on the

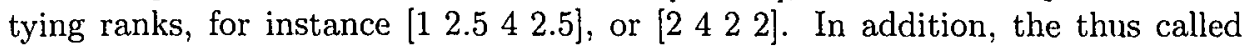
SOV-SI item ipsative scores in Part I could be dichotomised as well, like the MCI version. To test for a difference the Wilcoxon matched-pairs signed-ranks test is used. The one-tail probability will be used since the MCI format is expected to result in higher profile similarity than the SI format. Statistical analyses were performed with SPSS and Excel using an alpha level of 0.05 .

\subsubsection{Participants}

The SOV-MCI and SOV-SI were both administered by computer to 529 psychology freshmen with an interval of two weeks. The order of presentation was balanced in that 251 students first completed the SOV-MCI. In between the SOV-PC was administered in a paper-and-pencil format. In total 505 students completed all three versions. After excluding incomplete responses 439 subjects remained included. The exclusion rate was considerable, because 57 students failed to comply with the instruction in Part II of the SOV-MCI. Instead of rank ordering the options, they mistakenly distributed 10 points (i.e. the added total of the rank numbers) over the four options. They thus permitted themselves ties in the rank order, for instance: [ [ [ $\left.\begin{array}{llll}3 & 3 & 2 & 2\end{array}\right]$.

\subsection{Results}

\subsubsection{Consistency in the SOV-PC}

In total $361(82.2 \%)$ respondents gave completely consistent results without any circular triad in their preference choices and 44 (10.0\%) subjects exhibited just 
Table 4.1: Split-half reliability of the SOV-MCI and SOV-SI ipsative scores

\begin{tabular}{|c|c|c|c|c|c|c|c|c|}
\hline Part & & & Theoretical & Economic & Aesthetic & Social & Political & Religious \\
\hline \multirow[t]{6}{*}{$1+11$} & $\mathrm{MCl}$ & ips. split-half & 0.76 & 0.72 & 0.76 & 0.75 & 0.57 & 0.74 \\
\hline & & & $0.70-0.80$ & $0.66-0.77$ & $0.71-0.81$ & $0.70-0.80$ & $0.48-0.65$ & $0.68-0.79$ \\
\hline & SI & ips. split-half & 0.76 & 0.71 & 0.77 & 0.78 & 0.57 & 0.81 \\
\hline & & & $0.71-0.81$ & $0.65-0.76$ & $0.73-0.81$ & $0.73-0.82$ & $0.48-0.65$ & $0.77-0.84$ \\
\hline & & ZPF & 0.309 & -0.338 & 0.35 .1 & 0.973 & -0.079 & 2.499 \\
\hline & & $p$ & 0.758 & 0.735 & 0.723 & 0.331 & 0.937 & 0.012 \\
\hline \multirow[t]{6}{*}{ I } & $\mathrm{MCl}$ & ips. split-half & 0.66 & 0.45 & 0.60 & 0.52 & 0.54 & 0.67 \\
\hline & & & $0.58-0.72$ & $0.33-0.55$ & $0.51-0.67$ & $0.42-0.60$ & $0.44-0.62$ & $0.60-0.73$ \\
\hline & SI & ips. split-half & 0.70 & 0.55 & 0.50 & 0.63 & 0.39 & 0.71 \\
\hline & & & $0.63-0.75$ & $0.45-0.63$ & $0.39-0.59$ & $0.55-0.70$ & $0.26-0.50$ & $0.65-0.76$ \\
\hline & & ZPF & $0.9 \pi 1$ & 1.602 & -1.814 & 2.200 & -2.080 & 1.138 \\
\hline & & $p$ & 0.331 & 0.109 & 0.070 & 0.028 & 0.039 & 0.255 \\
\hline \multirow[t]{6}{*}{11} & $\mathrm{MCl}$ & ips. split-half & 0.62 & 0.69 & 0.63 & 0.70 & 0.43 & 0.60 \\
\hline & & & $0.54-0.69$ & $0.63-0.75$ & $0.56-0.70$ & $0.63-0.75$ & $0.31-0.53$ & $0.51-0.67$ \\
\hline & $\mathrm{SI}$ & ips. split-half & 0.62 & 0.60 & 0.73 & 0.52 & 0.52 & 0.60 \\
\hline & & & $0.54-0.69$ & $0.52-0.68$ & $0.67-0.77$ & $0.42-0.61$ & $0.42-0.61$ & $0.52-0.67$ \\
\hline & & $\mathrm{ZPF}$ & -0.031 & -2.040 & 2.309 & -3.550 & 1.273 & 0.144 \\
\hline & & $\mathrm{p}$ & 0.975 & 0.041 & 0.021 & 0.000 & 0.203 & 0.886 \\
\hline
\end{tabular}

Note. $n=404$; one subject exhibited no variance in the variable scores in one half of the SOV-SI Part I, therefore no deviation ipsative scores could be computed. The split-half correlations are corrected by the Spearman-Brown formula and provided with the $95 \%$ confidence intervals. ZPF indicates the Pearson-Filon statistic applied to the Fisher Z-transformed uncorrected correlations. Any ZPF with $\mathrm{p}<0.05$ (two-tailed) is printed in boldface. If the Bonferroni-Hochberg procedure is adopted to correct for the familywise error rate within each separate Part (i.e. I, II, or I+II), only the difference in reliability of Part II Social is statistically significant.

one circular triad in their responses. The remaining 34 (7.8\%) subjects produced 2 to 5 circular triads in their answers and were excluded from further analyses. The research sample thus consists of $405(92.2 \%)$ subjects (117 men and 288 women). The age ranges from 17 to 53 years (mean: 21.4; SD: 5.1; median: 19). The overall preference rank order in the SOV-PC ranging from most preferred value to least preferred value goes from Social, Theoretical, Aesthetic, Economic, Political to Religious.

\subsubsection{Between-formats comparative reliability design}

Table 4.1 shows the split-half reliability coefficients of the SOV-MCI and SOV-SI deviation ipsative scores. An evaluation of both item formats separately reveals that in the complete SOV-MCI the ipsative split-half reliability of the variable Political is rather low (0.57). The reliability coefficients of the remaining variables range from 0.72 to 0.76 . They are distinctly lower than the mean split-half reliability of 0.90 that was stated by Allport et al. (1960). Considering the two 
Table 4.2: Split-half reliability of the SOV-MCI and SOV-SI raw scores

\begin{tabular}{|c|c|c|c|c|c|c|c|c|}
\hline Part & & & Theoretical & Economic & Aesthetic & Social & Political & Religious \\
\hline \multirow[t]{6}{*}{$1+11$} & $\mathrm{MCl}$ & raw split-half & 0.79 & 0.76 & 0.78 & 0.77 & 0.64 & 0.76 \\
\hline & & & $0.75-0.83$ & $0.70-0.80$ & $0.74-0.82$ & $0.72-0.81$ & $0.57-0.71$ & $0.71-0.80$ \\
\hline & SI & raw split-half & 0.88 & 0.84 & 0.89 & 0.84 & 0.80 & 0.87 \\
\hline & & & $0.86-0.90$ & $0.81-0.87$ & $0.86-0.91$ & $0.81-0.87$ & $0.75-0.83$ & $0.84-0.89$ \\
\hline & & ZPF & 4.535 & 3.306 & 5.136 & 2.890 & 4.247 & 4.812 \\
\hline & & $p$ & 0.000 & 0.001 & 0.000 & 0.004 & 0.000 & 0.000 \\
\hline \multirow[t]{6}{*}{1} & $\mathrm{MCl}$ & raw split-half & 0.70 & 0.54 & 0.61 & 0.53 & 0.56 & 0.69 \\
\hline & & & $0.63-0.75$ & $0.44-0.62$ & $0.53-0.68$ & $0.43-0.61$ & $0.46-0.64$ & $0.63-0.75$ \\
\hline & $\mathrm{SI}$ & raw split-half & 0.85 & 0.74 & 0.68 & 0.71 & 0.69 & 0.82 \\
\hline & & & $0.82-0.88$ & $0.69-0.79$ & $0.61-0.73$ & $0.64-0.76$ & $0.62-0.74$ & $0.79-0.86$ \\
\hline & & $\mathrm{ZPF}$ & 5.416 & 4.366 & 1.430 & 3.637 & 2.536 & 4.417 \\
\hline & & $\mathrm{p}$ & 0.000 & 0.000 & 0.153 & 0.000 & 0.011 & 0.000 \\
\hline \multirow[t]{6}{*}{ II } & $\mathrm{MCl}$ & raw split-half & 0.63 & 0.71 & 0.66 & 0.69 & 0.48 & 0.60 \\
\hline & & & $0.55-0.69$ & $0.65-0.76$ & $0.59-0.72$ & $0.62-0.74$ & $0.37-0.58$ & $0.52-0.67$ \\
\hline & SI & raw split-half & 0.74 & 0.74 & 0.86 & 0.64 & 0.70 & 0.71 \\
\hline & & & $0.69-0.79$ & $0.68-0.79$ & $0.83-0.88$ & $0.57-0.71$ & $0.63-0.75$ & $0.65-0.77$ \\
\hline & & ZPF & 2.814 & 0.834 & 6.714 & -0.967 & 4.033 & 2.467 \\
\hline & & $p$ & 0.005 & 0.405 & 0.000 & 0.334 & 0.000 & 0.014 \\
\hline
\end{tabular}

Note. $n=404$; the same subject is excluded as in Table 4.1. The split-half correlations are corrected by the Spearman-Brown formula and provided with the $95 \%$ confidence intervals. ZPF indicates the Pearson-Filon statistic applied to the Fisher Z-transformed uncorrected correlations. Any ZPF with $\mathrm{p}<0.05$ (two-tailed) is printed in boldface. If the Bonferroni-Hochberg procedure is adopted to correct for the familywise error rate within each separate Part (i.e. I, II, or I+II), all boldfaced differences remain statistically significant.

parts of the MCI version in isolation, the reliability of Part I is troublesome with three scales dropping below 0.60. In Part II the reliability coefficients are slightly better, varying between 0.60 and 0.70 with the exception of the variable Political (0.43). The ipsative split-half reliability coefficients in the complete SOV-SI appear somewhat higher than in the SOV-MCI, ranging from 0.71 to 0.81 with the exception of the variable Political (0.57). Reviewing the two separate parts of the SI shows that the reliability of Part I is problematic as well with three scales dropping below 0.60 . In Part II the reliabilities are a little better, varying between 0.52 and 0.77 .

With ipsative deviation scores the reliability of the SOV-SI version seems not systematically superior to the SOV-MCI version. The Religious variable is more reliably assessed with the complete SOV-SI. Within Part I the SOV-MCI is more reliable than the SOV-SI in measuring the Political variable, whereas the opposite is true for the variable Social. In Part II the SOV-MCI is the better version for the variables Economic and Social. The Aesthetic variable is more reliably indicated by Part II of the SOV-SI. If within each part, i.e. Part I, 
Table 4.3: Cronbach's $\alpha$ of the SOV-MCI and SOV-SI raw scores

\begin{tabular}{|c|c|c|c|c|c|c|c|c|}
\hline Part & & & Theoretical & Economic & Aesthetic & Social & Political & Religious \\
\hline \multirow[t]{4}{*}{$1+11$} & $\mathrm{MCl}$ & Cronbach's $\alpha$ & 0.75 & 0.73 & 0.74 & 0.73 & 0.53 & 0.74 \\
\hline & & & $0.71-0.78$ & $0.69-0.77$ & $0.70-0.77$ & $0.69-0.76$ & $0.46-0.59$ & $0.70-0.78$ \\
\hline & SI & Cronbach's $\alpha$ & 0.88 & 0.83 & 0.87 & 0.84 & 0.80 & 0.85 \\
\hline & & & $0.86-0.89$ & $0.80-0.85$ & $0.85-0.89$ & $0.82-0.87$ & $0.77-0.83$ & $0.83-0.87$ \\
\hline \multirow[t]{4}{*}{ I } & $\mathrm{MCl}$ & Cronbach's a & 0.64 & 0.49 & 0.56 & 0.51 & 0.41 & 0.62 \\
\hline & & & $0.58-0.69$ & $0.41-0.56$ & $0.49-0.62$ & $0.44-0.58$ & $0.32-0.49$ & $0.57-0.67$ \\
\hline & $\mathrm{SI}$ & Cronbach's $\alpha$ & 0.82 & 0.71 & 0.73 & 0.73 & 0.69 & 0.80 \\
\hline & & & $0.79-0.85$ & $0.67-0.75$ & $0.69-0.77$ & $0.69-0.77$ & $0.65-0.74$ & $0.77-0.83$ \\
\hline \multirow[t]{4}{*}{ II } & $\mathrm{MCl}$ & Cronbach's $\alpha$ & 0.55 & 0.67 & 0.64 & 0.68 & 0.32 & 0.62 \\
\hline & & & $0.49-0.62$ & $0.62-0.72$ & $0.59-0.69$ & $0.63-0.72$ & $0.21-0.41$ & $0.56-0.67$ \\
\hline & $\mathrm{SI}$ & Cronbach's $\alpha$ & 0.73 & 0.69 & 0.82 & 0.71 & 0.64 & 0.70 \\
\hline & & & $0.69-0.77$ & $0.64-0.73$ & $0.79-0.84$ & $0.67-0.75$ & $0.58-0.69$ & $0.66-0.74$ \\
\hline
\end{tabular}

Note. $n=405$; the Cronbach's $\alpha$ coefficients are provided with a $95 \%$ confidence interval.

Part II, and the complete version, a Bonferroni-Hochberg correction is applied to control the nominal alpha, only the difference in the reliability of Social with Part II remains statistically significant (Hochberg, 1988). All in all, with ipsative deviation scores the reliability of both versions roughly agrees.

The agreement in reliability between both versions disappears if the raw scores are used. This is evidenced by the overall higher reliability coefficients of the SOV-SI (see Table 4.2). The only exception is the reliability of Social within Part II. This difference is not statistically significant, nor are the differences in reliability of Aesthetic within Part I and Economic within Part II. A correction for chance capitalization by the Bonferroni-Hochberg procedure does not alter that picture. In both the SOV-MCI and SOV-SI the reliability coefficients are raised as compared to those in Table 4.1. The coefficients in the SOV-MCI benefit from the added between-subjects variability in the within-subjects dispersion of the variable scores. The SOV-SI, however, also profits from the extra betweensubjects differences in the within-subjects average variable scores.

Finally, Table 4.3 lists the Cronbach's $\alpha$ reliability coefficients of both the SOV-MCI and SOV-SI. A comparison with Table 4.2 reveals that in the SOV-MCI all Cronbach's $\alpha$ coefficients are a little reduced as compared to the raw score splithalf reliability coefficients, except for the variable Religious in Part II. The current results compare quite favourably to those of Kopelman et al. (2003), except for the variable Political. The Cronbach's $\alpha$ of Religious is inferior to theirs as well, but still acceptable. Apart from a few exceptions, the Cronbach's $\alpha$ coefficients of the SOV-SI are also a bit reduced as compared to the raw score split-half reliability coefficients in Table 4.2, although the differences appear less outspoken than with the MCI format. So again the difference in reliability between the MCI and SI format is substantial. In all parts the reliability of the SI version exceeds 
Table 4.4: Distribution of the rank correlations with profiles of the SOV-PC

\begin{tabular}{llccccccc}
\hline Part & & mean & SD & min & $\mathbf{Q}_{1}$ & median & $\mathbf{Q}_{3}$ & max \\
\hline I+II & MCI raw & 0.67 & 0.29 & -0.87 & 0.55 & 0.76 & 0.89 & 1.00 \\
& SI var raw/ips. & 0.68 & 0.26 & -0.46 & 0.54 & 0.77 & 0.84 & 1.00 \\
& SI var norm. & 0.38 & 0.40 & -0.94 & 0.09 & 0.49 & 0.71 & 1.00 \\
& SI item ips. & 0.68 & 0.26 & -0.29 & 0.55 & 0.77 & 0.89 & 1.00 \\
\hline I & MCI raw & 0.62 & 0.31 & -0.88 & 0.46 & 0.70 & 0.83 & 1.00 \\
& SI var raw/ips. & 0.60 & 0.31 & -0.70 & 0.43 & 0.67 & 0.83 & 1.00 \\
& SI var norm. & 0.33 & 0.42 & -0.89 & 0.09 & 0.37 & 0.66 & 1.00 \\
& SI item ips. & 0.59 & 0.32 & -0.55 & 0.41 & 0.70 & 0.83 & 1.00 \\
\hline II & MCl raw & 0.61 & 0.34 & -0.97 & 0.49 & 0.70 & 0.84 & 1.00 \\
& SI var raw/ips. & 0.65 & 0.28 & -0.77 & 0.49 & 0.71 & 0.84 & 1.00 \\
& SI var norm. & 0.34 & 0.41 & -1.00 & 0.09 & 0.43 & 0.66 & 1.00 \\
& SI item ips. & 0.63 & 0.28 & -0.60 & 0.49 & 0.71 & 0.83 & 1.00 \\
\hline
\end{tabular}

Note. $n=405$; ips. = ipsatized; norm. = normatized; $\mathrm{Q}_{1}=$ first quartile; $\mathrm{Q}_{3}=$ third quartile.

the MCI version. As each part contains six variables, this is equally significant in each part (two-tailed Sign test $p=2 \times 1 / 2^{6} \Rightarrow p<0.05$; Wilcoxon $Z=-2.201$, two-tailed $\mathrm{p}<0.05$ ).

\subsubsection{Between-formats comparative profile similarity design}

Table 4.4 demonstrates the distribution parameters of the within-subjects Spearman rank correlations of the SOV-MCI and the SOV-SI raw/ipsative, normative, and item ipsative profile scores with the SOV-PC. The descriptive statistics used to obtain the z-scores for the SOV-SI normative profiles are included in Appendix A.4.1. The profile similarity coefficient distributions are first presented for the total questionnaire (Part I+II) and then for each part alone. A rough comparison of the total profiles with the profiles of the separate parts reveals that the total profiles correlate best with median profile similarities from 0.76 to 0.77 , then the profiles of Part II with median profile similarities from 0.70 to 0.71 and finally the profiles of Part I with median profile similarities from 0.67 to 0.70 . The profile similarity coefficients of the SI normative profiles are an exception. They really stand out with median profile similarities ranging from 0.37 to 0.49 . The other profiles seem more or less the same.

The influence of dichotomising the graded comparison item in Part I was checked as well. The resulting distributions of the profile similarity coefficients are included in Appendix A.4.2. The dichotomisation does neither improve the SOV-MCI profiles in the total questionnaire or Part I alone, nor the SOV-SI item ipsatized profiles in the total questionnaire or just Part I.

The planned Wilcoxon matched-pairs signed-ranks tests allow these distributions to be scrutinized for any differences more thoroughly. Table 4.5 includes 
all relevant comparisons between the $\mathrm{MCI}$ profile similarity coefficients and the SI profile similarity coefficients. The rows are divided in three parts. The upper part shows the various comparisons with the SOV-SI raw/ipsative profile similarity coefficients. The middle part tabulates the set of comparisons with the SOV-SI normative profile similarity coefficients. And the bottom part lists the assorted comparisons with the SI item ipsative profile similarity coefficients. This main division in the rows is evidenced by the labels in the first four columns and more specifically by the labels in columns three and four.

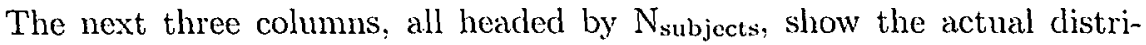
bution of the profile comparisons. The columm headed ' $\mathrm{MCl}<\mathrm{SI}$ ' indicates the number of subjects in which the profile similarity of the SI score exceeds the profile similarity of the MCI score. The column headed ' $\mathrm{MCI}>\mathrm{SI}$ ' depicts the number of subjects in which the profile similarity of the MCI score surpasses the profile similarity of the SI score. According to the hypothesis the subject counts in this middle column should be greater than the former column. And the column headed ' $\mathrm{MCI}=\mathrm{SI}$ ' includes the number of subjects in which the profile similarity of the MCI score equals the profile similarity of the SI score. This column represent the subjects in which the profile similarity coefficients of both item formats tie. The final four columns list the essential statistics for the Wilcoxon matched-pairs signed-ranks test. The first column of this group shows the sum of the negative ranks. The second column lists the sum of the positive ranks. The next column renders the associated Wilcoxon $\mathrm{Z}$ values. And the final column tabulates the related left-tail probabilities.

Table 4.4 already demonstrated that the SI normative profile similarity coefficients are noticeably reduced. They are all inferior to the agreement of the MCI raw profile scores with the SOV-PC profiles. That is evidenced by the middle row group. In 301 to 309 subjects the MCI profile similarity coefficient exceeds the SI normative profile similarity coefficient. These differences are all statistically significant with Wilcoxon $\mathrm{Z}$ varying between -11.314 and -12.283 (in all: $\mathrm{p}<0.05$ ).

Contrary to the hypothesis the top rows reveal that the SOV-MCI profile similarity coefficients do not differ from the SOV-SI raw/ipsative profile similarity coefficients. If the SI item responses are compared at the stimulus level conform the combinations in the MCI version, it affects the resulting profile similarity with the SOV-PC profiles in Part I. That is evidenced by the statistical significant difference in profile similarity of the SOV-MCI with the SOV-SI item ipsative scores (Wilcoxon $\mathrm{Z}=-2.013 ; \mathrm{p}=0.022$ ). Dichotomising the Part I SOV-SI item ipsative scores increases this difference (Wilcoxon $\mathrm{Z}=-2.292 ; \mathrm{p}=0.011$ ) ${ }^{4}$ Conversely, dichotomising the Part I SOV-MCI item scores nullifies the difference with either the standard SOV-SI item ipsative scores (Wilcoxon $Z=-0.299$; $\mathrm{p}=0.383$ ), or the dichotomised SOV-SI item ipsative scores (Wilcoxon $\mathrm{Z}=0.258$;

\footnotetext{
4 The effects of dichotomising the item scores of Part I are not included in Table 4.4, but can be found in Tables A.4.3 and A.4.4 in Appendix A.4.2.
} 
Table 4.5: Profile similarity comparisons with Wilcoxon Z coefficients

\begin{tabular}{|c|c|c|c|c|c|c|c|c|c|c|}
\hline \multirow{2}{*}{ Part } & \multirow{2}{*}{$\begin{array}{c}\mathrm{MCl} \text { item } \\
\text { level }\end{array}$} & \multirow{2}{*}{$\begin{array}{c}\text { SI } \\
\text { item level }\end{array}$} & \multirow{2}{*}{$\begin{array}{c}\text { SI var } \\
\text { level }\end{array}$} & \multicolumn{3}{|c|}{$N_{\text {subjects }}$} & \multirow{2}{*}{$\begin{array}{l}\text { Neg. } \\
\text { ranks }\end{array}$} & \multirow{2}{*}{$\begin{array}{l}\text { Pos. } \\
\text { ranks }\end{array}$} & \multirow{2}{*}{$\begin{array}{c}\text { Wilcoxon } \\
Z\end{array}$} & \multirow[b]{2}{*}{ 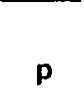 } \\
\hline & & & & $\mathrm{MCl}<\mathrm{SI}$ & $\mathrm{MCl}>\mathrm{SI}$ & $\mathrm{MCl}<\mathrm{SI}$ & & & & \\
\hline III & ips. & man & raw/ips. & 185 & & & 33859.5 & 330 & 0.047 & 0.51 \\
\hline I & 1 & & /ips. & . & & & & & & 0.059 \\
\hline II & ips. & raw & raw/ips. & 199 & 79 & 27 & 37392.0 & 34 & & 0.771 \\
\hline 11 & ing & (2) & norm & 82 & 202 & 20 & .5 & 6 & 3 & 0.0 \\
\hline 1 & & & & & & 8 & & & & 0.000 \\
\hline II & ps. & 1000 & norm. & 89 & 309 & 7 & 13719.5 & 65681.5 & -11.314 & 0.000 \\
\hline & & & & 190 & & 36 & & & & 0.542 \\
\hline 1 & s. & ips. & raw/ips. & 169 & 216 & 20 & & & & 0.022 \\
\hline II & ips. & ips. & raw/ips. & 185 & 185 & 35 & 34469.5 & 34165.5 & -0.074 & 0.471 \\
\hline
\end{tabular}

Note. $n=405 ;$ ips. = ipsative; norm. = normative.

$\mathrm{p}=0.602)$.

Appendix A.4.3 includes the frequency polygons based on the profile similarity coefficients of the SOV-MCI, the SOV-SI raw/ipsative, and the SOV-SI item ipsative scores for the total questionnaire and each part separately. They illustrate the almost perfect agreement in the profile similarity coefficients of the three measurement approaches. Figure A.4.2 suggests that the statistical significant benefit of the SOV-MCI over the SOV-SI item ipsative scores in Part I is due to a small difference in the profile similarity range between 0.8 and 0.9 . Bear in mind though that this difference is only found to be statistically significant with the SOV-SI item ipsative profile similarity coefficients, not the SOV-SI raw/ipsative profile similarity coefficients.

\subsection{Discussion}

\subsubsection{Consistency in the SOV-PC}

Less than $10 \%$ of the sample demonstrated more than one violation of transitivity in the preference ordering of the SOV-PC variable descriptions. Hence, it seems safe to conclude that the subjects answered the questionnaires carefully. The data is thus considered valid.

\subsubsection{Between-formats comparative reliability design}

The comparisons between the reliability coefficients support the argument against the use of Cronbach's $\alpha$ or KR-20 with the MCI format. The split-half coefficients over the ipsative deviation scores did not reveal any difference between the MCI and the SI format. In case the raw scores were used the differences between the split-half coefficients became significant in favour of the SI format. Apply- 
ing Crombach's $\alpha$ instead of the split-half coefficients seemed to widen the gap even further. So, the empirical evidence supports the warning against the use of Cronbach's $\alpha$ or KR-20 for estimating the reliability in MCI data. This is in contrast with current practice. Cronbach's $\alpha$ is the default reliability coefficient, irrespective of the questionnaire type (Hogan, Benjamin, \& Brezinski, 2000). In a MCI questionnaire, however, reliability should not be estimated by Cronbach's $\alpha$ nor KR-20.

Still, the primary cause for the difference in the reliability coefficients between both item formats was the use of raw scores instead of deviation ipsative scores. With the use of raw scores the reliability of the SOV-SI selectively profits from the added between-subjects score variance. The additive scoring of the SOV-MCI yields variable scores that are already ipsatively standardized, at least with respect to the within-subjects average. If the aim is to derive ipsative deviation scores, the individual differences in the average or dispersion of someone's variable scores are immaterial. The increase in reliability of the SI format due to the use of raw scores must therefore be considered spurious. Note by the way, that within the MCI the reliability as estimated by Cronbach's $\alpha$ (see Table 4.3), only marginally differed from the reliability as estimated by the split-half correlations (see Table 4.2). So, the violation of essential $\tau$-equivalence by the $\mathrm{MCI}$ format contributes only marginally to the difference in estimated reliability as evaluated against the SI item format. For a proper comparison of reliability between the MCI and SI format, it is of utmost importance that the scores of both formats are expressed in the same ipsative standard scores.

\subsubsection{Between-formats comparative profile similarity design}

Contrary to the expectation the SOV-MCI and SOV-SI did not differ in profile similarity with the SOV-PC. The SOV-MCI and SOV-SI score profiles correlated well with the SOV-PC profiles. The distributions of the profile similarity coefficients by the separate parts only slightly deviated from the distributions by the complete questionnaire. So, both in the overall questionnaire and in the isolated parts the SOV-MCI and the SOV-SI agreed with the SOV-PC in an equal extent. The MCI format therefore appears not to offer a benefit over the SI format in the assessment of individual score profiles.

With normative standard scores, however, the profile correlations of the SOV-SI were distinctly lower. Obviously, this must be attributed to the homogeneity of the represented population. As explained in the previous chapter normative standardization may correct for a response habit. But only, if the compared traits are equally distributed in the population. In the homogeneous student population that the current sample represented, this is clearly not the case. The low profile correlations of the normative standardized SOV-SI profiles with the SOV-PC profiles thus actually indicate that the six values are not equally distributed in this population.

If the SOV-SI was ipsatized at the item level, the difference in profile simi- 
larity in Part I became statistically significant (Wilcoxon $\mathrm{Z}=-2.013 ; \mathrm{p}=0.022$ ). This is caused by a disparate reduction of information in the SOV-SI item ipsative scores due to ties. With repeated comparisons at the item level ties are bound to occur more frequently than if the ipsatization is limited at the variable level only. The MCI is always credited for preventing this loss of information due to ties. Yet the current results indicate that this alleged benefit of the MCI at the item level is accounted for by the SI at the variable level. The errors in the individual SI scores average out in the variable score: the foundation of classical test theory.

The results nevertheless hint at a benefit of the graded comparison item format in Part I (Wilcoxon $\mathrm{Z}=-1.566 ; \mathrm{p}=0.059$ ). Admittedly, Figure A.4.2 in Appendix A.4.3 emphasizes that the difference is quite subtle. And the failure of the effect to surface in a sample of 405 subjects does not suggest that the effect is large. But the dichotomisation of the SOV-MCI Part I scores did lower the profile similarity coefficients. Consequently, the variance in the stimulus score distributions within the graded comparison items of Part I must be considered to represent valid score variance. The graded comparison item therefore deserves more attention in ensuing investigations of the MCI format.

\subsubsection{Overview}

The current study was aimed to demonstrate the advantage of the MCI format for the purpose it seems best fit: the assessment of individual score profiles. The results failed to establish its superiority over the SI format. Both item formats are equally suitable for the assessment of individual score profiles. Thus, anyone who hesitates between using the SI or MCI format for an additively scored questionnaire, should choose the SI format. This format is by far the easiest to construct, the fastest to respond to, the simplest to score, the clearest to interpret, and the most direct to analyse.

In addition, existing MCI questionnaires should dispense with the Cronbach's $\alpha$ reliability coefficient. The MCI is fundamentally in conflict with the assumption of essential $\tau$-equivalence. Instead the split-half, test-retest, or alternate form approaches should be adopted. For a split-half reliability coefficient the items with a similar composition of traits should be distributed equally over both halves. Finally, the results do imply that respondents are able to make a graded comparison between two disparate stimuli. This particular MCI format therefore deserves to be explored more fully. 


\title{
The benefit of the multidimensional compound item in feedback reports: The customer is always right
}

\author{
A set of $[. .$.$] scores that are the "absolute"$ \\ counterparts of those yielded by an ipsative instrument \\ should not be considered superior unless it can be demonstrated \\ empirically that it does indeed contain more information.
} (Clemans, 1966, p. 53, italics from the original)

\subsection{Introduction}

The previous chapter failed to establish the superiority of the multidimensional compound item (MCI) in profile assessments. The current study nevertheless reattempts to demonstrate the specific aptitude of the MCI for profile assessments. But now a different kind of criterion is adopted. This time the verdict is trusted to the respondents themselves. The subjects are presented with two feedback reports: one with a profile based on the own $\mathrm{MCI}$ scores and one with a profile based on the own singular item (SI) scores. The subjects simply have to specify which profile fits best. The proof of the pudding is in the eating.

An intermediate problem is that it is actually unknown how respondents evaluate the fit of a score profile with their own self image. Subjects might judge each separate variable score by calling the set of completed stimuli into remembrance, by positioning oneself for each variable within a group of imaginary reference subjects, by relating one's endowment with the reflected trait to the own control of the other measured traits, or by comparing one's present position with the personal growth or decline in the represented trait. In Chapter 2 it was explained that these four types of score interpretation respectively call for a domain-referenced, normative, ipsative, and iterative standardization. In interest measurement the third interpretation, ipsative standardization, is deemed most important. Not surprisingly therefore most interest questionnaires make use of 
the MCI. Whether respondents actually do relate a particular interest to their other interests remains however a moot question.

This poses a central weakness in the choice to invoke the respondents themselves as ultimate referees. Subjects could well prefer the profile of the SI scores over that of the MCI scores. But to conclude that the SI format yields the better profile then, may be premature. Subjects might simply interpret their feedback scores in a normative sense. This scenario features respondents who just fail to appreciate the ipsative aspect of the measurement. So, the MCI could still provide the more accurate information in an ipsative sense. In that reading a main preference for the SI version would not discard the MCI format. To validate the criterion, therefore, it must be checked whether subjects interpret the feedback in an ipsative sense.

\subsection{Hypotheses}

\subsubsection{Design}

To resolve the intermediate problem whether respondents judge their profile scores in an ipsative sense or not, the current study uses an experimental approach. First, every subject is invited to complete both an SI and MCI version of an interest questionnaire. Then informed consent is obtained to use their scores in an investigation for which they remain anonymous. Upon consent the respondent is presented with another form and a feedback report with the own score results of both versions. This new form instructs the respondent to compare the results of both versions. The subject simply indicates which version has yielded the score that comes closest to the own perception of each separate interest and the interest profile as a whole. What the subject does not know, however, is that he or she is randomly assigned to one of two conditions. The subject receives the scores of both the SI and MCI version in either domain-referenced standard scores or ipsative standard scores. The benefit of this arrangement is that for the respondent who receives domain-referenced standard scores the MCI scores will remain more or less ipsative, whereas the SI scores will not. On the other hand, for the respondent who receives ipsative standard scores both the SI scores and MCI scores are equally ipsative.

\subsubsection{Predictions}

If respondents judge the personal fit of the score profile in an ipsative sense, they will clearly prefer the MCI version over the SI version if both profiles are based on domain-referenced standard scores. So the first null hypothesis is that respondents do not prefer the $\mathrm{MCl}$ profile over the SI profile if they are derived from domainreferenced standard scores. Secondly, if the MCI yields more information for ipsative standardization than the SI, respondents will also prefer the MCI version over the SI version if the scores are standardized in an ipsative sense. Hence, the 
Figure 5.1: Example item of the VIT-MCI

\begin{tabular}{ll}
\hline & Build a brick wall \\
$\square$ & Work in a shop \\
$\square$ & Read a history book \\
$\square$ & Work in a children's home \\
\hline
\end{tabular}

Note. Item translated from Evers et al. (1999) by the author.

second null hypothesis is that respondents do not prefer the MCI profile over the SI profile if they are based on ipsative standard scores. This investigation aims to reject both null hypotheses.

\subsection{Methods}

\subsubsection{Materials}

The Vocational Interests Test (VIT) is a Dutch adaptation of the German Berufs Interessen Test (Evers, Lucassen, \& Wiegersma, 1999; Wiegersma, 1959). It includes the following eleven variables: 1. Technical Handcraft (TH), doing practical technical work using tools and/or machines; 2. Traditional Design (TD), designing and creating things with all kinds of materials; 3 . Engineering and Natural Sciences (EN), investigating mathematics and exact sciences; 4 . Nutrition (NU), managing, organising, and preparing food, working in the catering industry; 5. Farm Work $(F W)$, working in agriculture, forestry, and horticulture, or environmental protection; 6 . Trade (TR), buying and selling, making profits, maintaining business contacts; 7 . Office Work $(\mathrm{OW})$, processing commercial data, accounting and administration; 8. Language and Culture (LC), being active in the area of language, culture, history, or ideology; 9. Man and Society (MS), studying and solving social problems; 10 . Social Work $(S W)$, offering practical support to children and adults with problems; and 11. Medical Work (MW), investigating, treating, or nursing patients. The original version uses a multiple comparison tetrad. This type of MCI presents the subject with four stimuli, that represent different variables. The respondent is required to mark the preferred activity. Figure 5.1 presents the example item.

If the respondent selects the first option, one point is added to the $T H$ variable; should the subject mark the second option the $T R$ variable receives one point instead; if the third option is preferred, the point is awarded to the $L C$ variable; and finally, if the fourth option is chosen, the $S W$ variable gets the point. With each response the three unmarked options receive no credit. All eleven variables comprise of 14 stimuli and each stimulus is included in four MCIs. Since every MCI includes four stimuli, the VIT-MCI questionnaire originally consists of: 14 (stimuli) $\times 11$ (variables) $\times 4$ (repetitions) $/ 4$ (stimuli per item) $=154$ items. As a result a stimulus obtains a score from 0 (never selected) to 4 (always 
Figure 5.2: Example item of the VIT-SI

\begin{tabular}{lccccccc}
\hline & extremely & very & moderately & \multicolumn{3}{c}{ moderately very extremely } \\
unpleasant & unpleasant & unpleasant & neutral & pleasant & pleasant & pleasant \\
Build a brick wall & $\square$ & $\square$ & $\square$ & $\square$ & $\square$ & $\square$ & $\square$ \\
Work in a shop & $\square$ & $\square$ & $\square$ & $\square$ & $\square$ & $\square$ & $\square$ \\
Read a history book & $\square$ & $\square$ & $\square$ & $\square$ & $\square$ & $\square$ & $\square$ \\
Work in a children's home & $\square$ & $\square$ & $\square$ & $\square$ & $\square$ & $\square$ & $\square$ \\
\hline
\end{tabular}

Note. Stimuli derived from Evers et al. (1999) and adapted by the author.

selected). So, the variable score ranges from 0 to $4 \times 14=56$.

An SI version of the VIT is developed by supplying each stimulus with a 7-point Likert scale. Figure 5.2 shows the four resulting SI's of the example MCI. Now the subject is instructed to indicate one's own pleasure in undertaking each activity separately. If the respondent finds building a brick wall extremely unpleasant, the corresponding left checkbox is marked. This awards the stimulus with one point. Should the subject take extreme pleasure in building a brick wall he or she ticks the corresponding right checkbox, crediting the stimulus with seven points. Every stimulus is presented only once, so the VIT-SI contains $11 \times 14=154$ items as well. To prevent systematic stimulus order effects the fourteen subsequent blocks of eleven stimuli include all eleven variables. The order of the stimuli within each block is varied according to a Latin square design. It offers different variable orders with an optimal distance between stimuli that represent the same variable. Each variable score ranges from $1 \times 14=14$ to $7 \times 14=98$.

The feedback form that collects the respondent preferences is referred to as the VIT-FB and is included in Appendix A.5.2. The subject is first requested to indicate whether the VIT-MCI or VIT-SI yielded the preferred result for each variable separately. The respondent is only allowed to omit a preference if both scores are exactly the same. Finally, the respondent is required to indicate the version that produced the overall better fitting profile. This last question does not allow the respondent to express no preference. It was intended to have the respondent first compare each variable separately and then the profile as a whole. This arrangement forces the respondent to take all variables into careful consideration before choosing the better overall profile.

\subsubsection{Score transformations}

For the feedback either a domain-referenced standardization or an ipsative standardization is applied. However, the VIT-MCI scores cannot simply be converted into domain-referenced standard scores by a linear transformation. That is, because the average variable score of the added multiple comparison item scores will not be located in the middle of the score range, i.e. a domain-referenced standard score of 0.50 . The minimum variable score is 0 and the maximum is 56 . But as 
154 points are to be distributed over 11 variables the average variable score will be $154 / 11=14$.

One might in the first place dispute the necessity to associate the VIT-MCI raw score 14 with the domain-referenced standard score of 0.50 . If a score of 14 is just thought to reflect a domain-referenced score of $14 / 56=0.25$, a simple linear score transformation would suffice: $X^{\prime}=X / 56$. Actually, the feedback reports were first printed applying this linear score transformation after the VIT-SI and VIT-MCI responses were obtained. One of the co-workers, H.C.M. Vorst, scrutinized the pile of feedback reports. He noted that the within-subjects average of the VIT-MCI was often distinctly lower (i.e. 0.25) than that of the VIT-SI (actually around 0.41, see Table A.5.3 in Appendix A.5.4). It was feared that this effect would be responsible for a dominating VIT-SI preference in this group.

If it is accepted that the raw VIT-MCI score of 14 should be associated with a domain-referenced score of 0.50 , it implies that the unit of measurement changes across the score range. In that case it also presents a problem for ipsative standardization. Although the unit of measurement may differ across respondents, ipsative standardization requires the measurement unit to be constant across variables within a subject. This will not be the case if the variable scores differ. So for both the domain-referenced standard scores and the ipsative standard scores a score transformation is used.

\section{Domain-referenced standard scale}

A domain-referenced score can be derived using a non-linear score transformation. If a raw VIT-MCI score of 0 is associated with a domain-referenced VIT-MCI score of 0 , a raw VIT-MCI score of 14 with a domain-referenced VIT-MCI score of $\frac{1}{2}$, and a raw VIT-MCI score of 56 with a domain-referenced VIT-MCI score of 1 , a plausible transformation curve is obtained by applying the transformation function:

$$
X^{\prime}=\frac{3 X}{2 X+56} .
$$

The suggested score transformation is based on the proportion between the distance from the defined raw variable score midpoint (14) to the maximum (56) and the distance from the minimum (0) to the midpoint (14). It generates a monotonously increasing function without an inflection point (see Figure 5.3). This function can be derived from the general transformation function that is outlined in Appendix A.5.1. Observe that the curve crosses the anchor points $[0 ; 0.00],[14 ; 0.50]$, and $[56 ; 1.00]$. Each dot in the curve represents a possible MCI variable score in the range of 0 to 56 .

The VIT-SI scores represent a linear score range from 14 to 98 . To derive domain-referenced scores it just requires a linear transformation, conform Formula 2.1 in Chapter 2:

$$
X^{\prime}=\frac{X-14}{98-14} \text {. }
$$


Figure 5.3: VIT-MCl domain-referenced score transformation curve

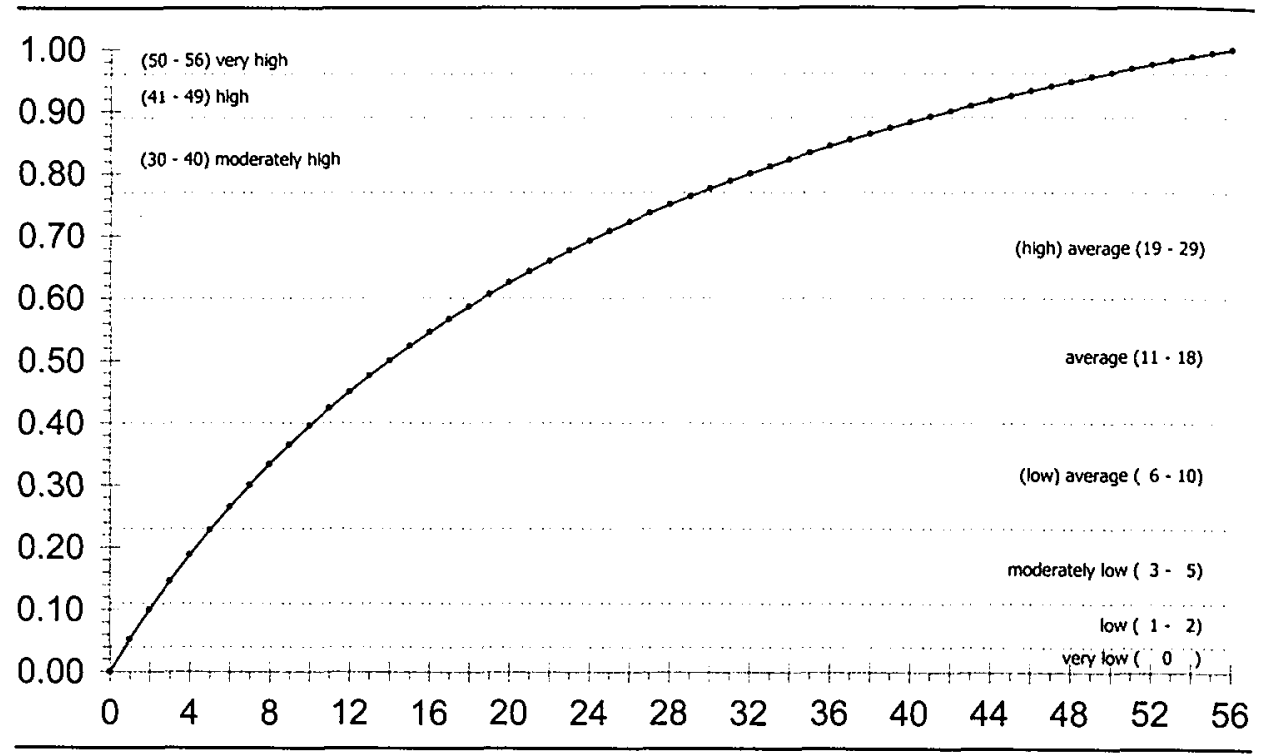

This transformation equally results in a score distribution ranging from 0.00 to 1.00 .

\section{Donine scale}

In order to make the domain-referenced standard scores easily interpretable for users it was chosen to reduce the scores to nine score classes. Then the obtained results can be qualified with unambiguous verbal labels. This domain-referenced nine point scale adopts the distribution of the stanine score classes. But instead of referring to a percentage of subjects as in the proper stanine score classes, these classes refer to a proportion of the scale maximum. The term stanine originates from a contraction of 'standard' with 'nine'. By combining 'domain' with 'nine', this scale is therefore referred to as the donine scale. The classes with the corresponding score labels that are used in the feedback reports are listed in Table 5.1.

The associated VIT-MCI raw score ranges are also indicated in Figure 5.3. It suggests that the discrimination increases with the score. After all, a very low score is only obtainable by a raw VIT-MCI score of 0 points, whereas a very high score is covered by the raw VIT-MCI score range from 50 to 56 . The increase in score resolution towards the higher end suggests that the multiple comparison item produces heteroscedastic error variances. This issue will be further explored in the section addressing the between formats differences in reliability. 
Table 5.1: Donine scale classes with associated labels and score ranges

Donine scale class Scale class label Domain-referenced VIT-MCI range VIT-SI range

\begin{tabular}{llccc}
\hline 1 & very low & $0.00-0.04$ & 0 & $14-17$ \\
2 & low & $0.04-0.11$ & $1-2$ & $18-23$ \\
3 & moderately low & $0.11-0.23$ & $3-5$ & $24-33$ \\
4 & (low) average & $0.23-0.40$ & $6-10$ & $34-47$ \\
5 & average & $0.40-0.60$ & $11-18$ & $48-64$ \\
6 & (high) average & $0.60-0.77$ & $19-29$ & $65-78$ \\
7 & moderately high & $0.77-0.89$ & $30-40$ & $79-88$ \\
8 & high & $0.89-0.96$ & $41-49$ & $89-94$ \\
9 & very high & $0.96-1.00$ & $50-56$ & $95-98$ \\
\hline
\end{tabular}

\section{Ipsative standard scale}

The transformation to obtain a domain-referenced score of the MCI version is non-linear. As a result the mean of the domain-referenced scores will not remain equal among subjects. For example, two raw scores of 14 (mean $=14$ ) result in two domain-referenced scores of $\frac{1}{2}$ (mean $=\frac{1}{2}$ ), whereas the raw scores 8 and 20 $($ mean $=14)$ yield the domain-referenced scores of $\frac{1}{3}$ and $\frac{5}{8}$ respectively (mean $=\frac{23}{48}$ ). Therefore, the domain-referenced MCI data cannot be considered strictly ipsative anymore. One might choose to use the raw MCI data instead. But that would be odd, because Figure 5.3 exactly implies that a raw score of 20 is not as much above the within-subjects raw mean of 14 as a raw score of 8 is below it. So, although the raw score scale does represent an ipsative scale, it cannot be considered to reflect an interval level of measurement. The unit of measurement, i.e. the slope of the curve in Figure 5.3, decreases as the score increases.

Contrary, the domain-referenced scores are presumed to reflect an interval level. As a consequence the ipsative comparison of the MCI version with the SI

Table 5.2: Ipsine classes with associated labels and score ranges

Ipsine scale class Scale class label Domain-referenced VIT-MCI range VIT-SI range

\begin{tabular}{|c|c|c|c|}
\hline 1 & very low & $-\infty--1.75$ & \\
\hline 2 & low & $-1.75--1.25$ & The exact raw score ranges are \\
\hline 3 & moderately low & $-1.25--0.75$ & unavailable as they differ be- \\
\hline 4 & (low) average & $-0.75--0.25$ & tween the subjects. The scores \\
\hline 5 & average & $-0.25-\quad 0.25$ & depend on the within-subjects \\
\hline 6 & (high) average & $0.25-\quad 0.75$ & mean and within-subjects stan- \\
\hline 7 & moderately high & $0.75-\quad 1.25$ & dard deviations between the raw \\
\hline 0 & high & $1.25-1.75$ & variable scores. \\
\hline 9 & very high & $1.75-$ & \\
\hline
\end{tabular}


version requires the ipsative standardization of the domain-referenced scores of both item formats. The scores will be fully ipsatized as defined by Cattell and Bremnan (1994). That implies that each domain-referenced score is subtracted by the within-subjects mean and divided by the within-subjects standard deviation (see Formula 2.4b). The resulting ipsative standard score expresses the deviation from the within-subjects mean in within-subjects standard deviations.

\section{Ipsine scale}

Like the domain-referenced standard scores the ipsative standard scores are reduced to nine score classes. The assigmment to the nine score classes is listed in Table 5.2. This scale will be referred to as the ipsine scale, derived from the contraction of 'ipsative' with 'nine'. The scale class labels are the same as those used for the donine scale. ${ }^{1}$

\subsubsection{Procedure}

Both the VIT-SI and VIT-MCI are administered by computer within a single test session. In between both instruments additional tests are administered for other research purposes. The total group is non-randomly distributed over two plenary sessions. The order is balanced in that one group first answers the VIT-MCI version, whereas the other group starts with the VIT-SI. The results of the VIT-MCI and VIT-SI will therefore become available before the subjects are randomly allocated to either the donine or ipsine scale condition. Consequently, the VIT-MCI and VIT-SI results are first checked for influences of sex and order of presentation, i.e. the VIT-MCI first or the VIT-SI first. This could provide a rationale to stratify the sample for order and sex before the randomisation. After the subjects are randomised the personal VIT results will then be prepared by using either donine or ipsine scores according to the assigned condition.

After one week informed consent is obtained to use the data for an experiment. Another week later all participants receive a printed copy of their personal VIT report with the results of both the VIT-MCI and VIT-SI. The variable score reports are provided with the same short variable descriptions as presented in the Materials section. Both the SI and MCI results are illustrated by a profile graph (see Appendix A.5.3 for an example sheet). However their results are either reported according to the donine scale or the ipsine scale. The subjects are randomly assigned to one of these conditions. The personal VIT report is presented with the feedback questionnaire form, the VIT-FB (see Appendix A.5.2). The respondent is asked to indicate for each variable score separately as well as for the overall profile which version is preferred.

${ }^{1}$ The stanine originally clusters percentiles of the subject sample. Analogously, the donine scale clusters percentiles of the domain sample. So, the ipsine scale should cluster percentiles of the variable sample. However, with only eleven variables such a clustering would be far to crude. 


\subsubsection{Analyses}

\section{Reliability}

In accordance with the recommendation of the previous chapter the reliability will be approximated using the split-half coefficient. In the VIT-MCI every stimulus is four times evaluated. The VIT-MCI is therefore split in two halves so that each half contains all stimuli two times. ${ }^{2}$ This kind of split is not possible for the VIT-SI, because each stimulus is rated only once. Instead, the stimuli can be ranked on the basis of the assigned item number within each scale. The VIT-SI is then split by assigning the even ranks to one half and the uneven ranks to the other half, for each variable separately. The correlations are adjusted by the Spearman-Brown formula.

\section{Between formats profile comparison}

The item format preference of each subject can be derived in two ways. The simple approach just looks at what the subject indicates as the version that produced the overall better fitting profile (question 12 of the VIT-FB, see Appendix A.5.2). The more elaborate method counts the version preferences indicated to each of the eleven variables. It accepts as selected version the one that is preferred in the majority of variables (questions 1 to 11 of the VIT-FB, see Appendix A.5.2). Respondents who received their scores expressed in the donine scale will prefer the VIT-MCI over the VIT-SI, if they evaluate their results in an ipsative sense. Respondents who received their scores expressed in the ipsine scale will prefer the VIT-MCI over the VIT-SI, if the VIT-MCI generates more precise profile scores than the VIT-SI. In case the preference in either group is arbitrary $50 \%$ of the respondents will prefer the VIT-SI and $50 \%$ the VIT-MCI. The observed distribution is compared with this even distribution using the binomial test.

To transform these proportions into an estimate of effect size the arcsine transformation as was proposed by Cohen (1977) is used:

$$
\varphi=2 \arcsin (\sqrt{\mathrm{P}}),
$$

where $P$ indicates the proportion. The effect size index $h$ is then defined as:

$$
\mathrm{h}=\varphi_{1}-\varphi_{2} \text {. }
$$

As a zero effect is associated with a proportion of 0.50 , the effect size becomes:

$$
h=2 \arcsin (\sqrt{P})-2 \arcsin (\sqrt{0.50})=2 \arcsin (\sqrt{P})-1.571 .
$$

2 One half includes item numbers: $1,3,5,8,10,12,14,16,19,21,23,25,27,30,32,34,36$, $38,40,41,42,43,44,45,46,54,55,56,57,58,59,60,68,69,70,71,72,73,74,79,81,83,84$, $86,88,90,92,94,95,97,99,101,103,105,106,108,110,112,114,116,124,125,126,127,128$, $129,130,138,139,140,141,142,143,144,152,153$, and 154 . 
Conform the suggestions of Cohen (1977) an effect size of 0.20 is regarded a small effect, 0.50 a medium effect, and 0.80 a large effect. SPSS and Excel are used for the statistical analyses. The hypotheses are tested with alpha set to 0.05 .

\subsubsection{Participants}

After the informed consent procedure a total of 469 psychology freshmen agreed to participate in the study. One group of 261 students first answered the VIT-MCI version, the other group of 208 started with the VIT-SI. Four students were excluded from further participation because they skipped too many questions. The remaining 465 students completed both versions satisfactory. Only eight students skipped one item of the SI version. Of the MCI version one student skipped one item and two students skipped two. The omitted SI items were assigned the rounded within-subjects average stimulus score of the particular variable. In the omitted MCI items each of the four stimuli was accredited 0.25 points. These 465 students were then randomly assigned to one of the two conditions, stratified by sex and the order in which both versions were presented.

The 465 students received their personal VIT report after two weeks. Due to absence on this test session only 450 students completed the VIT-FB. A data check revealed that 34 students expressed a preference for a version on a variable that had exactly the same result on both versions. These students were excluded from further analysis. It was hypothesised that they might not have compared both versions very carefully, or may have received and judged the results of somebody else. Of the remaining 416 students 31 indicated no preference when the variable scores between the two versions did in fact differ. It was regarded a less serious violation of the instruction, because a lack of preference when a difference is present is still quite imaginable. Nevertheless, the 14 students who indicated no preference with disparate variable scores more than once were excluded.

The omission of the last item of the VIT-FB was not considered a criterion for exclusion. This item was omitted more frequently than the others, because it was the last item and set apart, due to the added instruction (see Appendix A.5.2). The influence of this unfortunate effect will be addressed in the results. Focussing on the first eleven VIT-FB items one student was excluded because she omitted two items. The four students that omitted just one item were still deemed eligible for inclusion; the omitted item was taken to indicate no preference. The research sample thus consists of 401 subjects (116 men and 285 women). The age ranges from 17 to 58 years (mean: 21.5; SD: 5.5; median: 19).

\subsection{Results}

\subsubsection{Descriptive statistics of the VIT-MCI and VIT-SI}

The Spearman-Brown corrected split-half reliability coefficients of the VIT-MCI variable scores varied between 0.92 and 0.97 and of the VIT-SI variable scores 
Table 5.3: Research sample distribution over the conditions

\begin{tabular}{|c|c|c|c|c|}
\hline \multirow[b]{2}{*}{ Order } & \multirow[b]{2}{*}{ Sex } & \multicolumn{2}{|c|}{ Condition } & \multirow[b]{2}{*}{ Total } \\
\hline & & donine scale & ipsine scale & \\
\hline \multirow[t]{2}{*}{ VIT-MCl first } & Men & 38 & 42 & 80 \\
\hline & Women & 74 & 74 & 148 \\
\hline \multirow[t]{3}{*}{ VIT-SI first } & Men & 17 & 19 & $\overline{36}$ \\
\hline & Women & 73 & 64 & 137 \\
\hline & Total & 202 & 199 & 401 \\
\hline
\end{tabular}

between 0.86 and 0.96 . So both versions came out very reliable. The sample averages of the domain-referenced variable scores indicate that Man and Society, Social Work, and Language and Culture were the top three variables in both versions for both sexes. The only exception was that Nutrition dispels Man and Society from the top three variables in women on the VIT-SI. Appendix A.5.4 includes the tables that provide a complete overview of the split-half reliability coefficients (Table A.5.1) and the means and standard deviations of the domainreferenced scores in both the VIT-MCI and VIT-SI (Table A.5.2).

\subsubsection{Group differences in the within-subjects statistics}

One group received the VIT-MCI first and the other group the VIT-SI. These groups were not established by random allocation. It came out that both groups had a different sex distribution (see the right marginal subtotals in Table 5.3). In the process of ipsative standardization the within-subjects means and withinsubjects standard deviations are used. Before the subjects were randomly allocated an interim analysis revealed that both sex and the administration order of the VIT versions had affected these within-subjects distribution statistics. In the VIT-MCI men on average exhibited a statistically significant higher withinsubjects mean $\left(\mathrm{t}=5.06 ; \mathrm{df}^{3}=183.9 ; \mathrm{p}<0.05\right)$ and lower within-subjects standard deviation $\left(\mathrm{t}=-5.17 ; \mathrm{df}^{3}=163.5 ; \mathrm{p}<0.05\right)$ than women. In the VIT-SI men only had on average a lower within-subjects mean $(t=-6.52 ; \mathrm{df}=399$; $\mathrm{p}<0.05)$ than women. The order effect was evidenced by the finding that the respondents who answered the MCI version first showed a higher within-subjects mean in the VIT-MCI $(\mathrm{t}=4.73 ; \mathrm{df}=399 ; \mathrm{p}<0.05)$, a lower within-subjects standard deviation in the VIT-MCI $\left(\mathrm{t}=-4.49 ; \mathrm{df}^{3}=393.3 ; \mathrm{p}<0.05\right)$, and a lower within-subjects mean in the VIT-SI $(\mathrm{t}=-3.07 ; \mathrm{df}=399 ; \mathrm{p}<0.05)$ than those who completed the SI version first. The exact values of the withinsubjects means and standard deviations are listed in Table A.5.3 that is included in Appendix A.5.4.

\footnotetext{
3 The degrees of freedom deviates from 399 , because Levene's test indicated a significant inequality of the variances.
} 
Due to the sex and order influences it appeared imperative to stratify the sample for both sex and administration order before randomisation. The resulting sample distribution over the conditions is listed in Table 5.3. In order to check whether the stratified randomisation made up for the influence of sex and administration order a MANOVA was performed. The ipsine scale transformation makes use of the within-subjects means and standard deviations of both the VIT-MCI and the VIT-SI. The MANOVA was therefore applied over the VIT-MCI within-subjects means, the VIT-MCI within-subjects standard deviations, the VIT-SI within-subjects means, and the VIT-SI within-subjects standard deviations (INTERCEPT + SEX + ORDER + CONDITION + SEX $\times$ ORDER + SEX $\times$ CONDITION + ORDER $\times$ CONDITION + SEX $\times$ ORDER $\times$ CONDITION). A statistically significant main effect of $\operatorname{sex}(F=12.59 ; \mathrm{df}=4,390 ; \mathrm{p}<0.05)$ and order $(\mathrm{F}=6.75 ; \mathrm{df}=4,390 ; \mathrm{p}<0.05)$ appeared. This is conform the sex and order effects just reported (see for the t-tests also Table A.5.3 in Appendix A.5.4). No main effect of condition emerged $(F=1.11$; df $=4,390 ; p=0.35)$, nor of the interaction between sex and order $(F=0.56 ; \mathrm{df}=4,390 ; \mathrm{p}=0.69)$, sex and condition $(F=0.86 ; \mathrm{df}=4,390 ; \mathrm{p}=0.49)$, order and condition $(F=0.45$; $\mathrm{df}=4,390 ; \mathrm{p}=0.77)$, or sex, order, and condition $(\mathrm{F}=0.12 ; \mathrm{df}=4,390$; $\mathrm{p}=0.98$ ). The lack of a main or interaction effect of condition therefore indicates that the stratification before the randomisation successfully accounted for

Table 5.4: Crosstables of overall profile preference vs. majority of preferences

\begin{tabular}{|c|c|c|c|c|}
\hline \multicolumn{5}{|c|}{ A. Result in the donine scale } \\
\hline \multirow{2}{*}{$\begin{array}{l}\text { Overall profile } \\
\text { preference }\end{array}$} & \multicolumn{3}{|c|}{ Majority of preferences in 11 variables } & \multirow[b]{2}{*}{ Tota } \\
\hline & $\mathrm{N}_{\mathrm{SI}}>\mathrm{N}_{\mathrm{MCl}}$ & $\mathrm{N}_{\mathrm{SI}}<\mathrm{N}_{\mathrm{MC}}$ & $N_{S 1}=N_{M C 1}$ & \\
\hline Version SI & 33 & 6 & 4 & 43 \\
\hline Version $\mathrm{MCl}$ & 13 & 122 & 11 & 146 \\
\hline Equal* & 0 & 0 & 1 & 1 \\
\hline Omitted & 3 & 7 & 2 & 12 \\
\hline Total & 49 & 135 & 18 & 202 \\
\hline
\end{tabular}

B. Result in the ipsine scale

\begin{tabular}{lcccr}
\hline Overall profile & \multicolumn{4}{c}{ Majority of preferences in 11 variables } \\
preference & $N_{\mathrm{SI}}>N_{\mathrm{MCl}}$ & $\mathrm{N}_{\mathrm{SI}}<\mathrm{N}_{\mathrm{MCI}}$ & $\mathrm{N}_{\mathrm{SI}}=\mathrm{N}_{\mathrm{MCl}}$ & Total \\
\hline Version SI & 64 & 2 & 13 & 79 \\
Version $\mathrm{MCl}$ & 7 & 76 & 20 & 103 \\
Equal* & 0 & 1 & 2 & 3 \\
Omitted & 3 & 5 & 6 & 14 \\
\hline Total & 74 & 84 & 41 & 199 \\
\hline
\end{tabular}

Note. ${ }^{*}$ The response option 'equal' was not part of the original VIT-FB item, but added by the respondents. The column $\mathrm{N}_{\mathrm{SI}}>\mathrm{N}_{\mathrm{MCI}}$ tabulates the subjects who prefer the SI score in the majority of variables, $N_{\mathrm{SI}}<\mathrm{N}_{\mathrm{MCI}}$ lists the subjects who prefer the MCI score in the majority of variables, and $\mathrm{N}_{\mathrm{SI}}=\mathrm{N}_{\mathrm{MCI}}$ depicts the subjects who prefer the score of either version in an equal number of variables. 
the sex and order effects. It permits an unrestrained interpretation of the between formats profile comparisons.

Finally, as the within-subjects dispersion affects the within-subjects mean domain-referenced VIT-MCI scores, it may be questioned in what extent it has remained ipsative. Ipsative standardization incorporates the subtraction of the within-subjects mean. So for every subject the within-subjects mean ipsative standard score equals zero. As a result the standard deviation in the withinsubjects mean of ipsative standard scores equals zero. So, before addressing the main hypotheses, it seems wise to demonstrate the ipsative nature of the domainreferenced VIT-MCI scores first.

Table A.5.3 in Appendix A.5.4 shows that the sample standard deviation of the within-subjects means is in the VIT-MCI four times lower than in the VIT-SI. In the VIT-MCI it ranges from 0.023 to 0.027 , whereas in the VIT-SI it is between 0.099 and 0.116 . The sample mean of the within-subjects standard deviations is also higher in the VIT-MCI (between 0.262 and 0.291 ) than in the VIT-SI (between 0.176 and 0.210 ). Although the latter difference appears not that outspoken, expressed in effect sizes the differences are huge (effect sizes varying from 1.56 to 2.03). This suggests that the domain-referenced VIT-MCI is still fairly ipsative in nature. The within-subjects means in the VIT-MCI hardly differ between the subjects. In addition, the ipsative data collection approach boosts the within-subjects standard deviation, because it forces the respondent to choose between stimuli.

\subsubsection{Between formats profile comparison}

Naturally, the profiles were expected to agree on some variables within a subject. As was anticipated the extent of agreement depended on the standardization method. In the group of 202 subjects that received donine scale scores, the profiles corresponded on average in 3.67 variables (SD: 1.97; min: 0; median: 4; max: $9)$. In the group of 199 subjects that were given ipsine scale scores, the profiles corresponded on average in 5.13 variables (SD: 1.74 ; min: 1; median: 5; max: 11). The maximum that all eleven variables were the same occurred in only one subject. Hence, for this subject both profiles were identical.

The two 'Total' columns in Table 5.4 show the overall profile preference subject counts. On the total of 202 subjects who compared the results expressed in the donine scale, $43(21 \%)$ preferred the VIT-SI overall profile and $146(72 \%)$ preferred the VIT-MCI overall profile. One subject annotated to have no preference and 12 subjects omitted the question. Censoring the latter 13 subjects $(6 \%)$ the binomial test evidences that the VIT-MCI preference $(146 / 189=77 \%)$ deviates statistically significantly from an even distribution of the version preferences $(p<0.05)$. The effect size $h=2 \arcsin (\sqrt{0.77})-1.571=2.147-1.571=0.576$, which constitutes a medium effect (see Formula 5.5).

On the total of 199 subjects who compared the results expressed in the ipsine scale, $79(40 \%)$ preferred the VIT-SI overall profile and $103(52 \%)$ pre- 
ferred the VIT-MCI overall profile. Three subjects declared to have no preference, among whom the subject with the identical profiles. And 14 subjects omitted the question. Censoring the latter 17 subjects $(9 \%)$ the binomial test reveals that the VIT-MCI preference $(103 / 182=57 \%)$ also deviates statistically significantly from an even distribution of the version preferences $(\mathrm{p}<0.05)$. The effect size $h=2 \arcsin (\sqrt{0.57})-1.571=1.703-1.571=0.132$, which constitutes less than a small effect.

The previous counts relied on a single indication of preference concerning the overall profile. Instead, the number of preference choices for the eleven separate variables could also be counted. Within each subject the version that is preferred in the majority of the variables is yet another approach to check whether the respondent prefers the VIT-MCI or the VIT-SI. The two 'Total' rows in Table 5.4 show the majority of preferences subject counts. Of the 202 subjects that compared the results expressed in the donine scale, $49(24 \%)$ preferred in most of the variables the VIT-SI score and $135(67 \%)$ the VIT-MCI score. Eighteen subjects $(9 \%)$ preferred either version in an equal number of variables. Censoring the latter 18 subjects the binomial test shows again that the VIT-MCI preference (135/184 $=73 \%$ ) deviates statistically significant from an even distribution over the versions $(p<0.05)$. The effect size $h=2 \arcsin (\sqrt{0.73})-1.571=2.057-1.571=0.486$, which constitutes a medium effect.

Of the 199 subjects that compared the results expressed in the ipsine scale, 74 (37\%) preferred in most of the variables the VIT-SI score and $84(42 \%)$ the VIT-MCI score. Forty-one subjects $(21 \%)$ preferred either version in an equal number of variables. Censoring the latter 41 subjects the binomial test now shows that the VIT-MCI preference $(84 / 158=53 \%)$ does not deviate statistically significant from an even distribution over the versions $(p=0.237)$. The effect size $\mathrm{h}=2 \arcsin (\sqrt{0.53})-1.571=1.634-1.571=0.063$, which constitutes less than a small effect. The cross tabulation in Table 5.4 between the preferred version on the overall profile and the preferred version in the majority of variables indicates that both criteria quite agree. It attests to their validity.

\subsubsection{Between formats reliability comparison}

The reliability coefficients of both versions were impressive and almost equal (see Table A.5.1, Appendix A.5.4). Remember, however, that the asymmetry in the raw scores of the VIT-MCI was corrected by a non-linear transformation (see Formula 5.1). This adjustment might well have caused the measurement precision to differ across the range of variable scores. This influence was already suggested with the presentation of the $\mathrm{MCI}$ domain-referenced score transformation curve (see Figure 5.3). That suggestion is substantiated by inspecting the scatterplots of the split-half correlations of the domain-referenced scores. These plots reveal a heteroscedastic distribution in the domain-referenced scores of all variables in the VIT-MCI. They are in sharp contrast with the same scatterplots of the correlations between the domain-referenced scores of the VIT-SI halves. Appendix 
A.5.5 includes the 22 scatterplots of both versions for all variables. It entails that the precision in the domain-referenced variables scores increases as the scores increase. Consequently, the split-half coefficients of the VIT-MCI in Table A.5.1 must be considered to overestimate the measurement precision in the lower score range. In the upper score range the measurement precision is underestimated.

This divergence in measurement precision across the scale range might cause the subjects to prefer the SI version in the lower score range. Note that the precision of the SI version is more constant. So, in the lower score range (MCI raw variable scores 0 thru 14) the SI version could be more precise than the $\mathrm{MCI}$ version. Conversely, in the higher score range (MCI raw variable scores 15 thru 56) subjects might prefer the MCI version, because in that range the $\mathrm{MCI}$ appears more accurate. That influence is explored by subdividing both condition groups in such a low and high scoring group and testing this shift in preference by Fisher's exact probability test.

The subject counts for the eleven variables in both conditions are depicted in Appendix A.5.6 together with the two-sided probabilities. The boxes demarcate the tested $2 \times 2$ tables. The accentuated boxes indicate a statistical significant interaction effect. The donine group exhibits a significant interaction in five variables: Traditional Design (TD), Farm Work (FW), Office Work (OW), Man and Society (MS), and Medical Work (MW). But only three of them are in the anticipated direction ( $T D, M S$, and $M W$ ). The two opposing variables ( $F W$ and $O W$ ) suffer from a small number of subjects in the high scoring group. The effect might thus be ascribed to chance fluctuations. In the ipsine group, however, only two variables demonstrate an interaction effect: Nutrition and Social Work. Social Work is in the anticipated direction, but suffers from a small number of subjects in the low scoring group. Nutrition, to the contrary, is in the opposite direction and both scoring groups are quite adequately filled. As the direction of the effects is exactly balanced it suggests again to be attributable to chance fluctuations.

These findings, therefore, do not corroborate the hypothesized association between version preference and variable score. In the donine group only three of the eleven variables represent a significant interaction in the anticipated direction, whereas two demonstrate the opposite effect. In the ipsine group just one variable shows an effect in the anticipated direction and one evidences the opposite effect. So, these results do not independently reveal a change in measurement precision across the scale range.

\subsubsection{Recapitulation}

The results indicated that the reliability of both the VIT-MCI and VIT-SI are very good. In the donine group the subjects clearly preferred the VIT-MCI profile over the VIT-SI profile. In the ipsine group the respondents still primarily chose the VIT-MCI profile. If instead the profile as a whole, the majority of the separate variables formed the criterion, the preference for the VIT-MCI ceased to be statistically deviant from the preference for the VIT-SI. The scatterplots of the 
split-half correlations indicated that measurement precision increases as the trait position increases. This relation was not empirically substantiated by a relation between version preference and variable score.

\subsection{Discussion}

Questioning the appropriateness of the adopted score transformation casts doubts on the validity of any of its ensuing conclusions. The VIT-MCI raw score of 14 was associated with a domain-referenced standard score of 0.50 , whereas the minimum was 0 and the maximum was 56 . Only a non-linear transformation can compensate for such a skewed score distribution. Nevertheless, many different score transformations fit the three anchor points $[0 ; 0.00]$, [14;0.50], and [56;1.00]. The choice for the adopted function was not well grounded. It might, for instance, also have been a quadratic function.

But even if the proposed score transformation is not accepted, the current study deserves proper attention. In the first place, it underlines the need for any comparison between the SI format and the $\mathrm{MCI}$ format to focus at the profile score level. In the second place, it establishes a simple but new study design in the evaluation of both formats: a comparative profile evaluation by respondent preferences. And in the third place, the critic is challenged to come up with a better score transformation. The weakness in the study essentially provides a new research question. Which score transformation might adequately compensate asymmetric stimulus preferences in item responses?

If the proposed score transformation is accepted, the current study nicely supplements the previous investigation. The empirical approach grants a new insight into how the scores are interpreted by a respondent, i.e. domain-referenced versus ipsative. The current design also produced an effect size. What is the exact benefit of using the MCI format instead of the SI format if ipsative scores are to be established?

\subsubsection{Descriptive statistics of the VIT-MCI and VIT-SI}

Aside from the heteroscedastic scatterplots of the VIT-MCI, the reliability of both versions is impressive. Both the VIT-MCI and VIT-SI are sufficiently reliable to draw meaningful conclusions from the data. The sample top three variable scores were: Man and Society, Social Work, and Language and Culture. These vocational interests are to be expected from psychology students. So, the found top three does not raise any doubts about the validity of the VIT.

\subsubsection{Group differences in the within-subjects statistics}

Both the VIT-MCI and VIT-SI domain-referenced scores exhibited an influence of sex and administration order. The higher within-subjects standard deviations of the VIT-MCI and VIT-SI in women imply that the female students were more 
heterogeneous in their vocational interests than the male students. The sex difference in the within-subjects means of the VIT-MCI is regarded secondary to the increased within-subjects standard deviations. ${ }^{4}$ The increased within-subjects means of the VIT-SI in the group that first received the VIT-SI indicate that subjects responded more acquiescently to the VIT-SI if it was presented first. The reduced within-subjects standard deviations of the VIT-MCI in the group that first took the VIT-MCI suggest that subjects were less polarized in their responses to the VIT-MCI if it was completed first. As with the sex influence, the order effect on the within-subjects means of the VIT-MCI is regarded secondary to the increased within-subjects standard deviations. ${ }^{4}$ The MANOVA revealed that these sex and order influences were successfully accounted for by stratifying the sample before randomisation. It also excluded an interaction effect between sex and order.

The within-subjects distribution statistics were also evaluated to check whether the domain-referenced VIT-MCI scores can still be regarded ipsative in nature. After all, the non-linear score transformation caused subjects to differ in their within-subjects means. Nevertheless, the differences in the within-subjects means were shown to be negligible. Also the within-subjects standard deviations were found higher in the VIT-MCI than the VIT-SI. This agrees with what would be expected to result from ipsative data collection. So, the domain-referenced VIT-MCI scores are still considered ipsative.

\subsubsection{Between formats profile comparison}

In the donine group the profiles of both versions agreed on average in 3.67 variables. In the ipsine group, however, the profiles of both versions corresponded on average in 5.13 variables. One might question whether the results in the two groups are still comparable. But, the increase in overlap exactly evidences that ipsative standardization in a certain extent covers for any differences in the raw data that is collected by both item formats. The question to be addressed is whether the differences that remain after ipsative standardization still represent valid variance. And if so, does it favour the MCI format? The only effect of the increase in profile agreement is that the power to detect a difference in the ipsine group is reduced as compared to the donine group.

With the overall profile version preference criterion the results from the donine group clearly demonstrated that most subjects prefer the MCI format over the SI format. So, the first null hypothesis, that respondents do not prefer the MCI profile if it is based on domain-referenced scores, is rejected. The

\footnotetext{
4 The non-linear score transformation makes the domain-referenced within-subjects mean of the $\mathrm{MCl}$ version dependent upon the domain-referenced within-subjects standard deviation. An increase in the standard deviation causes a decrease in the mean, because the score transformation weights the scores above the scale midpoint, i.e. 14, less than below the scale midpoint (see also the score example in Section 5.3.2 Scale transformations: Ipsative standard scale). This differential weighting is witnessed by the flattening of the transformation curve (see Figure 5.3).
} 
transformed domain-referenced scores of the MCI version are still fairly ipsative. The preference thus shows that subjects tend to judge their own vocational interest profile in an ipsative sense. They mainly relate the subjective quantity of a vocational interest domain to their other interest domains.

The results from the ipsine group revealed a consolidation in the overall profile version preference for the MCI format. The second null hypothesis, respondents do not prefer the MCI profile if it is based on ipsative scores, is therefore rejected as well. Evidently, the preference for the MCI format is not completely offset by ipsative standardization of the SI format. Hence, the MCI format reveals its expected superiority in profile assessment, even if the scores of both formats are expressed in ipsative standard scores.

Nevertheless, the ipsative standardization did attenuate the benefit of the $\mathrm{MCI}$ format in a large extent. The arcsine transformation of proportions as proposed by Cohen (1977) demonstrated that the effect size in the donine group amounts to 0.576 , which is a medium effect. The ipsative standardization reduced the effect to 0.132 . This is less than a small effect size, which is defined as 0.200 . So it seems that ipsative standardization renders the difference between the SI and MCI version almost negligible. The current study evidences that the benefit of the MCI is mainly attenuated for by the ipsative standardization of the SI version. Although, the attenuation is not complete: there remains a slight benefit of the MCI.

The results of the overall profile version preference depended on one single response. Also, the outcome in the ipsine group was barely significant. In order to validate these findings, the version preference in the majority of the separate variables was used as criterion as well. With the donine scale most subjects still preferred the MCI version over the SI version in the majority of variables. With the ipsine scale the divergence in preference in the majority of variables between the MCI and SI was, however, not statistically significant. So, subjects do interpret their score profiles in an ipsative sense, even if they rate the appropriateness of the separate variable scores. The majority of variables preference criterion, however, did not corroborate the finding that the MCI remains slightly beneficial to profile measurement if the scores are ipsatively standardized anyhow.

This contrasting result actually underscores the anticipated benefit of the MCI. In Chapter 4 it was suggested that the correlation between the errors of the separate variables might result in more accurate overall profiles. This assumed correlation is now regarded responsible for this divergence in $\mathrm{MCI}$ preference between the two criteria. The overall profile preference criterion may profit from the correlation between the errors of the separate variables. Such a rating requires the respondent to take all variables into account together. With the majority of variables criterion, however, the scores of the two versions are compared for each variable in isolation. Then a correlation between the errors of the separate variables cannot affect each individual rating.

Consequently, the current benefit of the MCI format over the SI format in the assessment of the overall profile within a subject, is mainly of theoreti- 
cal importance. It stresses the appropriateness to regard the MCI as producing vector scores. Because within a vector, i.e. the overall profile, the MCI comes out advantageous. Over the separate traits, i.e. the isolated vector coordinates, the improvement disappears. Nevertheless, even for profile assessments, if the data is ipsatized the effect size reduces to 0.132 . This difference may well be compensated for by a little increase in the test length if an SI format is opted. And with the SI format different respondents become comparable again, as the results are expressed in a common measurement unit. So, the present victory of the MCI format over the SI format must be considered of Pyrrhic proportions. For practical purposes the SI format appears to remain the item format of choice.

\subsubsection{Between formats reliability comparison}

The scatterplots of the split-half correlations between the domain-referenced variable scores of the VIT-SI were rather homoscedastic. Due to the non-linear score transformation these same scatterplots were quite heteroscedastic in the VIT-MCI (see Appendix A.5.5). It implied that the precision in the domain-referenced variable scores of the VIT-SI would be fairly constant, whereas it should increase across the score range of the VIT-MCI. This was investigated by comparing the version preferences of the low scorers with the high scorers. Low scorers were expected to favour the VIT-SI more. High scorers were regarded to prefer the VIT-MCI. Unfortunately, the results did not corroborate this anticipated effect.

Is the applied non-linear domain-referenced score transformation of the VIT-MCI then out of place? The lack of the anticipated relation between version preference and trait location actually casts doubts on the appropriateness of this score transformation. After all, the non-linearity of this score transformation is responsible for the heteroscedastic split-half correlations. Without it, the splithalf scatterplots of the VIT-MCI would have been homoscedastic as well. And that seems more in accordance with the finding that the measurement precision in the VIT-MCI did not appear to change along the score range.

First, however, the effect must be fairly small. So, the failure to detect it does not imply that it is non existent. The current study was not designed to answer that question. The adopted approach was ad hoc. Mellenbergh (1996) explained that the estimation of measurement precision at the subject level in classical test theory requires repeated measurements. The issue would therefore be better addressed with a repeated measurement design. A more practical approach is perhaps a simulation study.

Secondly, the suggested domain-referenced score transformation should not be considered a structural solution, but an expedient approach to correct for the skewed distribution of the raw variable score. The adopted scoring of the multiple comparison item is the proper cause for the skewed score distribution with a minimum of 0 a maximum of 56 and a midpoint of 14 . An alteration in the item response instruction can prevent the raw variable score from being skewed. The heart of the problem is that the average stimulus score does not 
equal the midpoint of the rating scale. The VIT-MCI requires the subject to choose one of four stimuli. The chosen stimulus receives 1 point and the other three 0 points. As a result the average stimulus score is $(0+0+0+1) / 4=\frac{1}{4}$. The midpoint of the rating scale is on the other hand $(\max -\min ) / 2=(1-0) / 2=\frac{1}{2}$. These two outcomes do not match. The solution would be to select the two most preferred activities. If both receive a score of 1 , the average stimulus score becomes $(0+0+1+1) / 4=\frac{1}{2}$. Another way out is to have the respondent indicate which activity is preferred most and which one least. This response might be scored by awarding the least preferred activity with a score of 0 , the two activities to which the subject is indifferent with a score of $\frac{1}{2}$, and the most preferred activity with a score of 1 . Then the average stimulus score becomes $\left(0+\frac{1}{2}+\frac{1}{2}+1\right) / 4=\frac{1}{2}$. So, changing the stimulus response instruction constitutes the more fundamental approach to prevent the variable raw scores from being skewed.

\subsubsection{Final overview}

This study established the superiority of the MCI format over the SI format in profile assessment as judged by the respondent self. The experimental approach actually did show that respondents evaluate their own profile in an ipsative sense. It also revealed that the MCI remains advantageous in individual profile assessments, even if the data is ipsatized. Still, ipsative standardization in a large extent attenuates the benefit of the MCI format over the SI format. And, for the assessment of isolated variables, the $\mathrm{MCI}$ does not appear beneficial. Considering the associated shortcomings of the MCI, the SI remains therefore more suitable for practical purposes.

Also, the additive scoring of the current multiple comparison item format resulted in a skewed distribution of the raw scores. This may be prevented by adapting the item response instruction. Instead, the current study employed a score transformation. It was expected to result in an uneven distribution of the measurement precision over the score range. The anticipated association between version preference and variable score, however, was not supported by empirical evidence. 


\title{
A new kind of ipsative measurement: Ipsative data collection without ipsative standardization
}

\author{
"[...] You couldn't deny that, even if you tried with both hands." \\ "I don't deny things with my hands," Alice objected. \\ "Nobody said you did," said the Red Queen. "I said you couldn't if you tried." \\ "She's in that state of mind," said the White Queen, "that she wants \\ to deny something - only she doesn't know what to deny!"
}

(Carroll, 1871/1960, p. 319, italics from the original)

The previous chapter demonstrated just a slight benefit of the multidimensional compound item (MCI) over the singular item (SI) in the assessment of profiles. The experimental approach made it clear that data obtained with the SI was valued about equally to MCI data after the SI data was ipsatively standardized. The current investigation therefore reverses the approach. It is aimed to develop an MCI questionnaire that yields data not automatically standardized in an ipsative sense. The SI format is known for its susceptibility to either yea-saying or acquiescence, or the opposite nay-saying or dissentience. The MCI is robust against this response style. However, as the MCI consists of multiple stimuli, it may be vulnerable to within-item order effects of its encompassing stimuli. The relative influence of these two sources of bias are included in the evaluation of both item formats.

\subsection{Ipsative data collection free from ipsative standardization}

A questionnaire that employs the MCI typically just consists of indicative stimuli. In the rare occasion it contains contra-indicative stimuli as well, they are almost certainly coupled together within the same item. Only in the early history of the compound item have indicative stimuli been paired with contra-indicative stimuli within the same item (Sisson, 1948). The items were tetrads containing two indicative and two contra-indicative stimuli. One of both indicative and 
one of both contra-indicative stimuli were keyed as crediting the variable with a score. The respondent had to indicate the most and least preferred stimulus. The selection of the keyed indicative stimulus as most preferred yielded one point, as did the selection of the keyed contra-indicative stimulus as least preferred. Theoretically, it would be possible to respond to these items in the opposite way. A dissenter could select the keyed indicative stimulus as least preferred, or the keyed contra-indicative stimulus as most preferred for that matter. Unfortunately, no record was found of the actual response frequencies on these early compound item formats.

The current investigation elaborates on the approach of Sisson (1948) by combining an indicative with a contra-indicative stimulus in the same item. Contrary to the historical examples, however, it is limited to two stimuli that represent different variables. So, the envisioned item will just include one indicative stimulus and one contra-indicative stimulus. Such an item will be referred to as an opposed MCI. It will be used along the classic MCI that includes either indicative or contra-indicative stimuli exclusively. This latter item is called the aligned MCI. In addition, a polytomous response scale will be employed, to warrant sufficient response variability. After all, the combination of an indicative with a contra-indicative stimulus strongly favours the indicative stimulus. So, if subjects mainly opt for the indicative stimulus, a ceiling effect is lurking. The exact scoring of the aligned and opposed MCI are outlined in the next two sections.

\subsubsection{Scoring the aligned $\mathrm{MCl}$}

Figure 6.1 schematically visualizes two multidimensional compound items positioned in a coordinate system that represents a joint bivariate preference space containing both stimuli and subjects. The dots at the end of the axes mark the joint trait positions of four stimuli. The top right item is located in quadrant $I$ and requires the respondent to compare the two indicative stimuli $\mathrm{x}_{1+}$ and $\mathrm{y}_{1+}$. The bottom left item is located in quadrant III and requires the respondent to compare the two contra-indicative stimuli $\mathrm{x}_{2-}$ and $\mathrm{y}_{2-}$. Instead of indicating amounts of trait $\mathrm{X}$ or $\mathrm{Y}$, the coordinate values on the axes represent the score that is acquired by marking the corresponding checkbox. The avoidance of negative stimulus scores in combination with the reverse coding of contra-indicative stimuli, causes the inconsequent repetition of the scores 0 to 3 along each axis. Note that the summed coordinates of any checkbox equals 3 . The upper checkbox in quadrant $I$, for instance, has coordinates 0 and 3 that sums to 3 . It attests to the ipsative nature of the data.

The choice of the respondent is thought to depend upon the relative distances between the subject position and the stimuli locations. The subject will choose the response alternative closest to the own position. The four response alternatives of each item thus divide the joint preference space into four regions, indicated by the diagonal dashed lines. The region marked $X \ll Y$ contains the subjects whose position on trait $Y$ far exceeds their position on trait $X$, the region 
Figure 6.1: A schematic view of two aligned $\mathrm{MCls}$

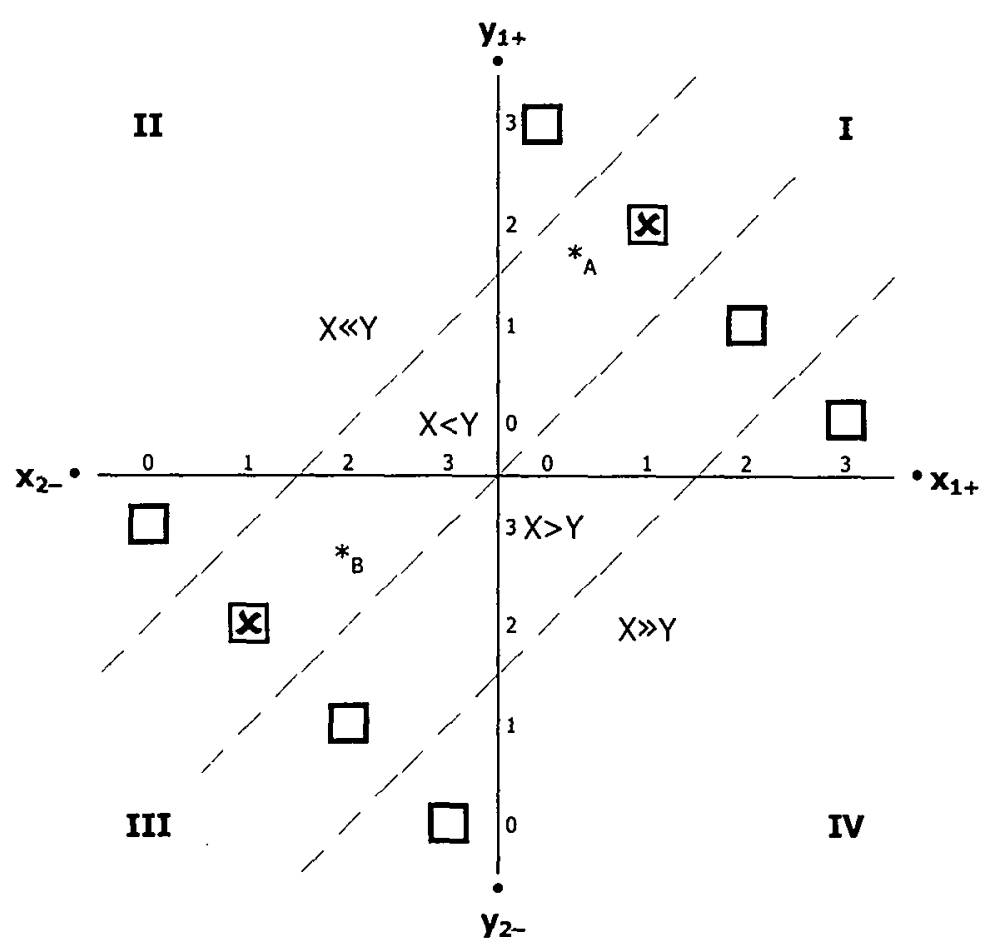

Note. The dots indicate stimulus positions: $-\mathrm{x}_{1+}:$ stimulus 1 indicative of trait $X, \cdot \mathrm{x}_{2-\text { : }}$ stimulus 2 contra-indicative of trait $X, \bullet y_{1+}:$ stimulus 1 indicative of trait $Y, \bullet y_{2-}$ : stimulus 2 contra-indicative of trait $Y$; the asterisks locate subject positions: ${ }^{*} \mathrm{~A}$ : subject $\mathrm{A} ;{ }^{*} \mathrm{~B}$ : subject $\mathrm{B}$; and the checkboxes point to the scale points positions; I: quadrant 1; II: quadrant 2 ; III: quadrant 3 ; IV: quadrant 4.

marked $X<Y$ contains the subjects whose position on trait $Y$ is slightly higher than their position on trait $X$, the region marked $X>Y$ contains the subjects whose position on trait $X$ is slightly higher than their position on trait $Y$, and the region marked $X \gg Y$ contains the subjects whose position on trait $X$ far exceeds their position on trait $Y$. The position of two subjects, $A$ and $B$, is indicated by two asterisks. They occupy the same region. Subject $A$ is located on trait $Y$ slightly above trait $X$. Subject $B$ is located on trait $Y$, if you will, slightly less low than on trait $X$. Logically, they agree in their responses to the two items and each of them is awarded $1+1=2$ points to variable $X$ and $2+2=4$ points to variable $\mathrm{Y}$. But the figure reveals that their absolute trait positions differ. Hence, their absolute trait positions cannot be derived from the raw responses. Only the relative location on trait $\mathrm{X}$ as compared to trait $\mathrm{Y}$ can be estimated. 


\subsubsection{Scoring the opposed $\mathrm{MCl}$}

Figure 6.2 depicts two multidimensional compound items that show how the combination of an indicative with a contra-indicative stimulus is pictured. The top left item is positioned in quadrant II and requires the respondent to compare the contra-indicative stimulus $x_{2-}$ with indicative stimulus $y_{1+}$. The bottom right item is located in quadrant IV and requires the respondent to compare the indicative stimulus $\mathrm{x}_{1+}$ with the contra-indicative stimulus $\mathrm{y}_{2-}$. Again the coordinate values on the axes represent the score that is acquired by marking the corresponding checkbox. But note that the summed coordinates of the checkboxes are not invariant anymore. The upper checkbox in quadrant II has the coordinates 3 and 3 , which sums to 6 . The sum can achieve the values $0,2,4$, and 6 . It witnesses the breakdown of the ipsative nature of the data. Moreover, both stimuli receive the same score as they both ascertain the subject location in the bivariate preference space in the same direction.

Analogous to Figure 6.1 the dashed lines in Figure 6.2 presumably indicate the regions in which the response alternatives divide the preference space. The region marked $X+Y \ll$ contains the subjects who are endowed with a very high level on the combination of traits $X$ and $Y$, the region marked $X+Y>$ contains the subjects who acquire an above average level on the combination of traits $X$ and $Y$, the region marked $X+Y<$ contains the subjects who acquire a below average level on the combination of traits $X$ and $Y$, and the region marked $X+Y \gg$ contains the subjects who are endowed with a very low level on the combination of traits $\mathrm{X}$ and $\mathrm{Y}$. Now, the response can still be regarded ipsative in nature, in that it rests upon a comparison between stimuli that represent different variables. Yet, if the model turns out to be correct, it allows subject A and B to be discriminated, although they more or less agree in their relative trait positions on traits $\mathrm{X}$ and $\mathrm{Y}$. Because now subject $A$ most likely chooses both top right response alternatives, gaining $3+3=6$ points on both variables $X$ and $Y$. Subject $B$, to the opposite, probably marks the two bottom left response alternatives, contributing no points to either variable: $0+0=0$.

\subsubsection{Combining the aligned with the opposed $\mathrm{MCl}$}

If the scores on the two aligned MCIs of Figure 6.1 are combined with the scores on the two opposed MCls of Figure 6.2, subject $\mathrm{A}$ acquires $2+6=8$ points on variable $X$ and $4+6=10$ on variable $Y$. Subject $B$ merely receives $2+0=2$ points on variable $X$ and $4+0=4$ points on variable $Y$. The complementary aspect of both item formats can be visualized by projecting Figure 6.2 over Figure 6.1. The result will be a raster that allows best to locate the position of the respondent. Each ensuing cell will be associated with a unique variable score vector that results from adding the scores of the four items in both figures.

These score vectors are shown in Figure 6.3. The first vector coordinate represents the score of trait $\mathrm{X}$, the second of trait $\mathrm{Y}$. Note, by the way, that 
Figure 6.2: A schematic view of two opposed $\mathrm{MCls}$

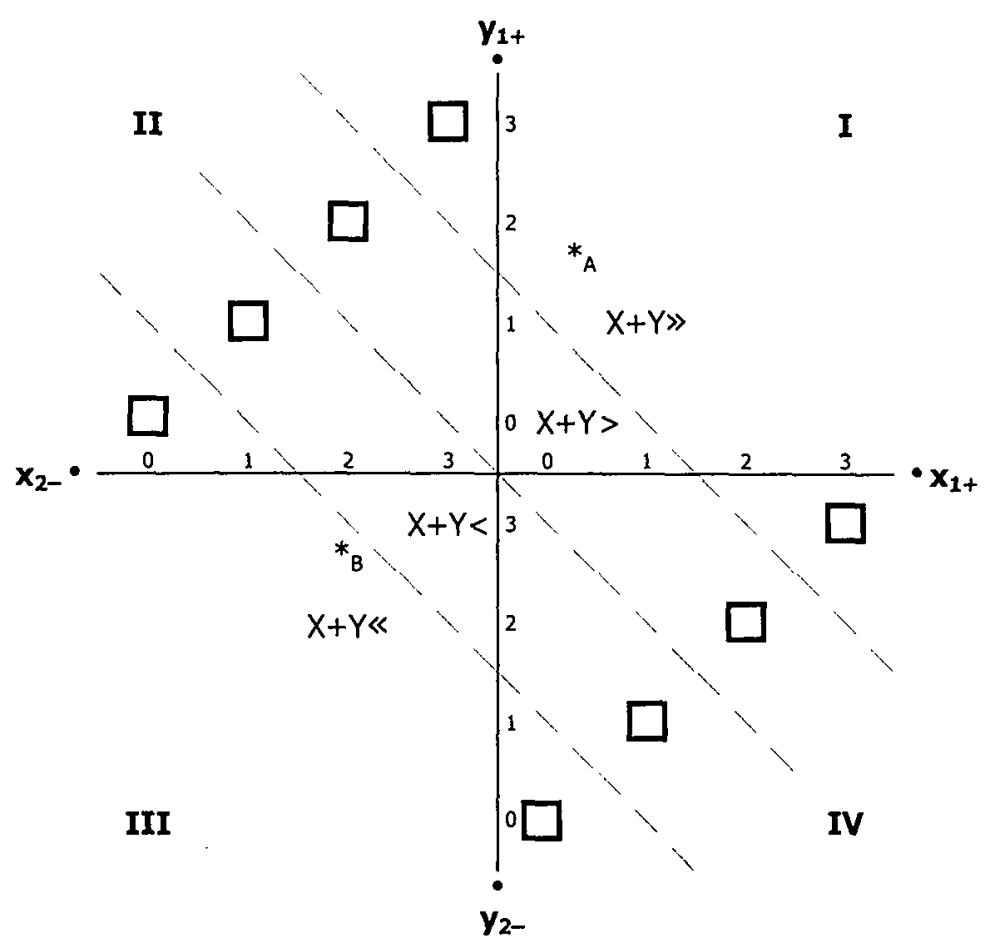

Note. The dots indicate stimulus positions: $-\mathrm{x}_{1+}:$ stimulus 1 indicative of trait $X, \bullet \mathrm{x}_{2-}$ : stimulus 2 contra-indicative of trait $X, \bullet y_{1+}:$ stimulus 1 indicative of trait $Y, \bullet y_{2-}$ : stimulus 2 contra-indicative of trait $Y$; the asterisks locate subject positions: ${ }^{*} \mathrm{~A}$ : subject $\mathrm{A}$; ${ }^{*} \mathrm{~B}$ : subject $B$; and the checkboxes point to the scale points positions; I: quadrant 1 ; II: quadrant 2 ; III: quadrant $3 ;$ IV: quadrant 4.

along any vertical line within the raster the first vector coordinate remains rather constant. It deviates by just two points. Along any horizontal line within the raster the same is true for the second vector coordinate. This is not true for either Figure 6.1 or Figure 6.2 alone. It indicates that the $X$ and $Y$ variable scores have become independent by combining the opposed MCIs with the aligned MCIs.

The scoring model thus illustrates that the approach might result in raw data that are not automatically expressed in ipsative standard scores. Moreover, if these data are expressed in ipsative deviation scores, both subjects A and B are credited with a score of -1 on variable $X$ and 1 on variable $Y$ (see Table 6.1). It matches exactly the ipsative standard scores that each of them would receive on the basis of the aligned MCls alone. The current investigation aims to establish whether the presented model will work in practice as well. 
Table 6.1: The derivation of the deviation ipsative scores of subjects $A$ and $B$

\begin{tabular}{lccccccccc}
\hline & \multicolumn{1}{l}{ Subject A } & \multicolumn{1}{c}{ Subject B } \\
\cline { 2 - 9 } & Raw & $\begin{array}{c}\text { Deviation } \\
\text { score }\end{array}$ & $\begin{array}{c}\text { Squared } \\
\text { seviation } \\
\text { score }\end{array}$ & $\begin{array}{c}\text { Ipsative } \\
\text { standard } \\
\text { score }\end{array}$ & $\begin{array}{c}\text { Raw } \\
\text { score }\end{array}$ & $\begin{array}{c}\text { Deviation } \\
\text { score }\end{array}$ & $\begin{array}{c}\text { Squared } \\
\text { deviation } \\
\text { score }\end{array}$ & $\begin{array}{c}\text { Ipsative } \\
\text { standard } \\
\text { score }\end{array}$ \\
\hline $\mathrm{X}$ & 8 & -1 & 1 & -1 & 2 & -1 & 1 & -1 \\
Y & 10 & 1 & 1 & 1 & 4 & 1 & 1 & 1 \\
\hline Sum & 18 & 0 & 2 & & 6 & 0 & 2 &. \\
Average & 9 & 0 & 1 & & 3 & 0 & 1 & \\
\hline
\end{tabular}

Note. The deviation score is obtained by subtracting the average raw score from the raw score. The average of the squared deviation scores equals the within-subjects standard deviation. So, the ipsative standard score is then acquired by dividing the deviation score by the average squared deviation score.

\subsection{The control of response biases}

Ipsative data collection methods have been forwarded as a means to eliminate the influence of response styles (Nederhof, 1985). A response style is the differential use of a rating scale between judges, and with self-report questionnaires the respondents are themselves the judges. But, if these data collection methods automatically result in ipsative standardized data, this approach gives the impression to overshoot itself. It was explained in Chapter 3 that ipsative standard scores cannot be compared directly between subjects. Ipsative standardization basically develops a subject-specific unit of measurement. Direct comparisons require the assumption that the derived measurement unit in the compared subjects is the same. This will only be the case if the within-subjects grand total of the traits that are covered by the reference variables is equal across the compared subjects. Or, in other words, if the between-subjects differences in the withinsubjects means that are removed by ipsative standardization are completely due to response styles. This assumption is generally too far-fetched (see also Section $3.3)$.

However, the inclusion of both aligned and opposed MCIs might offer an ipsative data collection method that does render raw unstandardized data. With the opposed MCIs the sum constraint is lost. Then, the assigned raw scores can be interpreted to represent the same quantity across subjects. Remind that with ipsative standardization such an interpretation is forfeited as the scores are expressed relative to the within-subjects mean. This new procedure makes it therefore unnecessary to assume that the reference traits are equally distributed in the compared subjects. As a corollary, the issue whether ipsative data collection could support the battle against response styles becomes germane again. 
Figure 6.3: A schematic view of two aligned and two opposed $\mathrm{MCls}$

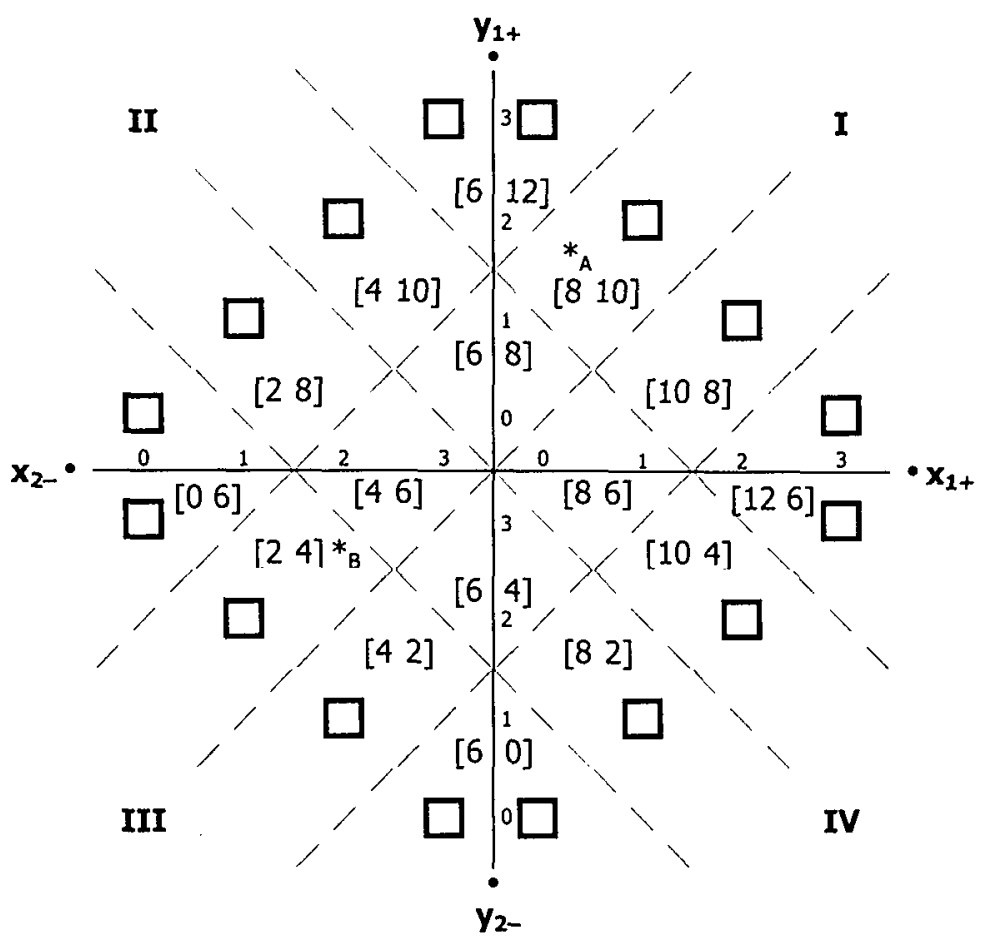

Note. The dots indicate stimulus positions: $-\mathrm{x}_{1+}:$ stimulus 1 indicative of trait $X, \bullet \mathrm{x}_{2-}$ : stimulus 2 contra-indicative of trait $X, \bullet y_{1+}:$ stimulus 1 indicative of trait $Y, \bullet y_{2 \rightarrow}$ : stimulus 2 contra-indicative of trait $Y$; the asterisks locate subject positions: ${ }^{*} A$ : subject $A ;{ }^{*} B$ : subject $B$; the score vectors indicate the expected profile score on the variables $X$ and $Y$ resulting from the combination of the four items; and the checkboxes point to the scale points positions; I: quadrant 1; II: quadrant 2; III: quadrant 3; IV: quadrant 4.

\subsubsection{Response styles}

In Chapter 3 two types of response styles were distinguished: the translating response styles and the homothetic response styles. The translating response styles point at individual differences in the used midpoint of the rating scale. They may reveal themselves in yea-saying or acquiescence, or in nay-saying or dissentience. The homothetic response styles refer to individual differences in the applied measurement unit of the rating scale. It includes a preference for the more extreme scale points, the extremity response style, or an inclination towards the middle scale points, the midpoint response style.

In the ipsative data collection method acquiescence and dissentience cannot 
play a role. In the exemplified aligned $\mathrm{MCI}$ the checkboxes represent the score vectors [ $\left[\begin{array}{ll}0\end{array}\right]$, [1 2 ], [ $\left[\begin{array}{ll}2 & 1\end{array}\right]$, and [ 30$]$. In the suggested opposed MCI the checkboxes represent the score vectors [0 0], [ $\left.\begin{array}{ll}1 & 1\end{array}\right],\left[\begin{array}{ll}2 & 2\end{array}\right]$, and [3 3$]$. A translating response style results in an increased or reduced endorsement, i.e. acquiescence or dissentience, respectively. This increased or reduced endorsement is defined as irrespective of the stimulus content. So, with an MCI the heightened or reduced endorsement applies to all included stimuli whether indicative or contra-indicative. In the opposed MCI acquiescence will equally induce endorsement of the indicative stimulus, i.e. towards the [3 3 ] response score vector, as it induces endorsement of the contra-indicative stimulus, i.e. towards the $\left[\begin{array}{ll}0 & 0\end{array}\right]$ response score vector. As a net result this effect is cancelled out in the final response score.

The example MCIs make use of a polytomous response scale. Consequently, the ipsative data collection method becomes equally susceptible to the extremity and midpoint response style. The extremity response style can be expected to enhance the selection of the checkboxes associated with the response score vectors $\left[\begin{array}{ll}0 & 3\end{array}\right]$ and $\left[\begin{array}{ll}3 & 0\end{array}\right]$ in the aligned MCI and [ $\left[\begin{array}{ll}0 & 0\end{array}\right]$ and $\left[\begin{array}{ll}3 & 3\end{array}\right]$ in the opposed MCI. The midpoint response style on the other hand will increase the preference for the checkboxes [1 2 ] and [2 1 1] in the aligned MCI and [1 1 ] and [2 2$]$ in the opposed MCI. So, like with the SI, the overall trait profile will become more pronounced with an extremity response style, and less pronounced with a midpoint response style. And the total score aggregated over all variables is also expected to remain more or less constant within the respondent.

\subsubsection{Stimulus order effects}

Still, the MCI might be liable to another kind of response bias. Judges or respondents are perhaps differentially susceptible to the stimulus presentation order. Some could have an extra preference for the first stimulus, whereas others might tend to prefer the last stimulus more. A tendency towards the first presented stimulus is referred to as a primacy response bias. A relative preference for the last presented stimulus is called a recency response bias.

\subsection{Hypotheses}

The suggested ipsative data collection method is thought to result in raw unstandardized data, if the scores to aligned MCIs and opposed MCIs are combined. To test this hypothesis it is in the first place important to check whether the raw MCI total score, if it is aggregated over all variables, reveals any betweensubjects score variance. This between-subjects score variance must come from individual differences in the total score of the opposed MCIs. As was outlined with the scoring of the aligned $\mathrm{MCI}$, its summed stimulus score is constant, i.e. 3 . Hence, the subjects will not differ in the total score of the aligned MCIs. The raw MCI between-subjects score variance will thus completely depend on the between-subjects variance in the total score of the opposed MCIs. The first hy- 
pothesis is consequently that the sample variance in this latter subtotal deviates substantially from zero. The null hypothesis maintains that the variance in the aggregated total score of the opposed MCIs equals zero. Simple evaluation of this subtotal as well as the separate variable scores should lead to a rejection of this null hypothesis.

The establishment that this method of ipsative data collection results in raw unstandardized data is of course just an intermediary step. It grants the permission to use parametric statistics to the total scores summed over both the aligned and opposed MCIs. Still, the proposed data collection approach needs to be validated. The second hypothesis, therefore, holds that this new ipsative procedure yields data that largely agrees with the data obtained with a data collection method using the SI. The null hypothesis declares no difference between the scores obtained by either the ipsative or interactive data collection method. The study aspires to corroborate this second null hypothesis.

Finally, it was outlined that the innovative way of ipsative data collection cannot suffer from acquiescence or dissentience. To the contrary it might be susceptible to an order effect which can be regarded a primacy or recency response bias. The hypothesis is that in SI data acquiescence or dissentience might be partly explained by an order effect in the rating scale points. Acquiescence is then positively associated with a primacy effect, if the 'agree' rating scale point is presented first, or negatively if it comes last. Dissentience is thought to be positively associated with a primacy effect, if the rating scale starts with the 'disagree' rating scale point, or negatively if it ends with 'disagree'. It is therefore expected that a small correlation will occur between the primacy or recency response bias in MCI data and the acquiescence or dissentience response style in SI data. The null hypothesis is that this correlation equals zero. It is the intention to reject this null hypothesis.

\subsection{Methods}

\subsubsection{Instruments}

The Bermond Vorst Alexithymia Questionnaire (BVAQ) was selected because it is a balanced questionnaire that contains an equal number of indicative and contraindicative stimuli. In addition, the questionnaire has favourable psychometric properties (Bermond, Vorst, \& Vingerhoets, 1999; Vorst \& Bermond, 2001). The questionnaire aims to measure alexithymia: the inability to describe emotions. The questionnaire is based on a theory that distinguishes a cognitive and an affective component of alexithymia. The cognitive component is represented by three variables: Verbalizing, Identifying; and Analyzing emotions. The affective component is covered by two variables: Emotionalizing and Fantasizing about emotions. Two parallel versions exist. If both versions are combined each variable is represented by four indicative and four contra-indicative 5-point Likert-scale items. The scale point labels range from 5 , 'This definitely applies' to 1, 'This in 
Figure 6.4: Example items of the BVAQ-SI

\section{A: Indicative item of Emotionalizing}

14. When friends around me argue violently, I become emotional.

This definitely applies

This in no way applies

\section{B: Contra-indicative item of Emotionalizing}

9. When I see somebody crying uncontrollably, I remain unmoved.

This definitely applies

This in no way applies

Note. The original Dutch items were translated in English by Vorst and Bermond (2001).

no way applies'. In the SI version therefore, the variable score ranges from 8 to 40. An indicative and contra-indicative example item of the BVAQ-SI are shown in Figure 6.4.

To develop an MCI version each stimulus is used in two combinations. It is once paired with an indicative stimulus of one of the other scales and once combined with a contra-indicative stimulus. As a result the MCI version consists of 40 stimulus pairs. Each variable is represented in eight aligned MCIs as well as eight opposed MCIs. Comparable to the instruction of part I of the Study of Values (see Figure 4.3) the respondent is instructed to distribute three points over the two options. Three points must be assigned to the preferred option if the other option is disliked. If the subject likes or dislikes both options the most liked or least disliked option should be assigned two points and the other one. Consequently, in the MCI version the variable score ranges from 0 to 48 . Figure 6.5 lists some example items of the BVAQ-MCI.

The stimuli are matched to be as closely together in their attractiveness, as revealed by the endorsement averages in a previous sample. The data for this matching has been kindly provided by test author H.C.M. Vorst. The difference between the endorsement averages were expressed in effect sizes as defined by Cohen (1977). That is, the absolute difference is divided by the square root of the

Table 6.2: The differences between the paired stimuli in the BVAQ-MCI

\begin{tabular}{lccccc}
\hline stimulus pair & mean & SD & min & median & max \\
\hline indicative \& indicative & 0.06 & 0.08 & 0.01 & 0.03 & 0.28 \\
contra-indicative \& contra-indicative & 0.19 & 0.12 & 0.03 & 0.17 & 0.44 \\
indicative \& contra-indicative & 1.37 & 0.08 & 1.25 & 1.37 & 1.50 \\
contra-indicative \& indicative & 1.27 & 0.21 & 0.77 & 1.27 & 1.57 \\
\hline
\end{tabular}

Note. The unit in which the values are expressed is the square root of the pooled variances of the two stimuli in question. 
Figure 6.5: Example items of the BVAQ-MCI

A: Aligned $\mathrm{MCl}$ containing two indicative stimuli (Fantasizing vs. Emotionalizing)

5. Which description is the more applicable?

a. Before I fall asleep, I imagine all kinds of events, encounters and conversations.

b. When friends around me argue violently, I become emotional.

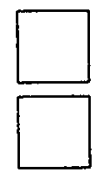

B: Aligned $\mathrm{MCl}$ containing two contra-indicative stimuli (Emotionalizing vs. Analyzing)

18. Which description is the more applicable?

a. When I see somebody crying uncontrollably, I remain unmoved.

b. When I feel uncomfortable, I will not trouble myself even more by asking myself why.

C: Opposed $\mathrm{MCl}$ containing one contra-indicative and one indicative stimulus (Emotionalizing vs. Verbalizing)

33. Which description is the more applicable?

a. When I see somebody crying uncontrollably, I remain unmoved.

b. I like to tell others about how I feel.

Note. The original Dutch items were translated in English by Vorst and Bermond (2001).

pooled variances of the two matched stimuli. Table 6.2 lists the mean, standard deviation, minimum, median and maximum of the absolute differences in these thus standardized endorsement averages between the two stimuli. It is obvious that the matching is the closest in dual indicative and dual contra-indicative stimulus pairs. The combination of an indicative with a contra-indicative stimulus differs about 1.3 standard deviation. The presentation order of the items adopts a suggestion made by Wherry (1938). He proposed to present paired comparison in the following order of combinations: $1-2,3-4,5-1,2-3,4-5,3-1,4-2,5-3,1-4$, and $2-5 .{ }^{1}$ This order is repeated four times. The sequence of indicative and contra-indicative stimuli does not follow a fixed pattern, but the distribution is well spread.

\subsubsection{Participants}

Of the 518 psychology freshmen that participated in the study 508 students completed both the standard SI version and the newly developed MCI version of the

1 The numbers refer to the scales as follows: 1. Verbalizing, 2. Identifying, 3. Analyzing, 4. Fantasizing, and 5. Emotionalizing. 
BVAQ. Both versions were administered by computer within a two week period. One student was excluded because she omitted more than one iten. A total of 42 students was further excluded because they failed to adhere to the instruction to distribute three points over each two item options. As a result only 465 students were eligible for inclusion (132 males: 333 females). The order of administration was balanced in that 218 students first received the SI version and 247 first the $\mathrm{MCI}$ version. The median age was 20 years $($ mean $=21.5 ; \mathrm{SD}=5.3 ; \min =17$; $\max =58$ ).

\subsubsection{Analysis}

\section{Ipsativity of the raw response scores}

The first hypothesis regards whether the combination of indicative and contraindicative stimuli in the so-called opposed MCIs results in between-subjects variance. As explained, an opposed item evenly distributes 0 to 6 points over the two represented stimuli. So, with 20 opposed MCIs this subtotal, aggregated over all variables, may range from 0 to 120 in principle. If all subjects, however, strongly prefer the indicative stimulus invariably, no between-subjects variance will emerge. This hypothesis cannot be tested directly. Naturally it implies that the sample variance in the opposed MCI subtotal should deviate from zero. It is known that $(n-1) S^{2} / \sigma^{2}$ is $\chi^{2}$ distributed with $n-1$ degrees of freedom, where $n$ indicates the number of subjects, $S^{2}$ the sample variance, and $\sigma^{2}$ the population variance (see Theorem 1 of Hoel, 1984, p. 281). However, since the null hypothesis assumes $\sigma^{2}$ to equal zero, this approach is invalid. Instead the cumulative score distribution of the opposed $\mathrm{MCI}$ is compared with the cumulative normal distribution using the Kolmogorov-Smirnov test. If the score distribution of the opposed MCI agrees with the normal distribution, its variance cannot equal zero. In addition, the score distribution of the separate variables as obtained with the MCI version is compared with the score distributions of the SI version.

\section{Multitrait-multimethod analysis}

The second hypothesis tackles the issue whether the new method of ipsative data collection results in valid data. If the variable scores of the SI version are correlated with the variable scores of the MCI version, the resulting correlation matrix can be regarded a multitrait-multimethod (MTMM) matrix. After all, the BVAQ aims to assess five alexithymia traits: Verbalizing, Identifying, Analyzing, Fantasizing, and Emotionalizing. And the BVAQ-SI and the BVAQ-MCI versions constitute two different methods.

For the MTMM analysis, however, it is important to keep two aspects in mind. In the first place, the BVAQ-MCI needs to combine the scores of the opposed and aligned MCIs. The variable scores of the aligned MCIs alone will be expressed in ipsative standard scores. And in that case factor analysis would not be meaningful (see also Section 4.1.2). In the second place, restricted factor 
analysis requires each trait to be identified by more than two variables. Otherwise the factor model is not identified. Therefore, instead of the complete variable scores, the split-half correlation table is used. Then each trait is indicated by 2 (halves) $\times 2$ (methods or versions) $=4$ variable scores.

But this split-half correlation matrix is first qualitatively evaluated according to six common-sense desiderata with regard to the pattern of correlations within such a matrix (Campbell \& Fiske, 1959; Marsh \& Grayson, 1994). These six interpretative guidelines are: (1) the convergent validity coefficients, i.e. the monotrait-heteromethod correlations should be substantial; (2) the convergent validity coefficients should exceed the associated heterotrait-heteromethod (HTHM) correlations; (3) the convergent validity coefficients should exceed the associated heterotrait-monomethod (HTMM) correlations; (4) the pattern of the HTMM and HTHM correlations should be similar; (5) the HTMM and HTHM correlations should be substantially lower than the reliability coefficients, i.e. the monotraitmonomethod correlations; and (6) the difference between the parallel HTMM and HTHM correlations should be small. Guideline 1 evidences convergent validity, guidelines 2,3 , and 5 demonstrate the discriminant validity, guideline 4 testifies to the independence of trait effects and method effects, and guideline 6 gives an indication of the quantity of the method effects.

The MTMM matrix is then quantitatively evaluated using restricted factor analysis in line with the hierarchically nested covariance structure models that were proposed by Widaman (1985). The restricted factor analysis is in the first place aimed to demonstrate the validity of the $\mathrm{MCI}$ measurement approach. If the MCI version shares a substantial part of the trait variance with the SI version, it demonstrates to be valid. In addition, this analysis allows to partition the observed variance of the separate variables of both versions into trait variance, method variance and unique variance. So, in case the MCI version shows to be valid, it becomes possible to determine in what extent the MCI version shares method variance with the SI version as well.

Four different factor models are fitted. The most inclusive model is the correlated traits-correlated methods (CTCM) model (Widaman's model 3C). It consists of seven factors, the five trait factors: Verbalizing, Identifying, Analyzing, Fantasizing, and Emotionalizing, and the two method factors: the SI and the MCI version. The trait factors are allowed to correlate with each other, and so are the method factors. The square of the latter correlation coefficient reveals the proportion method variance that both item formats share. But all correlations between a trait factor and a method factor are fixed to zero. The second model is the correlated traits-uncorrelated methods (CTUM) model (Widaman's model $3 \mathrm{~B}^{\prime}$ ). Now the method factors are not allowed to correlate with each other anymore. Hence, it is more parsimonious than the CTCM model, for the correlation between the method factors is fixed to zero. This model takes both item formats to be totally different methods. The third model is the correlated traitsjoint methods (CTJM) model (Widaman's model $3 \mathrm{~B}$ ). It is as parsimonious as the CTUM model, but in this model the correlation between the method factors 
is fixed to one. It implies that the two item formats are essentially the same. The final model is the correlated traits-no methods (CTNM) model (Widaman's model 3A). As the name already suggests, this model is the most parsimonious. It does not incorporate a method factor at all.

The four models are hierarchically nested according the following lattice structure:

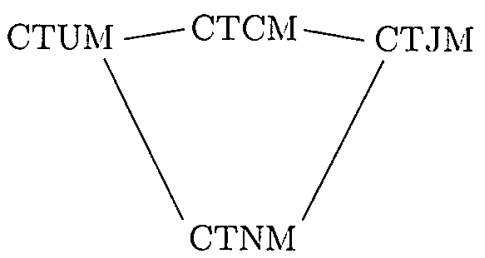

A reduction in the number of model parameters will always result in a reduction of model fit. But the lattice structure allows to compare the models with each other. The difference in model fit is itself $\chi^{2}$ distributed with the difference in model parameters as the degrees of freedom. If the CTCM yields an acceptable fit, it shows the validity of the MCI measurement approach. It also indicates in what extent the MCI and SI methods correlate. Although the CTUM and CTJM models cannot be compared directly, their respective comparison with the CTCM and CTNM models grant a closer examination of the matter. Each relative reduction in fit gives a clue whether the two methods of data collection are more or less the same (favouring the CTJM) or should be considered fundamentally different (promoting the CTUM). The comparison of the CTNM model with the CTCM model gives an indication whether the data collection method is of any consequence at all.

In the lattice structure the CTNM is set apart from the other three models. That is, because the first three models are more similar. The CTUM and CTJM model differ from the CTCM model in only one parameter: they both fix the correlation between the two methods. As a result they gain one degree of freedom. The CTNM model, however, dispenses with the two method factors altogether. With five variables split in two halves the model reduces the number of model parameters by an additional: 5 (variables) $\times 2$ (halves) $\times 2$ (methods) $=20$ parameters. So the vertical distance from the CTCM model actually illustrates the gain in degrees of freedom.

\section{Comparative susceptibility to response styles}

The influence of the acquiescence/dissentience response style (ADRS) on the SI version is contrasted with the effect of the primacy/recency response bias (PRRB) on the MCI version. Both response styles are quantified using a specific index that yields an individual score for each scale within each version. To quantify the effect of the ADRS the Chapman-Bock acquiescence/dissentience response style index is adopted (Chapman \& Bock, 1958). For the measurement of the PRRB 
the same formula is used; it is only completed differently. Because a response style is defined as content independent the correlation between the ADRS indices of the different scales indicate the extent in which distortion by acquiescence or dissentience has occurred. The same approach applies to estimate the influence of the primacy/recency response bias. The correlation between the ADRS and PRRB indices across the two versions then reveal their interrelatedness.

The Chapman-Bock ADRS index The Chapman-Bock acquiescence/dissentience response style index is applicable to all types of response scales: dichotomous, polytomous, and continuous (Chapman \& Bock, 1958). The ADRS index does however require a questionnaire that consists of balanced scales, each containing an equal number of indicative as well as contra-indicative items. It assumes the average 'difficulty' or 'attractiveness' of both indicative and contraindicative items to be equivalent. Based on this assumption any discrepancy must be ascribed to acquiescence or dissentience. Because either effect operates in both directions the difference must be divided in half:

$$
\mathrm{ADRS}_{i}=\frac{1}{2}\left(\frac{\sum_{j=1}^{k} x_{i j}}{k}-\frac{\sum_{h=1}^{k} x_{i h}}{k}\right),
$$

where $x_{i j}$ reflects the score of subject $i$ on an indicative item $j, x_{i h}$ the score of subject $i$ on a contra-indicative item $h$, and $k$ is the number of indicative or contra-indicative items. This ADRS index is expressed in units of the used item scores. So, its minimum is minus half the difference between the minimum and maximum item score. And its maximum is plus half the difference between the minimum and the maximum item score. The 5-point Likert scale of the BVAQ-SI has its item scores ranging from 1 to 5 . This index therefore extends from -2 to 2 . A positive value indicates acquiescence, a negative value dissentience. The index is computed for each separate variable.

The adaptation of the ADRS index into a PRRB index The effect of a primacy/recency response bias is expressed using the same formula as for the ADRS index. But now $x_{i j}$ reflects the score of subject $i$ on a first presented stimulus, $x_{i h}$ the score of subject $i$ on a last presented stimulus, and $k$ is the number of primary or secondary stimuli. Like the ADRS index this PRRB index is expressed in units of the used stimulus scores. So, again its minimum is minus half the difference between the minimum and the maximum item score. And its maximum is plua half the difference between the minimum and the maximum item score. As the response scale of the BVAQ-MCI allows the stimulus scores to range from 0 to 3 , this index extends from $-1 \frac{1}{2}$ to $1 \frac{1}{2}$. A positive value indicates a primacy effect, a negative value a recency effect. For each scale the index is computed.

For the statistical analyses SPSS, LISREL, and Excel are used. The hypotheses are tested with alpha set to 0.05 . To correct for familywise error rates, the Bonferroni-Hochberg correction is used, if applicable (Hochberg, 1988). 


\subsection{Results}

\subsubsection{Ipsativity of the raw response scores}

The mean subtotal of the opposed MCIs aggregated over all variables is 82.9 with a standard deviation of 14.0 , the median score is 82 . Figure 6.6 shows the frequency histogram. On the possible score range of 0 to 120 the average is clearly shifted towards the upper limit. Nevertheless, the score distribution is fairly normal. The maximum absolute deviation from the cumulative normal distribution is 0.044 . And although the Kolmogorov-Smirnov test is statistically significant $(p=0.034)$, the difference is negligible in practice. The minimum score is 38 , the maximum 120 (occurring only once), the skewness is -0.071 (SE 0.113), and the kurtosis -0.154 (SE 0.226).

Table 6.3 lists the sample statistics of the separate variable total scores of both the SI version and the MCI version, that is after summing the scores of the aligned and opposed MCIs for each variable separately. The column headed ' $D$ ' lists the maximum absolute deviation from the normal cumulative frequency distribution. The Kolmogorov-Smirnov test of this statistic yields two-tailed probabilities that are lower than 0.05 in all but two variables. After BonferroniHochberg correction the SI version is found to deviate in a statistically significant way from the normal distribution in four variables and the MCI version in two variables (Hochberg, 1988). These are indicated by the p-values in boldface. Hence, the MCI version is at least comparable to the SI version in its amount of variation in the variable scores as well as in its deviation from normality.

Table 6.3: Sample statistics of the variables

\begin{tabular}{llccccccccc}
\hline & & mean & SD & skewness & kurtosis & min & median & max & D & p \\
\hline SI & Verbalizing & 27.6 & 6.84 & -0.519 & -0.405 & 8 & 29 & 40 & 0.091 & $\mathbf{0 . 0 0 1}$ \\
& Identifying & 31.3 & 5.15 & -0.411 & -0.112 & 16 & 32 & 40 & 0.087 & 0.002 \\
& Analyzing & 31.7 & 4.97 & -0.616 & 0.489 & 13 & 32 & 40 & 0.113 & $\mathbf{0 . 0 0 0}$ \\
& Fantasizing & 29.4 & 6.20 & -0.455 & -0.206 & 11 & 30 & 40 & 0.079 & $\mathbf{0 . 0 0 6}$ \\
& Emotionalizing & 27.5 & 4.89 & -0.327 & 0.226 & 10 & 28 & 40 & 0.067 & 0.031 \\
\hline MCI & Verbalizing & 29.3 & 6.58 & -0.506 & 0.254 & 6 & 30 & 46 & 0.088 & 0.001 \\
& Identifying & 28.8 & 4.21 & 0.039 & -0.054 & 16 & 29 & 41 & 0.065 & 0.039 \\
& Analyzing & 28.9 & 4.92 & -0.283 & 0.021 & 14 & 29 & 40 & 0.061 & 0.066 \\
& Fantasizing & 27.7 & 5.75 & -0.110 & -0.153 & 10 & 28 & 41 & 0.049 & 0.206 \\
& Emotionalizing & 28.2 & 5.17 & -0.582 & 0.685 & 7 & 29 & 41 & 0.081 & $\mathbf{0 . 0 0 5}$ \\
\hline
\end{tabular}

Note. $n=465 ; \mathrm{SD}=$ standard deviation $; \mathrm{D}=$ maximum absolute deviation from the normal cumulative frequency distribution; $p=$ two-tailed probability, the values in boldface indicate the statistical significant deviations after Bonferroni-Hochberg correction for the familywise error rate; skewness standard error $=0.113$; kurtosis standard error $=0.226$. 
Figure 6.6: Frequency histogram of the score subtotal of the opposed $\mathrm{MCls}$

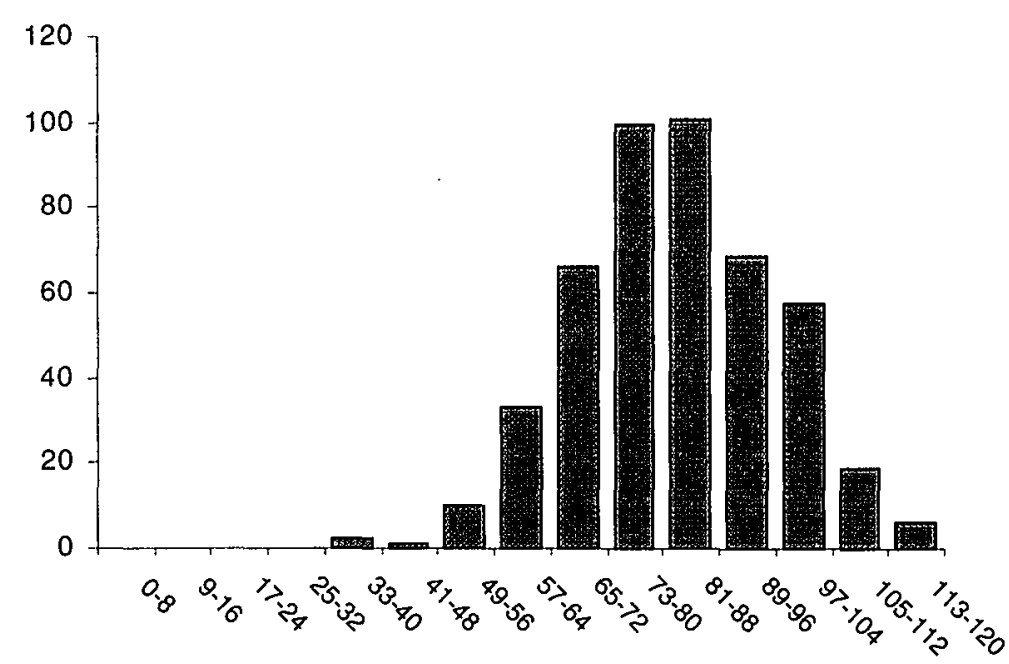

Note. $n=465$

\subsubsection{Multitrait-multimethod analysis}

Table 6.4 presents the split-half reliability coefficients of both BVAQ versions. The split-half reliability of the original SI version is actually computed over the two original parallel versions. The MCI version is split to ensure that every scale combination occurs equally often in both halves. Also each half contains an equal number of aligned and opposed MCIs. The split cannot be the same as with the SI version, because the MCI version contains every stimulus twice and the stimuli in the matched pairs do not necessarily originate from one half. The SI version is more reliable. The reliability of the MCI version is still satisfactory with only Identifying dropping below 0.70 .

Table 6.4: Split-half reliability coefficients

\begin{tabular}{lccccc}
\hline & Verbalizing & Identifying & Analyzing & Fantasizing & Emotionalizing \\
\hline BVAQ-SI & 0.90 & 0.84 & 0.84 & 0.88 & 0.81 \\
BVAQ-MCI & 0.89 & 0.68 & 0.74 & 0.76 & 0.76 \\
\hline
\end{tabular}

Note. $n=465$; the split-half reliability coefficients are corrected by the Spearman-Brown formula.

As was explained in the methods section the restricted factor analysis model of the MTMM matrix of the total variable scores is not identified. Therefore, the split-half correlation table is evaluated as a MTMM matrix (see Appendix A.6.1). First the matrix is explored applying the presented Campbell- 
Table 6.5: Fit indices of the MTMM structure models

\begin{tabular}{lccccccc}
\hline model & $\chi^{2}$ & df & $\mathbf{p}$ & $\chi^{2} / \mathbf{d f}$ & RMSEA & GFI & AGFI \\
\hline CTCM & 311.92 & 139 & 0.000 & 2.24 & 0.052 & 0.94 & 0.90 \\
CTUM & 322.05 & 140 & 0.000 & 2.30 & 0.053 & 0.94 & 0.90 \\
CTJM & 453.02 & 140 & 0.000 & 3.24 & 0.069 & 0.91 & 0.87 \\
CTNM & 674.42 & 160 & 0.000 & 4.22 & 0.083 & 0.87 & 0.87 \\
\hline
\end{tabular}

Note. $n=465$.

Fiske/Marsh-Grayson guidelines. The convergent validity coefficients range from 0.395 to 0.719 (mean: 0.569 ; SD: 0.095 ). ${ }^{2}$ That is quite acceptable. It is even remarkably good, if one realizes that now the uncorrected split-half reliability coefficients apply, since the test halves are used. ${ }^{3}$ Oddly enough, three of the four convergent validity coefficients of the variable Fantasizing are higher than the estimated reliability of the MCI halves. This suggests the SI and MCI versions to be more similar than the MCI versions with each other.

Each convergent validity coefficient is associated with eight HTHM correlations (halves $\mathrm{A}$ and $\mathrm{B}$ of the other version) and eight HTMM correlations (halves A and B of the same version). Every convergent validity coefficient exceeds all its associated HTHM and HTMM correlations. So guidelines 2 and 3 are completely satisfied. There are eight triangular submatrices of HTMM and eight triangular submatrices of HTHM correlations, each consisting of ten correlation coefficients. Guideline 4, the similarity in the pattern of correlations, is evaluated by computing the rank order of the correlations within each triangle. The standard deviation computed across the sixteen ranks of each of the ten correlations gives an indication of the similarity. These standard deviations range from 0.60 to 1.37 with an average $\mathrm{SD}^{4}$ of 1.08 . So, all in all, the pattern in the correlation coefficients across the triangles is quite similar. To evaluate guideline 5 , the difference between the HTMM and HTHM correlations and the reliability coefficients, the absolute HTMM and HTHM correlations are subtracted from the associated reliability coefficients. In the SI versions the mean difference is 0.599 (SD 0.114), in the MCI versions the mean difference is 0.509 (SD 0.116), with no occurrence of a negative difference. Finally, guideline 6 is investigated as the absolute difference between the parallel HTMM and HTHM correlations. In the SI versions the mean absolute difference is 0.076 (SD 0.053) and in the MCI versions the mean absolute difference is 0.045 (SD 0.032).

The parameter estimation in all four MTMM structure models converged and yielded a proper solution: no negative residual variances nor correlations

\footnotetext{
${ }^{2}$ The convergent validity coefficients are underlined in the split-half correlation table in Appendix A.6.1.

3 The reliability coefficients are printed in boldface in the split-half correlation table in Appendix A.6.1.

${ }^{4}$ Computed as the square root of the mean variance.
} 
Table 6.6: Comparisons between the hierarchically nested models

\begin{tabular}{lrrc}
\hline compared models & $\Delta \chi^{2}$ & df & p \\
\hline CTCM vs. CTUM & 10.13 & 1 & 0.001 \\
CTCM vs. CTJM & 141.10 & 1 & 0.000 \\
CTCM vs. CTNM & 362.50 & 21 & 0.000 \\
CTUM vs. CTNM & 352.37 & 20 & 0.000 \\
CTJM vs. CTNM & 221.40 & 20 & 0.000 \\
\hline
\end{tabular}

Note. $n=465$.

exceeding one occurred. The fit indices are depicted in Table 6.5. Formally, all models must be rejected. The $\chi^{2}$ of the CTCM model was significant. Yet, most other fit indices indicated that the CTCM model fits quite well. The $\chi^{2}$ of the CTUM model was significant as well. Still, the other fit indices revealed that the fit of this model is almost similar to the CTCM model. The $\chi^{2}$ of the CTJM and CTNM model were also significant. In these models the other fit indices evidenced a somewhat reduced fit. Note, however, that the AGFI of the CTNM model does not differ from that of the CTJM model, because the CTNM model reduces the number of estimated parameters by 20 .

Table 6.6 shows that all $\chi^{2}$ difference tests are significant. So, in first instance it seems that the CTCM model should be preferred. Appendix A.6.2 includes the standardized parameter estimates of all four models. The estimated trait factor loadings range from 0.872 to 0.636 with the SI version and from 0.798 to 0.500 with the MCI version. On average the trait factors of the CTCM model explain $62 \%$ of the SI variance and $51 \%$ of the MCI variance. The method factors explain on average $12 \%$ of the SI variance and $7 \%$ of the MCI variance. The correlation between the SI method factor and the MCI method factor is estimated at 0.434 . So it appears that both methods share $19 \%$ of their methods variance.

Although the $\chi^{2}$ difference test shows that the CTUM model fits significantly worse than the CTCM model in a statistical sense $\left(\Delta \chi^{2}=10.13 ; \mathrm{df}=1\right.$; $\mathrm{p}=0.001$ ), practically the difference is almost negligible. In the CTUM model the estimated trait factor loadings range from 0.885 to 0.677 with the SI version and from 0.784 to 0.521 with the $\mathrm{MCI}$ version. On average the trait factors now explain $64 \%$ of the SI variance and $52 \%$ of the MCI variance. The method factors explain on average $9 \%$ of the SI variance and $5 \%$ of the MCI variance. The CTUM model fixes the correlation between the SI method factor and the MCI method factor at 0 . So with this model both methods do not share methods variance.

\subsubsection{Comparative susceptibility to response styles}

Table 6.7 shows the correlations between the ADRS indices of the SI version and the PRRB indices of the MCI version. The correlations between the ADRS indices of the SI version all deviate statistically significantly from zero and range from 
0.104 to 0.269 (mean: 0.178; SD: 0.051). According to Cohen (1977) this must be considered a small to medium effect. So the proportion of variance in the ADRS index that is presumably accounted for by a response style appears to range from a mere $1 \%$ to $7 \%$. The correlations between the PRRB indices of the MCI version range from -0.062 to 0.094 . They do not deviate statistically significantly from zero, except for the correlation between Identifying and Emotionalizing. Finally, the correlations between the ADRS indices of the SI version and the PRRB indices of the MCI version range from -0.085 to 0.094 . They do not deviate statistically significantly from zero either, except for the correlations between SI-Identifying and MCI-Emotionalizing; and SI-Fantasizing and MCI-Analyzing.

Table 6.7: Correlations between the ADRS indices and PRRB indices

\begin{tabular}{|c|c|c|c|c|c|c|c|c|c|c|c|}
\hline & \multicolumn{5}{|l|}{$\mathrm{SI}$} & \multicolumn{5}{|l|}{$\mathrm{MCl}$} \\
\hline & & & \multicolumn{2}{|c|}{ Identifying } & \multicolumn{2}{|c|}{ Fantasizing } & \multicolumn{2}{|c|}{ Verbalizing } & Analyzing & \multicolumn{2}{|c|}{ Emotionalizing } \\
\hline & & \multicolumn{2}{|l|}{ Verbalizing } & Analyzing & \multicolumn{3}{|c|}{ Emotionalizing } & \multicolumn{2}{|c|}{ Identifying } & \multicolumn{2}{|c|}{ Fantasizing } \\
\hline \multirow[t]{5}{*}{ SI } & Verbalizing & - & & & & & & & & & \\
\hline & Identifying & 0.239 & - & & & & & & & & \\
\hline & Analyzing & 0.161 & 0.135 & - & & & & & & & \\
\hline & Fantasizing & 0.104 & 0.126 & 0.186 & - & & & & & & \\
\hline & Emotionalizing & $8 \quad 0.149$ & 0.185 & 0.269 & 0.229 & - & & & & & \\
\hline \multirow[t]{5}{*}{$\mathrm{MC}$} & Verbalizing & -0.085 & -0.026 & 0.045 & -0.042 & -0.061 & - & & & & \\
\hline & Identifying & 0.05 .4 & 0.022 & -0.024 & -0.032 & 0.063 & -0.062 & - & & & \\
\hline & Analyzing & 0.008 & 0.014 & 0.045 & 0.094 & 0.089 & 0.016 & 0.043 & - & & \\
\hline & Fantasizing & -0.031 & -0.069 & -0.044 & -0.052 & -0.073 & 0.041 & 0.070 & -0.031 & - & \\
\hline & Emotionalizing & $8 \quad 0.058$ & 0.094 & -0.070 & 0.048 & 0.059 & 0.031 & 0.094 & 0.054 & -0.038 & $\ldots$ \\
\hline
\end{tabular}

Note. $n=465$; with this number of subjects the absolute correlations exceeding 0.091 deviate from 0 with $\mathrm{p}<0.05$; the significant correlations are printed in boldface.

\subsection{Discussion}

\subsubsection{Ipsativity of the raw response scores}

The combination of indicative stimuli with contra-indicative stimuli in so-called opposed MCIs clearly resulted in between-subjects variance in the subtotal score. Consequently, the data collected with the opposed MCI is not automatically ipsatively standardized in the raw responses. If the opposed MCIs are combined with the aligned MCIs, the resulting variable scores showed sufficiently variance to allow the application of parametric statistics. The BVAQ-MCI variable score distributions deviated only marginally from the normal cumulative frequency distribution, although the Komogorov-Smirnov test was statistically significant in two variables. The score distributions of the BVAQ-MCI are therefore at least comparable to those of the BVAQ-SI. 


\subsubsection{Multitrait-multimethod analysis}

Both the positive Campbell-Fiske/Marsh-Grayson evaluation and the good fit of the CTCM and CTUM restricted factor models establish the validity of the new method of ipsative data collection. The models explained on average $62 \%$ and $64 \%$ of the trait variance in the SI version, and $51 \%$ and $52 \%$ of the trait variance in the MCI version, respectively. So, the SI version had some $10 \%$ of its trait variance more explained by both factor models. The stimuli had been specifically designed and selected for the original SI version, however. Hence, the relative superiority of the SI format should be no surprise. The obtained result with the MCI version is quite encouraging for this method of data collection.

The most discrepant variable with less than $30 \%$ of its variance contributing to a trait was Identifying in the MCI version (MCI-A: $32.1 \%$, MCI-B: $25.0 \%$, see Table A.6.1 in Appendix A.6.2). Perhaps this specific variable performed relatively badly, because some representing stimuli already incorporate a kind of a choice. A typical item reads for instance: 'When I feel at ease, it remains unclear to me whether I am cheerful, elated, or happy.' This characteristic may have made it extra hard for the respondent to compare it with another more direct stimulus. Still, the proposed ipsative data collection method appears sufficiently valid to warrant further investigation.

\subsubsection{Comparative susceptibility to response styles}

The low positive correlations between the ADRS indices within the SI version revealed that there was a minor influence of the acquiescence/dissentience response style. Yet, this effect did not contribute to the loadings of the SI method factor in any of the fitted factor models. After all, the SI version was balanced and thus largely corrects for this effect (see also Section 3.2.1). The small response style effect only emerged in the specific ADRS index. The fact that the influence was minimal also attests to the content saturation of the stimuli. Ambiguous stimuli make a respondent more susceptible to response tendencies. The PRRB indices did not indicate the existence of any primacy or recency response bias. As a result no relation between the ADRS and the PRRB can be established. It attests to the robustness of the new ipsative data collection method against this suggested response bias.

The classic ipsative data collection methods have been forwarded as a means to counter response styles. So far, ipsative data collection has primarily resulted in data that were already ipsatively standardized in the raw responses. As such the employed measurement unit had to be considered unique for each subject. A response style particularly hampers between-subjects comparisons. In essence, a method that results in data which cannot be compared across subjects is not much of a consolation against the response style.

The current ipsative data collection method does allow between-subjects comparisons. As a consequence it might be considered a viable strategy in the 
battle against response styles. In its practical use, however, the method does need both indicative and contra-indicative stimuli. With these two types of stimuli the influence can also be countered by applying the simpler SI fornat. Balancing the number of indicative and contra-indicative stimuli in fact prevents the influence of acquiescence or dissentience already. As a result the robustness of the new ipsative data collection method against these translating response styles should be regarded of minor importance. Nevertheless, many SI questionnaires exist that do not constitute of a balanced set of indicative and contra-indicative stimuli. Were they constructed according to the current ipsative data collection method, the constructor would have been forced to develop both indicative and contraindicative stimuli. So, a benefit of the current ipsative data collection method is that it obliges the development of indicative as well as contra-indicative stimuli.

\subsubsection{Concluding remark}

One might question whether the inclusion of the aligned MCI is actually essential. After all, the opposed MCI alone prevents the data from being ipsative. Still, the aligned MCI must be considered to supplement the opposed MCI. Although an opposed MCI suggests a contrasting choice, the response score actually indicates the combined score of the incorporated variables. Reviewing Figure 6.2 learns that an opposed MCI separates the joint preference space in areas, which are defined by the combined trait levels: $X+Y$. As a result a respondent might be either at the high end of trait $\mathrm{X}$ or of trait $\mathrm{Y}$ to opt for a checkbox that earns a high score. If the questionnaire consisted of two variables only, it would be impossible to ascertain the trait level of each separate variable with the opposed MCI. Only if the questionnaire contains at least three variables using opposed MCIs with different overlapping combinations of two traits, the separate variable scores may become available. How such score can be derived is explained in Appendix A.6.3.

Nevertheless, even if the inclusion of the aligned MCI is not imposed by the design of the questionnaire, some aspects could well favour its inclusion. In the first place, if the aim is to measure a profile of traits instead of separate traits, it could be slightly beneficial to use the aligned MCI. The aligned MCI may be more efficient in discerning slight differences between variable scores. This would be in keeping with the result reported in the previous chapter.

In the second place, choices between combinations of an indicative and a contra-indicative stimulus might better be alternated with choices between combinations of two indicative or two contra-indicative stimuli. If the questionnaire consists of opposed MCIs only, the respondent may select the indicative stimulus automatically. The alternation thus might help prevent the subject from becoming more detached during the response process.

And finally, if a respondent tends to depict himself more favourably, this will primarily affect the responses to the opposed MCIs. Without exception such a respondent will prefer the indicative stimulus over the contra-indicative stimulus. But a choice between either two indicative or two contra-indicative stimuli seems 
more robust against such a social desirability response set. As a result the response score of the opposed MCIs will suffer from a ceiling effect; the absolute trait amounts will become invalid. The relative composition of the traits, however, as indicated by the responses to the aligned MCIs, may still be assessed acceptably well. 


\title{
Matching stimuli to control for the social desirability response set: The case of individual differences
}

\author{
It is $[\ldots]$ quite clear that, \\ within a definable social group such as a college, \\ people differ in their notions of what constitute desirable traits, \\ and evaluations tend to reflect one's own personal traits (or vice versa): \\ what one does, he also tends to admire.
}

(Scott, 1963, p. 575)

Measurements resulting from a questionnaire are susceptible to the social desirability response set. Subjects may distort their responses in an attempt to look good. One of the strategies to control for this response bias is to present the respondent with compound items of which the stimuli are matched on their estimated social desirability (Nederhof, 1985; Paulhus, 1991). This is generally known as the forced-choice item format. If the stimuli are accurately equated, a respondent aiming to depict him or herself more favourably cannot doctor a profitable choice. The idea is that this deadlock will bring the subject to respond honestly, hence the name 'forced-choice'. For reasons made clear in Chapter 1, however, this term is abandoned. Instead of this functional designation the more structural descriptive term 'matched compound item format' is adopted here.

The rationally argued resistance of the matched compound item format against the social desirability response bias has not unequivocally withstood empirical scrutiny. The number of studies favouring the matched compound item has kept pace with the number of failures. Many have come to consider the matched compound item format inherently invalid, due to individual differences in the conception of what is socially desirable. After all, the stimuli are matched on the estimated mean social desirability scale value of the population. But an individual respondent may well regard one stimulus to be more socially desirable than the other, whereas someone else may think the other stimulus to be more desirable. If both aim to make a good impression, they will not feel 'forced' to 
answer truthfully. Instead, they will each choose the option deemed more gratifying. As a result one might conclude that the matching of stimnli on the basis of their population mean social desirability levels cannot control for the social desirability response set at the individual level.

The current study does not dispute the argument. The suggested course of the individual response behaviour is in fact well accepted. Still, it is believed that individual differences in the conceptions of what is socially desirable will not invalidate the matched compound item format. The individual social desirability attributions are thought to deviate from the population mean towards the own true scale positions. In other words, a subject will overestimate the social desirability of stimuli, which represent traits that the subject strongly possesses. The same respondent will underestimate the social desirability of stimuli, which represent traits that the subject commands in a lesser extent. This viewpoint is also reflected in the opening motto derived from Scott (1963). In conclusion, a subject that regards one stimulus as more socially desirable and selects it to make a positive impression, is likely to have chosen it anyway, if prepared to respond honestly.

\subsection{The problem of individual differences in social desirability}

The problem of individual differences in social desirability actually harbours three different objections against the matched compound item. First, subjects might diverge on different aspects of social desirability. Secondly, subjects could differ in the rated desirability of each separate stimulus. And finally, subjects possibly disagree in the perceived mismatch between the matched stimuli. The first objection stresses that the social desirability status may be a conglomerate index of what the respondent regards as desirable for society and what the respondent regards as desirable for himself. Rosen (1956) was the first to make this distinction between social desirability and personal desirability. Some stimuli may appear primarily socially desirable, whereas others may come out as mainly personally desirable. So the problem concentrates on the difficulty to match stimuli on a two-dimensional construct. It is essentially a multidimensional conception of social desirability.

The second objection focuses on individual differences in the ratings of the social desirability of stimuli. The explication by Scott (1963) leaves little room for imagination:

"[T]here were such wide [...] differences among individuals' conceptions of the desirable that the term "social desirability" could have little common meaning; hence the attempt to control distortion of personality test responses by a forced-choice technique, which assumes common conceptions, would seem fruitless." (Scott, 1963, p. 574)

The third objection points at the possibility of individual differences in the achieved matching accuracy within a matched compound item. This position 
differs with the previous in that it allows the occurrence of individual differences in the ratings of social desirability as long as the matching accuracy of the stimuli within the items remains the same between subjects. Somebody may find both matched stimuli highly desirable, whereas someone else may think the two stimuli not desirable at all. Still, for both respondents the stimuli appear equally well matched. To present an argument in favour of the matched compound item, each objection deserves to be addressed separately.

\subsubsection{The multidimensional interpretation of social desirability}

A multidimensional interpretation of social desirability threatens the validity of the matched compound item, because the method assumes a unidimensional continuum along which the stimuli can be matched (Messick, 1960; Wiggins, 1966). Rosen (1956) hypothesized that a respondent might be influenced by different facets of desirability in responding to an item. He asked respondents to indicate the social desirability and personal desirability of stimuli. The personal desirability variable was regarded to reflect the respondent's own opinion of desirability, in contrast to society's imputed desirability. Rosen failed however to establish a large difference between both components empirically (Rosen, 1956; Rosen \& Mink, 1961). Goodstein and Heilbrun (1959) reported a very high correlation $(r=0.90)$ between the mean social and mean personal desirability ratings over the 135 stimuli of the Edwards Personal Preference Schedule (EPPS).

Still, Heilbrun and Goodstein (1959) hypothesized that a response set towards personal desirable stimuli might reveal itself in different response behaviour than a response set towards social desirable stimuli. They, therefore, selected three groups of compound items from the EPPS containing stimuli that diverged maximally in mean personal and mean social desirability values. They started to select the 20 items of which one stimulus had the higher mean social desirability rating, whereas the other had the higher mean personal desirability rating (group 1). Because they were rare, the mismatch in social desirability between the two stimuli was not maximal. So they selected another group of 20 items, comparable in social desirability mismatch to the items of group 1, of which the same stimulus had both the higher mean social desirability rating and higher mean personal desirability rating (group 2). Finally, they selected the group of 20 items of which the stimuli actually diverged maximally in mean social desirability rating and, like the items in group 2, had the higher mean social desirability rating and higher mean personal desirability rating associated with the same stimulus (group 3).

Now, the idea was that there might be two different response sets: one guided by the social desirability of a stimulus and one governed by the personal desirability of a stimulus. If that idea was correct, it should result in an increased selection of the higher socially valued stimulus in both group 2 and 3, because that stimulus was also the higher personally valued stimulus. In group 1 , however, the endorsement frequencies should balance out. In a sample of 248 undergraduate students they only found a statistically significant increase in endorsement of the 
social desirable stimulus in the items of group 3 as compared to group 1 and 2 . Between group 1 and 2 no statistical significant difference in the endorsement frequencies occurred. Hence they conclude: "[U]tilization of only social values for matching purposes does not represent a crucial flaw in Edwards' attempt to minimize desirability of verbal statements as an important source of performance variance" (Heilbrun \& Goodstein, 1959, p. 304).

Since the Heilbrum and Goodstein (1959) study the social desirability construct has benefited some important theoretical improvements. The Rosen (1956) distinction between social and personal desirability fits closely the prevailing interpretation of the factors that comprise a social desirability measurement scale: an impression management and a self-deception component (Paulhus, 1984). The impression management score reflects the tendency to deceive others, the selfdeception score the disposition to deceive oneself. In deceiving others, subjects are thus expected to be more influenced by the mean social desirability of the stimuli. In deceiving oneself on the other hand, subjects are thought to be influenced by the mean personal desirability of stimuli. However, the relation of the two types of desirability ratings with impression management and self-deception has not yet been explored empirically.

\subsubsection{Individual differences in the stimulus desirability ratings}

Suppose the definition of the social desirability construct was strictly demarcated so that it constituted a single dimension. Even so, many regard the matched compound item format inadequate, due to a lack of consensus of the desirability of stimuli. The matching needs the collection of individual ratings of the social desirability values of stimuli. These stimuli are subsequently combined on the basis of equality in their mean social desirability ratings. The individual social desirability ratings may diverge widely, and they also have been found to do so (Orvik, 1972; Scott, 1963). Then the hope that the achieved matching accuracy on the population level reflects the achieved matching accuracy on the individual level evidences a naive faith in good fortune, to say the least. Confronted with such a matched pair of stimuli, someone may well regard stimulus $A$ to be more socially desirable. A colleague on the other hand, may attribute the higher social desirability scale value to stimulus B. If both aim to make a favourable impression, they will not feel compelled to respond honestly. Instead, they will each prefer the response option, that they consider themselves to enhance one's social image. As a result it may seem inevitable, but to conclude that the matching of stimuli on the basis of their population mean social desirability scale values cannot control for the social desirability response bias at the individual level.

Such a conclusion predicts, however, that if a subject aims to make a favourable impression the own endorsements will agree more with the own social desirability ratings than with the population mean social desirability ratings. J. B. Taylor (1959) was the first to compute within-subjects correlations between the stimulus endorsements and stimulus desirability ratings of the Minnesota Mul- 
tiphasic Personality Inventory (MMPI) in 70 subjects diagnosed with schizophrenia. The mean correlation between the individual stimulus endorsements and the individual stimulus desirability ratings was 0.36 . The reported mean correlation between the individual stimulus endorsements and the median stimulus desirability ratings was 0.39 . In view of the previous discussion the anticipated difference is clearly non-existent. This might be attributed to the homogeneity of the sample, as it comprised of schizophrenics only. So Boe and Kogan (1963) replicated the J. B. Taylor (1959) study in 112 college freshmen. They reported a mean correlation between the individual stimulus endorsements and the individual social desirability ratings of 0.40 . The mean correlation between the individual stimulus endorsements and the mean social desirability ratings was just 0.27 . This difference appeared statistically significant and in the predicted direction. The implication of this result for the matched compound item was, however, not discussed.

Boe and Kogan used a subset of 100 MMPI items to resolve the bimodality in the distribution of the mean social desirability ratings. In their opinion bimodal distributions "tend to produce spurious correlation" (Boe \& Kogan, 1963, p. 369). Edwards (1965), however, disqualified their approach as the distribution of the mean social desirability ratings of the MMPI simply happens to be bimodal. This finding occurred in other personality questionnaires as well. So, Edwards did not regard their result representative. Using a bimodal distribution of mean social desirability ratings in a new set of 176 personality statements, Edwards found an average within-subjects correlation between the individual stimulus endorsements and the mean social desirability ratings of 0.79 in 105 males and 0.82 in 103 females. Nevertheless, the accent was on the height of these within-subjects correlations. He did not compute the within-subjects correlations between the individual stimulus endorsements and the individual social desirability ratings. Apparently, he also failed to see the implication for the matched compound item of comparing these two different within-subjects correlation distributions.

Orvik (1972) in fact compared the within-subjects correlations at the respondent level. He asked 15 subjects first to complete an 82 item subset of the MMPI and then to rate the desirability of these items with regard to themselves, their social group, and society in general (in that order). He reported average within-subjects correlations between the individual item endorsements and desirability ratings of $0.56,0.47$, and 0.18 at the individual, group, and general level, respectively. The average within-subjects correlations between the individual item endorsements and the mean.MMPI desirability ratings as listed by Messick and Jackson (1961) was 0.29. Using the Sign test Orvik (1972) only reported the found average of 0.56 to differ statistically significant from the 0.18 and 0.29 . But actually all differences are statistically significant with alpha set to $0.05 .^{1}$ As the difference between the 0.18 and 0.29 is in the opposite direction to the result

${ }^{1}$ This was tested by using the within-subjects correlations that Orvik (1972) reported in Tables 5 and 6. 
reported by Boe and Kogan (1963), they are in this respect in conflict. This may be attributed to an order effect, since Orvik did not counterbalance the order of the desirability ratings. Nevertheless, Orvik concludes that the found individual differences in social desirability render the matched compound item approach no more valid than the presentation of singular items. And he adds:

"Even if the present findings were disregarded, the question may well be raised as to whether social desirability actually represents response bias per se. After all, no one yet has demonstrated that because a person responds in a socially desirable way he has given a biased (i.e., untrue) response. Even the high correspondence, shown in the present study, between one's own view of the desirable and one's self-report, allows no intrinsic basis for claiming dissimulation on the respondent's part. It would be indeed puzzling (and distressing) if we found a pervasive lack of correspondence between the values persons maintain and the descriptions they give of themselves. The only real way to "prove" that such a correspondence implies falsehood is to have some other, non-self report, access to personal reality; but then if we had that, the need for personality tests would be in jeopardy." (Orvik, 1972, p. 28, italics from the original.)

Recently, new empirical evidence favouring the matched compound item has been presented (Christiansen et al., 2005; D. N. Jackson et al., 2000). Still, the fundamental objection against the matched compound item as presented by Orvik (1972) among others has to date remained unchallenged. Does the increased agreement between the individual endorsements and the own social desirability ratings indicate biassed social desirability ratings that fit the own true trait positions? Or does it reflect biassed responding that fit the own social desirability ratings? The current study takes up the gauntlet. In the words of Orvik, it will have some other, be it self-report, access to personal reality to "prove" that such a correspondence implies falsehood, i.e. social desirable responding. But first another viewpoint on the matched compound item approach, permitting individuals to differ in their social desirability ratings, will have to be addressed.

\subsubsection{Individual differences in the achieved matching accuracy}

The previous section discussed the prevalence of individual differences in the social desirability ratings of stimuli and the fact that the individual stimulus endorsements are more in agreement with the own social desirability ratings than the population mean social desirability ratings. So it appears that the matched compound item has met its Waterloo. The matching of stimuli on the mean social desirability rating seems pointless if it fails to secure an accurate matching on the individual level.

R. E. Lapointe and Auclair (1961), nevertheless, granted subjects to differ in their social desirability ratings of the stimuli within a population. However, to prevent the occurrence of between-subjects differences in matching accuracy, subjects have to differ equally over the matched stimuli. This latter condition 
Figure 7.1: Two conditions of a stimulus pair matched for social desirability

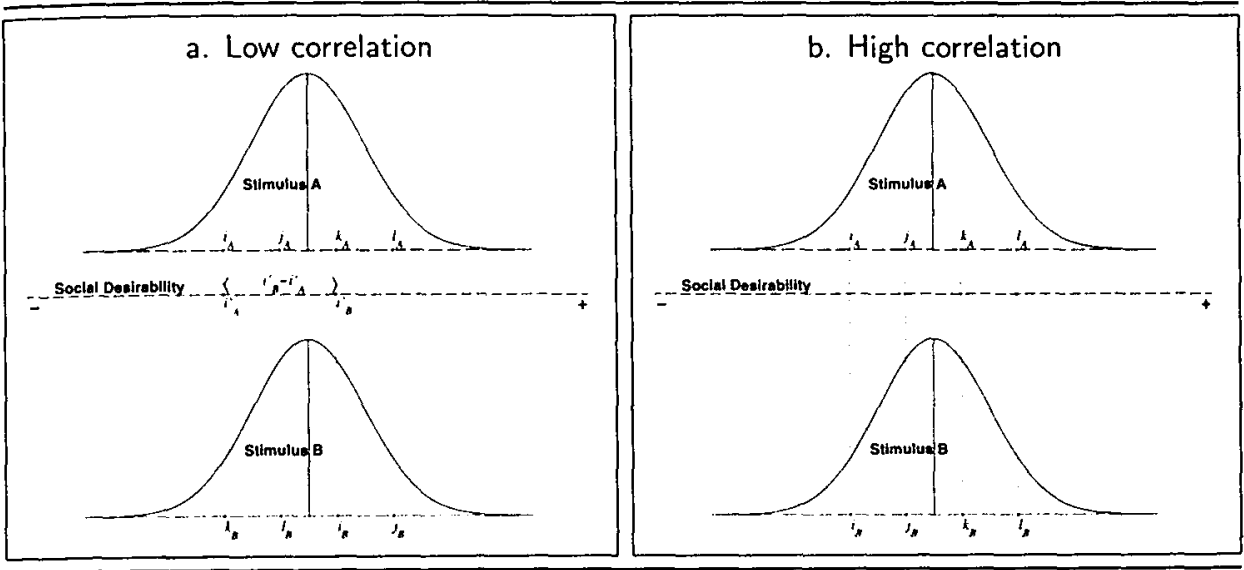

Note. The normal curves represent two population distributions of desirability ratings, one for stimulus $\mathrm{A}$, and one for stimulus $\mathrm{B}$. The letters $i, j, k$, and $l$ represent the desirability ratings of either stimulus by four subjects.

imposes two additional requirements on the stimulus matching strategy. The stimuli need not only to be matched on their population mean social desirability ratings. The Lapointe and Auclair provision dictates that the social desirability ratings of matched stimuli should also have equal population standard deviations of their respective social desirability ratings. In addition, the social desirability ratings of the two matched stimuli need to correlate highly positive. Norman (1963) by the way independently arrived at the same requirements, although he correctly pointed out that the correlation only needs to be high if the standard deviations do not approximate zero.

Figure 7.1 illustrates the issue. The two normal curves in either Figure 7.1a or Figure 7.1b represent the population distribution of the social desirability ratings of stimulus $A$ and $B$. The two curves are presented detached from the social desirability continuum in the middle. Otherwise, both curves would have coincided and complicated the comparison between the stimuli. The population mean social desirability ratings of the two stimuli are equivalent as the representing midlines meet each other on the social desirability continuum. So the first matching criterion is met with: both stimuli are on average equally desirable. Still, the subjects disagree as to how socially desirable each stimulus is. If not, the dispersion in the social desirability ratings within the population would have been zero. Both Figure 7.1a and Figure 7.1b demonstrate the two stimuli to agree with the second matching criterion. The standard deviations in the population desirability rating distributions of the two stimuli are equivalent, as indeed the two population distributions are congruent.

The importance of the third matching criterion, i.e. a high correlation be- 
tween the social desirability ratings, is evidenced by contrasting Figure 7.1a with Figure 7.1b. In both figures the ratings of four subjects $i$ to $l$ are indicated by points in the distribution of desirability ratings of each respective stimulus. In Figure 7.1a the order of the subjects on the basis of the individual desirability ratings of stimulus $A$ differs from the order of the subjects in the individual desirability ratings of stimulus $\mathrm{B}$. In stimulus A the order is $i, j, k, l$, whereas in stimulus $\mathrm{B}$ the order is $k, l, i, j$. Clearly, the stimuli do not match for subjects $i$ to $l$. The matching inaccuracy is shown for subject $i$. Consequently, the desirability ratings of both stimuli will not correlate highly positive. The order of the four subjects makes a negative correlation more likely. In Figure 7.1b, however, the order of the subjects is equal. Consequently, both options are for each of the subjects adequately matched. As a result the desirability ratings of both stimuli will correlate highly positively. So the third Lapointe and Auclair matching criterion, a high correlation between the social desirability ratings, actually guarantees that each subject judges the social desirability of both stimuli the same. Unfortunately, they claimed that the required level of correlation was very hard if not impossible to accomplish. They started with 150 adjectives allowing a total of $\frac{1}{2} \times 150 \times 149=11,175$ combinations. Nevertheless they merely could form 32 pairs that satisfied all three criteria. Their matching directives seem not to have been generally adopted.

Heilbrun and Goodstein (1961) used a different approach. They equated individual differences in matching accuracy by constructing a matched compound item questionnaire for each subject based on the individual stimulus desirability ratings. They investigated whether individualized matching would actually improve criterion validity. In a group of 57 subjects they failed to find a statistically significant improvement employing two different criterion measurements. The absence of any evidence that fine-tuning the matching to the subject might improve criterion validity clearly baffled the researchers. Honestly their results rather indicated the opposite. Therefore, they conclude that eliminating any effect of social desirability in fact reduces validity.

In this respect it is interesting to note that Scott (1963) correlated the stimulus endorsements with the stimulus social desirability ratings within each of 30 stimuli of the EPPS. In a total sample of 219 psychology students he found an average correlation of 0.53 , ranging from 0.28 to 0.77 . Tjoa (1973) replicated his result in two separate samples. In a sample of 100 men who were tested during a job selection procedure, Tjoa found over 210 Dutch EPPS stimuli an average within-stimulus correlation between endorsements and social desirability ratings of 0.44 , ranging from -0.05 to 0.86 . In a second sample of 33 men and 17 women, tested in the context of vocational guidance, Tjoa found over the same stimuli an average within-stimulus correlation between endorsements and social desirability ratings of 0.34 .

Scott (1963), therefore, concluded that: "[S]ocial desirability is not a characteristic of a test item, but rather depends on the relationship between subject and item" (p. 578). He admitted that the direction of causation responsible for 
these correlations had not been established. A person's conceptions of the desirable could either affect or reflect the own overt behaviour or self-concepts. The results by Tjoa (1973) suggest the former. Obviously, a job selection procedure exerts more pressure to respond favourably than a counselling setting. The disparity between the correlations in the two samples agrees with this difference. Unfortunately, Tjoa himself does not address the issuc. Conversely, the Heilbrun and Goodstein (1961) finding that administering an individualized matching version seemed to reduce the criterion validity, points in the other direction. After all, if individual differences in social desirability reflect true score variance, the individualized matching will remove it and thus lose validity. Scott (1963) did not take a stand, but asserted that if the individual's conception of the desirable is a reflection of the own self-rating, then there is no need to control for social desirability by the matched compound item.

\subsubsection{Conclusions}

The previous literature review can be summarized in three conclusions. First, comparisons between the mean social desirability ratings and the mean personal desirability ratings suggest that a social desirability response set is more related to the mean social desirability ratings than to the mean personal desirability ratings. Second, within-subjects correlations evidence that a subject's stimulus endorsements agree more with the own social desirability ratings than with the population mean social desirability ratings. Third, if individual differences in the matching accuracy of the matched compound item are resolved, it appears not to improve its criterion validity. Taken together, all these conclusions imply that the increased agreement between a subject's stimulus endorsements and the own social desirability ratings reflects true score variance rather than bias, due to the social desirability response set. If so, the incapacity of the matched compound item to control for individual differences in social desirability should be considered a merit rather than a defect, because otherwise the matching would filter out true score variance.

\subsection{Hypotheses}

\subsubsection{Research approach}

This research therefore attempts to establish in what extent the agreement between stimulus endorsements and desirability ratings reflects bias, and in particular the social desirability response set. To achieve this, the research will utilize four types of correlations. Normally, correlations are computed between variables over subjects. But this investigation also uses correlations between sample statistics over stimuli. In addition, the research uses within-subjects correlations between individual ratings over stimuli. Throughout this investigation these correlations will be indexed with an $i$, indicating the subject. The last type are within-stimulus 
correlations between individual ratings over subjects. These correlations will be indexed with a $j$, indicating the stimulus.

A central idea is that the within-subjects correlations between the stimulus endorsements and the desirability ratings represent a valid index of desirable responding. Although it was independently arrived at, this conception is not new. It was first employed by Block (1965). This within-subjects correlation yields a score for each subject. The higher the correlation the more the subject responded in agreement with the desirability of the stimuli.

This index of desirable responding can be expressed in four different ways. Rosen (1956) separated two kinds of desirability. He distinguished social desirability from personal desirability ratings. J. B. Taylor (1959), Boe and Kogan (1963), and Orvik (1972) provided two ways to compute the within-subjects correlations. They correlated the individual stimulus endorsements with either the population mean social desirability ratings or the individual stimulus social desirability ratings. These two distinctions can be combined. Hence, the stimulus desirability may be indicated by the own social desirability rating, by the population mean social desirability rating, by the own personal desirability rating, and by the population mean personal desirability rating. Within every subject the individual stimulus endorsements may be correlated with each of these four stimulus desirability parameters. As a result four different indexes of desirable responding by the subject become available.

These indices will be abbreviated as: $p o p S D R_{i}$, reflecting the extent of agreement between the population mean stimulus Social Desirability ratings and the stimulus Responses by subject $i_{\text {; }}$ indSDR $R_{i}$, indicating the degree of agreement between the individual stimulus Social Desirability ratings and the stimulus Responses of subject $i$; popPDR $R_{i}$, referring to the level of agreement between the population mean stimulus $P$ ersonal Desirability ratings and the stimulus Responses by subject $i$; indPDR $R_{i}$, signifying the amount of agreement between the individual stimulus Personal Desirability ratings and the stimulus Responses by subject $i$. These indices are computationally defined as:

$$
\begin{array}{lll}
\operatorname{popSDR}_{i}: & r_{i}\left(x_{i j}, \overline{S D}_{j}\right) \\
\text { indSDR } & : r_{i}\left(x_{i j}, S D_{i j}\right) \\
\operatorname{popPDR}_{i}: & r_{i}\left(x_{i j}, \overline{P D}_{j}\right) \\
\text { indPDR } & : r_{i}\left(x_{i j}, P D_{i j}\right),
\end{array}
$$

where $r_{i}$ indicates the within-subjects Pearson product-moment correlation coefficient of subject $i, x_{i j}$ represents the response of subject $i$ to stimulus $j, \overline{S D}_{j}$ refers to the mean Social Desirability rating of stimulus $j, S D_{0}$ denotes the $S$ ocial Desirability rating of subject $i$ to stimulus $j_{2}, \overline{P D}_{j}$ symbolizes the mean $P$ ersonal Desirability rating of stimulus $j_{1}$ and $P D_{\text {ij }}$ signifies the Personal Desirability rating of subject $i$ to stimulus $j{ }^{2}$ The present study will relate these indices to an

Q 2 To indicate the standard deviation the symbol $S$ is used, to avoid confision with $S D$ as abbreviationifor social desirability 
independent measure of social desirability.

This study will employ the stimuli of the Dutch EPPS. Tjoa (1973, Appendix III) established and listed the population mean stimulus social desirability ratings three decades ago. Instead of adopting the present population mean stimulus social desirability ratings, the within-subjects correlations could equally well utilize the original Tjoa ratings:

$$
\text { TjoaSDR }_{i}: r_{i}\left(x_{i j}, \overline{\text { TjoaSD }}_{j}\right)
$$

where $\overline{T j o a S D}_{j}$ indicates the population mean stimulus social desirability ratings as reported by Tjoa. The relation of this index with an independent social desirability measure provides an interesting perspective on the influence of longitudinal decay in matching accuracy.

\subsubsection{Predictions}

\section{Order effects}

Subjects will be requested to rate the social and personal desirability of stimuli. To control for order effects, as was for instance the criticism of the Orvik (1972) study, the ratings will be presented in counterbalanced order. Logically, such an approach demands that it is checked whether the order of social and personal desirability ratings influences the ratings. The null hypothesis simply declares these order effects to be absent. The intention is to corroborate this null hypothesis.

\section{The longitudinal stability of social desirability}

This study replicates the social desirability ratings of the Dutch EPPS stimuli that Tjoa (1973) already obtained. Consequently, a direct comparison of the present social desirability ratings with those obtained by Tjoa three decades ago, is feasible. It allows to estimate the longitudinal stability of the stimulus mean social desirability ratings as well as the longitudinal stability of the matching accuracy between the stimuli within the items. Particularly, the stability of the matching accuracy is in the current context deemed relevant. The between stimulus differences in social desirability within the items are expected to have increased since Tjoa constructed the item pairings $\left(\mathrm{H}_{1,1}\right)$. The null hypothesis maintains that the stimulus mismatch within the items has not increased. So, the study purports to reject the null hypothesis:

$\mathrm{H}_{0,1}$ : The mismatch in social desirability between paired stimuli has not increased.

In which case the following alternative hypothesis is accepted.

$\mathrm{H}_{1,1}$ : The mismatch in social desirability between paired stimuli has increased. 


\section{The multidimensional interpretation of social desirability}

As was already discussed in the introduction, social desirability is viewed to comprise of two factors: impression management and self-deception. Subjects who tend to respond conform their social desirability ratings are thought to exhibit impression management. On the other hand, subjects who are inclined to respond in accordance with their personal desirability ratings are considered to demonstrate self-deception. Consequently, the next two research hypotheses are formulated. Impression management is supposed to correlate positively with indSDR $\left(\mathrm{H}_{1,2}\right)$. Self-deception is regarded to correlate positively with $\operatorname{indPDR_{i}}\left(\mathrm{H}_{1,3}\right)$. The null hypotheses maintain that the two social desirability factors do not correlate positively with either indSDR or indPDR $R_{i}$ respectively $\left(\mathrm{H}_{0,2}\right.$ and $\left.\mathrm{H}_{0,3}\right)$. The study aims to reject both null hypotheses. Because the correlations are expected to be positive both hypotheses are subjected to one-tailed tests.

$$
\begin{aligned}
& \mathrm{H}_{0,2}: r\left(I M_{i}, \text { ind } S D R_{i}\right)=0 \quad \mathrm{H}_{1,2}: r\left(I M_{i} \text {, indSDR } R_{i}\right)>0 \text {, } \\
& \mathrm{H}_{0,3}: r\left(D C_{i} \text {, indPDR } R_{i}\right)=0 \quad \mathrm{H}_{1,3}: r\left(D C_{i} \text {, indPDR } R_{i}\right)>0 \text {, }
\end{aligned}
$$

where $I M_{i}$ indicates the score on an Impression Management measurement of subject $i$, indSDR $R_{i}$ represents the within-subjects correlation between the stimulus endorsements and the stimulus social desirability ratings of subject $i, D C_{i}$ denotes the score on a self-DeCeption measurement of subject $i$, and indPDR $R_{i}$ reflects the within-subjects correlation between the stimulus endorsements and the stimulus personal desirability ratings of subject $i$.

The previous hypotheses are tested by aggregating over the subject sample. The relation between social desirability, personal desirability, impression management, and self-deception can also be clarified by aggregating over the stimuli. Then for every stimulus an index is needed for its social desirability, its personal desirability, its susceptibility to impression management, and its vulnerability to self-deception. The stimulus mean personal desirability $\overline{P D}_{j}$ and stimulus mean social desirability $\overline{S D}_{j}$ are simply available, because they are being rated by the subject sample. The stimulus impression management and stimulus self-deception susceptibility are indexed by correlating the stimulus with either impression management or self-deception partialling out the content relevant variance. This is achieved by regressing for each separate stimulus the stimulus z-score to the variable z-score that the stimulus represents and the z-score of either impression management or self-deception. The following linear regression equations are used:

$$
\begin{aligned}
& \mathrm{z}\left(x_{i j}\right)=\beta_{X-x, j} \mathrm{z}\left(X_{i j}-x_{i j}\right)+\beta_{I M, j} \mathrm{z}\left(I M_{i}\right), \\
& \mathrm{z}\left(x_{i j}\right)=\beta_{X-x, j}^{\prime} \mathrm{z}\left(X_{i j}-x_{i j}\right)+\beta_{D C, j} \mathrm{z}\left(D C_{i}\right),
\end{aligned}
$$

where $\mathrm{z}\left(x_{i j}\right)$ is the z-transformed score of subject $i$ to stimulus $j, \beta_{X-x, j}$ and $\beta_{X-x, j}^{\prime}$ are the regression weights of stimulus $j$ onto the z-transformed variable score without the score of stimulus $j, \mathrm{z}\left(X_{i j}-x_{i j}\right)$ is the z-transformed score of subject $i$ on the variable that stimulus $j$ represents, with the score of subject $i$ to stimulus $j$ left out, $\beta_{I M, j}$ is the regression weight of stimulus $j$ onto impres- 
sion management, $\mathrm{z}\left(I M_{i}\right)$ is the z-transformed score of subject $i$ on impression management, $\beta_{D C, j}$ is the regression weight of stimulus $j$ onto self-deception, and $z\left(D C_{i}\right)$ is the z-transformed score of subject $i$ on self-deception.

The beta regression weights thus represent the partial correlations between the endorsements of stimulus $j$ with impression management $\left(\beta_{I M, j}\right)$ or self-deception $\left(\beta_{D C, j}\right)$, having the content relevant variable variance filtered out. Over the stimuli $\beta_{I M, j}$ is expected to correlate positively with both the stimulus mean social desirability rating $\overline{S D}_{j}\left(\mathrm{H}_{1,4}\right)$ and the stimulus mean personal desirability $\overline{P D}_{j}\left(\mathrm{H}_{1,5}\right)$. It is suggested that $\overline{P D}_{j}$ instead of personal desirability reflects social desirability as well. The mean personal desirability rating ceases to be personal, because it is averaged over all subjects. The individual stimulus personal desirability ratings may well be assumed to be evenly distributed around the stimulus mean social desirability value. Some may value the stimulus more desirable, whereas others find it less desirable. Then the stimulus mean personal desirability ratings will approximate the stimulus mean social desirability ratings, in accordance with the reported correlation of 0.90 (Goodstein \& Heilbrun, 1959). Therefore, $\beta_{D C, j}$ is thought not to correlate with $\overline{S D}_{j}\left(\mathrm{H}_{0,6}\right)$, nor with $\overline{P D}_{j}\left(\mathrm{H}_{0,7}\right)$. The four hypotheses are presented below. The idea is to reject the upper two null hypotheses related to $\beta_{I M, j}$ and to corroborate the lower two, addressing $\beta_{D C, j}$.

$\begin{array}{llll}\mathrm{H}_{0,4}: r\left(\beta_{I M, j}, \overline{S D}_{j}\right)=0 & \mathrm{H}_{1,4}: r\left(\beta_{I M, j}, \overline{S D}_{j}\right) & >0, \\ \mathrm{H}_{0,5}: r\left(\beta_{I M, j}, \overline{P D}_{j}\right)=0 & \mathrm{H}_{1,5}: r\left(\beta_{I M, j}, \overline{P D}_{j}\right) & >0, \\ \mathrm{H}_{0,6}: r\left(\beta_{D C, j}, \overline{S D}_{j}\right)=0 & \mathrm{H}_{1,6}: r\left(\beta_{D C, j}, \overline{S D}_{j}\right) & \neq 0, \\ \mathrm{H}_{0,7}: r\left(\beta_{D C, j}, \overline{P D}_{j}\right)=0 & \mathrm{H}_{1,7}: r\left(\beta_{D C, j}, \overline{P D}_{j}\right) \neq 0,\end{array}$

\section{Individual differences in the stimulus desirability ratings}

If individual differences in the perception of social desirability play a major role, then it suggests that the individual stimulus endorsements should be stronger related to the individual social desirability ratings (indSDR $R_{i}$ ) than to the population mean social desirability ratings ( $p o p S D R_{i}$ ). So, conform the results of Boe and Kogan (1963), the median indSDR $R_{i}$ is regarded to be larger than the median popSDR $R_{i}\left(\mathrm{H}_{1,8}\right)$. Parallel, the median indPDR $i$ is thought to exceed the median popPDR $\left(\mathrm{H}_{1,9}\right)$. In addition, following the result reported by Orvik (1972), the median indPDR $R_{i}$ is thought to be above the median popSDR $\left(\mathrm{H}_{1,10}\right)$ and median indSDR $R_{i}\left(\mathrm{H}_{1,11}\right)$. And finally, the median popPDR $i$ is expected to be larger than the median popSDR $\left(\mathrm{H}_{1,12}\right)$. No a priori hypothesis is formulated regarding the relationship between the median popPDR $R_{i}$ and the median indSDR $R_{i}$; it will be simply explored. The study aims to reject all null hypotheses listed below.

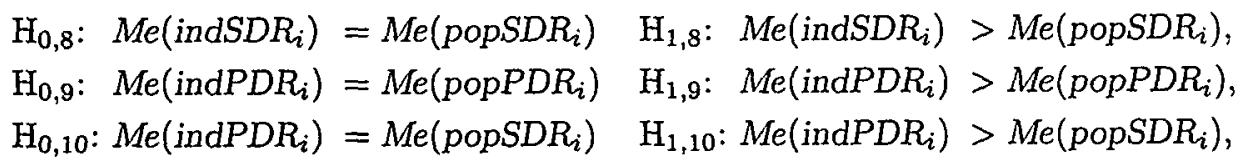




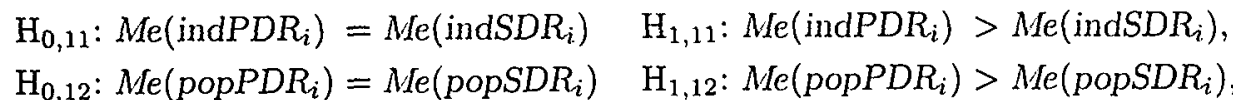

where $M e$ indicates the median over all subjects.

\section{Individual differences in the achieved matching accuracy}

This study actually assumes that individual differences in the social and personal desirability ratings of stimuli, as is captured by the previous hypotheses $\mathrm{H}_{1,8}$ thru $\mathrm{H}_{1,12}$, will be found. However, in correspondence with the results of Scott (1963), the idea is that most stimulus ratings will correlate positively with the stimulus endorsements. So, the median within-stimulus correlation between stimulus endorsements and social desirability ratings are expected to be greater than zero $\left(\mathrm{H}_{1,13}\right)$. The median within-stimulus correlations between stimulus endorsements and personal desirability ratings are also thought to be above zero $\left(\mathrm{H}_{1,14}\right)$. Finally, the within-stimulus correlations of the stimulus endorsements with the stimulus personal desirability ratings are expected to exceed the correlations between the stimulus endorsements and the social desirability ratings $\left(\mathrm{H}_{1,15}\right)$. So, the next formulated null hypotheses are meant to be rejected.

$$
\begin{array}{rlrl}
\mathrm{H}_{0,13}: M e\left[r_{j}\left(x_{i j}, S D_{i j}\right)\right] & =0 & \mathrm{H}_{1,13}: M e\left[r_{j}\left(x_{i j}, S D_{i j}\right)\right]>0, \\
\mathrm{H}_{0,14}: M e\left[r_{j}\left(x_{i j}, P D_{i j}\right)\right] & =0 & \mathrm{H}_{1,14}: M e\left[r_{j}\left(x_{i j}, P D_{i j}\right)\right]>0, \\
\mathrm{H}_{0,15}: M e\left[r_{j}\left(x_{i j}, P D_{i j}\right)\right] & =M e\left[r_{j}\left(x_{i j}, S D_{i j}\right)\right] \\
& \mathrm{H}_{1,15}: M e\left[r_{j}\left(x_{i j}, P D_{i j}\right)\right]>M e\left[r_{j}\left(x_{i j}, S D_{i j}\right)\right],
\end{array}
$$

where $M e$ indicates the median over all stimuli, $r_{j}$ signifies the within-stimulus correlation, $x_{i j}$ indicates the response of subject $i$ to stimulus $j, S D_{i j}$ denotes the social desirability rating of subject $i$ to stimulus $j$, and $P D_{i j}$ represents the personal desirability rating of subject $i$ to stimulus $j$.

The study now arrives at the same predicament that Scott (1963) found himself in. The above hypothesized positive within-stimulus correlations between stimulus endorsements and stimulus social or personal desirability ratings may either be taken to reflect a causal influence in that stimulus desirability enhances stimulus endorsement or, vice versa, stimulus endorsement enhances stimulus desirability. Naturally, a third variable could be the common cause of both as well. The crux of the study is that if stimulus desirability enhances stimulus endorsement then the supposed increase of indSDR $R_{i}$ relative to popSDR $R_{i}$ must be attributed to social desirable responding. Hence, the correlation of indSDR with impression management should exceed the correlation of popSDR $R_{i}$ with impression management $\left(\mathrm{H}_{1,16}\right)$. If on the other hand stimulus endorsement enhances stimulus desirability then the anticipated rise of indSDR $R_{i}$ as compared to $\operatorname{popSDR}_{i}$ is not caused by the social desirability response set. In that case indSDR $R_{i}$ is expected to correlate at least equally strong with impression management as popSDR $R_{i}$ does $\left(\mathrm{H}_{0,16}\right)$. Insofar personal desirability reflects social 


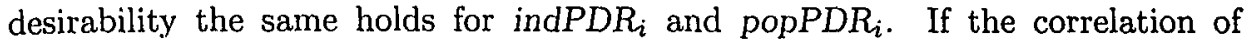
indPDR $i$ with impression management is above the correlation of popPDR $R_{i}$ with impression management $\left(\mathrm{H}_{1,17}\right)$, it evidences that stimulus desirability enhances stimulus endorsement. If indPDR $R_{i}$ correlates at least equally with impression management as popPDR does $\left(\mathrm{H}_{0,17}\right)$, it is more in line with the interpretation that stimulus endorsement enhances stimulus desirability. The study is directed at corroborating the null hypotheses of the following hypotheses.

$$
\begin{aligned}
& \mathrm{H}_{0,16}: r\left(I M_{i} \text {, indSDR } R_{i}\right)=r\left(I M_{i},{\left.\operatorname{pop} S D R_{i}\right)}\right.
\end{aligned}
$$

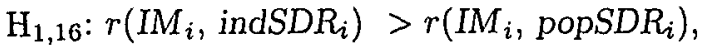

$$
\begin{aligned}
& \mathrm{H}_{0,17}: r\left(I_{i}, \text { indPDR } R_{i}\right)=r\left(I_{i}, p \text { opPDR } R_{i}\right) \\
& \mathrm{H}_{1,17}: r\left(I M_{i} \text {, indPDR } R_{i}\right)>r\left(I M_{i}, \text { popPDR } R_{i}\right) \text {. }
\end{aligned}
$$

In addition, the decay in matching accuracy, as reflected by hypothesis $\mathrm{H}_{1,1}$ should reveal itself in a reduced correlation between $T j o a S D R_{i}$ and impression management in contrast with the correlation between popSDR $R_{i}$ and impression management $\left(\mathrm{H}_{1,18}\right)$. After all, social desirable responding can be expected to result in conformism to the current social standards, not the social standards of thirty years ago, especially in a young research sample consisting of college students. If the correlation of TjoaSDR $i$ with impression management is comparable to the correlation of popSDR $i$ with impression management $\left(\mathrm{H}_{0,18}\right)$, it implies that social standards have not changed that much to warrant a revision of the stimulus pairings. It is the final null hypothesis this study aims to reject.

$\mathrm{H}_{0,18}: r\left(I_{i}, \operatorname{popSDR}_{i}\right)=r\left(I_{i}\right.$, TjoaSDR $\left._{i}\right)$
$\mathrm{H}_{1,18}: r\left(\mathrm{IM}_{i}\right.$, popSDR $\left._{i}\right)>r\left(\mathrm{IM}_{i}\right.$, TjoaSDR $\left._{i}\right)$

\subsection{Methods}

\subsubsection{Instruments}

\section{The Edwards Personal Preference Schedule}

Tjoa (1973) adapted the EPPS for the Dutch population. The instrument consists of 225 multidimensional compound items. Such an item requires the respondent to choose between two stimuli that each represent a different variable (see Figure 1.6 on page 11). The questionnaire covers 15 of the personality variables that are part of the need-press personality theory by Murray (1938): Achievement, Deference, Order, Exhibition, Autonomy, Affiliation, Intraception, Succorance, Dominance, Abasement, Nurturance, Change, Endurance, Heterosexuality, and Aggression. Edwards (1954) originally matched each pair of stimuli on social desirability using a total set of 135 stimuli.

To achieve an adequate level of matching Tjoa (1973) used many more stimuli. The Dutch EPPS even contains several variants of a stimulus, reflecting 
slight differences in wording. These variants could easily be identified as the associated mean social desirability ratings were exactly identical up to the level of two decimals. A first reduction of these variants resulted in a list of 238 stimuli (De Vries, 2005a). Of these original 238 stimuli only 224 were retained in the current study.

The 14 omitted stimuli all represent Tjoa's adaptation of the EPPS Heterosexuality variable. These stimuli inquire into the heterosexual orientation of the respondent and were deemed unethical according to current social standards. In addition, it was feared to frustrate the cooperation of the respondents. Moreover these stimuli were not regarded essential in the operationalization of Sexuality according to the need-press theory of Murray (1938). For although Murray separately discusses a latent need Homo-sex, he adds: "This is really not a separate need. It is the Sex drive focussed on an O[bject] of the subject's sex" (p. 146). He subsequently defines the manifest need Sex as: "The selection of the same or the opposite sex" (p. 167). Obviously, Murray does not regard the sexual orientation a defining characteristic of the Sex need.

In first instance, it was also intended to update the Dutch version of the EPPS. So, thirteen new stimuli were added to represent this reinterpreted Sex variable, free from sexual orientation. Also two new stimuli were included to complement the depleted Aggression scale. The resulting total set of 239 stimuli was provided with a 5-point Likert response scale, with endpoint labels 1, 'completely inapplicable', and 5, 'completely applicable'. This is regarded a singular item (SI) version, as the items require the endorsement of one stimulus. Hence this EPPS version is addressed as the EPPS-SI.

\section{The EPPS Social and Personal Desirability rating scale}

To collect the social and personal desirability ratings of the EPPS stimuli the 239 stimuli were dispersed over eight versions, each including 30 stimuli. The construction of the EPPS Social and Personal Desirability rating scale (EPPS-SPD) versions was such to include a maximum variation in stimulus content. Each of the variables was at least represented by one and at most by three stimuli. Stimulus 021 was included in two versions. The respondent was asked to rate the social desirability $\left(S D_{i j}\right)$ of every stimulus on a 5-point Likert scale with endpoint labels 1 , 'socially undesirable', and 5, 'socially desirable'. In addition, the respondent is requested to indicate his or her personal desirability $\left(P D_{i j}\right)$ of the same subset of stimuli employing a 5-point Likert scale with endpoint labels 1 , 'personally undesirable', and 5, 'personally desirable'. The order of the $S D_{i j}$ and $P D_{i j}$ ratings is counterbalanced over each version.

\section{The two-factor Desirability Questionnaire}

Hermans (1967) had adapted the Marlowe-Crowne Social Desirability Scale for the Dutch population. Yet, to make a clear distinction between impression manage- 
ment and self-deception a Dutch analogue of the Balanced Inventory of Desirable Responding was needed (Paulhus, 1991). Vorst had collected, adapted, composed and empirically evaluated a collection of 54 items covering the two aspects of the social desirability response set. However, Vorst (2005) had himself refrained from the construction of a general purpose social desirability questionnaire. In his opinion such a general purpose questionnaire is uncalled for. Stimuli covering social desirability should always relate to the constructs that are the focus of the measurement effort. Otherwise, the stimuli stand out. And a perceptive respondent might then identify them and thus respond evasively. Wicherts (2002), nevertheless, selected two balanced subsets of eight stimuli, one subset covering impression management and one covering self-deception. In two samples of college freshmen ( $n=248$ and $n=175$ ) the reliability of the self-deception variable was good, Cronbach's $\alpha$ was 0.85 and 0.80 , respectively. But the reliability of the impression management variable was disappointing: Cronbach's $\alpha$ was 0.64 and 0.60 , respectively.

Unaware of Wicherts' eight item version De Vries (2005b) constructed both variables anew, aiming to select a balanced subset of ten stimuli for each variable. His undertaking succeeded partly. The ten item version of impression management (IM) was not balanced. It contained four indicative and six contra-indicative items. Yet, the reliability was reasonably higher with a Cronbach's $\alpha$ of 0.72 . The reliability of the ten item version of self-deception $(D C)$ was comparable; Cronbach's $\alpha$ was 0.81 . Although the ten item version was constructed independently from the eight item version, both impression management variables have four stimuli in common, and the self-deception variables six stimuli. The productmoment correlation between both variables in the ten item version is 0.28 . The questionnaire will hereupon be called the two-factor Desirability Questionnaire (D2Q).

\subsubsection{Participants}

In total 530 psychology freshmen participated in the study. In about half of the research sample the D2Q was administered first, a week later the EPPS-SPD, and another week later the EPPS-SI. In the other half the D2Q and EPPS-SPD were administered during the same testing session, and a week later the EPPS-SI. Absence from one of the testing sessions resulted in 506 students who completed the EPPS-SI, the D2Q, and the EPPS-SPD. Nine subjects (1.8\%) skipped at least one item of the EPPS-SI, ten subjects (2.0\%) failed to answer at least one item of the $\mathrm{D} 2 \mathrm{Q}$, and 32 subjects $(6.3 \%)$ omitted at least one of the SD or PD ratings. These subjects were excluded from further analysis. So the research sample consists of 455 subjects ( 126 men; 329 women). The age ranges from 17 to 51 years (mean: 21.0 years; $S: 4.55$; median: 19 years). ${ }^{3}$ In 38 subjects $(8.4 \%)$ the native language deviates from Dutch (including nine subjects from

${ }^{3}$ The symbol $S$ is used to indicate the standard deviation. The abbreviation $S D$ refers to social desirability (see also Footnote 2). 
whom the native language is unknown). Still, these subjects remain included in the subsequent analysis.

The respondents were assigned a research ID number and remained anonymous. There was no incentive to respond in a social desirable fashion. The students could not acquire extra credits by responding favourably, nor were they explicitly instructed to fake. The aim was to evaluate the influence of the social desirability response set under normal testing conditions in a research setting.

\subsubsection{Analysis}

\section{The Social and Personal Desirability-Response correlation variables}

The study centres around the use of within-subjects correlations as independent indicators of social desirable response behaviour. In the section addressing the

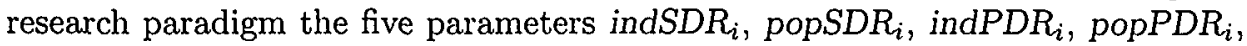
and $T$ joaSDR $i$ were already explained (see Formula 7.1). All the within-subjects correlations are computed over the 30 stimuli that the EPPS-SPD version contained. Otherwise a divergence between indSDR $R_{i}$ or indPDR $R_{i}$ at the one hand and popSDR $i$ or popPDR $i$ at the other, might be attributed to differences in the stimulus samples. The same limitation in the stimulus subset also applies to $T$ joaSDR $R_{i}$. Of course, for the 15 added stimuli no social desirability rating by Tjoa was available. So these were left out in the computation of the within-subjects correlations. TjoaSDR $i$ is therefore based on 27 to 29 stimuli.

As explained popSDR $i$ utilizes the stimulus mean social desirability rating $\left(\overline{S D}_{j}\right)$, and popPDR $R_{i}$ is based on the stimulus mean personal desirability rating $\left(\overline{P D}_{j}\right)$. The number of ratings on which each mean desirability rating is based ranges from 51 to 63 ratings (except for stimulus 021 that was rated 122 times). Since popSDR $R_{i}$ is contrasted with indSDR $R_{i}$ and popPDR $R_{i}$ with indPDR $R_{i}$ it is best to avoid any overlap between these mean desirability ratings and the individual desirability ratings. So for each within-subjects correlation the desirability ratings of the particular subject are left out from the used stimulus desirability averages. Therefore, contrary to Formula 7.1a popSDR $i$ is actually computed as:

$$
\text { popSDR } R_{i}: r_{i}\left(x_{i},\left(\frac{\sum_{a=1}^{n} S D_{a j}-S D_{i j}}{n-1}\right)\right) \text { for } i=1 \text { to } 455,
$$

and in contrast with Formula 7.1c popPDR is computed as:

$$
\text { popPDR } R_{i}: r_{i}\left(x_{i},\left(\frac{\sum_{a=1}^{n} P D_{a j}-P D_{i j}}{n-1}\right)\right) \text { for } i=1 \text { to } 455 \text {, }
$$

where $i$.indicates the index subject, $j$ indexes the 30 stimuli that subject $i$ rated in the administered EPPS-SPD version, $a$ indexes the subjects that rated the same EPPS-SPD version as subject $i$, and $n$ denotes the number of subjects that rated the same EPPS-SPD version as subject $i$. All correlations were computed according to Pearson's product-moment correlation coefficient. 


\section{Order effects}

The EPPS-SPD versions are checked for order effects by Hotellings $T^{2}$, with the independent variable being the two administration orders and the dependent variables the desirability ratings of the 30 stimuli of any version. The influence of order is separately tested for the $S D_{i j}$ part and the $P D_{i j}$ part. This requires two tests for every version. The eight versions are independent. So, over each set of eight versions a Bonferroni correction is applied as suggested by Hochberg (1988). Should a version exhibit a significant effect, the mean desirability ratings of all the 30 stimuli are compared between the two order groups by independent samples t-tests.

\section{The longitudinal stability of social desirability}

The obtained mean social desirability ratings in the 224 standard stimuli are compared with the social desirability ratings that Tjoa (1973) reported. Tjoa used, however, a 3-point Likert scale ranging from 0 to 2 . So, the obtained 5 -point Likert scale results are rescaled to fit his 3-point Likert scale range. The Likert response categories 1 and 2 are both recoded as the 0 response category, response category 3 is recoded as response category 1 , and the response categories 4 and 5 are both assigned to response category 2 .

To evaluate the actual effect of possible shifts in stimulus social desirability on the matching accuracy, the mismatch in the current social desirability assignments is compared with the mismatch obtained by Tjoa (1973). The change in matching accuracy applies to the stimulus pairs that Tjoa combined. Each mismatch is also quantified in terms of ES. It is defined as the mean of the differences divided by the standard deviation of the differences (Cohen, 1977, Formula 2.3.5). The mean of the differences equals the difference of the means. The standard deviation of the differences is, however, defined as (Cohen, 1977, Formula 2.3.6):

$$
S_{S D_{A}-S D_{B}}=\sqrt{S_{S D_{A}}^{2}+S_{S D_{B}}^{2}-2 r S_{S D_{A}} S_{S D_{B}}}
$$

where $S_{S_{A}-S D_{B}}$ is the standard deviation of the differences, $S_{S D_{A}}^{2}$ is the variance in the social desirability ratings of stimulus $\mathrm{A}, S_{S D_{B}}^{2}$ is the variance in the social desirability ratings of stimulus $\mathrm{B}, r$ is the correlation between the two stimulus social desirability ratings, and $S_{S D_{A}}$ and $S_{S D_{B}}$ are the standard deviations of the two stimulus social desirability ratings. When the EPPS-SPD versions were constructed, it was not deemed important to have both stimuli of the same item included in the same version. As a result the standard deviation of the differences is not directly available (left side of Formula 7.4). The correlations between the social desirability ratings of the matched stimuli, unfortunately, remain unknown 
as well. Consequently, the matching accuracy is just expressed as:

$$
\mathrm{ES}_{\mathrm{mm}}=\frac{\left|{\overline{S D_{A}}}_{-}-\overline{S D}_{B}\right|}{\sqrt{S_{S D_{A}}^{2}+S_{S D_{B}}^{2}}}
$$

where $\mathrm{ES}_{\mathrm{mm}}$ is the mismatch effect size, $\overline{S D}_{A}$ is the mean social desirability rating of stimulus $A$, and $\overline{S D}_{B}$ is the mean social desirability rating of stimulus $B$. The suggested approximation, therefore, assumes the stimulus social desirability ratings to be uncorrelated. As the ratings are probably positively correlated, the estimated pooled standard deviation as used in Formula 7.5 will exceed the result from the proper approach as defined in Formula 7.4. The reported effect size $\mathrm{ES}_{\mathrm{mm}}$ can thus be taken to underestimate the mismatch. Again to estimate the mismatch obtained by Tjoa (1973) the approximated standard deviations of the current differences are used. Any change in mismatch between the stimuli is tested over the items by the Sign test and the Wilcoxon signed ranks test. The Wilcoxon signed ranks test is more power efficient than the Sign test, but assumes the magnitude of the differences to be meaningful (Siegel, 1956).

\section{The multidimensional interpretation of social desirability}

The two correlations in hypotheses $\mathrm{H}_{1,2}$ and $\mathrm{H}_{1,3}$ that are regarded to deviate from zero are tested by the following $T$ statistic:

$$
T=r \sqrt{\frac{n-2}{1-r^{2}}}
$$

where $r$ is the correlation, and $n$ the number of data points. $T$ is t-distributed with $n-2$ degrees of freedom (see Van den Brink \& Koele, 2002, Formula 15.2).

\section{Individual differences in the stimulus desirability ratings}

The individual differences in the stimulus ratings of social desirability should result in higher within-subjects correlations based on the own stimulus social desirability ratings than based on the mean stimulus social desirability ratings. The differences between these within-subjects correlations are tested by the Sign test and the Wilcoxon signed ranks test. The first benefit of these non-parametric tests is that no additional assumptions are required about the sampling distribution of the within-subjects correlations. In addition, these statistics present as extra information the number of subjects whose endorsements are more in agreement with the own desirability ratings, versus the number of subjects whose endorsements are more conform the mean social desirability ratings. The comparisons between the within-subjects correlations are expressed in effect sizes as the difference between the means of both correlations divided by the pooled standard deviations of both within-subjects correlations. 


\section{Individual differences in the achieved matching accuracy}

The within-stimulus correlations of the stimulus endorsements with either the social or personal desirability ratings are computed as polychoric correlations using PRELIS. ${ }^{4}$ The medians of both distributions are expected to exceed zero. This is tested by the Sign test and the Wilcoxon signed ranks test. The hypotheses about the correlations between the within-subjects correlation indices with the D2Q impression management and self-deception variables are all comparisons between correlations that have one variable in common. Hence these correlations are tested for statistical significant differences using the $\mathrm{Z}$ statistic as outlined by Meng, Rosenthal, and Rubin (1992, see Formulas 1, 2, and 3).

All effect sizes are clustered by adopting the convention of Cohen (1977) to demarcate a small, medium, and large effect. But instead of using point definitions a range definition is employed. So items with an absolute effect size ranging from 0.2 to 0.5 are interpreted as displaying at least a small effect, items with an absolute effect size ranging from 0.5 to 0.8 are interpreted as demonstrating at least a medium effect, and items with an absolute effect size from 0.8 and up are interpreted as exhibiting at least a large effect. An absolute effect size less than 0.2 is considered to evidence no effect. In all tests a significance level of 0.05 is applied.

\subsection{Results}

\subsubsection{Order effects}

Each stimulus was on average rated by 56.8 subjects $(S: 3.4$; min: 51 ; max: 63 ; median: 56). Stimulus 021 was rated by 122 subjects, because it was included in two versions. The first research prediction was directed at corroborating the absence of an order effect. In the eight EPPS-SPD versions no statistically significant order effect was found. The resulting $F$ and $p$-values of the Hotelling's $T^{2}$ tests are tabulated in Table A.7.1 (see Appendix A.7.1).

\subsubsection{The longitudinal stability of social desirability}

The mean social desirability ratings correlate by 0.859 with the mean social desirability ratings that Tjoa (1973) reported. The first hypothesis predicted, however, that the mismatch in social desirability between the stimuli as paired by Tjoa would have increased $\left(\mathrm{H}_{1,1}\right)$. With the 224 reassessed stimuli the matching accuracy in 197 of the original 225 pairings can be compared with the matching accuracy found by Tjoa. In this item subset Tjoa obtained a mean social desirability mismatch ES of 0.288 ( $S: 0.287$; min: 0.000; max: 1.674; median: 0.212).

\footnotetext{
${ }^{4}$ For each separate stimulus the endorsements and the social and personal desirability ratings are indicated on a 5-point Likert scale by 51 to 63 subjects (except for stimulus 021 that is endorsed and rated by 122 subjects). To limit the influence of any deviations from normality, polychoric correlations are used.
} 
The current ratings yield a mean social desirability mismatch ES of 0.429 ( $S$ : 0.372; min: 0.000; $\max : 2.042$; median: 0.319). Table 7.1 lists the number of stimuli classified according to mean social desirability mismatch ES. The mean social desirability mismatch ES is correlated over the two studies by 0.402 . The difference in mismatch $\mathrm{ES}$ is statistically significant (Sign $\mathrm{Z}=-4.845, \mathrm{p}<0.05$; Wilcoxon $Z=-5.631, \mathrm{p}<0.05)$. As a conclusion the mean social desirability mismatch between the stimuli within the items has increased.

Table 7.1: Stimulus counts by mean social desirability mismatch ES

\begin{tabular}{lcccc}
\hline study & $\mathbf{0 . 0}$ to $\mathbf{0 . 2}$ & $\mathbf{0 . 2}$ to $\mathbf{0 . 5}$ & $\mathbf{0 . 5}$ to $\mathbf{0 . 8}$ & $\mathbf{0 . 8} \geq$ \\
\hline Tjoa (1973) & 95 & 65 & 25 & 12 \\
Current results & 66 & 70 & 29 & 32 \\
\hline
\end{tabular}

Note. $n=197$ stimulus pairs.

\subsubsection{The multidimensional interpretation of social desirability}

It was predicted that indSDR $R_{i}$ would correlate significantly with impression management $\left(\mathrm{H}_{1,2}\right)$ and indPDR $i$ would correlate significantly with self-deception $\left(\mathrm{H}_{1,3}\right)$. Table 7.2 lists all the correlations between the $\mathrm{D} 2 \mathrm{Q}$ variables and the within-subjects correlations. The correlation between indSDR $R_{i}$ and $\mathrm{D} 2 \mathrm{Q}$ impression management is 0.272 . The correlation between indPDR $i$ and $\mathrm{D} 2 \mathrm{Q}$ selfdeception is 0.120 . Both correlations deviate statistically significant from zero (respectively, $\mathrm{t}=5.996 ; \mathrm{df}=450 ; \mathrm{p}<0.05 ;$ and $\mathrm{t}=2.564 ; \mathrm{df}=450 ; \mathrm{p}<0.05$ ). ${ }^{5}$

Table 7.2: Correlations of the D2Q and the within-subjects correlations

\begin{tabular}{|c|c|c|c|c|c|c|c|}
\hline & $\mathrm{IM}_{i}$ & $\mathrm{DC}_{i}$ & TjoaSDR $_{i}$ & popSDR $_{i}$ & popPDR $_{i}$ & indSDR $R_{i}$ & indPDR $_{i}$ \\
\hline $\mathrm{IM}_{i}$ & $\overline{017}$ & & & & & & \\
\hline TjoaSDR $_{i}$ & $\begin{array}{l}0.216 \\
0.347\end{array}$ & $-0 . \overline{023}$ & . & & & & \\
\hline popSDR $_{i}$ & 0.345 & -0.043 & 0.901 & - & & & \\
\hline popPDR $_{i}$ & 0.282 & 0.010 & 0.767 & 0.828 & - & & \\
\hline indSDR ${ }_{i}$ & 0.272 & 0.043 & 0.642 & 0.707 & 0.630 & - & \\
\hline indPDR $R_{i}$ & 0.204 & 0.120 & 0.476 & 0.485 & 0.593 & 0.534 & - \\
\hline
\end{tabular}

Note. $n=452$; in three subjects the within-subjects correlations could not be computed due to a lack of variance in the EPPS responses to the 30 item subset that corresponds with the completed EPPS-SPD version. Absolute correlations $>0.092$ deviate statistically significantly from zero $(p<0.05)$.

5 The degrees of freedom is 450 , instead of the expected $455-2=453$, because in three subjects the within-subjects correlations could not be computed due to a lack of variance in the EPPS responses to the 30 item subset that corresponded with the completed EPPS-SPD version. 
The correlations of indSDR $R_{i}$ with $\mathrm{D} 2 \mathrm{Q}$ impression management and ind$P D R_{i}$ with $\mathrm{D} 2 \mathrm{Q}$ self-deception are both in accordance with the hypotheses. Yet, in both relations the effect is much smaller than anticipated. Three reasons may account for the low correlations found. First, the D2Q may not be a valid measure of impression management and self-deception. Second, the student sample may hardly exhibit a tendency to respond in a social desirable fashion. And third, the degree of correspondence between desirability ratings and endorsements may not be due to social desirability only.

To support the validity of at least the $\mathrm{D} 2 \mathrm{Q}$ impression management variable, the correlation of stimulus susceptibility to impression management and self-deception with mean social and personal desirability ratings were established across the 239 stimuli. First, the within-stimulus partial correlations were computed by regressing the stimulus z-scores either onto the $\mathrm{D} 2 \mathrm{Q}$ impression management $z$-score $\left(\beta_{I M, j}\right)$ or the D2Q self-deception z-score $\left(\beta_{D C, j}\right)$, after first entering the relevant variable z-score into the regression equations (see Formula 7.2). It was subsequently predicted that $\beta_{I M, j}$ would correlate highly with both the stimulus mean social desirability ratings $\left(\mathrm{H}_{1,4}\right)$ and the stimulus mean personal desirability ratings $\left(\mathrm{H}_{1,5}\right)$. On the other hand, $\beta_{D C, j}$ was expected not to correlate with the mean social desirability ratings $\left(\mathrm{H}_{0,6}\right)$, nor with the mean personal desirability ratings $\left(\mathrm{H}_{0,7}\right)$.

Table 7.3: The distribution of the stimulus standardized regression weights

\begin{tabular}{lrrrrrrrrr}
\hline & mean & \multicolumn{1}{c}{$\mathbf{S}$} & \multicolumn{2}{c}{ skewness kurtosis } & \multicolumn{1}{c}{ min } & \multicolumn{1}{c}{$\mathbf{Q}_{\mathbf{1}}$} & median & \multicolumn{1}{c}{$\mathbf{Q}_{\mathbf{3}}$} & max \\
\hline$\beta_{X-x, j}$ & 0.522 & 0.136 & -0.494 & 0.250 & 0.018 & 0.438 & 0.535 & 0.620 & 0.783 \\
$\beta_{I M, j}$ & 0.001 & 0.090 & -0.528 & 0.395 & -0.326 & -0.056 & 0.010 & 0.064 & 0.202 \\
\hline$\beta_{X-x, j}^{\prime}$ & 0.521 & 0.137 & -0.538 & 0.362 & 0.008 & 0.429 & 0.539 & 0.621 & 0.789 \\
$\beta_{D C, j}$ & -0.012 & 0.089 & 0.004 & 2.318 & -0.352 & -0.063 & -0.015 & 0.041 & 0.374 \\
\hline
\end{tabular}

Note. $n=239$ stimuli; $S:$ standard deviation; $Q_{1}$ : first quartile; $Q_{3}:$ third quartile; $\beta_{X-x, j}$ and $\beta_{X-x, j}^{\prime}$ are the standardized regression weights of stimulus $j$ on the represented variable score minus the score of stimulus $j ; \beta_{I M, j}$ is the standardized regression weight of stimulus $j$ on the $\mathrm{D} 2 \mathrm{Q}$ impression management variable; $\beta_{D C, j}$ is the standardized regression weight of stimulus $j$ on the D2Q self-deception variable.

Table 7.3 shows the distribution of the stimulus standardized regression weights on the variable score without the subject response on the regression stimulus, the $\mathrm{D} 2 \mathrm{Q}$ impression management, and the $\mathrm{D} 2 \mathrm{Q}$ self-deception variable. The content relevant regression weights of the 239 stimuli on the variable score without the index stimulus range from 0.018 to 0.783 (mean: $0.522 ; S: 0.136$ ) with impression management as second regression variable. The squared beta weights revealed that the variable explained on average $29.1 \%$ of the variance of the stimulus responses with the regression including impression management (median: $28.7 \%$, min: $0.0 \%$, max: $61.3 \%$ ). With self-deception as second variable these regression weights range from 0.008 to 0.789 (mean: $0.521 ; S: 0.137$ ). Now the 
content relevant variable explained on average $29.0 \%$ of the variance of the stimulus responses (median: $29.0 \%$, min: 0.0\%, max: $62.3 \%$ ). The two content relevant beta weights differ most in the skewness and kurtosis of both distributions. The two beta weights correlate by 0.978 , so they are practically identical $(95.6 \% \mathrm{com}$ mon variance). The minima of 0.018 and 0.008 indicate that not all stimuli fit the attributed variable well. The first quartile implies however that $75 \%$ of the stimuli correlate at least by 0.438 and 0.429 , respectively, with the attributed scale. In addition, the standard deviations ( 0.136 and 0.137 , respectively) suggest that these minima are really an exception. So, all in all, the regression on the variables can be considered to partial out the content relevant stimulus variance satisfactorily.

The beta weights on the $\mathrm{D} 2 \mathrm{Q}$ impression management variable range from -0.326 to 0.202 (mean: $0.001 ; S: 0.090$ ). The beta weights on the D2Q selfdeception variable range from -0.352 to 0.374 (mean: $-0.012 ; S: 0.089$ ). Impression management or self-deception itself just explained an additional $0.6 \%$ variance on average (for impression management median: $0.3 \%, \min : 0.0 \%$, max: $9.6 \%$; for self-deception median: $0.2 \%$, min: $0.0 \%$, max: $12.6 \%$ ). Considering some exceptionally high beta weights, a few isolated stimuli seemed to fit a social desirability questionnaire better than a personality questionnaire. Nevertheless, the influence of the social desirability response set itself at the stimulus level was almost negligible.

Table 7.4: Correlations of endorsements, desirability ratings, and beta weights

\begin{tabular}{lcccccc}
\hline & $\bar{x}_{j}$ & $\overline{S D}_{j}$ & $\overline{P D}_{j}$ & $\overline{T j o a S D}_{j}$ & $\beta_{I M, j}$ & $\beta_{D C, j}$ \\
\hline$\overline{\bar{x}}_{j}$ & - & & & & & \\
$\overline{S D}_{j}$ & 0.661 & - & & & & \\
$\overline{P D}_{j}$ & 0.909 & 0.806 & - & & & \\
$\overline{T j j o a S D}_{j}$ & 0.621 & 0.859 & 0.759 & - & & \\
$\beta_{I M, j}$ & 0.393 & 0.596 & 0.552 & 0.549 & - & - \\
$\beta_{D C, j}$ & -0.216 & -0.013 & -0.045 & 0.016 & 0.248 & - \\
\hline
\end{tabular}

Note. $n=239$ stimuli, except for the correlations with $\bar{T}_{j o a S D}$, which are based on the 224 common stimuli; $\bar{x}_{j}$ are the stimulus mean endorsements, $\overline{S D}_{j}$ are the mean social desirability ratings, $\overline{P D}_{j}$ are the mean stimulus personal desirability ratings, $\overline{T j o a S D}_{j}$ are the mean stimulus social desirability ratings as reported by Tjoa (1973), $\beta_{I M, j}$ are the standardized stimulus regression weights of impression management on stimulus endorsement, $\beta_{D C, j}$ are the standardized stimulus regression weights of self-deception on stimulus endorsement. Absolute correlations $>0.126$ deviate statistically significantly from zero $(p<0.05)$.

Table 7.4 depicts the correlation matrix of the mean endorsements, the mean social desirability ratings, the mean personal desirability ratings, and the standardized regression weights of impression management and self-deception all obtained over the 239 stimuli. Clearly the mean endorsements highly correlate with the mean personal desirability ratings $(r=0.909)$ and to a somewhat lesser extent with the mean social desirability ratings $(r=0.661)$, and even less 
with the beta weights of impression management $(r=0.393)$ and self-deception $(r=-0.216)$. Note also the relatively high correlation between the mean social desirability and mean personal desirability ratings $(r=0.806)$. In light of the hypotheses the most important finding is, however, that the mean social desirability ratings correlate considerably with the beta weights of impression management $(r=0.596)$, but not with the beta weights of self-deception $(r=-0.013)$. As predicted the mean personal desirability ratings also correlate noticeably with the beta weights of impression management $(r=0.552)$, but not with the beta weights of self-deception $(r=-0.045)$.

Remember that the found correlation between indSDR $R_{i}$ and $I M_{i}(r=$ $0.272)$ and indPDR $R_{i}$ and $D C_{i}(r=0.120)$, although statistically significant, were both rather low. Three explanations were forwarded: the D2Q may not be valid, the students may hardly employ a social desirability response set, and the degree of correspondence between desirability ratings and endorsements may not be entirely due to social desirability. The low standardized regression weights appear more to indicate that the students hardly exhibited a tendency to respond in a social desirable fashion. Moreover, the substantial correlations of $\beta_{I M, j}$ with the mean social desirability ratings and the mean personal desirability ratings attest to the validity of the $\mathrm{D} 2 \mathrm{Q}$ impression management variable. This approach however cannot support the validity of the $\mathrm{D} 2 \mathrm{Q}$ self-deception variable. The remaining question, whether the within-subjects correlations represent other variance as well, is the focus of the next sections.

\subsubsection{Individual differences in the stimulus desirability ratings}

If respondent differences in the ratings of stimulus social and personal desirability do matter, it would predict that subjects who aim to depict themselves favourably will respond more in agreement with the own desirability ratings, than with the population average desirability ratings. The hypotheses regarding the individual differences in social desirability therefore predict that within-subjects correla-

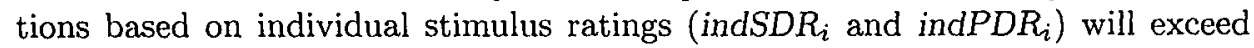
those using mean stimulus ratings (popSDR $R_{i}$ and popPDR $; \mathrm{H}_{1,8}$ and $\mathrm{H}_{1,9}$ respectively). Also within-subjects correlations using personal desirability ratings (ind$P D R_{i}$ and popPDR s $_{i}$ will exceed those using social desirability ratings (indSDR and popSDR $\left.R_{i}\right)\left(\mathrm{H}_{1,10}, \mathrm{H}_{1,11}\right.$, and $\left.\mathrm{H}_{1,12}\right)$. Consequently, indPDR $R_{i}$ will be highest and popSDR $R_{i}$ lowest. The relation between popPDR $R_{i}$ and indSDR $R_{i}$ was left open.

Table 7.5 lists the sample statistics of the within-subjects correlations between the stimulus endorsements and social or personal desirability ratings. In all ten possible comparisons the differences are statistically significant. The associated Sign and Wilcoxon statistics are listed in Table A.7.2 and the effect sizes of the differences in Table A.7.3 (see Appendix A.7.2). The most important result is that the mean indSDR $i$ is not larger than the mean popSDR $R_{i}$, but instead lower (ES: -0.218). The size of the effect demonstrates that the difference between popSDR $i$ and indSDR $i$ constitutes a small effect. The negative direc- 
tion evidences that the individual social desirability ratings predict the stimulus endorsements less well than the population mean social desirability ratings.

Still, conform the hypothesis, the mean indPDR $R_{i}$ does exceed the mean

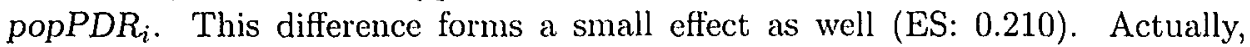
the large differences between indPDR $R_{i}$ and $p_{0 p S D R_{i}}$ (ES: 0.795), indPDR $R_{i}$ and indSDR $R_{i}$ (ES: 0.977), and popPDR $R_{i}$ and popSDR $R_{i}$ (ES: 0.629) make it quite clear that the respondent tends to respond more in agreement with the characteristics that are deemed personally desirable than by society as a whole. Interestingly, it does not matter much whether the individual desirability ratings or the mean desirability ratings are used. The large difference between popPDR $R_{i}$ and $p o p S D R_{i}$ in particular more or less implies that the subjects consider the stimuli personally desirable in rather the same way. If people disagree more in what they consider personally desirable then popPDR $R_{i}$ should have come more close to popSDR $R_{i}$. Because the agreement in personally desirable characteristics may be thought to reflect what is socially desirable by the group. So in a sense the lack of individual differences in social desirability could be attributed to the homogeneity of the research sample.

This conclusion might, nevertheless, be premature. It may well be that the large difference between $p o p P D R_{i}$ and $p o p S D R_{i}$ is characteristic for the whole population, and not just attributable to the homogeneity of the research sample. The assertion that everybody wants the same is not that outrageous. And then the large difference between popPDR $R_{i}$ and $p o p S D R_{i}$ is characteristic for the whole population, and not just due to the homogeneity of the research sample.

More interestingly, however, is the finding that $T$ joaSDR $i$ almost equals popSDR (ES: -0.107), and is slightly above indSDR $R_{i}$ (ES: 0.118 ). That puts the statistically significant difference in mismatch ES between the present stimulus mean social desirability ratings and those obtained by Tjoa in a whole new perspective. Obviously, one responded a little more in agreement with a view on social desirability from thirty years ago than the own conception on social desirability. A subject today seems more erroneous in correctly identifying the social desirability of a stimulus than the error that is caused by changes in social desirability over a thirty year period. Or the Tjoa ratings happen to match the current endorsements quite well, by coincidence. In the next section this issue will be reconsidered.

\subsubsection{Individual differences in the achieved matching accuracy}

The previous results did not agree with the hypothesized individual differences in social desirability ratings. The results do indicate, however, a slight influence of individual differences in the personal desirability ratings. Nevertheless, the within-stimulus correlations between the stimulus endorsements and the stimulus social $\left(\mathrm{H}_{1,13}\right)$ or personal desirability ratings $\left(\mathrm{H}_{1,14}\right)$ are still expected to correlate positively. In addition, the within-stimulus correlations of the stimulus endorsements with the personal desirability ratings are thought to exceed the 
Table 7.5: Sample statistics of the within-subjects correlations

\begin{tabular}{|c|c|c|c|c|c|c|c|c|c|}
\hline & mean & $S$ & skewness & kurtosis & $\min$ & $Q_{1}$ & median & Q3 & $\max$ \\
\hline $\operatorname{popSDR}_{i}$ & 0.379 & 0.235 & -0.452 & -0.125 & -0.308 & 0.219 & 0.402 & 0.553 & 0.863 \\
\hline indSDR $_{i}$ & 0.325 & 0.257 & -0.427 & -0.293 & -0.418 & 0.160 & 0.350 & 0.517 & 0.867 \\
\hline popPDR $_{i}$ & 0.521 & 0.214 & -0.860 & 0.786 & -0.319 & 0.405 & 0.559 & 0.671 & 0.897 \\
\hline indPDR ${ }_{i}$ & 0.568 & 0.241 & -1.138 & 1.294 & -0.400 & 0.454 & 0.630 & 0.743 & 0.953 \\
\hline TjoaSDR & 0.354 & 0.233 & -0.335 & -0.231 & -0.300 & 0.188 & 0.369 & 0.526 & 0.842 \\
\hline
\end{tabular}

Note. $n=452$; in three subjects the within-subjects correlations could not be computed due to a lack of variance in the EPPS responses to the 30 item subset that corresponds with the completed EPPS-SPD version; $S$ : standard deviation; $\mathrm{Q}_{1}$ : first quartile; $\mathrm{Q}_{3}$ : third quartile.

within-stimulus correlations of the stimulus endorsements with the social desirability ratings $\left(\mathrm{H}_{1,15}\right)$.

Table 7.6 shows that on a total of 239 stimuli the stimulus endorsements and stimulus social desirability ratings correlate on average by 0.165 (median: $0.184)$. In 53 stimuli $(22.2 \%)$ the correlation is negative and in $186(77.8 \%)$ positive. Hence, the median is statistically significant above zero (Sign $\mathrm{Z}=-8.538$, $\mathrm{p}<0.05$; Wilcoxon $\mathrm{Z}=-10.498, \mathrm{p}<0.05$ ). The stimulus endorsements correlate with the personal desirability ratings on average by 0.447 (median: 0.468 ). This correlation is negative in 3 stimuli (1.3\%) and positive in 236 stimuli (98.7\%). Naturally, this median also exceeds zero (Sign $Z=-15.007, p<0.05$; Wilcoxon $Z=-13.382, p<0.05)$. Conform the hypothesis in the majority of stimuli, 213 $(89 \%)$ to be exact, the within-stimulus correlation of the stimulus endorsements with the personal desirability ratings is greater than the within-stimulus correlation of the stimulus endorsements with the social desirability ratings (Sign Z $=-12.031, \mathrm{p}<0.05$; Wilcoxon $\mathrm{Z}=-12.461, \mathrm{p}<0.05$ ). So, in the majority of the stimuli the endorsement correlates positively with the desirability rating and the correlation with the personal desirability rating primarily exceeds the correlation with the social desirability rating.

Table 7.6: Polychoric correlations between endorsement and desirability

\begin{tabular}{llllllllll}
\hline & mean & $\mathbf{S}$ & skewness kurtosis & $\min$ & $\mathbf{Q}_{1}$ & median & $\mathbf{Q}_{3}$ & max \\
\hline$r_{j}\left(x_{i j}, S D_{i j}\right)$ & 0.165 & 0.182 & -0.269 & -0.581 & -0.331 & 0.029 & 0.184 & 0.299 & 0.551 \\
$r_{j}\left(x_{i j}, P D_{i j}\right)$ & 0.447 & 0.177 & -0.511 & 0.206 & -0.173 & 0.327 & 0.468 & 0.575 & 0.851 \\
\hline
\end{tabular}

Note. $n=239$ stimuli; $S$ : standard deviation; $Q_{1}$ : first quartile; $\mathrm{Q}_{3}$ : third quartile.

Faced with these correlations the key question is the classic directionality dilemma. Do the desirability ratings affect the endorsements? In that case the endorsements simply reflect a social desirability response set. Or do the endorsements, on the other hand, affect the desirability ratings? Then the individual differences in the desirability ratings are in fact guided by the individual trait differences. This question will be decided upon by considering the last hypotheses. 
If the endorsements reffect a social desirability response set, the within-subjects correlations based on the own desirability ratings (indSDR $i$ and indPDR, ) should correlate stronger with impression management than the within-subjects correlations based on the mean desirability ratings (popSDR $i$ and popPDR $; \mathrm{H}_{1,16}$ and $\mathrm{H}_{1,17}$, respectively). The final hypothesis puts the longitudinal stability of matching stimuli for social desirability to the test. The within-subjects correlations based on the current mean desirability ratings (popSDR $R_{i}$ ) is expected to correlate stronger with impression management than those reported by Tjoa (TjoaSDR $; \mathrm{H}_{1,18}$ ).

Table 7.2 showed that the correlation of indSDR $R_{i}$ with impression management $(r=0.272)$ does not exceed that of popSDR $R_{i}$ with impression management $(r=0.345)$. Two-tailed testing reveals in fact the opposite to be statistically significant $(Z=-2.081 ; \mathrm{p}<0.05)$. The correlation between indPDR $R_{i}$ and impression management $(r=0.204)$ is not larger than that between popPDR and impression management $(r=0.282)$ either. However, now two-tailed testing does not demonstrate the opposite to be statistically significant $(\mathrm{Z}=-1.901$; $\mathrm{p}>0.05)$.

Although both correlations do not deviate statistically significantly from zero, the correlation of indSDR $R_{i}$ with self-deception $(r=0.043)$ is significantly larger than that of popSDR $R_{i}$ with self-deception $(r=-0.043),(\mathrm{Z}=2.329 ; \mathrm{p}<$ $0.05)$. The correlation between popPDR, and self-deception $(r=0.010)$ does not deviate statistically significantly from zero either, but is significantly lower than that between indPDR $R_{i}$ and self-deception $(r=0.120),(Z=2.584 ; p<0.05)$.

Notice also that $T$ joaSDR $R_{i}$ correlates remarkably high with popSDR $(r=0.901)$. Two-tailed tests show that the correlation of TjoaSDR $R_{i}$ with impression management $(r=0.347)$ does not deviate statistically significantly from the correlation of popSDR $R_{i}$ with impression management $(r=0.345)$, $(\mathrm{Z}=-0.104 ; \mathrm{p}>0.05)$. Neither does the correlation between TjoaSDR $R_{i}$ and self-deception $(r=-0.023)$ diverge statistically significantly from the correlation between popSDR $R_{i}$ and self-deception $(r=-0.043),(\mathrm{Z}=-0.945 ; \mathrm{p}>0.05)$.

All the relevant correlations from Table 7.2 are summarized in Figure 7.2. The first column depicts the correlations of $T$ joaSDR $i$ with the $D 2 Q$ impression management variable (diamond) and the D2Q self-deception variable (circle). And the next two columns represent the change in correlation between the population mean desirability ratings and the individual desirability ratings.

Contrary to the hypotheses, ind $S D R_{i}$ correlates significantly less with $\mathrm{D} 2 \mathrm{Q}$ impression management than popSDR $i$ does (diamonds connected by a solid line). Although not statistically significant, that same trend is evidenced by a decline in the correlation of indPDR $i$ with $\mathrm{D} 2 \mathrm{Q}$ impression management as compared to popPDR $_{i}$ (diamonds connected by a dashed line). The effect on social desirability is deemed more important than on personal desirability. After all, impression management is conceptually regarded more closely associated with social desirability than personal desirability. Still, the correlations with D2Q impression management decline if the individual social desirability ratings are used instead 
Figure 7.2: Correlations of within-subjects correlations with $D 2 Q$ variables

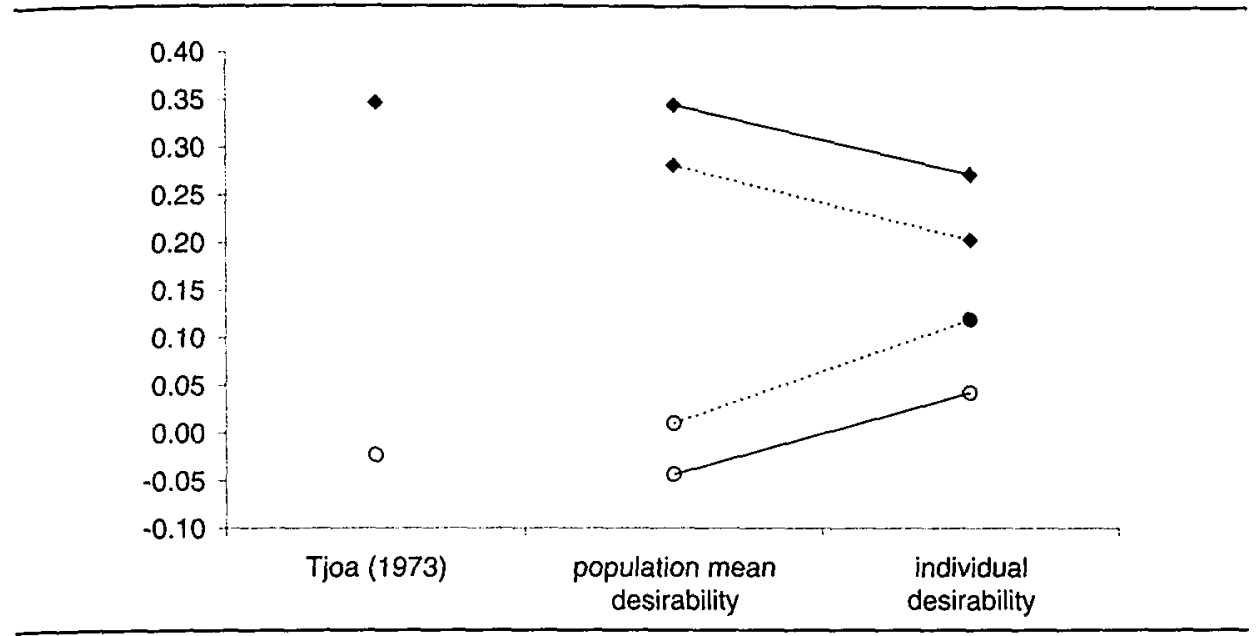

Note. $n=452$ subjects; in three subjects the within-subjects correlations could not be computed due to a lack of variance in the EPPS responses to the 30 item subset that corresponds with the completed EPPS-SPD version. The open markers represent correlations that do not significantly deviate from zero $(p>0.05)$.

- D2Q impression management $\left(I M_{i}\right) \quad \longrightarrow$ social desirability ratings $\left(S D R_{i}\right)$

-/० D2Q self-deception $\left(D C_{i}\right)$ personal desirability ratings $\left(P D R_{i}\right)$

of the population social desirability ratings. It suggests that the increased correspondence between endorsements and the own social desirability ratings does not reflect impression management. So, it appears that the individual differences in stimulus desirability do not cause a divergence in endorsements. Then the correspondence between endorsements and the own social desirability ratings should have correlated more strongly with $\mathrm{D} 2 \mathrm{Q}$ impression management. Apparently, the individual trait differences affect the diversity in stimulus desirability ratings. This causes the witnessed drop in the correlations with D2Q impression management.

The figure also illustrates that the correlation of indPDR $R_{i}$ with $D 2 Q$ selfdeception is increased as compared to the correlation of popPDR $i$ with D2Q self-deception (circles connected by a dashed line). The same effect is found between the correlation of indSDR $R_{i}$ with $\mathrm{D} 2 \mathrm{Q}$ self-deception and popSDR $R_{i}$ with $\mathrm{D} 2 \mathrm{Q}$ self-deception (circles connected by a solid line). The effect on personal desirability is considered more important, because self-deception is interpreted as a tendency to respond more in agreement with the own wished-for characteristics. And these do not necessarily match the average wished-for characteristics. That discrepancy is actually regarded to result in the increase in correlation between indPDR $R_{i}$ and $\mathrm{D} 2 \mathrm{Q}$ self-deception. The increased correlation of indSDR $R_{i}$ with $\mathrm{D} 2 \mathrm{Q}$ self-deception is taken to indicate that a subject's social desirability ratings 
are actually biased by what the subject regards to be desirable for him or herself.

Finally, it is evident that the correlations of TjoaSDR, with $\mathrm{D} 2 \mathrm{Q}$ impression management and self-deception do not differ from the correlations of popSDR with these variables. With the current modest levels of social desirable responding in mind this result does therefore suggest that for a comparable kind of use the social standards have not changed that much to necessitate a revision of the stimulus pairings. However, should the questionnaire be subject to more extreme social desirable response behaviour, the matching may still prove insufficient.

\subsection{Discussion}

\subsubsection{Order effects}

The subjects were required to rate both the social and personal desirability of the stimuli. So any influence by the sheer order of the ratings is well possible. Yet, the Hotellings $\mathrm{T}^{2}$ tests indicated that the order did not statistically significantly affect the ratings (see Table A.7.1 in Appendix A.7.1). So, the absence of any order effects allows an unrestricted interpretation of the results.

\subsubsection{The effect of longitudinal changes in social desirability}

Over three decades the matching accuracy of the stimuli was expected to have deteriorated. The matching accuracy according to the current desirability ratings was compared with that obtained by Tjoa (1973). The comparison indeed revealed a statistically and empirically significant increase in social desirability mismatch at the item level (see Table 7.1). Still, at the respondent level no significant difference emerged. Conformity to the Tjoa desirability ratings (TjoaSDR $R_{i}$ ) evidenced impression management in an equal extent as conformity to the current desirability ratings (popSDR $R_{i}$; see Table 7.2). Figure 7.2 also illustrated that the current social desirability ratings correlate equally with impression management as those obtained by Tjoa. It therefore implies that the mismatch of the stimuli has increased, whereas the correspondence with Tjoa's or the current desirability ratings, indicate impression management in an equal extent. How to reconcile these apparently conflicting results?

These results suggest that the significant increase in social desirability mismatch at the item level, is negligible at the respondent level. Remember that a social desirability mismatch was established as a difference between the population mean social desirability ratings. Although significant at the population level, this same difference may well remain unnoticed by an individual respondent aiming to depict himself more favourably. After all, the study results evidenced a divergence between the individual stimulus social desirability ratings and the population mean stimulus social desirability ratings. It demonstrated that respondents differ in their perception of social desirability. So, the enhanced social desirability mismatches may well remain within the error margins of a respon- 
dent's own social desirability ratings. An update of the stimulus social desirability ratings seems therefore uncalled for.

The current desirability ratings and those obtained by Tjoa (1973) equally indicated social desirable responding at the individual level. This came actually as a surprise. A much larger difference was anticipated. First and most importantly Tjoa failed to cross-validate the desirability ratings after he had paired the stimuli. So clearly, the social desirability mismatch based on the Tjoa ratings must be regarded too optimistic as the matching process capitalizes on chance fluctuations. Secondly, Tjoa employed a 3-point Likert scale, whereas the current study adopted a 5-point Likert scale. Thirdly, the subject samples as well as the testing settings diverged widely. Tjoa used a sample of 150 subjects with a schooling level of at least advanced primary education. The majority were men (89\%). And the social desirability ratings were collected within a job selection or vocational guidance setting. It contrasts sharply with the current data that were obtained in a sample of college students. The majority of whom were women (72\%). And the testing sessions were part of an introductory psychology course. So, apart from any changes in time, the found discrepancies in social desirability at the stimulus level might be attributed to chance capitalization, rating scale differences, and a disparity in the research population and testing setting.

\subsubsection{The multidimensional interpretation of social desirability}

The endorsement of stimuli conform the social desirability ratings (indSDR ) was regarded to reflect impression management, whereas the endorsement of stimuli in correspondence with the personal desirability ratings (indPDR $R_{i}$ ) was thought to evidence self-deception. The correlations were statistically significant, but much lower than anticipated. In addition, conformity to the social desirability ratings did not correlate with self-deception. Conformity to the personal desirability ratings, however, correlated with both self-deception and impression management.

The low correlations notwithstanding, the results indicate that the distinction between the social desirability ratings and personal desirability ratings by Rosen (1956) fits in part the multidimensional interpretation of social desirability as suggested by Paulhus (1984). The agreement between the own stimulus endorsements and the own social desirability ratings evidences impression management. Correspondence between the own stimulus endorsements and the own personal desirability ratings reflects self-deception, but for a large part impression management as well. Not surprisingly, it seems that the subject regards personally desirable what is to a large extent socially desirable. Hence, conformity to social desirability ratings reveals impression management and conformity to personal desirability ratings demonstrates both impression management and self-deception.

The low correlations might be attributed to a lack of validity of the $\mathrm{D} 2 \mathrm{Q}$. To secure the validity of the $\mathrm{D} 2 \mathrm{Q}$, the partial correlations of the stimuli to either impression management or self-deception were established by a linear regression 
approach, resulting in beta weights (see Formula 7.2). In turn, these beta weights were correlated with the population mean stimulus social and personal desirability ratings as well as the population mean stimulus desirability ratings provided by Tjoa (1973). The correlations between the stimulus beta weights of impression management and the population mean stimulus ratings of social desirability, personal desirability, and those of T.joa attested to the validity of the D2Q impression management variable (see also Table 7.4). The correlation coefficients with the stimulus beta weights self-deception variable did not deviate statistically significantly from zero. This result was anticipated. The approach was not capable of establishing the validity of the $\mathrm{D} 2 \mathrm{Q}$ self-cleception variable. The beta weights were obtained by averaging over the subject population. So, the stimulus selfdeception beta weight indicates the extent in which endorsement of the stimulus reflects self-deception in the population. But for one individual agreeing with the stimulus could have been self-deceptive, whereas for another subject disagreeing with the stimulus might have been self-deceptive. The beta weight indicates the population mean influence of self-deception on stimulus endorsement. As a result the beta weight cannot be taken to be an index of self-deception for this must be considered subject specific. Nevertheless, the found correlations with the stimulus beta weights of impression management support the validity of the D2Q impression management variable.

The stimulus beta weights also provided the explanation for the low correlations between the indices of agreement between endorsement and desirability ratings (indSDR $R_{i}$ and indPDR ) and the $\mathrm{D} 2 \mathrm{Q}$ variables impression management and self-deception. The cause for the low correlations was the little impact of a social desirability response set at all. The squared beta weights revealed that the social desirability response set only contributed sparingly to the stimulus response variance. In other words, neither impression management nor self-deception appear to have played a major role in these data.

That is quite understandable. In the first place the respondents were fairly anonymous, because they made use of a separate test ID number. And although the identity was registered centrally, the researcher had no access to this data. In the second place the respondents had nothing at stake. They were not judged, nor were credits to be gained by responding in a socially accepted way or otherwise. Consequently, there was no behavioural incentive to respond in a social desirable way.

\subsubsection{Individual differences in the stimulus desirability ratings}

In case individual differences in the ratings of social desirability exist, subjects should be expected to endorse stimuli more in correspondence with the own desirability ratings than the population mean desirability ratings. Also conformity to the personal desirability ratings would exceed the conformity to the social desirability ratings. The finding, however, that popSDR (mean: 0.379 ) exceeds indSDR $R_{i}$ (mean: 0.325) in most subjects is diametrically opposite to this hy- 
pothesis. The result indicates that subjects respond more in agreement with the population mean social desirability ratings than with their own social desirability ratings. It actually supports the earlier presented additional analysis of the results presented by Orvik (1972). With respect to the personal desirability ratings the results evidenced the existence of individual differences. This result therefore indicates that although subjects differ in their personal desirability ratings, they agree in their social desirability ratings.

A likely cause for not finding individual differences in the social desirability ratings is the relative increase of error in the individual social desirability profiles. The variable popSDR is a within-subjects correlation based on the stimulus social desirability ratings averaged over 51 to 63 subjects. So, the error in the mean social desirability profile is exceedingly low. In indSDR $R_{i}$ the stimulus social desirability ratings are just based on one measurement. Consequently, the error must be relatively large. A repeated measurements approach could reduce the error in the individual social desirability ratings. Although repeating the social desirability about 50 times is unrealistic, three times is feasible and may already yield the anticipated result that indSDR $R_{i}$ exceeds $p o p S D R_{i}$. Still, the current results do not necessitate the conclusion that individuals are importantly affected in their responses by their own social desirability ratings.

\subsubsection{Individual differences in the achieved matching accuracy}

A tangible influence of individual differences in social desirability ratings failed to emerge. Hence, the alleged individual differences in the achieved matching accuracy may well prove an idée fixe. Does that leave the ensuing investigation irrelevant? Not at all. Both Scott (1963) and Tjoa (1973) demonstrated the primarily positive within-stimulus correlations between stimulus endorsement and stimulus desirability rating. It prompted Scott (1963) to formulate the directionality problem: Does the social desirability rating raise the endorsement or endorsement raise the social desirability rating? It has a direct bearing on the returning issue whether social desirable responding represents true score variance instead of a response bias. Consequently, this finding alone deserves further explanation.

Like Scott (1963) and Tjoa (1973) the current results also showed positive polychoric correlations with either social desirability or personal desirability in the majority of stimuli. The positive correlations between stimulus endorsement and social desirability rating were not that prevalent in the current results as was hoped for. Scott reported positive correlations in all stimuli, although his results were limited to a subset of just 30 EPPS stimuli. Tjoa did hit upon negative correlations, but merely in 3 out of 209 stimuli $(1.4 \%)$ in the applicant group, and 8 out of 210 stimuli (3.8\%) in the counselling group. The current finding that 53 out of 239 stimuli (22.2\%) correlate negatively does imply that the stimulus social desirability enhances the stimulus endorsement instead of the opposite. After all, the current investigation lacks an incentive to respond in a social desirable 
fashion. So, the increase in the number of stimuli with a negative correlation fits the interpretation that the reduced social demands to depict oneself favourably elicits responses that are less in agreenent with the individually perceived social desirability.

A more conclusive answer to the directionality problem was offered by relating impression management to the conformity between stimulus endorsement and desirability rating. If the endorsements reflect a social desirability response set, the within-subjects correlations based on the own desirability ratings (indSDR; and indPDR $R_{i}$ ) should correlate stronger with impression management than the within-subjects correlations based on the mean desirability ratings ( $p O p S D R_{i}$ and popPDR ${ }_{i}$ ). This anticipated increase in correlation of impression management with the conformity indices that use individual desirability ratings instead of population mean desirability ratings, was not found. With the social desirability ratings even the opposite effect was statistically significant. (See also the negative slopes of the lines that comnect the diamonds in Figure 7.2.) So, conformity to the own desirability ratings evidences impression management in a lesser extent than conformity to the population mean desirability ratings. This result favours the explanation that the individual trait position influences the desirability ratings of its representing stimuli. The view that the individual desirability ratings guide the stimulus endorsements is not supported.

Note that this explanation is in agreement with the results of Heilbrun and Goodstein (1961). They constructed individualized matched compound item questionnaires, i.e. tailored to the respondent by using each subject's own social desirability ratings. They found that this procedure in fact reduced validity. This is quite understandable if the own desirability ratings are affected by the own trait positions.

That interpretation may even be elaborated on by a closer inspection of Figure 7.2. It shows that the reductions in the correlations with impression management were paired with increases in the correlations with self-deception. Hence, endorsement conform the own social desirability ratings increasingly reflects selfdeception, instead of impression management. Generally, the control for the social desirability response set is exclusively aimed at eliminating the effect of impression management. Self-deception invites the respondent to misrepresent oneself in accordance with a score profile that is respondent specific. That is exactly why self-deception is incorrigible.

In conclusion, the study suggests that the incapacity of the matched compound item to control for individual differences in the social desirability ratings is a blessing rather than a curse. The deviations of the own social desirability ratings from the population mean social desirability ratings must be regarded erroneous ascriptions of what society evaluates as desirable. The error appears to be related to the own trait position of the respondent. As Scott (1963, p. 575) noted in the opening motto: "[W]hat one does, he also tends to admire." So, the correspondence between the endorsements and the own desirability ratings seems primarily due to the fitting of individual errors in the desirability ratings by the 
individual differences in trait positions. Insofar the agreement is in fact based on desirable responding; an increasing part is attributable to self-deception, which is beyond repair.

\subsubsection{Overview}

This study started with the general idea that individual differences in the conception of what is socially desirable would not invalidate the matched compound item format. That idea has been substantiated by the results of the current study. The results suggest in the first place that over a period of thirty years the social desirability mismatch has increased in the majority of items of the Dutch EPPS. Nevertheless, stimulus endorsement conform the current mean social desirability ratings or Tjoa's mean social desirability ratings reflect in an equal extent impression management. Hence, although the social desirability ratings have changed considerably at the stimulus level, for the individual respondent the changes are negligible. In the second place, the agreement between the own endorsements and the own social desirability ratings appears to reflect primarily impression management. Conformity of the own endorsements to the own personal desirability ratings evidences both self-deception and impression management. So, the distinction by Rosen (1956) between social and personal desirability fits the two-factor model by Paulhus (1984) of impression management and self-deception.

In the third place, subjects did not tend to respond more conform the own social desirability ratings than the population mean social desirability ratings. As a result, any indication for an influence of individual differences in the ratings of social desirability is lacking. In the fourth place, responding in agreement with the population mean social desirability ratings evidences impression management in a greater extent than responding in agreement with the own social desirability ratings. Consequently, the own social desirability ratings appear less accurate judgements of the social desirability of stimuli. The agreement between the own endorsements and the own social desirability ratings seems to indicate that the error in the own social desirability ratings matches the own trait positions. Still, responding conform the own desirability ratings (both social and personal) can in part be linked to desirable responding. But it represents in an increasing extent self-deception, and that is incorrigible. 


\section{The failure to control for social desirability with the additive scoring of the matched multidimensional compound item}

[T]echniques other than the forced-choice technique will have to be devised if the problem of malingering $[. .$.$\} is to be overcome.$

(Longstaff \& Jurgensen, 1953, p. 89)

The strategy to match stimuli on the basis of population average social desirability ratings is not invalidated by individual differences in these ratings. The previous chapter in the first place established that subjects tended to respond more in agreement with the population average social desirability ratings than with the own social desirability ratings. In the second place conformity towards the population average social desirability ratings correlated stronger with impression management than conformity towards the own social desirability ratings. Conformity towards the own social desirability ratings gave in part evidence of self-deception, and in part seemed to reflect the true trait positions as in the majority of stimuli the social desirability ratings were positively correlated with the endorsements.

Besides its alleged weakness for individual differences in social desirability ratings the matching procedure has been accused of vulnerability to instability in the social desirability ratings of the stimuli. Usually, stimuli are rated for social desirability in isolation. Combining the stimuli may, however, alter their social desirability. The matching of the stimuli puts them in contrast with one or more other stimuli. This may change the meaning of the stimuli, and consequently their social desirability value. This interpretation is backed with empirical evidence. The first part of this chapter will address this issue. The second part will forward an alternative explanation for the empirical differences found. The third part will argue that as a consequence the additive scoring of the matched multidimensional compound item (matched MCI) must be regarded invalid. 


\subsection{The stability of stimulus desirability across item formats}

In the 1950s and 1960s studies appeared in which respondents wore asked to mark the most desirable stimulus in established matched MCI format questiomaires. It was hypothesized that each stimulus should be selected equally. If not, the matching was deemed insufficient. Significant deviations from uniformity were found in $67 \%$ of the items of a 30-item version of the Edwards Personal Preference Schedule (EPPS) (Corah et al., 1958) ${ }^{1}$, in $77 \%$ of the items of the Survey of Personal Values (SPV) (Braun \& Costantini, 1968) and the Trait Evaluation Index (TEI) (Braun \& Seamon, 1969), and in all the items of the Thorndike Dimensions of Temperament (TDOT) (Braum \& Tinley, 1968) and the Sclf-Descriptive Check List (SDCL) (Braun \& Tinley, 1969). The EPPS only includes dyads comparing two stimuli within an item. Both the SPV and TEI items are triads comparing three stimuli. The TDOT items comprise of ten stimuli. And lastly the SDCL items, which are only two in total, both contain 21 stimuli. The questionnaires were listed in ascending order with respect to the percentage of items in which the response distribution deviates from uniformity. This order remarkably agrees with the order based on the number of stimuli per item. Obviously, the more stimuli an item includes, the harder it becomes to match them all sufficiently.

Although these results suggest to combine stimuli economically, it does not disqualify the matched MCI format as such. It just demonstrates that the stimuli in these instruments are not adequately matched. Critics however questioned whether the stimuli in combination do retain their approximately equal social desirability status that was assessed in isolation. As Hofstee $(1967)^{2}$ noted when he used trait-descriptive adjectives as stimuli:

"[A]ny particular item will have its meaning more closely defined if contrasted with another specific item, than in a general context of many traits. So "quick" could mean anything from handy, clever, efficient, fluent, to superficial, careless, hasty, or quick-tempered; in absolute judgment, its favorability index should come out as a sort of weighted mean of all these connotations. However when "quick" is contrasted to "patient" in comparative judgment, some of its connotations like "hasty" or "impatient" should be weighted more heavily; when "quick" is contrasted to "thorough", secondary meanings like "careless" and "hasty" should be stressed." (Hofstee, 1967, pp. 29-30)

From this viewpoint refinement of the matching process would not result in a complete accommodation of the mismatch between the absolute and comparative judgements of social desirability. So Feldman and Corah (1960) constructed a new forced-choice questionnaire with the variables: Achievement, Hostility and

${ }^{1}$ Edwards, Wright, and Lunneborg (1959) replicated the study by Corah et al. (1958) incorporating the entire EPPS. Regretfully, they fail to report the actual number of items that deviated significantly from uniformity.

2 The author is indebted to professor Hofstee for bringing his investigation to his attention. 
Sex. An initial pool of 126 stimuli was administered to 100 male psychology students. They were instructed to rate the social desirability of each stimulus on a 10-point Likert scale. The stimulus ratings were rescaled by the method of successive intervals (Edwards, 1952). They managed to construct 36 item pairs by matching the stimuli with less than 0.10 scale unit difference. Thirty item pairs diverged even less than 0.05 scale unit. This result compares favourably with the EPPS in which $24 \%$ of the pairs suffered a mismatch in excess of 0.50 scale unit (Edwards, 1957, p. 60). Despite their matching success, still 19 of the 36 pairs yielded significant differences in social desirability ratings. A systematic preference for the first or second stimulus was not found, precluding an order effect in these comparisons. The 36 pairs were subdivided into three groups of 12 pairs according to absolute social desirability value. It revealed that nine differences occurred in the 12 lowest rated pairs, two in the middle group, and eight in the 12 highest rated pairs. Feldman and Corah (1960) simply interpreted this finding as evidencing that "pairs were equated relatively better for SD in the middle range than at either extreme" (p. 481). They concluded that the combined presentation of the stimuli magnifies subtle differences in desirability.

\subsection{Hofstee's investigations}

\subsubsection{Hypothesis}

Hofstee $(1966,1967,1969)$ hypothesized that the deviations from uniformity in the previously discussed studies might be caused by position and order effects in the original stimulus social desirability ratings. A position effect is operative if an item at the beginning of an inventory is responded to differently then if it is placed in the middle or at the end of the list. An order effect may become manifest as an assimilation or contrast effect. An assimilation effect involves that a stimulus is rated in a similar vein as its preceding stimulus. A contrast effect implies that a stimulus is judged more discrepant from its preceding stimulus. The matching of stimuli alters their position and order in the list. So these position and order effects might explain the divergence between the stimuli when matched.

In a preliminary study, Hofstee (1966) found an order effect: the direction of the mismatch was predictable from the desirability of the preceding stimulus. The influence of a position effect was not substantiated. So in an extensive followup study, Hofstee $(1967,1969,1970)$ set himself the task to match pairs controlling for position and order effects.

\subsubsection{Favourableness judgements of singular stimuli}

\section{Methods}

As part of a screening procedure for military duty 12674 recruits rated the favourableness of 196 trait-descriptive adjectives on a 5-point Likert scale with the an- 
chor labels: 'very good', 'good', 'neutral', 'poor', and 'very poor'. Every respondent was randomly assigned to one of 14 versions in which the position as well as the order of the adjectives was counterbalanced by rotation. The subject was instructed to judge the favourableness of each stimulus.

\section{Results}

The results clearly showed a position effect. Positive adjectives were rated less positive and negative adjectives less negative the closer they were positioned towards the end of the list. This position effect was linear. Additionally, at the very begimning and very end of the list the adjectives received an extremely favourable rating more often than in the other positions.

Hofstee $(1967,1969)$ demonstrated an order effect as well: The more positive the preceding item was judged, the more positive the item under consideration became rated. Or, the more negative the preceding item was judged, the more negative the item under consideration became rated. There was neither an influence from the second preceding adjective, nor from the first subsequent adjective.

\section{Conclusions}

Hofstee explained the position effect by hypothesizing that the respondent might tend to mix up ratings of traits and persons, oneself included. He called it the 'mixture' hypothesis (Hofstee, 1967, 1969). The order effect, i.e. assimilation effect, was quite ephemeral. He interpreted this as a very short-lived carry-over effect: "Each item seems to create an atmosphere of "goodness" or "badness", in varying degrees" (Hofstee, 1969, p. 599; see for a similar quote also Hofstee, 1967, p. 26).

\subsubsection{Favourableness choices of matched stimulus pairs}

\section{Methods}

Controlling for these position and order effects by averaging over the 14 versions Hofstee used a subset of 174 adjectives to form 406 stimulus pairs. The stimuli of each pair were matched on favourableness avoiding the coupling of near-synonyms. Twenty-five positive pairs and 26 negative pairs were combined to form a list without repeating one stimulus within a list. In the eight constructed lists ${ }^{3}$ the average differences in favourableness between the matched stimuli varied between 0.083 and 0.100 scale point ${ }^{4}$ with a standard deviation between 0.064 and 0.097 . Of every list two versions were made, reversing the stimuli within each pair and

\footnotetext{
3 Two pairs appeared on two lists

4 This is in units of the Likert-scale, which runs from 1 to 5 . Hofstee did not apply the method of successive intervals to derive a common psychological continuum (Edwards, 1952). Due to the difference in measurement unit this result is incommensurable with the matching result obtained by Edwards (1957) and Feldman and Corah (1960).
} 
the order and position of the pairs. In total 16380 new recruits were randomly assigned to one of the 16 versions and were asked to choose the more favourable stimulus.

\section{Results}

No position or order effect of the pairs was found. The location of the stimulus within each pair did however have an effect. Of the 200 positive pairs, the first stimulus was selected more often in 133 pairs; of the 206 negative pairs, the second stimulus was chosen more often in 124 pairs. In the ensuing analysis this effect was cancelled out by averaging over each two versions.

In as much as 344 pairs (85\%) the response distribution deviated significantly from uniformity. Hofstee (1967) dubbed this result the 'choice effect' (p. 38 ). These choice judgements of favourableness were compared with the single judgements of favourableness. In 166 pairs the direction of dominance agreed with a significant difference in the single judgements of favourableness, in 98 pairs the difference in the single judgements of favourableness was not significant, and in 80 pairs the difference in the single judgements in favourableness was significant but in the opposite direction.

Additionally, the choice judgements allowed to derive an overall rank order of favourableness by inference. Hofstee $(1967$, p. 36$)$ provided an example with a first degree inference:

$\begin{array}{lcr}\text { VOORZICHTIG prudent } & \succ \text { ZELFVERZEKERD self-assured } & \text { (by observation) } \\ \text { ZELFVERZEKERD self-assured } & \succ \text { HOFFELIJK courteous } & \text { (by observation) } \\ \text { VOORZICHTIG prudent } & \succ \text { HOFFELIJK courteous } & \text { (by inference) }\end{array}$

And he supplied a second degree inference by continuing:

$$
\begin{array}{llr}
\text { HOFFELIJK courteous } & \succ \text { ENTHOUSIAST enthusiastic } & \text { (by observation) } \\
\text { VOORZICHTIG prudent } & \succ \text { ENTHOUSIAST } \text { enthusiastic } & \text { (by inference) }
\end{array}
$$

These inferences carried a risk that one might hit upon a conflict between an observed and inferred preference choice of favourableness. If the favourableness rating of a stimulus would suffer from contextual influences one should indeed expect to hit upon circular triads that violate this transitivity. After all, on average Hofstee paired each stimulus with 4.6 different stimuli. From the 406 observed choice ratings a manifold of favourableness rank orders could be deduced. But not one single triad violated weak transitivity.

\section{Conclusions}

The finding that in $85 \%$ of the pairs the comparative judgements deviated from uniformity indicated that position and order effects in the favourableness judgements of singular stimuli are not responsible for the choice effect. The lack of 
any violation in transitivity brought Hofstee (1967) to three conclusions. First, the groups of subjects that responded to one of the eight different lists must have been very similar. Second, it was unlikely to hit upon genuine intransitivity in comparative judgements of stimulus favourableness. Third --- and most importantly - the differences between the single judgements and choice judgements of favourableness could not be attributed to a context effect. After all, with a context effect the favourableness of one stimulus would have differed, depending on its combination with another stimulus. Then, at least one circular triad would certainly have occurred.

Instead, Hofstee concludes the 'choice effect' to be a general effect: "[T]he act of choosing stresses other aspects of favorability than rating does" (Hofstee, 1967, p. 41). In search for an explanation, he interpreted the contents of the items that demonstrated a difference in rank order of 10 or more. Hofstee noted that a subject in a choice situation selects the more conservative or guarded stimulus, as he called it (for instance: OPRECHT sincere; DEGELIJK solid; WEIFELEND waveringi SLOOM sluggish). As opposed to expansive stimuli which excelled in absolute judgements (for instance: HANDIG handy; ENTHOUSIAST enthusiastic; GESLEPEN sly; OPDRINGERIG obtrusive). If the standard deviations in the ratings were taken to reflect item ambiguity, the less ambiguous stimulus was preferred. Regarding the forced-choice format Hofstee's final verdict is "that in the construction of forcedchoice tests, where balanced items are desired, pairs should be pretested as such" (Hofstee, 1967, p. 42).

Unknown to Hofstee, in an earlier report Norman (1963) in fact applied such an approach in the construction of the Descriptive Adjective Inventory (DAI). Unfortunately, he employed the criterion-keying construction method. Starting with an original set of 200 pairs, the attempt failed miserably. Norman hardly found items that provided a robust scoring key, irrespective of the assumed response set of the respondent.

\subsection{Supplementary analysis with the Hofstee (1967) stimuli}

So, Hofstee (1967) suggested two effects to explain for his results: a mixture effect and a choice effect. The mixture effect, or actually the mixture hypothesis as Hofstee (1967, p. 33) properly called it, assumes the respondent to mix up the favourableness of a stimulus with the applicability of a stimulus to a person, and in particular to himself. Hofstee held the mixture hypothesis to be responsible for the position effect in favourableness judgements of singular stimuli. According to this view a subject is increasingly influenced by the stimulus applicability in his or her favourableness ratings as the list continues.

Hofstee (1967) did not consider the mixture effect relevant for the choice judgements of the paired stimuli as well. At least he did not bring it up in his discussion of the origin of the choice effect. He considered the choice effect to constitute a general tendency to prefer the more conservative or less ambiguous 
alternative. He did not suggest that the choice judgements might actually reflect self judgements.

\subsubsection{Hypothesis}

The present author, however, believes this mixture hypothesis to be the exact explanation of the choice effect. When confronted with two stimuli to select the more favourable stimulus the respondent might select the more applicable stimulus instead. This effect is thought to transpire the more forcefully as the stimuli are better matched on favourableness. This alternative explanation bears relevance to the interpretation of deviations from uniformity in choice judgements of matched stimuli. Then, these deviations cannot be taken to indicate a poor matching.

The mixture hypothesis predicts that in the 344 stimulus pairs in which the choice judgements of favourableness deviated from uniformity the stimulus with the higher 'attractiveness' or the lesser 'difficulty' - as might be obtained by endorsement frequencies - should have come out as the more favourable. Regretfully, Hofstee (1967) did not tabulate the separate preference frequency distributions of these pairs. As a result, it was not possible to identify and compare the set of pairs in which the choice judgements deviated from uniformity with those that did not deviate from uniformity.

Still, Hofstee did list the favourableness rank order of the adjectives as resulted from the choice judgements and how the adjectives were paired. Because the ranking satisfied weak transitivity, it could be deduced which adjective was preferred from each pair. He also included the mean and standard deviation of the single judgement favourableness ratings. This information allowed to predict which stimulus of each pair should have been preferred on the basis of the single favourableness judgements. Remember that the uniformity of the choice judgements between stimulus pairs was found to be violated in two directions. In most stimulus pairs the uniformity deviated in the same direction as the single judgements would prescribe. But in a considerable number of pairs the uniformity deviated in the opposite direction as the single judgements would prescribe. By the information that Hofstee provided both type of pairs can be identified.

This information makes a limited test of the mixture hypothesis possible. Pairs deviating from uniformity in the opposite direction should reveal a more serious discrepancy in attractiveness or difficulty than pairs deviating in the same direction. The reason is that any deviation from uniformity can be the result of two effects. First, the deviation might simply be due to an imperfect matching of favourableness. The more favourable stimulus is chosen in agreement with the single favourableness judgements. Second, the deviation might be caused by a difference in attractiveness or difficulty. This is the essence of the mixture hypothesis for explaining the choice effect. So, in pairs deviating from uniformity in the same direction both effects may contribute to the deviation. In pairs deviating from uniformity in the opposite direction it is completely dependent upon the difference in attractiveness or difficulty. Any existing difference in favourableness 
should even be compensated for by the difference in attractiveness or difficulty. Consequently. pairs that deviate from uniformity in the opposite direction should demonstrate a larger difference in attractiveness or difficulty between its stimuli than pairs that deviate from uniformity in the sane direction.

\subsubsection{Methods}

To supplement the Hofstee (1967) stimulus set with the necessary information about endorsement frequencies, another dataset was used. Between 1989 and 1999 1324 male psychology freshmen had completed a Dutch version of the Adjective Check List (ACL). They judged themselves by endorsing 361 adjectives on a 5 -point Likert scale. ${ }^{5}$ Of this instrument 91 adjectives happened to match literally the stimuli that Hofstee used. The addition of the ACL data set supplemented 110 of Hofstee's original 406 pairs with the mean endorsements of both stimuli. In 50 of these pairs the choice judgement order of favourableness was reversed as compared to the single judgements. In the remaining 60 pairs both favourableness orders agreed. The population mean endorsement of the preferred stimulus in the favourableness choice judgements was subtracted by the population mean endorsement of the other stimulus.

\subsubsection{Results}

The average difference in mean endorsement between the stimuli was 0.17 (SD 0.43 ) in the 50 pairs with favourableness reversal and -0.03 (SD 0.51) in the 60 pairs without favourableness reversal. The difference between the averages was statistically significant $(t=2.18 ; \mathrm{df}=108 ; \mathrm{p}<0.05)$.

\subsubsection{Conclusions}

The found difference in the mean endorsement is in agreement with the mixture hypothesis. The more attractive or less difficult stimulus appears to be preferred mostly. That finding suggests that subjects are influenced by the applicability of the stimulus if asked to select the favourable stimulus in the comparative judgment of pairs of which the stimuli are already matched. Essentially this view attests to the quality of the matching as offered by the favourableness ratings by single judgments. As such it is in sharp contrast with the interpretations by Hofstee (1967) and Feldman and Corah (1960) who both conclude that the favourableness ratings by comparative judgment are superior. It also suggests that Hofstee's recommendation to pretest the quality of the matching in the construction of forced-choice items by comparative favourableness ratings should not be obeyed. The ramifications of this result will be elucidated in the next part of this chapter.

\footnotetext{
${ }^{5}$ Due to missing values and minor modifications of the ACL over the years, the number of respondents per stimulus varied from 1123 to 1324 .
} 
To validate the mixture effect the current results should be replicated by a more carefully designed study. For one might object that the two samples do not match as the ACL data are obtained in psychology students, whereas Hofstee sampled military recruits. Also both data collection periods are separated by a huge time interval. And, in addition, the order and position effects in the ACL self-report data are not controlled as was perfected in Hofstee's research. Nevertheless, one could also take these differences to indicate the robustness of the mixture effect.

This supplementary analysis of the study by Hofstee (1967) addressed the cause for the recurring deviations from uniformity if respondents were asked to select the more desirable stimulus in established matched MCIs. It is known for a long time that the matching of an experimental and a control group in quasiexperimental research can produce an effect, which is attributable to regression to the mean (Campbell \& Erlebacher, 1970; Campbell \& Stanley, 1963; McNemar, 1940; Thorndike, 1942). But the suggestion that a similar regression artefact could be responsible for the recurring skewed distribution of the choice judgements of favourableness has not been ventilated before. Still, its operation is not imaginary. The stimuli are selected from different universes representing different traits with different mean social desirability values. The use of thousands of respondents by Hofstee (1967), however, precludes the necessary measurement error for the regression artefact to take effect. So, the regression to the mean effect cannot account for the choicc effect in his study. Nevertheless, if the social desirability values are obtained in smaller samples, it may definitely contribute to the divergence of matched stimuli.

\subsection{The invalidity of the additive scoring model}

The supplementary analysis of the study by Hofstee (1967) revealed that the asymmetric choice judgements of favourableness could be explained by the mixture effect. Subjects appear to choose the more applicable stimulus if the stimuli are properly matched for their favourableness. This produces asymmetric preference distributions if the matched stimuli are not equally attractive or difficult. The deviations from uniformity in the choice judgements, therefore, do not disqualify the matching. The previous chapter demonstrated that individual differences in social desirability ratings do not invalidate the approach of matching stimuli on the basis of the population mean social desirability ratings. Can the matched MCI now be expected to control for the social desirability response set? No, the remainder of this chapter will argue that with an additive scoring model this expectation is an illusion.

A matched MCI consists of multiple stimuli that represent different traits by definition. The response to a matched MCI will determine how the score is distributed over the represented traits. The score is only determined by the response. Stimuli are not differentially weighted themselves. This scoring practice 
scores within each subject agrees with a subject's order in the trait positions, i.e. from lowest to highest $i: \mathrm{A}, \mathrm{B} ; j: \mathrm{A}, \mathrm{B} ; k: \mathrm{B}, \mathrm{A} ;$ and $l: \mathrm{B}, \mathrm{A}$.

\subsubsection{The additive scoring of $\mathrm{MCls}$ matched for desirability}

Figure 8.2 again depicts the population distributions of the two traits. But now the traits are matched for social desirability. The social desirability continuum is indicated by the middle dashed line. Trait B is considered more socially desirable than trait A. Due to this difference there are only four items possible of which the stimuli are matched for social desirability. The matching is illustrated by the dotted lines between the stimuli. As these items differ from those in Figure 8.1, they are marked by a prime. So item $1^{\prime}$ consists of the pair $A_{\text {low }}$ vs. $B_{\text {lowest }}$, item $2^{\prime}$ of $A_{\text {middle }}$ vs. $B_{\text {low }}$, item $3^{\prime}$ of $A_{\text {high }}$ vs. $B_{\text {middle, }}$, and item $4^{\prime}$ of $A_{\text {highest }}$ vs. $B_{\text {high }}$. Both trait continua still show the trait levels of the same four subjects. And the subjects are assumed to follow the same response strategy.

If the respondents in Figure 8.2 are assumed to adopt the same response behaviour as was formalized in the previous section, the choices and variable scores as listed in Table 8.2 can be expected. It identifies a remarkable result. The order of each separate variable sum score between the subjects still agrees with the order of the trait positions of the subjects. But now the order of the variable scores within each subject does not agree with a subject's order in the trait positions. In subject $k$ the expected variable scores tie (A: $2 ; \mathrm{B}: 2$ ), whereas his trait position is above average on trait $A$ and below average on trait $B$. The trait positions of subject $j$ are exactly the reverse of subject $k$ : below average on trait $A$ and above average on trait $B$. But subject $j$ shows a definite difference in the expected variable scores (A: $1 ; \mathrm{B}: 3$ ). A likewise comparison can be made between subjects $i$ and $l$. They also have contrasting but equally dispersed trait profiles, whereas the difference between the expected variable scores are more outspoken in subject $i$ than in subject $l$. The expected variable scores are in fact

Table 8.2: Expected choices and variable scores on the items of Figure 8.2

\begin{tabular}{|c|c|c|c|c|c|c|c|c|c|c|c|c|c|}
\hline & \multirow{2}{*}{$\begin{array}{l}\text { Stimulus } \\
\text { combination }\end{array}$} & \multicolumn{3}{|c|}{ Subject $i$} & \multicolumn{3}{|c|}{ Subject $j$} & \multicolumn{3}{|c|}{ Subject $k$} & \multicolumn{3}{|c|}{ Subject $l$} \\
\hline & & choice & $E\left(X_{A}\right)$ & $E\left(X_{B}\right)$ & choice & $\varepsilon\left(X_{A}\right)$ & $E\left(X_{B}\right)$ & choice & $E\left(X_{A}\right)$ & $E\left(X_{B}\right)$ & choice & $E\left(X_{A}\right)$ & $E\left(X_{B}\right)$ \\
\hline Item $1^{\prime}$ & $A_{\text {low }} \& B_{\text {lon }}$ & $B$ & 0.0 & 1.0 & $A / B$ & 0.5 & 0.5 & $A / B$ & 0.5 & 0.5 & $A / B$ & 0.5 & 0.5 \\
\hline & $A_{\text {middle }}$ \& & B & 0.0 & 1.0 & B & 0.0 & 1.0 & $A / B$ & 0.5 & 0.5 & $A$ & 1.0 & 0.0 \\
\hline & $A_{\text {high }} \& B_{\text {middle }}$ & B & 0.0 & 1.0 & B & 0.0 & 1.0 & $A / B$ & 0.5 & 0.5 & A & 1.0 & 0.0 \\
\hline ten & $A_{\text {highest }} \& B_{\text {high }}$ & B & 0.0 & 1.0 & $A / B$ & 0.5 & 0.5 & $A / B$ & 0.5 & 0.5 & $A / B$ & 0.5 & 0.5 \\
\hline $\mathrm{Fl}$ & & & 0.0 & & & 1.0 & & & 2.0 & & & 3.0 & \\
\hline & & & & 4.0 & & & 3.0 & & & 2.0 & & & 1.0 \\
\hline
\end{tabular}

Note. $\mathrm{E}\left(\mathrm{X}_{\mathrm{A}}\right)$ indicates the expected item score to variable $\mathrm{A}, \mathrm{E}\left(\mathrm{X}_{\mathrm{B}}\right)$ indicates the expected item score to variable $B, E\left(\Sigma X_{A}\right)$ indicates the expected sum score of variable $A$, and $E\left(\Sigma X_{B}\right)$ indicates the expected sum score of variable $B$. 
Figure 8.2: Two traits with their stimuli matched for desirability in four MCls

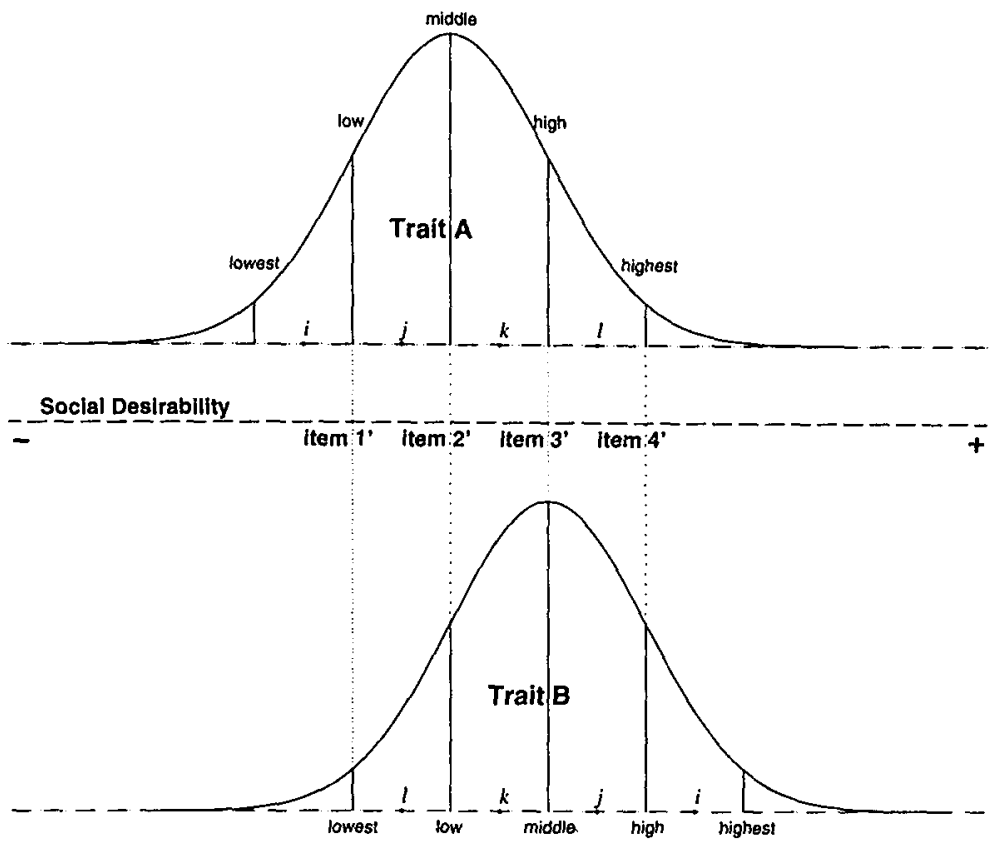

shifted in the direction of the social desirability of the trait.

This result demonstrates that the matching of stimuli does not automatically yield unbiased variable scores. The matching does eliminate any influence of social desirability on the response behaviour. Ironically, this same matching procedure also ensures that the matched stimulus pairs are systematically displaced with regard to their attractiveness or difficulty. So, if the scoring does not take these systematic differences in stimulus difficulty into account, it will not correct the difference in social desirability in the resulting variable scores.

\subsubsection{The thickening of the plot}

In Table 8.2 the expected sum scores of variable $\mathrm{A}$ are shifted relative to the expected sum scores of variable $B$. Both variables have an equal dispersion in the stimuli, but the expected sum scores of variable $A$ range from 0 to 3 , whereas the expected sum scores of variable B range from 1 to 4 . This shift is due to the differences in difficulty or attractiveness of the representing stimuli. Such a shift could easily be corrected by a standard adjustment of one of the variable scores. The variable score of trait A might be increased by a score of 1 or the variable 
score of trait B might be reduced by a score of 1 . Either transformation of the variable score would compensate the shift.

Still, such a correction will only work if both stimulus samples are equally dispersed over both trait continua. This condition will in practice hardly ever been met. If both variables differ in their relation to social desirability, the stimulus dispersions will differ. Then a simple linear transformation, like for instance a normative standardization, cannot account for the variable score differences.

This contention is illustrated by Figure 8.3. Trait A is matched with another trait: Trait C. Again both traits are normatively standardized separately within each trait and assumed to be equally distributed in the population. But now trait $\mathrm{C}$ is differently related to social desirability than trait $\mathrm{A}$. Notice that the order of subjects $i, j, k$, and $l$ on trait $\mathrm{C}$ matches their order on trait $\mathrm{A}$. Trait $\mathrm{C}$ is equally displaced to Trait $\mathrm{A}$ on the social desirability continuum as was Trait B (see Figure 8.2). However, the scales of both trait continua differ as they are differently related to social desirability. As a result item 7 matches two stimuli that are equal in social desirability and in difficulty. It is crucial for the argument to recognize that person $i$ is low on trait A and although still low somewhat higher on trait $\mathrm{C}$. Person $j$ is below average on trait $\mathrm{A}$ and somewhat lower on trait $\mathrm{C}$, person $k$ is above average on trait $\mathrm{A}$ and slightly below average on trait $\mathrm{C}$, and person $l$ is high on trait $\mathrm{A}$ and slightly above average on trait $\mathrm{C}$.

As a result the responses of these subjects to items 6 to 10 will produce expected variable scores that are the same in all subjects. These expected variable scores are listed in Table 8.3. Nevertheless, the trait position of each subject is different in both traits. Since the expected variable scores are all equal, the unbiased variable scores are beyond recovery by any score transformation.

Table 8.3: Expected choices and variable scores on the items of Figure 8.3

\begin{tabular}{|c|c|c|c|c|c|c|c|c|c|c|c|c|c|}
\hline & \multirow{2}{*}{$\begin{array}{c}\text { Stimulus } \\
\text { combination }\end{array}$} & \multicolumn{3}{|c|}{ Subject $i$} & \multicolumn{3}{|c|}{ Subject $j$} & \multicolumn{3}{|c|}{ Subject $k$} & \multicolumn{3}{|c|}{ Subject $l$} \\
\hline & & choice & $E\left(X_{A}\right)$ & $E\left(X_{B}\right)$ & choice & $E\left(X_{A}\right)$ & $E\left(X_{B}\right)$ & choice & $E\left(X_{A}\right)$ & $E\left(x_{B}\right)$ & choice & $E\left(X_{A}\right)$ & $E\left(x_{B}\right)$ \\
\hline Item 6 & $A_{\text {lowest }} \& C_{\text {lower }}$ & $\mathrm{A} / \mathrm{C}$ & 0.5 & 0.5 & $\mathrm{~A} / \mathrm{C}$ & 0.5 & 0.5 & $A / C$ & 0.5 & 0.5 & $\mathrm{~A} / \mathrm{C}$ & 0.5 & 0.5 \\
\hline Item 7 & $A_{\text {low }} \& C_{\text {low }}$ & $A / C$ & 0.5 & 0.5 & $\mathrm{~A} / \mathrm{C}$ & 0.5 & 0.5 & $A / C$ & 0.5 & 0.5 & $\mathrm{~A} / \mathrm{C}$ & 0.5 & 0.5 \\
\hline Item 8 & $A_{\text {middle }} \& C_{\text {below middle }}$ & $A / C$ & 0.5 & 0.5 & $A / C$ & 0.5 & 0.5 & $A / C$ & 0.5 & 0.5 & $\mathrm{~A} / \mathrm{C}$ & 0.5 & 0.5 \\
\hline Item 9 & $A_{\text {high }} \& C_{\text {middle }}$ & $\mathrm{A} / \mathrm{C}$ & 0.5 & 0.5 & $A / C$ & 0.5 & 0.5 & $A / C$ & 0.5 & 0.5 & $A / C$ & 0.5 & 0.5 \\
\hline Item 10 & $A_{\text {highest }} \& C_{\text {obove middle }}$ & $A / C$ & 0.5 & 0.5 & $A / C$ & 0.5 & 0.5 & $\mathrm{~A} / \mathrm{C}$ & 0.5 & 0.5 & $\mathrm{~A} / \mathrm{C}$ & 0.5 & 0.5 \\
\hline$E\left(\Sigma X_{A}\right)$ & & & 2.5 & & & 2.5 & & & 2.5 & & & 2.5 & \\
\hline$E\left(\Sigma X_{B}\right)$ & & & & 2.5 & & & 2.5 & & & 2.5 & & & 2.5 \\
\hline
\end{tabular}

Note. $\mathrm{E}\left(\mathrm{X}_{\mathrm{A}}\right)$ indicates the expected item score to variable $\mathrm{A}, \mathrm{E}\left(\mathrm{X}_{\mathrm{C}}\right)$ indicates the expected item score to variable $C, E\left(\Sigma X_{A}\right)$ indicates the expected sum score of variable $A$, and $E\left(\Sigma X_{C}\right)$ indicates the expected sum score of variable $C$. 
Figure 8.3: Five matched $\mathrm{MCls}$ of two traits differently related to desirability

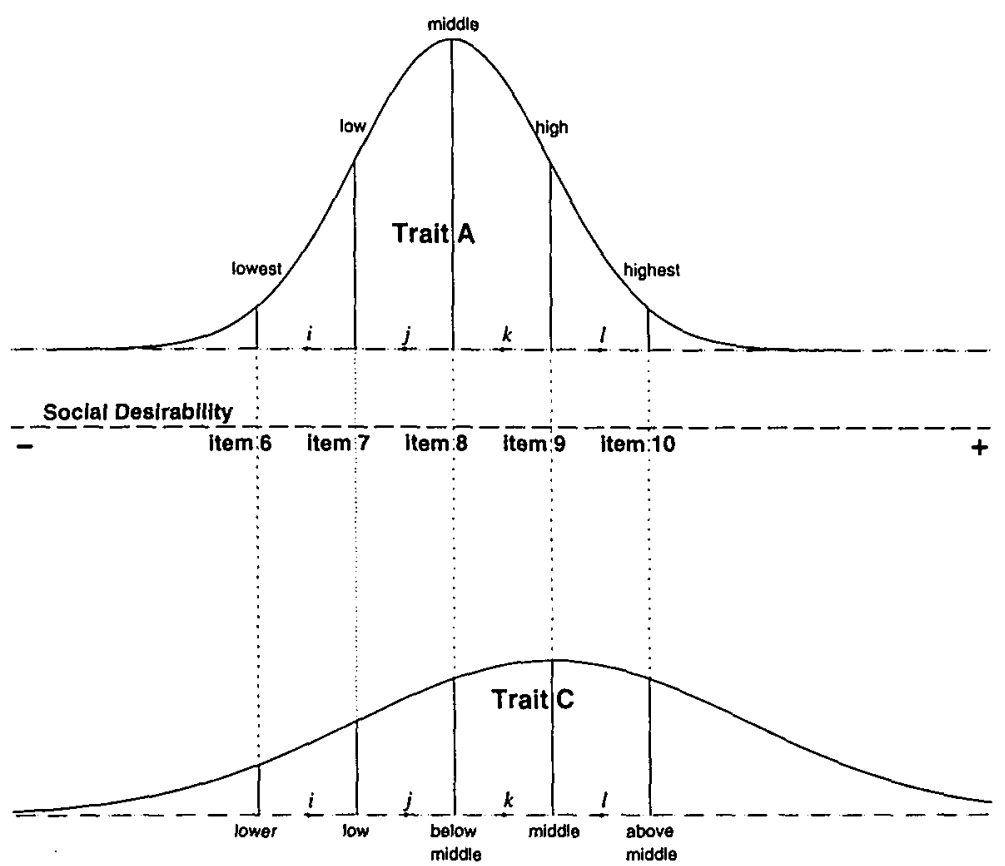

Note. The scale of trait A does not equal that of trait C. Notice, for instance, that the distance between 'low'and 'middle' of trait $\mathrm{C}$ is twice that of trait $\mathrm{A}$. It is to indicate that trait $\mathrm{A}$ and trait $\mathrm{C}$ are separately standardized and differ in their relation with social desirability.

\subsection{Discussion}

The deviations from uniformity in comparative social desirability judgements of matched stimuli have been ascribed to a context effect. It has been claimed that the stimuli acquire a different meaning, by pairing them to another stimulus. As a result, the social desirability of the stimuli would alter due to the matching process itself. In a thorough study Hofstee (1967) convincingly falsified this explanation. He rightfully claims that if a context effect would have been responsible, he should at least have found one circular triad in his comparative social desirability judgements of matched trait-descriptive adjectives.

Nevertheless, the deviations from uniformity in these comparative social desirability judgements of matched stimuli remained themselves largely unexplained. The current study demonstrated that this result must be due to a mixture effect: the respondent selects the more applicable stimulus instead of the more desirable one. This kind of response bias is thought to occur particularly if the stimuli are closely matched. Should the represented traits differ in social desirability, the 
Figure 8.4: Ceiling effect due to faking in the raw score profile of one subject

\section{Big Five raw score profile}

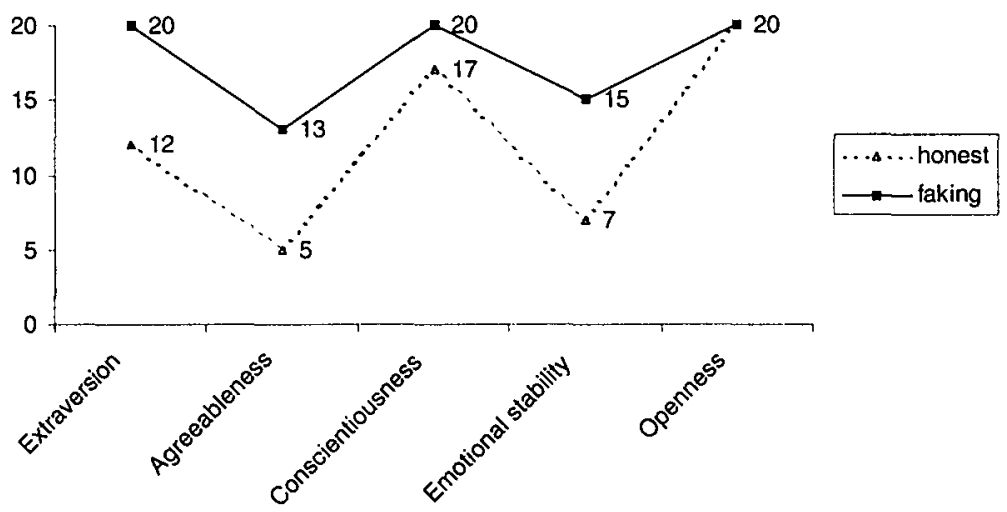

matching process will combine stimuli that are differently attractive or difficult. As a result the more attractive or easy stimulus will be preferred by the majority of the respondents. The mixture effect thus explains the recurrent deviations from uniformity in the comparative desirability judgements of matched stimuli.

The failure of the matched MCI to control for social desirability is due to the inadequacy of the additive scoring model itself. The critical assumption of the additive scoring model is that the compared traits are equally represented by stimuli. The matching process violates this assumption as it induces a systematic shift in the attractiveness or difficulty of the combined stimuli. Only when the traits are equally social desirable the matching of the stimuli will not systematically displace the difficulty of the combined stimuli. Yet, the whole rationale for the matching is that the traits do differ in social desirability. Otherwise, the responses to a questionnaire with unmatched stimuli would not be biased. In a perfectly matched questionnaire the additive scoring of the matched $\mathrm{MCI}$, therefore, perpetuates the social desirability response bias. Hence, the additive scoring of the matched MCI to control for social desirability should be relegated to the archives of methodological folly.

Although the matched MCI has been found susceptible to faking, it still comes out beneficial in empirical comparisons with the singular item format (SI) (Martin et al., 2002; Stanush, 1997). The benefit of the matched MCI typically emerges when the respondent is instructed to fake. An explicit faking instruction will induce a ceiling effect in the separate variable scores. Figure 8.4 illustrates the issue. After a faking instruction the scores are all increased by adding 8 points. On 
a 5-point Likert item the response is usually scored as ranging from 1 to 5 . With four such items per variable the maximum score is thus by definition 20 . In the example subject the raw scores on the variables Extraversion, Conscientiousness, and Oppenness will become the same. Many respondents will have maximal SI scores in some variables. Such a variable profile will merely consist of ties. Since the matched MCI item results in direct ipsative data, the scores cannot be maximal in all variables. In effect the data collected with the matched MCI format will remain more close to the true score profile than data obtained with the SI format. So, the increased robustness of the matched MCI against faking should be attributed to the prevention of a ceiling effect. The matching of the stimuli is then actually irrelevant. The MCI without matched stimuli would presumably have been equally robust. 


\section{Epilogue}

This research project was directed at establishing the merit of ipsative measurement. It aimed to permit an educated decision when to adopt this measurement method in instruments for practical purposes. A thorough review of the literature made it painstakingly clear that previous research primarily stayed within the differential psychology research tradition: it concentrated on individual differences in isolated variables. This rigor mentis was interspersed with an aggravating negligence that ipsative measurement generates interdependent variable scores. It gave rise to recurrent violations of basic assumptions for the statistical analyses. Consequently, many results were irrelevant at best, if not unfounded. Furthermore, several types of forced-choice items were lumped together, which should not be treated as if they were similar. They differed in scoring method and some consisted of stimuli that were matched on social desirability, whereas others were not. This state of affairs prohibited a fair evaluation of the measurement method and frustrated its informed use.

The main strategy of the first, theoretical part of this thesis, therefore, was to distinguish ipsative data collection from ipsative standardization. The main strategy of the second, empirical part of this thesis was to use the within-subjects profile agreement as a primary criterion. These two research strategies produced five new insights in total.

Firstly, the current discourse on ipsative data collection resulted in the redefinition of the forced-choice item as compound item. The issue whether stimuli were actually matched on social desirability, or not, was considered immaterial to the item format. Three different compound items were classified conform their scoring method: the unidimensional, indeterminate, and multidimensional compound item (MCI) format. All three could also use matched stimuli. From then on the emphasis was on the MCI, because it yields direct ipsative scores on multiple variables. It helped realize that the MCI response essentially constitutes a vector. For it is this vector that holds together the scores of the various variables as they are expressed relative to each other.

Secondly, the present research produced a new typology of response ten- 
dencies. Ipsative standardization was put in perspective by relating it to domainreferenced, normative, and iterative standardization. The tcrm iterative standardization was introduced. More importantly, however, the relation between ipsative, normative and iterative standardization culminated in the composition of a new typology of response tendencies. This typology clarified the intricate connection between standardization methods and response tendencies. It brought about the identification of four new response tendencies, one of which is the response habit. The response habit indicates the differential rating scale use across variables. This is the response tendency that particularly undermines ipsative standardization, whereas normative standardization is immune to it. Normative standardization is susceptible to the response style, that is, the differential response scale use across subjects. So, ipsative standardization could be preferred over normative standardization for its robustness against the response style, but it yields scores that are vulnerable to the response habit instead.

Thirdly, the current evaluations did not reveal a relevant benefit of the MCI. The studies rigorously employed the within-subjects profile agreement as criterion. The importance of the within-subjects profile agreement was suggested by the viewpoint that the MCI response represents a vector and the idea that the response habit undermines ipsative standardization. Both imply that if a benefit of the MCI was to emerge, it should surface in the accuracy of profile assessments within subjects. The studies of this thesis that used this within-subjects profile agreement, did not indicate the MCI format to offer a relevant advantage over the singular item format.

Fourthly, this thesis argued the additive scoring model, i.e. the weighted or unweighted sum of the stimulus preferences, to be too restrictive to accommodate the matched MCI. The use of within-subjects profile agreement with various desirability ratings revealed that the matched MCI approach is not invalidated by individual differences in social desirability. In addition, the idea that the process of matching stimuli alters their social desirability was exposed as illfounded. As a result the item response itself can be considered free from any bias. Matching stimuli on social desirability cause the stimuli, however, to diverge in their representation of the trait domain. More specifically, it can be expected to cause a systematic shift in their attractiveness or difficulty. This is particularly alarming, as the current additive scoring model does not and cannot take this shift into account.

Fifthly, the present research demonstrated a method to construct a MCI questionnaire that does not automatically result in ipsative standard scores. A questionnaire should not only consist of MCIs that contain either indicative or contra-indicative stimuli exclusively, i.e. aligned MCIs. This questionnaire should also make use of MCIs that combine both indicative and contra-indicative stimuli within one item, i.e. opposed MCIs. If the questionnaire includes an equal number of aligned and opposed MCIs, it seems more in agreement with the additive scoring model. The current investigation did construct such a fully balanced MCI questionnaire and showed it to be comparable to a questionnaire with the same 
stimuli presented in a singular item format.

These five insights taken together imply that the MCI as it is currently employed serves no practical measurement purpose. This might be attributed to the injudicious use of the additive scoring model. If a new scoring model is developed, the use of a MCI questionnaire that is balanced in aligned and opposed MCIs could be advantageous. This questionnaire may guide the development of a new scoring model, for it was already shown to meet the additive scoring model. Hence, the new scoring model should produce comparable scores. But in fact an elaborate multidimensional test theory is called for. This test theoretical model should take the correlation between the error scores of variables into account. And, hopefully, it could cover for the differences in the attractiveness or difficulty between matched stimuli. Then, the MCI may well appear a valuable measurement tool. But until then, the MCI should not be employed in instruments for practical measurement purposes. 


\section{The merit of ipsative measurement: Second thoughts and minute doubts}

In this research project the merit of ipsative measurement is assessed. Ipsative measurement is in Chapter 1 subdivided into a data collection method and a data standardization method. Ipsative data collection is related to an item format that incorporates multiple stimuli. The stimuli within one item represent different variables. It is termed the multidimensional compound item (MCI) format. A MCI invites the respondent to indicate his relative preferences for the stimuli, either by making a clear-cut choice, a ranking, or a graded rating. In such a composite preference judgement each stimulus attains a particular position. That position determines what score is added to the variable it stands for.

This way of scoring causes MCIs to produce ipsative standard scores directly. The purpose of standardization is in Chapter 2 emphasized to be the development of a measurement unit. Domain-referenced standardization generates a unit by taking the minimum and maximum variable score as two anchor points for a measurement scale. Measurement-referenced standardization methods derive the measurement unit from the score distribution statistics of a set of measurements. These measurements may either be sampled over subjects, variables, or occasions. It characterizes normative, ipsative, and iterative standardization, respectively. Ipsative standardization relates everyone's variable score to one's own score distribution on a set of variables. It yields a measurement unit that expresses the scores of all covered variables within a subject in a common metric; it makes the variables within a subject commensurable.

One of its acclaimed benefits is that ipsative standardization is not biased by response styles, like acquiescence. The response style is a type of response tendency. In Chapter 3 a response tendency is defined as the differential use of the rating scale. The rating scale can be used differentially over judges or not, differentially over variables or not, and differentially over occasions or not. These are roughly the same aspects that classify the measurement-referenced standardization methods. All combinations of these aspects yield eight possible response 
tendencies. It puts the four known response tendencies into a common framework: the response consistency, the response style, the response set, and the response shift. This typology also recognizes four new response tendencies: the response habit, the response fashion, the response drift, and the response whim. Ipsative standardization sure is robust against response styles, but it is on the other hand vulnerable to response habits.

The response habit indicates the differential rating scale use across variables. The stimuli of some variables may be more easily endorsed than the stimuli of other variables. For example, the Likert scale point 'moderately applicable' may define a different amount of applicability if it refers to stimuli representing $E x$ traversion than to stimuli reflecting Conscientiousness. It damages ipsative standardization in particular, since an ipsative standard score expresses an amount relative to other variable scores. If the raw variable scores use different units, it knocks the bottom out of the standardization approach. Still, the response habit has not yet been established empirically. So, it may come out to be more of a figment in the fancy envisioned by the theorist than a fragment in the variance observed by the practician.

In keeping with the position of the practician the MCI is in Chapter 4 empirically evaluated against the more prevalent singular item (SI). The SI just asks the respondent to endorse a single stimulus. The MCI rather requires the subject to compare stimuli that represent different variables. Profile scores contrast the scores of one subject on separate variables against each other. As a corollary, the MCI format might be more suitable for producing profile scores than the SI format. This is examined by checking whether the profile scores obtained with a $\mathrm{MCl}$ questionnaire are more in agreement with the profile scores of an independent criterion measurement than the profile scores of a SI version. This study does not result in a statistical significant difference between the MCI and SI versions in profile agreement with the criterion.

In Chapter 5 the same issue is addressed again. But, instead of using a criterion measure, the judgement of the respondent himself is called upon. After completing a MCI and SI version of a questionnaire, the subject receives a feedback report. It contains two profiles: one derived from his MCI responses and one from his SI responses. Both profiles are either expressed in domain-referenced or ipsative standard scores. The subject is asked to indicate which version profile he prefers. A clear majority of the group that receives their profiles in domainreferenced standard scores likes the MCI profile better than the SI profile. Most of those, who receive both profiles in ipsative standard scores also prefer the MCI profile over the SI profile. But, although still statistically significant, the majority has become very small indeed. A medium effect with the domain-referenced standard scores reduces to an unimportant effect with ipsative standard scores.

If the MCI would not result in ipsative standard scores automatically, it might come out beneficial. Hence, in Chapter 6 a new way of data collection with the MCI is outlined and implemented. The MCI usually combines either indicative or contra-indicative stimuli exclusively, yielding so-called aligned MCIs. 
The idea is to combine indicative with contra-indicative stimuli within the same item as well, labelled opposed MCIs. Responding in the direction of the indicative stimulus increases the credit for both represented variables. Responding in the direction of the contra-indicative stimulus reduces the score assigned to both variables. It counteracts the total sum constraint and thereby prevents the MCI from automatically producing ipsative standard scores. A multitrait-multimethod analysis reveals that the scores of the combined aligned and opposed MCIs are comparable to the scores of only SIs.

The final two chapters target the adequacy of matching stimuli on social desirability to limit the social desirability response set. To construct a matched MCI a representative sample of the target population needs to rate the social desirability of potential stimuli. The stimuli are subsequently combined on the basis of their mean social desirability ratings. The study in Chapter 7 tests whether the matched MCI is vulnerable to individual differences in these social desirability ratings. After all, the stimuli are matched on their mean social desirability. This approach may fail to control its influence on the response process at the individual level. If subjects differ widely in their conceptions of social desirability, then there are many whose own social desirability ratings deviate from the population mean. It would render the matching inadequate. Each subject would then select the stimulus that he himself considers the more desirable, because for him the stimuli are not equally desirable.

The possibility that any subject responds more in agreement with his own conceptions of social desirability is granted by the first central hypothesis. But the second central hypothesis maintains that anyone's deviations from the mean social desirability ratings can be taken to reflect error in his own social desirability ratings. However, this error witnesses the genuine trait positions of the subject himself. A subject is in fact expected to overestimate the social desirability of traits that he is endowed with in a large degree. He is regarded to underestimate the desirability of traits that he commands to a lesser extent. If a respondent intends to depict himself more favourably, his fabricated responses will deviate towards his true responses. In that case the individual differences in social desirability conceptions pose no threat.

The results refute the first central hypothesis. On average subjects respond slightly more in agreement with the population mean social desirability ratings than with their own social desirability ratings. The second central hypothesis is corroborated. Responding conform the population mean social desirability ratings is stronger related to an independent measure of impression management than responding conform the own desirability ratings. The individual differences in the social desirability ratings, therefore, appear to reflect true score variance.

Another idea is challenged in Chapter 8. The process of matching stimuli has been accused of altering their social desirability. A stimulus in a different context, by coupling it to another stimulus, allegedly acquires a different desirability. This effect has been shown previously by comparative preference judgements of matched stimuli. Subjects are then asked to select the stimulus that is the 
more desirable in matched MCIs. The rationale is that if stimuli are adequately matched, they ought to be preferred equally in the population. In all discussed studies, however, deviations from uniformity were reported.

It is hypothesized that with closely matched stimuli, a subject tends to choose the stimulus that is to him the more applicable instead of the more desirable. This would be in line with the conclusion of Chapter 7. Hofstee (1967), who calls it the mixture effect, provides a closely matched stimulus set. A part of it is combined with the endorsement frequencies from another data set. The results support the mixture effect. This effect explains the deviations from uniformity. For the matching on social desirability causes the coupled stimuli to differ systematically in attractiveness or difficulty. The additive scoring model cannot take this systematic shift in attractiveness or difficulty between the matched stimuli into account. The influence of the social desirability response set is therefore transmitted in the derived variable scores.

In conclusion, ipsative measurement as it is currently implemented does not offer much of a benefit. The statistical significant advantage of the MCI over the SI in the profile assessments of Chapter 5 is the only available indication. But with ipsative standardization the advantage is negligible. It cannot justify ipsative measurement. Its properties hinder direct between-subjects comparisons and impose restrictions on data analysis. At the moment, ipsative measurement must be considered unsuitable for practical measurement purposes.

For research on measurement methods the combination of aligned and opposed MCIs may offer a new vantage point for future developments. The approach seems better in accord with the additive scoring model. Another benefit may come from inproving the test theoretical model that underlies the MCI. A new scoring model might cope with the differences in attractiveness or difficulty between matched stimuli. 


\section{De waarde van ipsatief meten: Afwegingen en reserves}

In dit onderzoeksproject wordt de waarde van ipsatief meten beoordeeld. Ipsatief meten wordt in Hoofdstuk 1 onderverdeeld in een methode om gegevens te verzamelen en een methode om gegevens te standaardiseren. De ipsatieve methode van gegevens verzamelen is gerelateerd aan een vraagstructuur bestaande uit meerdere stimuli per item. De stimuli in één item representeren verschillende eigenschappen. Deze vraagstructuur wordt het meerdimensionaal complex item (MCI) genoemd. Een MCI vraagt de respondent om zijn relatieve voorkeuren voor de stimuli aan te geven door middel van een directe keuze, een rangordening, of een gegradeerd oordeel. In zo'n samengesteld voorkeursoordeel krijgt elke stimulus een eigen positie. Die positie bepaalt welke score de stimulus bijdraagt aan de eigenschap die deze weerspiegelt.

Deze manier van scoring zorgt ervoor dat MCI's direct ipsatieve standaardscores opleveren. In Hoofdstuk 2 wordt benadrukt dat standaardisatie tot doel heeft een meeteenheid te ontwikkelen. Domeingeoriënteerde standaardisatie vormt een meeteenheid door de minimum en maximum eigenschapscore als twee ankerpunten voor een meetschaal te nemen. Metinggeoriënteerde standaardisatie methoden ontlenen de meeteenheid aan de kengetallen van een scoreverdeling van een reeks metingen. Deze metingen kunnen verzameld worden over personen, eigenschappen, of meetmomenten. Dit typeert respectievelijk normatief, ipsatief, en iteratief standaardiseren. Ipsatief standaardiseren brengt ieders eigenschapscore in verband met zijn eigen scoreverdeling op een reeks eigenschappen. Het verschaft een meeteenheid die de scores op alle betrokken eigenschappen binnen een proefpersoon in hetzelfde metrische stelsel plaatst; het maakt de eigenschappen binnen een persoon vergelijkbaar.

Een veelgeprezen voordeel is dat ipsatieve standaardisatie bestand is tegen antwoordstijlen, zoals de bevestigende antwoordstijl (acquiescence). De antwoordstijl is een type antwoordneiging. In Hoofdstuk 3 wordt een antwoordneiging gedefinieerd als een verschillend gebruik van de beoordelingsschaal. De beoor- 
delingsschaal kan al dan niet ongelijk gebruikt worden over beoordelaars, eigenschappen, en meetmomenten. Dit zijn ongevecr dezelfde cenheden die de metinggeoriënteerde standaardisatie methoden indelen. Alle mogelijke combinaties plaatsen de vier bekende antwoordneigingen in een gemeenschappelijk kader: de antwoordconsistentie (response consistency), de antwoordstijl (response style), de antwoordhouding (response set), en de antwoordkentering (response shift). Deze typologie laat ook ruimte voor vier nieuwe antwoordneigingen: de antwoordtraditie (response habit), de antwoordtrend (response fashion), de antwoordstroming (response drift), en de antwoordbevlieging (response whim). Ipsatieve standaardisatie is weliswaar ongevoelig voor antwoordstijlen, miar daarentegen kwetsbaar voor antwoordtradities.

De antwoordtraditie duidt op een verschillend gebruik van de beoordelingsschaal tussen eigenschappen. Met de stimuli van sommige eigenschappen wordt misschien gemakkelijker ingestemd dan met de stimuli van andere eigenschappen. Bijvoorbeeld, het Likert schaalpunt 'matig van toepassing' zou een andere mate van toepasbaarheid kunnen aangeven als het betrekking heeft op stimuli die Extraversie weergeven dan als het betrekking heeft op stimuli die Consciëntieusheid weerspiegelen. Het tast juist ipsatieve standaardisatie aan, omdat een ipsatieve standaardscore de hoeveelheid uitdrukt relatief ten opzichte van andere eigenschapscores. Als de ruwe eigenschapscores van verschillende eenheden gebruikmaken, verdwijnt het fundament voor deze manier van standaardisatie. Niettemin is de antwoordtraditie nog altijd niet empirisch aangetoond. Het kan dus eerder een door de theoreticus bedachte, dan een door de practicus beduchte bron van foutenvariantie zijn.

Overeenkomstig de zienswijze van de practicus wordt het MCI in Hoofdstuk 4 afgezet tegen het meer gangbare simplex item (SI). Het SI verlangt van de respondent dat hij slechts één enkele stimulus al dan niet bekrachtigt. Het MCI vraagt juist om een vergelijking tussen stimuli die verschillende eigenschappen representeren. Profielscores zetten de scores van één persoon op afzonderlijke eigenschappen tegenover elkaar. Het $\mathrm{MCl}$ zou daarom beter geschikt kunnen zijn voor profielscores dan het SI. Dit wordt onderzocht door na te gaan of de profielscores verkregen met een MCI-vragenlijst meer in overeenstemming zijn met de profielscores van een onafhankelijke criteriummeting, dan de profielscores van een SI-versie. Dit onderzoek laat echter geen statistisch significant verschil zien tussen de MCI en SI-versie in profiel overeenstemming met het criterium.

In Hoofdstuk 5 wordt deze kwestie opnieuw aan de orde gesteld. Maar in plaats van een criteriummeting te gebruiken, wordt op het oordeel van de respondent zelf vertrouwd. Na het invullen van een MCI en SI-versie van een vragenlijst, krijgt de respondent een terugrapportageformulier. Het bevat twee profielen: één gebaseerd op zijn MCI antwoorden en één op zijn SI antwoorden. Beide profielen zijn uitgedrukt in óf domeingeoriënteerde óf ipsatieve standaardscores. De proefpersoon wordt hierbij gevraagd aan te geven welke profielversie zijn voorkeur heeft. Een duidelijke meerderheid van de groep die hun profielen in domeingeoriënteerde standaardscores ontvangt, kiest het MCI-profiel in plaats 
van het SI-profiel. Van degenen die beide profielen in ipsatieve standaardscores ontvangen verkiezen ook de meesten het MCI-profiel boven het SI-profiel. Maar $\mathrm{nu}$ is de meerderheid, ofschoon nog steeds statistisch significant, erg klein geworden. Een gemiddeld effect met domeingeoriënteerde standaardscores neemt af tot een onbeduidend effect met ipsatieve standaardscores.

Indien het MCI nict automatisch ipsatieve standaardscores zou produceren, dan zou het wellicht een aanwinst kumnen zijn. Daarom wordt in Hoofdstuk 6 een nieuwe manier van gegevens verzamelen met het $\mathrm{MCI}$ geschetst en toegepast. Gewoonlijk bestaat het MCI alleen uit óf indicatieve of contra-indicatieve stimuli, resulterend in zogenoemde gelijkgerichte MCI's. Het idee is om ook indicatieve stimuli met contra-indicatieve te combineren binnen hetzelfde item, aangeduid als tegengestelde MCI's. Een antwoord in de richting van de indicatieve stimulus verhoogt de opbrengst voor beide eigenschappen. Een antwoord in de richting van de contra-indicatieve stimulus vermindert de punten die aan beide eigenschappen worden toegekend. Dit doet de constantic van de totale somscore teniet. Het voorkomt daarmee dat de MCI automatisch ipsatieve standaardscores oplevert. Een multitrek-multimethode-analyse geeft aan dat de scores van de gelijkgerichte en tegengestelde MCI's tezamen vergelijkbaar zijn met de scores van de SI's.

De laatste twee hoofdstukken richten zich op de juistheid om stimuli te matchen op sociale wenselijkheid om de sociaal wenselijke antwoordhouding te beperken. Voor het maken van gematchte MCI's moet een representatieve steekproef van de doelgroep de sociale wenselijkheid van potentiële stimuli beoordelen. De stimuli worden vervolgens gekoppeld op basis van hun gemiddelde sociale wenselijkheidbeoordelingen. Het onderzoek in Hoofdstuk 7 toetst of het gematchte MCI kwetsbaar is voor individuele verschillen in deze sociale wenselijkheidbeoordelingen. De stimuli worden immers gematcht op grond van hun gemiddelde sociale wenselijkheid. Deze aanpak schiet misschien tekort om de invloed ervan op het antwoordproces op individueel niveau te beperken. Als personen sterk variëren in hun voorstelling van sociale wenselijkheid, dan zijn er veel personen die in hun eigen sociale wenselijkheidbeoordelingen afwijken van het populatiegemiddelde. Dat zou het matchen ongeschikt maken. Dan zou iedere persoon toch de stimulus kunnen kiezen die hijzelf het meest wenselijk acht, omdat voor hem de stimuli niet even wenselijk zijn.

De mogelijkheid dat iedere persoon meer in overeenstemming met de eigen voorstelling van sociale wenselijkheid antwoordt, wordt in het onderzoek voor waar aangenomen met de eerste centrale hypothese. De tweede centrale hypothese stelt echter dat ieders afwijkingen van de gemiddelde sociale wenselijkheid beschouw kunnen worden als fouten in de eigen sociale wenselijkheidbeoordelingen. Deze fouten laten echter de werkelijke trekposities van de persoon zelf zien. Eigenlijk is de gedachte dat iemand de sociale wenselijkheid van de eigenschappen waarover hij in sterke mate beschikt, overschat. En hij wordt geacht de wenselijkheid van de eigenschappen die hij in mindere mate beheerst te onderschatten. Als een respondent zichzelf meer sociaal wenselijk wil voordoen, dan wijken zijn gekleurde antwoorden af in de richting van zijn ware antwoorden. In dat geval 
vormen individuele verschillen in de voorstelling van sociale wenselijkheid geen gevaar voor het gematchte MCI.

De resultaten verwerpen de eerste centrale hypothese. Personen antwoorden gemiddeld iets meer conform het populatiegemiddelde van de sociale wenselijkheidbeoordelingen dan conform hun eigen sociale wenselijkheidbeoordelingen. De tweede centrale hypothese wordt ondersteund. Het antwoorden overeenkomstig het populatiegemiddelde van de sociale wenselijkheidbeoordelingen correleert sterker met een onafhankelijke meting van impression management dan het antwoorden overeenkomstig de eigen sociale wenselijkheidbeoordelingen. De individuele verschillen in de sociale wenselijkheidbeoordelingen lijken dus te getuigen van ware score variantie.

Een andere opvatting wordt weerlegd in Hoofdstuk 8. Het matchen van stimuli zou een verandering in hun sociale wenselijkheid kunnen bewerkstelligen. Een stimulus zou in een andere context, door het te koppelen aan een andere stimulus, een andere wenselijkheid kunnen krijgen. Deze invloed is eerder aangetoond met vergelijkende preferentieoordelen van gematchte stimuli. Respondenten moeten de stimulus kiezen die het meest wenselijk is in gematchte MCI's. De grondgedachte is dat als stimuli adequat gematcht zijn, ze even vaak verkozen worden in de populatie. In alle besproken onderzoeken zijn echter afwijkingen van een uniforme verdeling gevonden.

De hypothese is dat als stimuli nauwkeurig gematcht zijn, een persoon die stimulus kiest die voor hem het meest toepasselijk is in plaats van het meest wenselijk. Dit zou aansluiten op de conclusie van Hoofdstuk 7. Hofstee (1967), die dit het mixture effect noemt, voorziet in een verzameling van nauwkeurig gematchte stimulusparen. Een deel daarvan wordt gekoppeld aan de antwoordfrequenties uit een andere gegevensverzameling. De resultaten duiden op het mixture effect. Dit effect kan de afwijkingen van de uniforme verdeling verklaren. Want het matchen op sociale wenselijkheid zorgt ervoor dat de gematchte stimuli systematisch verschillen in aantrekkelijkheid of moeilijkheid. Het additief scoringsmodel kan geen rekening houden met deze systematische verschuiving in aantrekkelijkheid of moeilijkheid tussen de gematchte stimuli. De invloed van de sociaal wenselijke antwoordhouding wordt daardoor overgebracht op de scores van de gemeten eigenschap.

De conclusie luidt dat ipsatief meten, zoals het op dit moment wordt toegepast, nauwelijks een voordeel biedt. De statistisch significante verbetering van het MCI ten opzichte van het SI in de profielmetingen van Hoofdstuk 5 is de enig beschikbare aanwijzing. Maar met ipsatieve standaardscores is het voordeel verwaarloosbaar. Het vormt geen rechtvaardiging voor ipsatief meten. De eigenschappen ervan verhinderen directe vergelijkingen tussen personen en beperken de mogelijkheden voor data-analyse. Op dit moment moet ipsatief meten als ongeschikt beschouwd worden voor praktische meetdoeleinden.

Voor het onderzoek van meetmethoden kan de combinatie van gelijkgerichte en tegengestelde MCI's een nieuw startpunt bieden voor toekomstige ontwikkelingen. Deze benadering lijkt meer in harmonie met het additief scoringsmodel. Een 
ander voordeel zou voort kunnen vloeien uit verbeteringen van het testtheoretisch model dat aan het MCI ten grondslag ligt. Een nieuw scoringsmodel zou met de verschillen in aantrekkelijkheid of moeilijkheid tussen gematchte stimuli wellicht weten om te gaan. 
Appendices 


\section{A.4 Appendices to Chapter 4}

\section{A.4.1 Supplementary results of the SOV-SI and SOV-MCI}

Table A.4.1: Descriptive statistics of the SOV-SI and the SOV-MCI

\begin{tabular}{lllrllll}
\hline & & \multicolumn{2}{c}{ Part I } & \multicolumn{2}{c}{ Part II } & \multicolumn{2}{c}{ Part I+II } \\
& & mean & SD & mean & SD & mean & SD \\
\hline SI & Theoretical & 40.8 & 10.0 & 39.6 & 8.6 & 80.4 & 17.5 \\
& Economic & 36.3 & 7.9 & 36.2 & 8.1 & 72.4 & 14.7 \\
& Aesthetic & 37.8 & 9.1 & 42.0 & 9.7 & 79.8 & 17.6 \\
& Social & 45.7 & 8.1 & 46.9 & 7.5 & 92.6 & 14.7 \\
& Political & 37.8 & 8.1 & 35.0 & 7.9 & 72.7 & 14.7 \\
& Religious & 30.3 & 10.0 & 32.8 & 7.6 & 63.1 & 16.3 \\
\hline $\mathrm{MCl}$ I & Theoretical & 17.0 & 4.3 & 25.8 & 4.1 & 42.8 & 7.5 \\
& Economic & 14.3 & 3.6 & 24.2 & 5.0 & 38.5 & 7.5 \\
& Aesthetic & 16.6 & 4.1 & 25.0 & 4.8 & 41.7 & 7.7 \\
& Social & 18.5 & 3.7 & 31.4 & 4.7 & 49.8 & 7.2 \\
& Political & 12.9 & 3.3 & 22.9 & 3.6 & 35.8 & 5.7 \\
& Religious & 10.7 & 4.0 & 20.8 & 4.6 & 31.5 & 7.4 \\
\hline
\end{tabular}

Note. $n=405$.

Table A.4.2: Congruent correlations between the SOV-SI and the SOV-MCI

\begin{tabular}{lccc}
\hline & Part I & Part II & Part I+II \\
\hline Theoretical & 0.622 & 0.544 & 0.647 \\
Economic & 0.397 & 0.461 & 0.459 \\
Aesthetic & 0.517 & 0.499 & 0.581 \\
Social & 0.495 & 0.364 & 0.490 \\
Political & 0.281 & 0.403 & 0.403 \\
Religious & 0.619 & 0.465 & 0.603 \\
\hline
\end{tabular}

Note. $n=405$. 


\section{A.4.2 Dichotomising the item in the SOV Part I}

The graded comparison item in Part I influences the profile scores of both Part I and Part I+II. In addition the derived SI item ipsatized profile scores could also be based on a dichotomised graded comparison item in Part I. This results in the distributions of the profile similarity coefficients as tabulated in Table A.4.3 and the Wilcoxon $\mathrm{Z}$ coefficients of the profile comparisons as shown in Table A.4.4.

Table A.4.3: Distribution of the rank correlations with profiles of the SOV-PC

\begin{tabular}{llccccccc}
\hline & & mean & SD & $\min$ & $\mathbf{Q}_{1}$ & median & $\mathbf{Q}_{3}$ & max \\
\hline Part 1+ll & MCl raw(d) & 0.65 & 0.32 & -0.87 & 0.55 & 0.74 & 0.86 & 1.00 \\
& SI item ips.(d) & 0.67 & 0.27 & -0.60 & 0.54 & 0.71 & 0.89 & 1.00 \\
Part I & MCl raw(d) & 0.58 & 0.32 & -0.88 & 0.41 & 0.67 & 0.81 & 1.00 \\
& SI item ips.(d) & 0.58 & 0.33 & -0.81 & 0.41 & 0.65 & 0.83 & 1.00 \\
\hline
\end{tabular}

Note. $(\mathrm{d})=$ Part I dichotomised; ips. = ipsatized; norm. = normatized; $\mathrm{Q}_{1}=$ first quartile; $\mathrm{Q}_{3}$ $=$ third quartile; $n=405$, except for the Part I SI item ips.(d) profiles, due to a lack of variance in one profile $n=404$.

Table A.4.4: Profile similarity comparisons with Wilcoxon $\mathrm{Z}$ coefficients

\begin{tabular}{|c|c|c|c|c|c|c|c|c|c|c|}
\hline \multirow[b]{2}{*}{ Part } & \multirow{2}{*}{$\begin{array}{c}\mathrm{MCl} \\
\text { item level }\end{array}$} & \multirow{2}{*}{$\begin{array}{c}\text { SI } \\
\text { item level }\end{array}$} & \multirow{2}{*}{$\begin{array}{c}\text { SI } \\
\text { I var level } \\
\end{array}$} & \multicolumn{3}{|c|}{ Nsubjects } & \multirow{2}{*}{$\begin{array}{l}\text { Neg. } \\
\text { ranks }\end{array}$} & \multirow{2}{*}{$\begin{array}{l}\text { Pos. } \\
\text { ranks }\end{array}$} & \multirow{2}{*}{$\begin{array}{c}\text { Wilcoxon } \\
\mathrm{Z}\end{array}$} & \multirow[b]{2}{*}{$\mathbf{p}$} \\
\hline & & & & $\mathrm{MCl}<\mathrm{SI}$ & $\mathrm{MCl}>\mathrm{SI}$ & $\mathrm{MCl}=\mathrm{SI}$ & & & & \\
\hline+11 & $\begin{array}{l}\operatorname{raw}(d) \\
\operatorname{raw}(d)\end{array}$ & $\begin{array}{l}\text { raw } \\
\text { raw }\end{array}$ & $\begin{array}{l}\mathrm{raw} / \mathrm{ips} . \\
\mathrm{raw} / \mathrm{ips} .\end{array}$ & & & $\begin{array}{r}34 \\
8\end{array}$ & & & & $\begin{array}{l}0.858 \\
0.787 \\
\end{array}$ \\
\hline HII & $\begin{array}{l}\operatorname{raw}(d) \\
\operatorname{raw}(d)\end{array}$ & $\begin{array}{l}\text { raw } \\
\text { raw }\end{array}$ & & $\begin{array}{r}89 \\
113 \\
\end{array}$ & & $\begin{array}{r}13 \\
4 \\
\end{array}$ & & & $\begin{array}{ll}5 & -11.437 \\
5 & -10.416 \\
\end{array}$ & $\begin{array}{l}0.000 \\
0.000 \\
\end{array}$ \\
\hline $\begin{array}{l}1+11 \\
1+11 \\
1+11 \\
1 \\
1 \\
1\end{array}$ & $\begin{array}{l}\operatorname{raw}(d) \\
\operatorname{raw} \\
\operatorname{raw}(d) \\
\operatorname{raw}(d) \\
\operatorname{raw} \\
\operatorname{raw}(d)\end{array}$ & $\begin{array}{l}\text { ips. } \\
\text { ips.(d) } \\
\text { ips.(d) } \\
\text { ips. } \\
\text { ips.(d)* } \\
\text { ips.(d)* }\end{array}$ & $\begin{array}{l}\text { raw/ips. } \\
\text { raw/ips. } \\
\text { raw/ips. } \\
\text { raw/ips. } \\
\text { raw/ips. } \\
\text { raw/ips. }\end{array}$ & $\begin{array}{l}189 \\
182 \\
190 \\
198 \\
179 \\
201 \\
\end{array}$ & $\begin{array}{l}185 \\
183 \\
198 \\
206 \\
195 \\
\end{array}$ & $\begin{array}{r}38 \\
32 \\
9 \\
19 \\
8 \\
\end{array}$ & $\begin{array}{l}36289.0 \\
32839.5 \\
36162.0 \\
39984.0 \\
32145.0 \\
38715.5 \\
\end{array}$ & $\begin{array}{l}31976.0 \\
34688.5 \\
33589.0 \\
38622.0 \\
42160.0 \\
39890.5 \\
\end{array}$ & $\begin{array}{r}1.052 \\
-0.455 \\
0.617 \\
-0.299 \\
-2.292 \\
0.258 \\
\end{array}$ & $\begin{array}{l}0.854 \\
0.325 \\
0.732 \\
0.383 \\
0.011 \\
0.602 \\
\end{array}$ \\
\hline
\end{tabular}

Note. (d) = Part I dichotomised; ips. = ipsatized; norm. = normatized; ${ }^{*}$ the Part I SI item ips.(d) profiles yield only 404 profile similarity coefficients, because one profile exhibited no variance. 


\section{A.4.3 Frequency polygons of the profile similarity coefficients}

Figure A.4.1: Frequency polygon $\mathrm{r}_{\mathrm{s}}$ Part $\mathrm{I}$ and $\mathrm{II}$

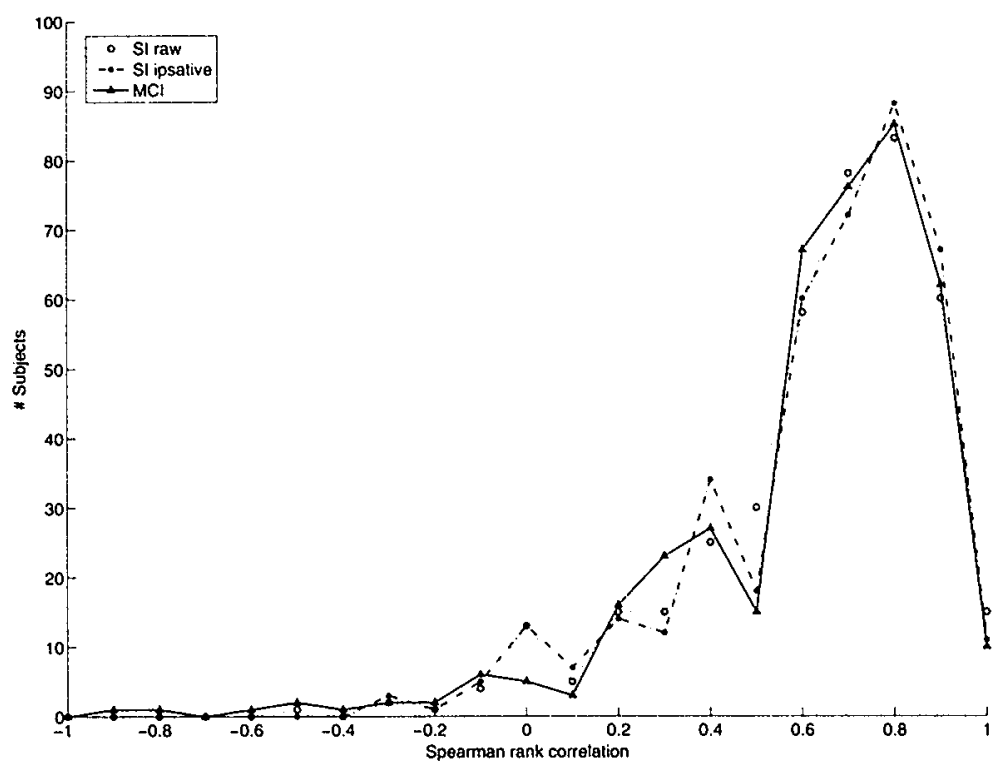


Figure A.4.2: Frequency polygon $r_{s}$ Part I

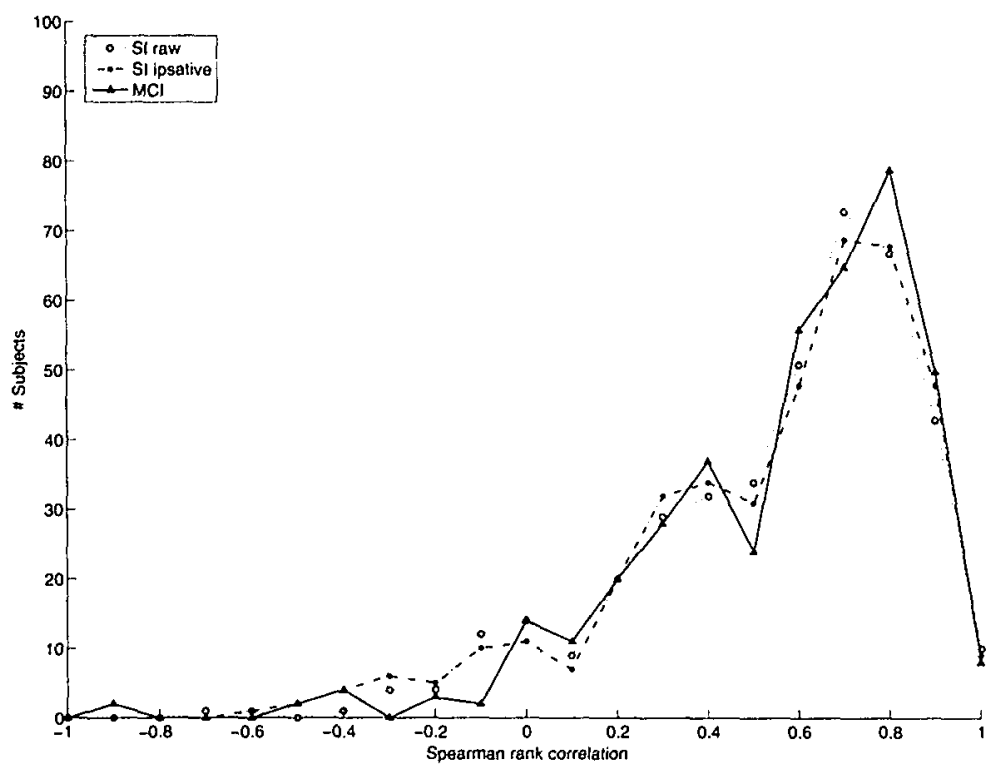

Figure A.4.3: Frequency polygon $r_{s}$ Part II

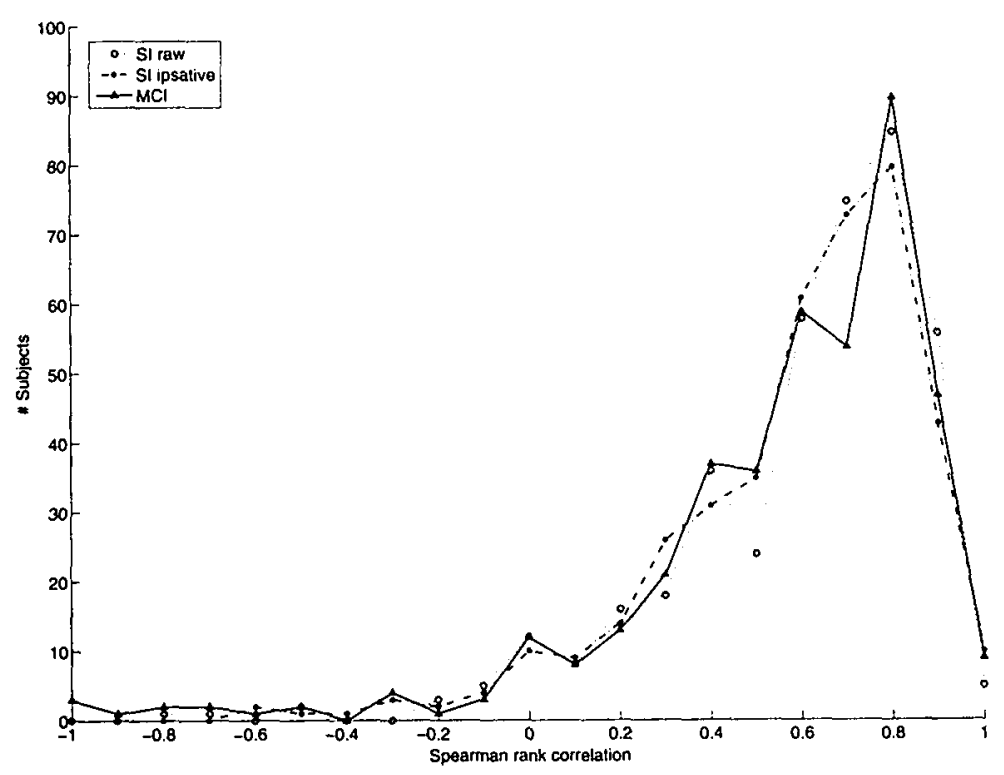




\section{A.5 Appendices to Chapter 5}

\section{A.5.1 The domain-referenced score transformation}

The following function transforms an asymmetric scale $X$ resulting from a multiple comparison item with a scale minimum of $\min (X)$, a scale maximum of $\max (X)$, and scale midpoint of $\bar{X}$ into a symmetric scale with a scale minimum of 0 , a scale maximum of 1 and a scale midpoint of 0.5 :

$$
X^{\prime}=\frac{\frac{\max (X)-\bar{X}}{\bar{X}-\min (X)}(X-\min (X))}{\left(\frac{\max (X)-\bar{X}}{\bar{X}-\min (X)}-1\right)(X-\min (X))+\max (X)-\min (X)} .
$$

The current VIT-MCI has a scale minimum of 0 , a scale maximum of 56 , and a scale midpoint of $154 / 11=14$. In a symmetric scale the midpoint would be 28 instead. To adjust the scale for its larger score range above the midpoint of 14 its reference scale points are substituted in Formula A.1:

$$
X^{\prime}=\frac{\frac{56-14}{14-0}(X-0)}{\left(\frac{56-14}{14-0}-1\right)(X-0)+56-0}=\frac{3 X}{2 X+56} .
$$

The result equals Formula 5.1 (see p. 97). Figure 5.3 shows the outcome of this scale transformation. Notice by the way that if the scale ranging from 0 to 56 would have been symmetric, substituting the midpoint parameter by 28 instead of 14 in Formula 5.6 generates the function:

$$
X^{\prime}=X / 56
$$

Formula A.3 equals the domain referenced score transformation at interval measurement that would also have resulted from Formula 2.1 (see p. 26), except for the rescaling constant of 100 . 


\section{A.5.2 The Vocational Interests Test-Feedback form (VIT-FB)}

SUBJECT NUMBER

\begin{tabular}{|l|l|}
\hline TESTNUMBER: & $958-\mathrm{C}$ \\
\hline
\end{tabular}

\begin{tabular}{|l|l|l|l|l|}
\hline 3 & 5 & & & \\
\hline
\end{tabular}

\section{VIT-FB}

In one of the previous test sessions you have completed two versions of the Vocational Interests Test. The current questionnaire aims to check whether these two versions differ. You have received a separate form with your results on both versions. Look at your results on this VIT results form now. Check per variable which result describes you best. In the questions below you can indicate per variable which version you prefer. Use the response option 'Both versions are similar' only if the two scores correspond exactly. The last question asks you to indicate your preference for the interests profile as a whole.

Important:

Check first whether the subject number on the VIT results form is actually your own subject number.

Which version produced the result that matches best your own self image about your interest in:
1. Technical Handcraft
(] SI version
a $\mathrm{MCl}$ version
Doth versions are similar
2. Traditional Design
口 SI version
a $\mathrm{MCI}$ version
Both versions are similar
3. Engineering and Natural Sciences
SI version
a $\mathrm{MCl}$ version
口 Both versions are similar
4. Nutrition
- SI version
- $\mathrm{MCI}$ version
Doth versions are similar
5. Farm Work
口 SI version
- $\mathrm{MCI}$ version
Doth versions are similar
6. Trade
口 SI version
口 MCI version
- Both versions are similar
7. Office Work
a SI version
a $\mathrm{MCl}$ version
ㅁoth versions are similar
8. Language and Culture
口 SI version
口 $\mathrm{MCI}$ version
b Both versions are similar
9. Man and Society
a SI version
a $\mathrm{MCI}$ version
a Both versions are similar
10. Social Work
a Sl version
口 $\mathrm{MCl}$ version
D Both versions are similar
11. Medical Work
SI version
D $\mathrm{MCl}$ version
Both versions are similar

Which version produced the interest profile that best matches your self image as a whole?
12. Interest profile as a whole
a SI version
$\square \mathrm{MCl}$ version

THANK YOU FOR YOUR COOPERATION.

PLEASE PUT THIS FORM IN THE FOLDER.

Note. The respondent was not informed that the acronyms SI and MCI actually referred to the employed item formats. The form is a translation; it was administered in Dutch. 


\section{A.5.3 Example of a personal report sheet of the VIT results}
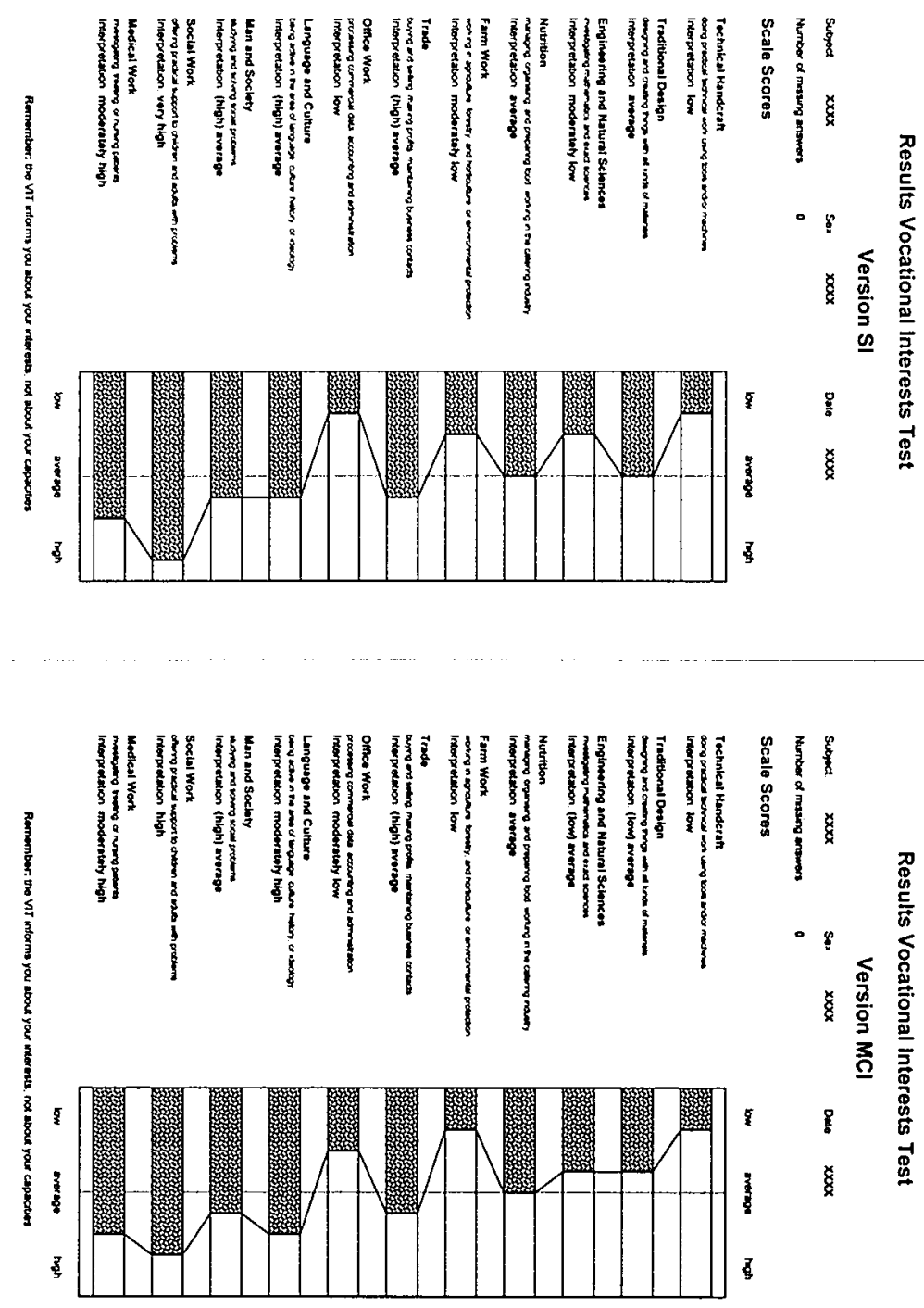

Note. The form is a translation; it was administered in Dutch. 


\section{A.5.4 Supplementary results of the VIT-MCI and VIT-SI}

Table A.5.1: Split-half reliability coefficients of the VIT-MCI and VIT-SI

\begin{tabular}{lccccccccccc}
\hline & TH & TD & EN & NU & FW & TR & OW & LC & MS & SW & MW \\
\hline VIT-MCI & 0.94 & 0.94 & 0.94 & 0.93 & 0.93 & 0.94 & 0.92 & 0.94 & 0.93 & 0.97 & 0.97 \\
VIT-SI & 0.96 & 0.95 & 0.95 & 0.95 & 0.94 & 0.92 & 0.96 & 0.93 & 0.86 & 0.92 & 0.96 \\
\hline
\end{tabular}

Note. Split-half reliability coefficients arc corrected by the Spearman-Brown formula.

Table A.5.2: Descriptive statistics of the domain-referenced VIT scores

\begin{tabular}{lllllllll}
\hline & \multicolumn{4}{c}{ VIT-MCl } & \multicolumn{3}{c}{ VIT-SI } \\
\cline { 2 - 9 } & \multicolumn{2}{c}{$\begin{array}{c}\text { men } \\
\end{array}$} & \multicolumn{2}{c}{$n=116$} & \multicolumn{2}{c}{$\begin{array}{c}\text { women } \\
n=285\end{array}$} & \multicolumn{2}{c}{ men } \\
& mean & SD & mean & SD & mean & SD & \multicolumn{2}{c}{ momen } \\
& mean & SD \\
\hline TH & 0.231 & 0.209 & 0.076 & 0.131 & 0.286 & 0.188 & 0.168 & 0.150 \\
TD & 0.449 & 0.216 & 0.496 & 0.230 & 0.432 & 0.203 & 0.504 & 0.196 \\
EN & 0.405 & 0.214 & 0.229 & 0.196 & 0.379 & 0.184 & 0.288 & 0.171 \\
NU & 0.399 & 0.252 & 0.511 & 0.213 & 0.453 & 0.205 & 0.551 & 0.185 \\
FW & 0.296 & 0.237 & 0.194 & 0.209 & 0.322 & 0.190 & 0.296 & 0.191 \\
TR & 0.482 & 0.251 & 0.385 & 0.197 & 0.421 & 0.208 & 0.373 & 0.154 \\
OW & 0.179 & 0.197 & 0.152 & 0.165 & 0.202 & 0.181 & 0.186 & 0.154 \\
LC & 0.589 & 0.228 & 0.616 & 0.215 & 0.517 & 0.191 & 0.550 & 0.194 \\
MS & 0.642 & 0.171 & 0.597 & 0.172 & 0.531 & 0.166 & 0.519 & 0.153 \\
SW & 0.637 & 0.241 & 0.799 & 0.166 & 0.532 & 0.178 & 0.672 & 0.173 \\
MW & 0.386 & 0.257 & 0.478 & 0.282 & 0.387 & 0.202 & 0.463 & 0.226 \\
\hline
\end{tabular}

Note. TH: Technical Handcraft, TD: Traditional Design, EN: Engineering and Natural Sciences, NU: Nutrition, FW: Farm Work, TR: Trade, OW: Office Work, LC: Language and Culture, MS: Man and Society, SW: Social Work, and MW: Medical Work.

Table A.5.3: Student's t-tests of differences in within-subjects statistics

\begin{tabular}{|c|c|c|c|c|c|c|c|c|c|c|}
\hline & & \multirow[b]{3}{*}{$n$} & \multicolumn{4}{|c|}{ VIT-MCI } & \multicolumn{4}{|c|}{ VIT-SI } \\
\hline & & & \multicolumn{2}{|c|}{ WS mean } & \multicolumn{2}{|c|}{ WS SD } & \multicolumn{2}{|c|}{ WS mean } & \multicolumn{2}{|c|}{ WS SD } \\
\hline & & & mean & SD & mean & SD & mean & $\mathrm{SD}$ & mean & SD \\
\hline \multirow[t]{3}{*}{ Sex } & men & 116 & 0.427 & 0.027 & 0.262 & 0.054 & 0.406 & 0.116 & 0.176 & 0.044 \\
\hline & women & 285 & 0.412 & 0.023 & 0.291 & 0.038 & 0.415 & 0.099 & 0.210 & 0.049 \\
\hline & $t\left(d f^{*}\right) p$ & & \multicolumn{2}{|c|}{$5.06(183.9)<0.05$} & \multicolumn{2}{|c|}{$-5.17(103.5)<0.05$} & $-0.86(399.0$ & 0) 0.39 & \multicolumn{2}{|c|}{$-6.52(399.0)<0.05$} \\
\hline \multirow[t]{3}{*}{ Order } & $\mathrm{MCl}$ first & 22 & 0.421 & 0.025 & 0.274 & 0.047 & 0.399 & 0.099 & 0.199 & 0.049 \\
\hline & SI first & 173 & 0.410 & 0.024 & 0.294 & 0.040 & 0.431 & 0.109 & 0.201 & 0.051 \\
\hline & $t\left(d f^{*}\right) p$ & & \multicolumn{2}{|c|}{$4.73(399.0)<0.05$} & $-4.49(39$ & $3.3)<0.05$ & \multicolumn{2}{|c|}{$-3.07(399.0)<0.05$} & \multicolumn{2}{|c|}{$-0.51(399.0)$} \\
\hline
\end{tabular}

Note. * If the degrees of freedom deviate from 399 it was adapted, because Levene's test indicated a significant inequality of the variances; WS mean: within-subjects mean; WS SD: within-subjects standard deviation. 
A.5.5 Scatterplots of domain-referenced scores on VIT halves

Technical Handcraft (MCI)

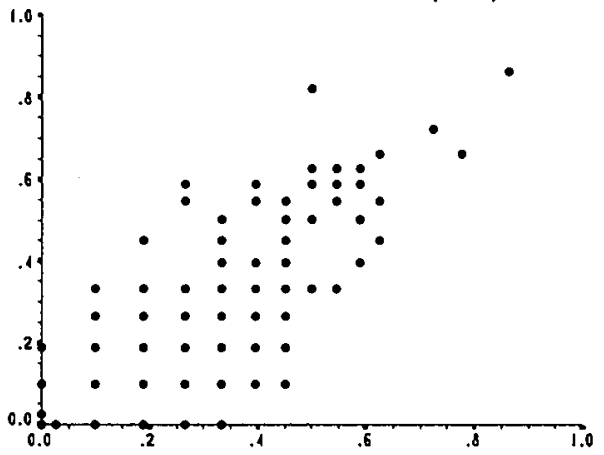

Traditional Design (MCl)

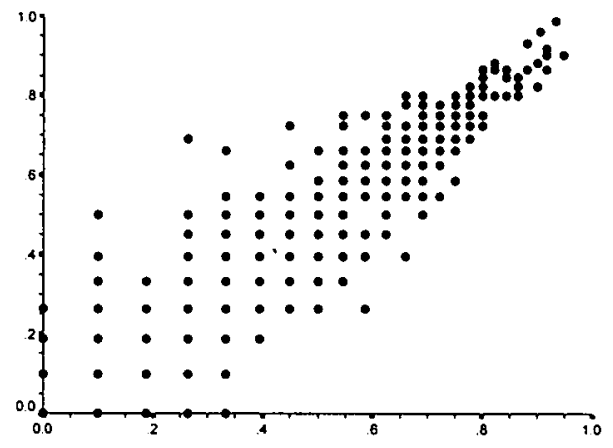

Engineering and Natural Sciences (MCl)

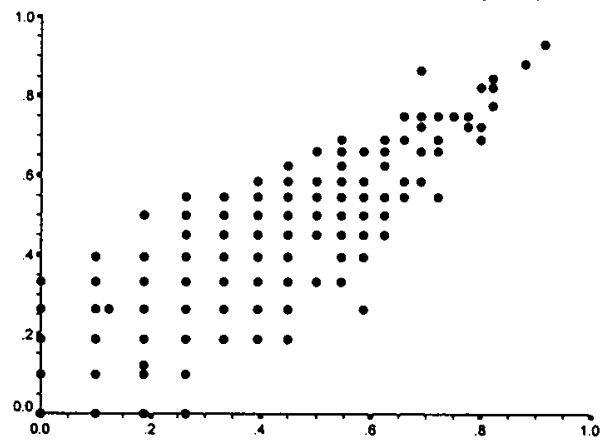

Technical Handcraft (SI)

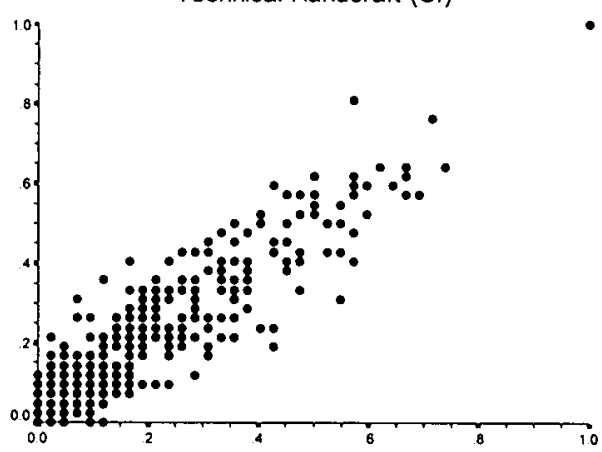

Traditional Design (SI)

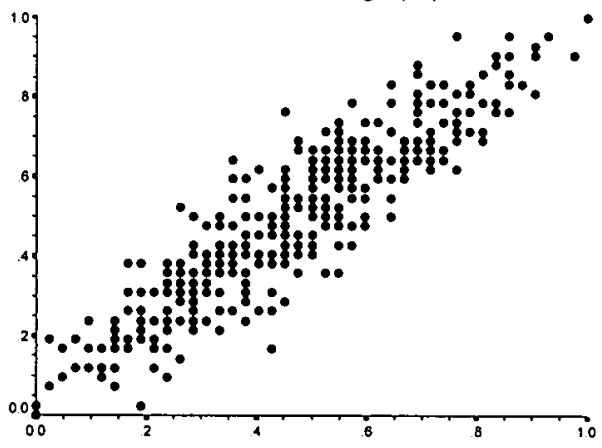

Engineering and Natural Sciences (SI)

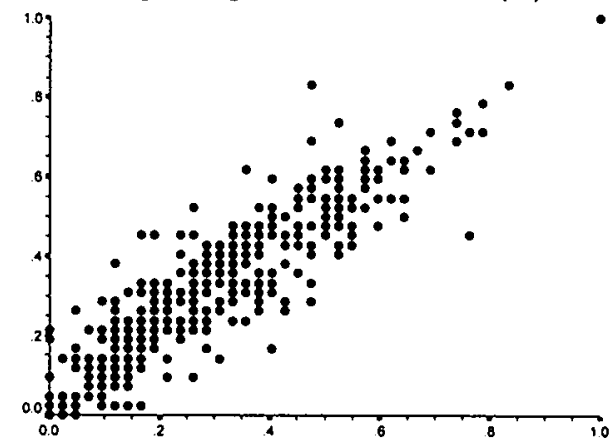


Nutrition (MCl)
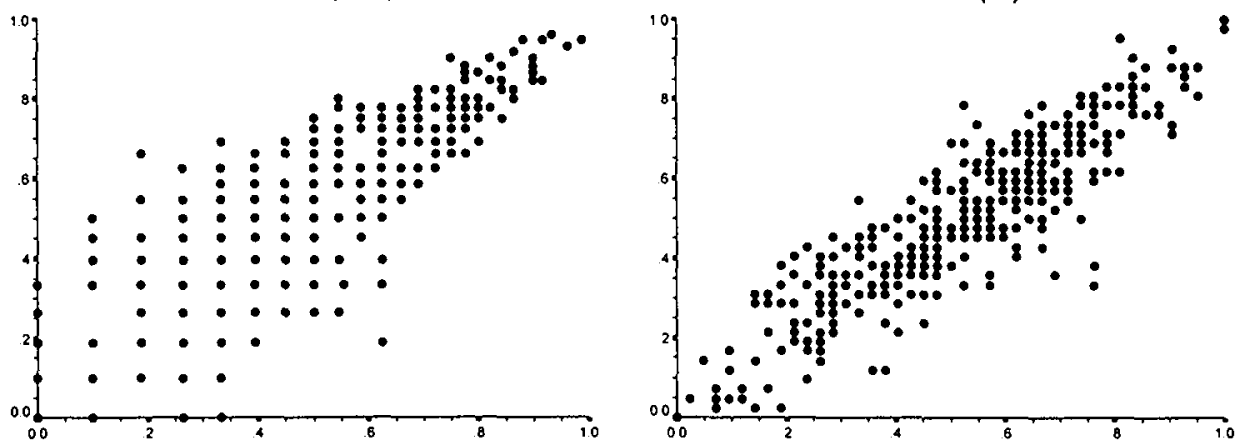

Farm Work

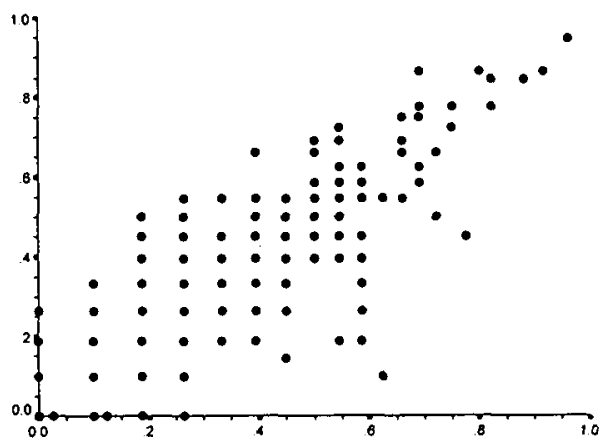

Trade (MCl)

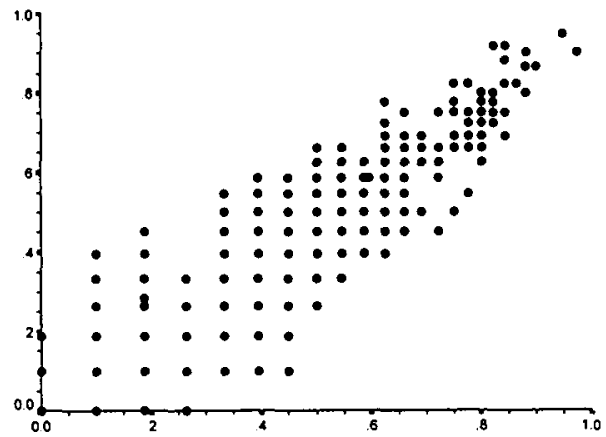

Farm Work (SI)

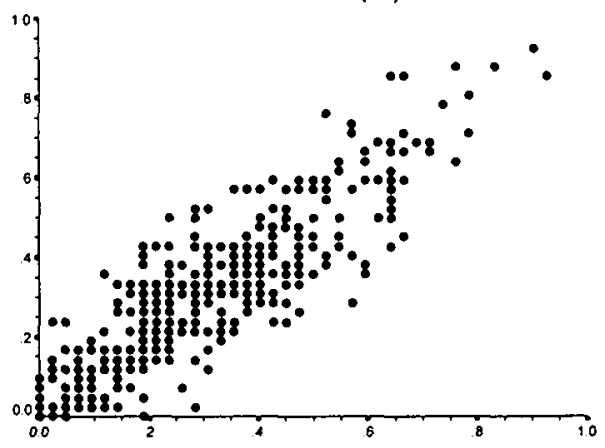

Trade (SI)

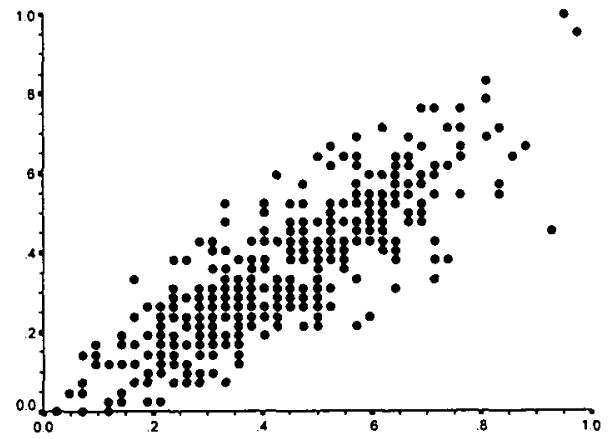


Office Work (MCl)

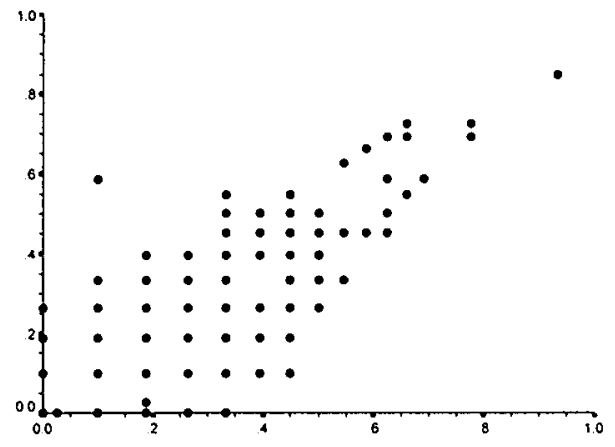

Language and Culture (MCl)

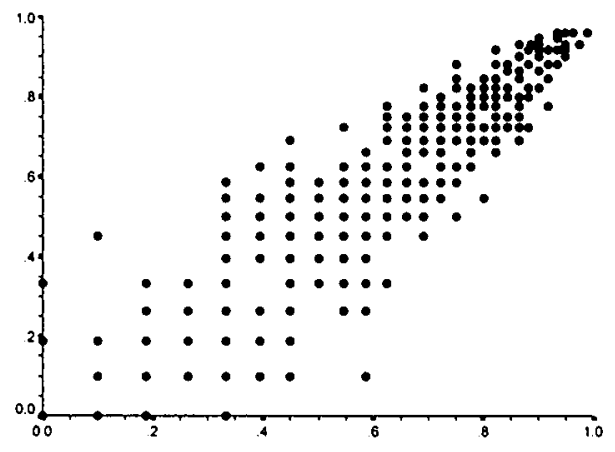

Man and Society (MCl)

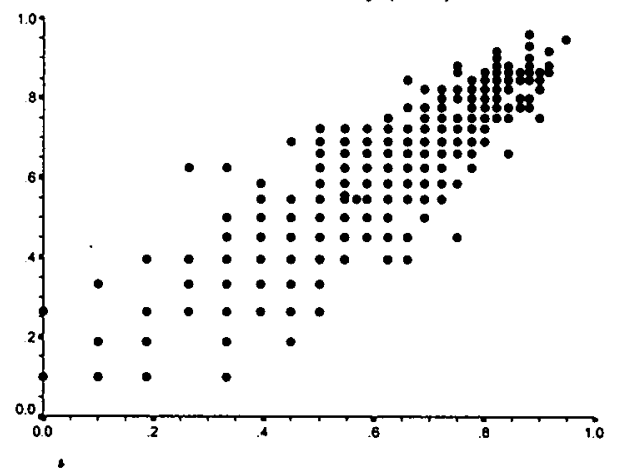

Office Work (SI)

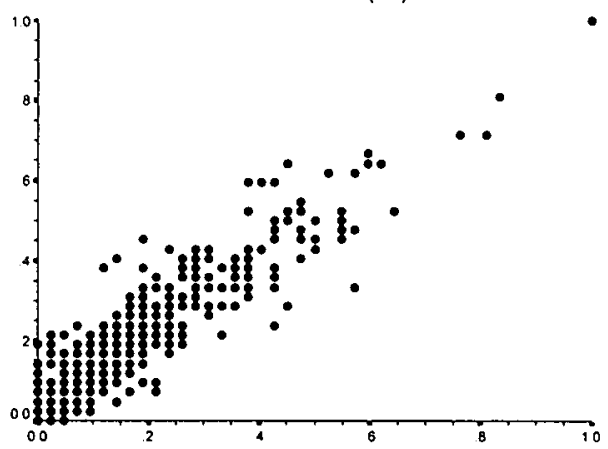

Language and Culture (SI)

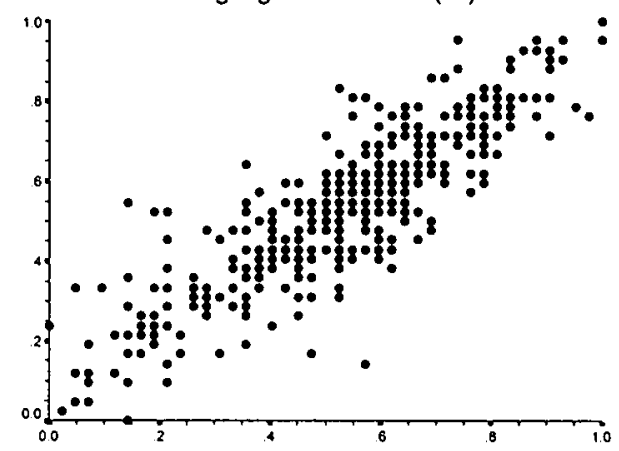

Man and Society (SI)

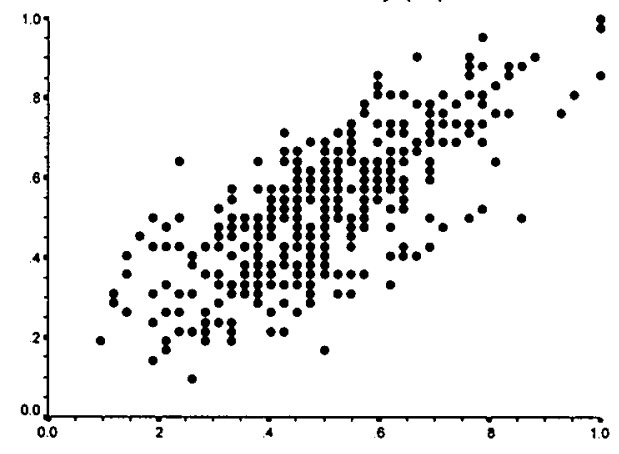



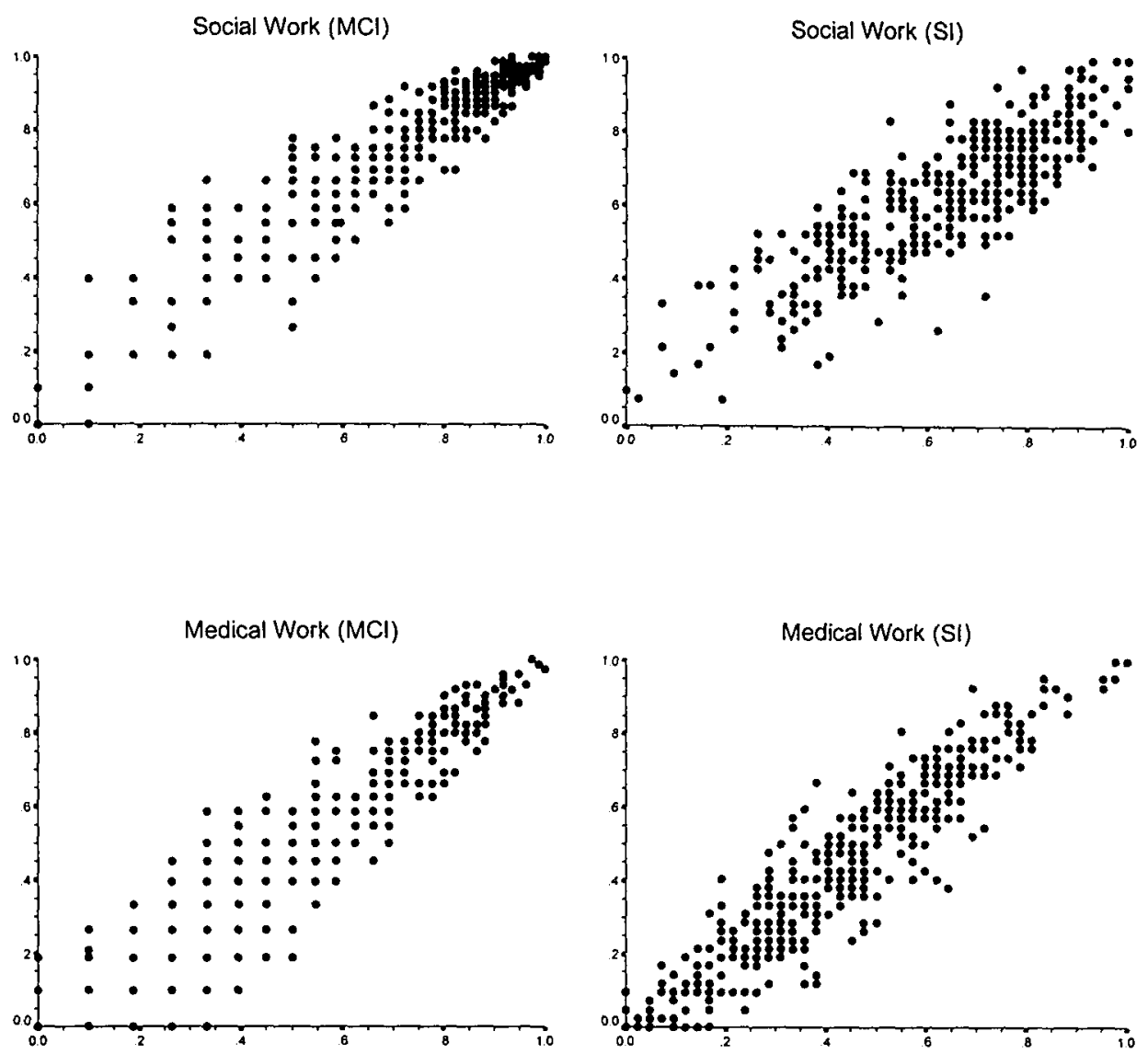

Note. The dots in the scatterplots do not have the aspect of a random cloud; they all occur at fixed distances. In fact, the dots appear tied to the intersections of a grid. This grid aspect of the scatterplots is caused by the limited range in the raw scores. One half of the VIT-MCI allows for a mere 29 raw score categories (ranging from 0 to 28), whereas one half of the VIT-SI includes 43 raw score categories (ranging from 7 to 49). As a result of these restricted score ranges many subjects are projected over each other. In the MCI scatterplots some dots seem to deviate from the grid (see for instance point $[0.10 ; 0.21]$ in the MCI scatterplot Medical Work above). These are due to the handling of an omitted item. Then the four stimuli are each credited with 0.25 point. 


\section{A.5.6 Subject counts of preference on VIT-FB items 1 to 11}

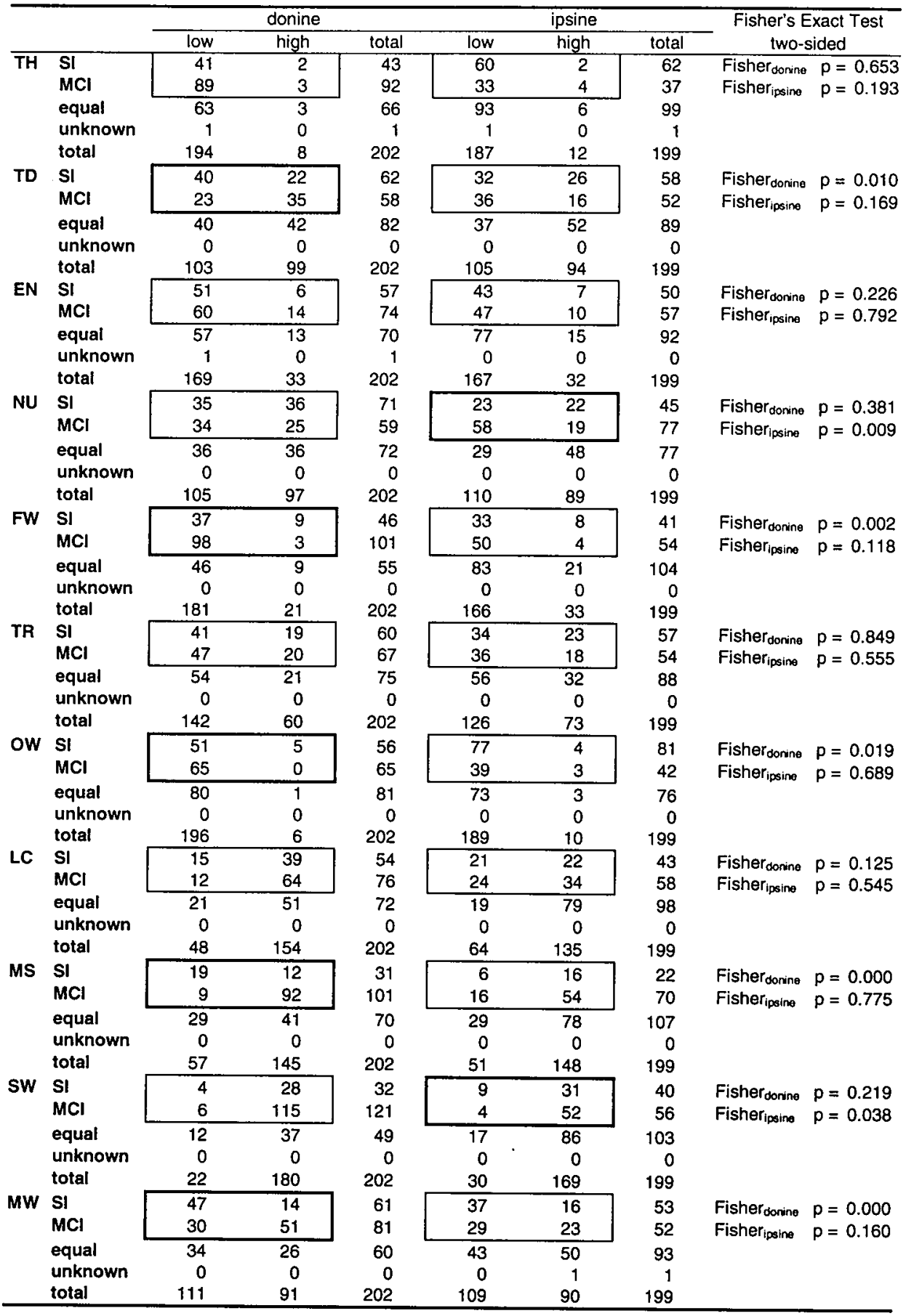




\section{A.6 Appendices to Chapter 6}

\section{A.6.1 Split-half correlation matrix}

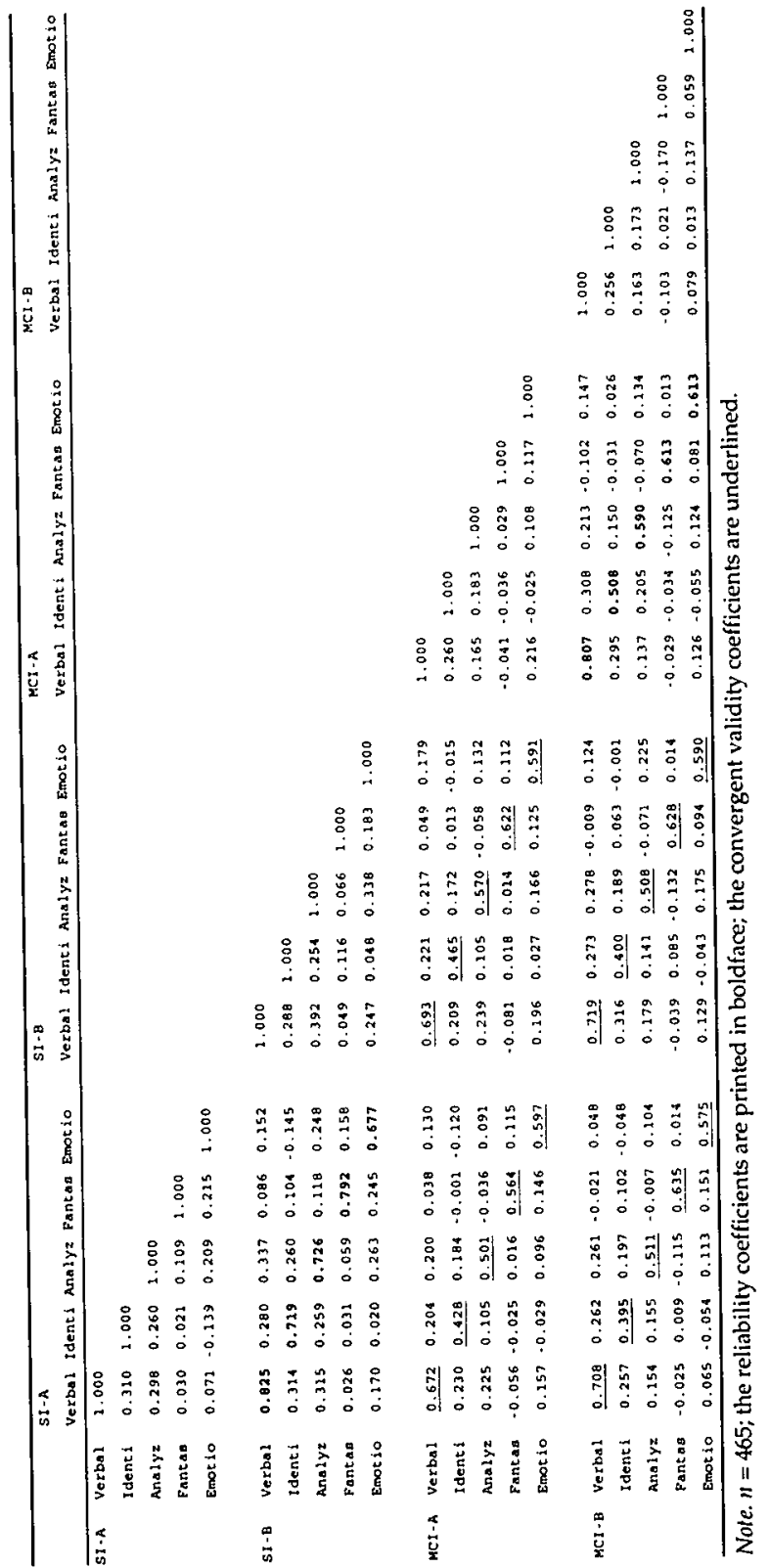


Table A.6.3: Correlated Traits-Joint Methods model

\begin{tabular}{|c|c|c|c|c|c|c|c|c|c|c|c|c|c|}
\hline \multirow[b]{3}{*}{ SI-A } & \multirow{3}{*}{ CTJM } & \multirow{2}{*}{\multicolumn{2}{|c|}{ erbalizing }} & \multicolumn{3}{|c|}{ Fantasizing } & \multirow{2}{*}{ SI } & \multirow{3}{*}{$\mathrm{MCl}$} & \multirow{2}{*}{$\begin{array}{l}\text { Unique- } \\
\text { ness }\end{array}$} & \multicolumn{3}{|c|}{$\%$ Variance } & \multirow{2}{*}{$\begin{array}{r}\text { Total } \\
\text { variance }\end{array}$} \\
\hline & & & & Analyzing & Em & tionaliz & & & & \multicolumn{2}{|c|}{ trait method } & \multirow{2}{*}{$\begin{array}{r}\text { unique } \\
25.6\end{array}$} & \\
\hline & & 0.805 & & & & & 0.311 & & 0.256 & 6.1 .7 & 9.7 & & 14.292 \\
\hline & Identi & & 0.778 & & & & 0.240 & & 0.337 & 60.6 & 5.8 & 33.7 & 7.031 \\
\hline & Analyz & & & 0.638 & & & 0.499 & & 0.344 & 40.7 & 24.9 & 34.4 & 7.363 \\
\hline & Fantas & & & & 0.834 & & 0.294 & & 0.219 & 69.5 & 8.7 & 21.9 & 10.497 \\
\hline & Emotio & & & & & 0.755 & 0.274 & & 0.354 & 57.0 & 7.5 & 35.4 & 7.309 \\
\hline \multirow[t]{5}{*}{ SI-B } & Verbal & 0.802 & & & & & 0.403 & & 0.193 & 64.4 & 16.3 & 19.3 & 11.438 \\
\hline & Identi & & 0.803 & & & & 0.247 & & 0.295 & 64.4 & 6.1 & 29.5 & 8.422 \\
\hline & Analyz & & & 0.681 & & & 0.556 & & 0.227 & 46.4 & 30.9 & 22.7 & 6.934 \\
\hline & Fantas & & & & 0.859 & & 0.219 & & 0.214 & 73.8 & 4.8 & 21.4 & 10.988 \\
\hline & Emotio & & & & & 0.739 & 0.384 & & 0.305 & 54.7 & 14.8 & 30.5 & 6.965 \\
\hline \multirow[t]{5}{*}{ MCl-A } & Verbal & 0.852 & & & & & & 0.076 & 0.268 & 72.7 & 0.6 & 26.8 & 12.245 \\
\hline & Identi & & 0.611 & & & & & 0.005 & 0.627 & 37.3 & 0.0 & 62.7 & 6.171 \\
\hline & Analyz & & & 0.784 & & & & 0.056 & 0.382 & 61.5 & 0.3 & 38.2 & 8.382 \\
\hline & Fantas & & & & 0.715 & & & 0.010 & 0.488 & 51.2 & 0.0 & 48.8 & 9.714 \\
\hline & Emotio & & & & & 0.762 & & 0.103 & 0.409 & 58.0 & 1.1 & 40.9 & 7.644 \\
\hline \multirow[t]{5}{*}{$\mathrm{MCl}-\mathrm{B}$} & Verbal & 0.871 & & & & & & 0.110 & 0.229 & 75.9 & 1.2 & 22.9 & 11.719 \\
\hline & Identi & & 0.526 & & & & & 0.116 & 0.710 & 27.6 & 1.3 & 71.0 & 5.605 \\
\hline & Analyz & & & 0.700 & & & & 0.111 & 0.498 & 49.0 & 1.2 & 49.8 & 6.899 \\
\hline & Fantas & & & & 0.768 & & & -0.026 & 0.410 & 59.0 & 0.1 & 41.0 & 10.771 \\
\hline & Emotio & & & & & 0.754 & & 0.089 & 0.423 & 56.9 & 0.8 & 42.3 & 8.975 \\
\hline \multicolumn{2}{|c|}{ Verbalizing } & 1.000 & & & & & & & & $x^{2}$ & & 453.02 & \\
\hline \multicolumn{2}{|c|}{ Identifying } & 0.365 & 1.000 & & & & & & & $\mathrm{~d} \mathbf{f}$ & & 140 & \\
\hline \multicolumn{2}{|c|}{ Analyzing } & 0.295 & 0.250 & 1.000 & & & & & & p-vals & & 0.000 & \\
\hline \multicolumn{2}{|c|}{ Fantasizing - } & -0.054 & 0.024 & -0.103 & 1.000 & & & & & $\chi^{2} / \mathrm{df}$ & & 3.24 & \\
\hline \multicolumn{2}{|c|}{ Emotionalizing } & 0.144 & -0.145 & 0.194 & 0.157 & 1.000 & & & & RMSI & & 0.069 & \\
\hline & $\mathrm{Sl}$ & & & & & & 1.000 & & & GFI & & 0.91 & \\
\hline & $\mathrm{MCl}$ & & & & & & 1.000 & 1.000 & & AGFI & & 0.87 & \\
\hline
\end{tabular}

Note. $n=465$; LISREL warns that the estimated latent trait correlation matrix is not positive definite, as the correlation between $\mathrm{SI}$ and $\mathrm{MCI}$ is fixed to 1 . If instead of the current seven factor model a six factor model is fitted, with the two method factors merged into one, the exact same model is achieved without the warning. 
Table A.6.4: Correlated Traits-No Methods model

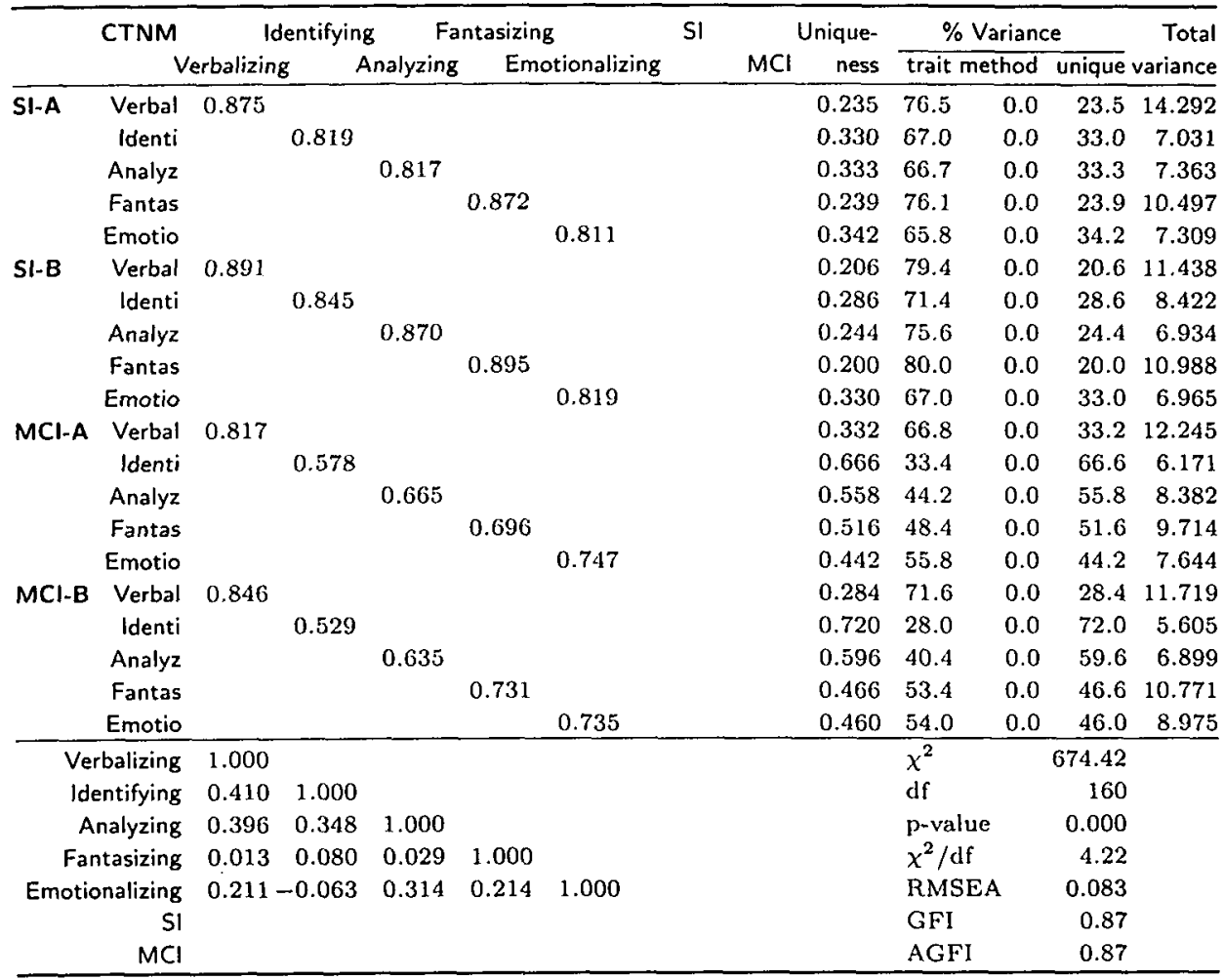

Note. $n=465$. 


\section{A.6.3 Scoring only opposed multidimensional compound items}

If the set of opposed MCIs includes different overlapping combinations of two traits, the separate trait levels may become available. Suppose for instance the total questionnaire covered three traits $X, Y$, and $Z$. The three paired combinations of the traits $X, Y$, and $Z$ received, for instance, the following scores:

$$
\begin{aligned}
& X+Y \rightarrow 3 \\
& X+Z \rightarrow 4 \\
& Y+Z \rightarrow 5
\end{aligned}
$$

Adding all scores it follows that:

$$
\begin{aligned}
(X+Y)+(X+Z)+(Y+Z) & =3+4+5 \\
2 X+2 Y+2 Z & =12 \\
X+Y+Z & =6 .
\end{aligned}
$$

Then by subtracting A.4 from A.5 the separate variable scores would become available:

$$
\begin{aligned}
& X=X+Y+Z-(Y+Z)=6-5=1 \\
& Y=X+Y+Z-(X+Z) \quad 6-4=2 \\
& Z=X+Y+Z-(X+Y) \quad 6-3=3 .
\end{aligned}
$$

If the questionnaire covers more than three traits, the above approach would remain feasible by consequently selecting a subset of three overlapping pairs: $A$ $+\mathrm{B}, \mathrm{B}+\mathrm{C}$, and $\mathrm{A}+\mathrm{C}$; or $\mathrm{A}+\mathrm{C}, \mathrm{C}+\mathrm{D}$, and $\mathrm{A}+\mathrm{D}$; or $\mathrm{B}+\mathrm{C}, \mathrm{C}+\mathrm{D}$, and $\mathrm{B}+\mathrm{D}$, et cetera. So, the aligned MCI only appears essential if the questionnaire includes just two variables, or non-overlapping variable combinations.

The use of Formula A.5 to obtain separate variable scores with the opposed MCI, depends on the assumption that the variable score of $\mathrm{X}$ in combination with variable $Y$ (Formula A.4a) is equal to the variable score $X$ in combination with variable $\mathrm{Z}$ (Formula $\mathrm{A} .4 \mathrm{~b}$ ). This would be best guaranteed if the same stimuli were used in both combinations. If not, at least a fair number of stimuli should be used, to secure that both stimulus samples represent $X$ about equally. With lots of variables, however, the use of the same stimuli over and over again in all variable combinations might increase boredom or fatigue. On the other hand, the use of a reasonable number of stimuli would result in quite a sizeable questionnaire. So, if $\mathrm{X}$ is falsely assumed equal, the above approach might increase measurement error more than would be attained by using aligned MCIs along with opposed MCIs. 


\section{A.7 Appendices to Chapter 7}

\section{A.7.1 Order effects in the EPPS-SPD}

Table A.7.1: Two Hotelling's $\mathrm{T}^{2}$ tests of order effects per EPPS-SPD version

\begin{tabular}{|c|c|c|c|c|c|c|c|c|}
\hline & & Number & subjects & & & & & \\
\hline & & $\overline{S D}$ first & PD first & F-value & $d f_{1}$ & $\mathrm{df}_{2}$ & $p$-value & \\
\hline Version 1 & SD & 32 & 31 & 0.648 & 30 & 32 & 0.882 & \\
\hline & PD & 32 & 31 & 1.176 & 30 & 32 & 0.325 & \\
\hline Version 2 & SD & 28 & 28 & 0.985 & 30 & 25 & 0.521 & \\
\hline & PD & 28 & 28 & 1.152 & 30 & 25 & 0.362 & \\
\hline Version 3 & $\mathrm{SD}$ & 31 & 26 & 2.467 & 30 & 26 & 0.011 & $*$ \\
\hline & PD & 31 & 26 & 0.772 & 30 & 26 & 0.754 & \\
\hline Version 4 & $S \bar{D}$ & 32 & 27 & 1.133 & 30 & 28 & 0.372 & \\
\hline & $\mathrm{PD}$ & 32 & 27 & 0.964 & 30 & 28 & 0.541 & \\
\hline Version 5 & SD & 30 & 26 & 1.448 & 30 & 25 & 0.174 & \\
\hline & PD & 30 & 26 & 1.380 & 30 & 25 & 0.207 & \\
\hline Version 6 & $\mathrm{SD}$ & 29 & 22 & 0.684 & 30 & 20 & 0.831 & \\
\hline & $P D$ & 29 & 22 & 1.108 & 30 & 20 & 0.413 & \\
\hline Version 7 & $\mathrm{SD}$ & 27 & 27 & 1.629 & 30 & 23 & 0.116 & \\
\hline & PD & 27 & 27 & 0.745 & 30 & 23 & 0.778 & \\
\hline Version 8 & SD & 31 & 28 & 1.160 & 30 & 28 & 0.348 & \\
\hline & $P D$ & 31 & 28 & 1.265 & 30 & 28 & 0.267 & \\
\hline
\end{tabular}

Note. *Although $p<0.05$, if the Bonferroni-Hochberg method is applied for the familywise error-rate, the result is not significant (see Hochberg, 1988); SD: Social Desirability rating; PD: Personal Desirability rating. 


\section{A.7.2 Differences in the within-subjects correlations}

Table A.7.2: Non-parametric tests of differences in within-subjects correlations

\begin{tabular}{|c|c|c|c|c|c|c|c|}
\hline & Var $1-\operatorname{Var} 2$ & Negatives & Positives & Ties & Total & $z$ & p-value \\
\hline Sign & $\operatorname{popSDR}_{i}$ indSDR & 145 & 307 & 0 & 452 & -7.573 & 0.00 \\
\hline Wilcoxon & & 31392 & 70986 & & & -7.125 & 0.00 \\
\hline Sign & $\operatorname{popSDR}_{i}$ popPDR & 389 & 63 & 0 & 452 & -15.287 & 0.00 \\
\hline Wilcoxon & & 95882 & 6496 & & & -16.084 & 0.00 \\
\hline Sign & popSDR $R_{i}$ indPDR & 368 & 84 & 0 & 452 & -13.311 & 0.00 \\
\hline Wilcoxon & & 90478 & 11900 & & & -14.139 & 0.00 \\
\hline Sign & $\operatorname{popSDR}_{i}$ TjoaSDR $_{i}$ & 183 & 269 & 0 & 452 & -3.998 & 0.00 \\
\hline Wilcoxon & & 37663 & 64715 & & & -4.868 & 0.00 \\
\hline Sign & indSDR $_{i}$ popPDR & 378 & 74 & 0 & 452 & -14.252 & 0.00 \\
\hline Wilcoxon & & 93872 & 8506 & & & -15.361 & 0.00 \\
\hline Sign & indSDR $R_{i}$ indPDR & 391 & 58 & 3 & 452 & -15.668 & 0.00 \\
\hline Wilcoxon & & 94947 & 6078 & & & -16.152 & 0.00 \\
\hline Sign & indSDR $_{i}$ TjoaSDR $_{i}$ & 260 & 192 & 0 & 452 & -3.151 & 0.00 \\
\hline Wilcoxon & & 61200 & 41178 & & & -3.603 & 0.00 \\
\hline Sign & $p o p P D R_{i}$ indPDR $R_{i}$ & 273 & 179 & 0 & 452 & -4.374 & 0.00 \\
\hline Wilcoxon & & 66090 & 36288 & & & -5.363 & 0.00 \\
\hline Sign & popPDR $_{i}$ TjoaSDR $_{i}$ & 59 & 393 & 0 & 452 & -15.663 & 0.00 \\
\hline Wilcoxon & & 6054 & 96324 & & & -16.243 & 0.00 \\
\hline Sign & indPDR TjoaSDR $_{i}$ & 72 & 380 & 0 & 452 & -14.440 & 0.00 \\
\hline Wilcoxon & & 9330 & 93048 & & & -15.064 & 0.00 \\
\hline
\end{tabular}

Note. $n=452$ subjects; in three subjects the within-subjects correlations could not be computed due to a lack of variance in the EPPS responses to the 30 item subset that corresponds with the completed EPPS-SPD version.

Table A.7.3: Effect sizes of the differences in within-subjects correlations

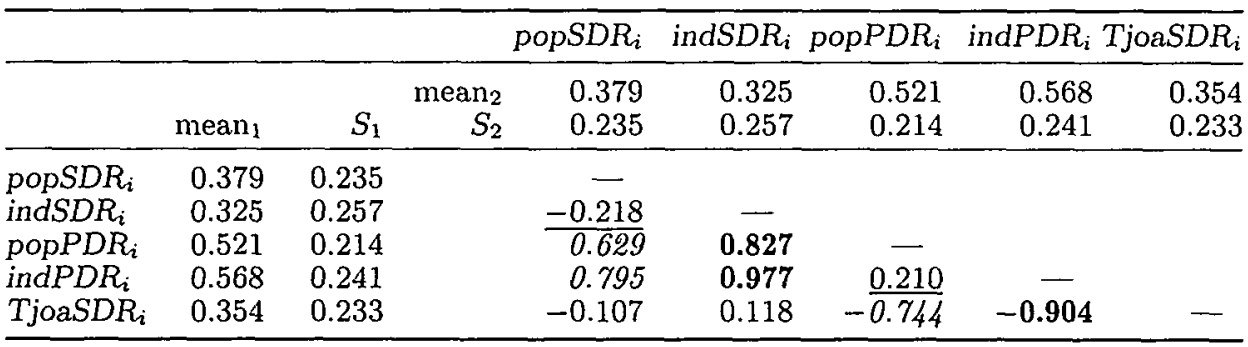

Note. Effect sizes are defined: $\left(\right.$ mean $_{1}-$ mean $\left._{2}\right) / \sqrt{ }\left(\left[S_{1}^{2}+S_{2}^{2}\right] / 2\right)$. A small effect is underlined $(0.2 \leq|\mathrm{ES}|<0.5)$, a medium effect is printed in italics $(0.5 \leq|\mathrm{ES}|<0.8)$, and a large effect is set in boldface $(0.8 \leq|\mathrm{ES}|)$. 


\section{References}

Aitchison, J. (1983). Principal component analysis of compositional data. Biometrika, $70(1), 57-65$.

Aitchison, J. (1986). The statistical analysis of compositional data. London: Chapman and Hall.

Allport, G. W., Vernon, P. E., \& Lindzey, G. (1960). Manual: Study of Values: A scale for measuring the dominant interests in personality (3rd ed.). Boston, MA: Houghton Mifflin.

Angoff, W. H. (1962). Scales with nonmeaningful origins and units of measurement. Symposium: Standard scores for aptitude and achievement tests. Educational and Psychological Measurement, 22(1), 27-34.

Angoff, W. H. (1971). Scales, norms, and equivalent scores. In R. L. Thorndike (Ed.), Educational measurement. Washington, D.C.: American Council on Education.

Angoff, W. H. \& Donlon, T. F. (1971). The Scholastic Aptitude Test. In W. H. Angoff (Ed.), The College Board admissions testing program: A technical report on research and development activities relating to the Scholastic Aptitude Test and Achievement Tests (pp. 15-47). New York, NY: College Entrance Examination Board.

Appel, V. (1956). An experimental test of the superiority and theory of the forced-choice questionnaire construction ( $\mathrm{PhD}$ thesis, New York University). Dissertation Abstracts, 20, 1067-1068. University Microfilms No. 59-02437.

Baier, D. E. (1951). Reply to Travers' "A critical review of the validity and rationale of the forced-choice technique". Psychological Bulletin, 48(5), 421434.

Bartlett, C. J., Quay, L. C., \& Wrightsman, L. S., Jr. (1960). A comparison of two methods of attitude measurement: Likert-type and forced choice. Educational and Psychological Measurement, 20(4), 699-704.

Beck, A. T., Ward, C. H., Mendelson, M., Mock, J., \& Erbaugh, J. (1961). An inventory for measuring depression. Archives of General Psychiatry, 4, $561-571$.

Bermond, B., Vorst, H. C. M., \& Vingerhoets, A. J. J. M. (1999). The Amsterdam Alexithymia Scale: Its psychometric values and correlations with other personality traits. Psychotherapy and Psychosomatics, 68(5), 241-251.

Bernardin, H. J. (1987). Development and validation of a forced choice scale to measure job-related discomfort among customer service representatives. Academy of Management Journal, 30(1), 162-173.

Bernardin, H. J. \& Beatty, R. W. (1985). Performance appraisal: Assessing human behavior at work. Boston, MA: Kent Publishing Company Wadsworth.

Beutell, N. J. \& Kressel, S. S. (1984). An investigation of Kolb's Learning Styles Inventory: Social desirability and normative scoring. Psychological Reports, 55(1), 89-90. 
Block, J. (1957). A comparison between ipsative and normative ratings of personality. Joumal of Abnormal and Social Psychology, 54(1), 50-54.

Block, J. (1965). The challenge of response sets: Unconfounding meaning, acquiescence, and social desirability in the MMPI. New York, NY: AppletonCentury-Crofts.

Boe, E. E. \& Kogan, W. S. (1963). Social desirability response set in the individual. Jourmal of Consulting Psychology, 27(4), 369.

Braun, J. R. \& Costantini, A. (1968). Fakability and control for social desirability of the Survey of Personal Values. Proceedings of the 76th Annual Convention. of the American Psychological Association, 3, 161-162.

Braun, J. R. \& Seamon, J. (1969). Control for social desirability in the Trait Evaluation Index. Journal of Projective Techniques and Personality Assessment, $33(3), 279-280$.

Braun, J. R. \& Tinley, J. (1968). Control for social desirability in the Thorndike Dimensions of Temperament. Psychological Reports, 23(3, Pt. 2), 1150.

Braun, J. R. \& Tinley, J. J. (1969). Comment on Fricke's approach to controlling social desirability in the forced-choice format. Psychological Reports, 25(1), 93-94.

Broverman, D. M. (1961). Effects of score transformations in $Q$ and $R$ factor analysis techniques. Psychological Review, 68(1), 68-80.

Broverman, D. M. (1962). Normative and ipsative measurement in psychology. Psychological Review, 69(4), 295-305.

Buxton, C. E. (1966). Evaluations of forced-choice and Likert-type tests of motivation to academic achievement. British Journal of Educational Psychology, $36,192-201$.

Caminada, H., Evers, A., \& Brouwer, A. (1981). Hoe werkt men met tests? De Psycholoog, 16(1), 43-47.

Campbell, D. T. \& Erlebacher, A. (1970). How regression artifacts in quasiexperimental evaluations can mistakenly make compensatory education look harmful. In J. Hellmuth (Ed.), Disadvantaged child, vol. III: Compensatory education - a national debate (pp. 185-210). New York, NY: Brunner/Mazel.

Campbell, D. T. \& Fiske, D. W. (1959). Convergent and discriminant validation by the multitrait-multimethod matrix. Psychological Bulletin, 56(2), 81105.

Campbell, D. T. \& Stanley, J. C. (1963). Experimental and quasi-experimental designs for research on teaching. In N. L. Gage (Ed.), Handbook for research on teaching (pp. 171-246). Chicago, IL: Rand McNally \& Co.

Carroll, L. (1960). Through the looking glass and what Alice found there. In M. Gardner (Ed.), The annotated Alice (pp. 166-346). New York, NY: Bramhall House. (Original work published 1871)

Cattell, R. B. (1944). Psychological measurement: Normative, ipsative, interactive. Psychological Review, 51(5), 292-303. 
Cattell, R. B. (1952). The three basic factor-analytic research designs - their interrelations and derivatives. Psychological Bulletin, 49(5), 499-520.

Cattell, R. B. \& Brennan, J. (1994). Finding personality structure when ipsative measurements are the unavoidable basis of the variables. American Journal of Psychology, 107(2), 261-274.

Chan, W. (2003). Analyzing ipsative data in psychological research. Behaviormetrika, 30(1), 99-121.

Chan, W. \& Bentler, P. M. (1993). The covariance structure analysis of ipsative data. Sociological Methods \& Research, 22(2), 214-247.

Chan, W. \& Bentler, P. M. (1996). Covariance structure analysis of partially additive ipsative data using restricted maximum likelihood estimation. Multivariate Behavioral Research, 31(3), 289-312.

Chan, W. \& Bentler, P. M. (1998). Covariance structure analysis of ordinal ipsative data. Psychometrika, 63(4), 369-399.

Chapman, L. J. \& Bock, R. D. (1958). Components of variance due to acquiescence and content in the F Scale measure of authoritarianism. Psychological Bulletin, 55(5), 328-333.

Christiansen, N. D., Burns, G. N., \& Montgomery, G. E. (2005). Reconsidering forced-choice item formats for applicant personality assessment. Human Performance, 18(3), 267-307.

Clemans, W. V. (1966). An analytical and empirical examination of some properties of ipsative measures. Psychometric Monograph, 14, vi-56.

Closs, S. J. (1976). Ipsative vs. normative interpretation of interest test scores or 'What do you mean by "like"?'. Bulletin of the British Psychological Society, 28, 289-299.

Closs, S. J. (1996). On the factoring and interpretation of ipsative data. Journal of Occupational and Organizational Psychology, 69(1), 41-47.

Cohen, J. (1977). Statistical power analysis for the behavioral sciences (revised ed.). New York, NY: Academic Press.

Coombs, C. H. (1953). Theory and methods of social measurement. In L. Festinger \& D. Katz (Eds.), Research methods in the behavioral sciences (pp. 471535). New York, NY: The Dryden Press.

Corah, N. L., Feldman, M. J., Cohen, I. S., Gruen, W., Meadow, A., \& Ringwall, E. A. (1958). Social desirability as a variable in the Edwards Personal Preference Schedule. Journal of Consulting Psychology, 22(1), 70-72.

Cornwell, J. M. \& Dunlap, W. P. (1994). On the questionable soundness of factoring ipsative data: A response to Saville \& Willson. Journal of Occupational and Organizational Psychology, 67(2), 89-100.

Cronbach, L. J. (1942). Studies of acquiescence as a factor in the true-false test. Journal of Educational Psychology, 33(6), 401-415.

Cronbach, L. J. (1946). Response sets and test validity. Educational and Psychological Measurement, 6, 475-494.

Cronbach, L. J. (1950). Further evidence on response sets and test design. Educational and Psychological Measurement, 10, 3-31. 
Cronbach, L. J. (1970). Essentials of psychological testing (3rd ed.). New York, NY: Harper \& Row.

Cronbach, L. J. (1990). Essentials of psychological testing (5th ed.). New York, NY: Harper Collins.

Cruse, D. B. (1966). Some relations between minimal content, acquiescentdissentient, and social desirability scales. Journal of Personality and Social Psychology, 3(1), 112-119.

Davis, T. M. \& Chissom, B. (1981). Factor analysis (R-technique) of ipsatized data may be misleading. Psychological Reports, 49(2), 643-647.

De Vries, A. L. (2005a). Herziening van Edwards' Personal Preference Schedule: Een interim rapport (Tech. Rep.). Maastricht: Universiteit van Maastricht.

De Vries, A. L. (2005b). Intern rapport over de $S W$-vragenlijst (Tech. Rep.). Maastricht: Universiteit van Maastricht.

Dunlap, W. P. \& Cornwell, J. M. (1994). Factor analysis of ipsative measures. Multivariate Behavioral Research, 29(1), 115-126.

Ebel, R. L. (1962). Content standard test scores. Symposium: Standard scores for aptitude and achievement tests. Educational and Psychological Measurement, 22(1), 15-25.

Edwards, A. L. (1952). The scaling of stimuli by the method of successive intervals. Journal of Applied Psychology, 36(2), 118-122.

Edwards, A. L. (1953). The relationship between the judged desirability of a trait and the probability that the trait will be endorsed. Journal of Applied Psychology, 37(2), 90-93.

Edwards, A. L. (1954). Edwards Personal Preference Schedule: Manual (revised 1959 ed.). New York, NY: The Psychological Corporation.

Edwards, A. L. (1957). The social desirability variable in personality assessment and research. New York, NY: Dryden Press.

Edwards, A. L. (1959). Social desirability and personality test construction. In B. M. Bass \& I. A. Berg (Eds.), Objective approaches to personality assessment (pp. 100-118). Princeton, NJ: Van Nostrand.

Edwards, A. L. (1965). Measurement of individual differences in ratings of social desirability and in the tendency to give socially desirable responses. Journal of Experimental Research in Personality, 1(2), 91-98.

Edwards, A. L., Wright, C. E., \& Lunneborg, C. E. (1959). A note on "social desirability as a variable in the edwards personal preference schedule". Journal of Consulting Psychology, 23(6), 558 .

Eekhof, J. A. H., Mol, S. S. L., \& Pielage, J. C. (1992). Is doorgaans vaker dan dikwijls; of hoe vaak is soms? Nederlands Tijdschrift voor Geneeskunde, $136(1), 41-42$.

Evers, A., Lucassen, W., \& Meijaard, D. (1983). Een empirische vergelijking tussen de ipsatieve en de vrije-keuze vorm van een vragenlijst. Gedrag Tijdschrift voor Psychologie, 11(2/3), 135-146.

Evers, A., Lucassen, W., \& Wiegersma, S. (1999). Beroepen Interessen Test (BIT) versie 1997: Handleiding. Lisse: Swets \& Zeitlinger. 
Evers, A., Van Vliet-Mulder, J. C., \& Groot, C. J. (2000). Documentatie van tests en testresearch in Nederland. Amsterdam: Nederlands Instituut van Psychologen; Assen: Van Gorcum.

Fan, X. \& Thompson, B. (2001). Confidence intervals about score reliability coefficients, please: An EPM guidelines editorial. Educational and Psychological Measurement, 61(4), 517-531.

Fedorak, S. \& Coles, E. M. (1979). Ipsative vs normative interpretation of test scores: A comment on Allen and Foreman's (1976) norms on Edwards Personal Preference Schedule for female Australian therapy students. Perceptual and Motor Skills, 48(3, Pt. 1), 919-922.

Feij, J. A. \& Van Zuilen, R. W. (1984). Handleiding Spanningsbehoefte Lijst, $S B L$. Lisse: Swets \& Zeitlinger.

Feldman, M. J. \& Corah, N. L. (1960). Social desirability and the forced choice method. Journal of Consulting Psychology, 24(6), 480-482.

Feldt, L. S. (1980). A test of the hypothesis that Cronbach's alpha reliability coefficient is the same for two tests administered to the same sample. Psychometrika, 45(1), 99-105.

Flanagan, J. C. (1939). The cooperative achievement tests; a bulletin reporting the basic principles and procedures used in the development of their system of scaled scores. New York, NY: The Cooperative Test Service of the American Council on Education.

Frederiksen, N. (1965). Response set scores as predictors of performance. Personnel Psychology, 18(3), 225-244.

Fritz, M. F. (1927). Guessing in a true-false test. Journal of Educational Psychology, 18(8), 558-561.

Furnham, A. (1986). Response bias, social desirability and dissimulation. Personality and Individual Differences, 7(3), 385-400.

Galton, F. (1885). Some results of the anthropometric laboratory. Journal of the Anthropological Institute, 14, 275-287.

Geiger, M. A., Boyle, E. J., \& Pinto, J. K. (1993). An examination of ipsative and normative versions of Kolb's revised Learning Style Inventory. Educational and Psychological Measurement, 53(3), 717-726.

Glaser, R. (1963). Instructional technology and the measurement of learing outcomes: Some questions. American Psychologist, 18(7), 519-521.

Golembiewski, R. T., Billingsley, K., \& Yeager, S. (1976). Measuring change and persistence in human affairs: Types of change generated by OD designs. Journal of Applied Behavioral Science, 12, 133-157.

Goodstein, L. D. \& Heilbrun, A. B., Jr. (1959). The relationship between personal and social desirability values of the Edwards Personal Preference Schedule. Journal of Consulting Psychology, 23(2), 183.

Gordon, L. V. (1951). Validities of the forced-choice and questionnaire methods of personality measurement. Journal of Applied Psychology, 35(6), 407-412.

Guilford, J. P. (1952). When not to factor analyze. Psychological Bulletin, 49(1), 26-37. 
Heilbrun, A. B., Jr. (1963). Evidence regarding the equivalence of ipsative and normative personality scales. Journal of Consulting Psychology, 27(2), 152156.

Heilbrun, A. B., Jr. \& Goodstein, L. D. (1959). Relationships between personal and social desirability sets and performance on the Edwards Personal Preference Schedule. Journal of Applied Psychology, 43(5), 302-305.

Heilbrun, A. B., Jr. \& Goodstein, L. D. (1961). Social desirability response set: Error or predictor variable? Journal of Psychology, 51, 321-329.

Heineman, C. E. (1953). A forced-choice form of the Taylor Anxiety Scale. Journal of Consulting Psychology, 17(6), 447-454.

Hermans, H. (1967). Motivatie en prestatie: Prestatie-motivatie, sociale wenselijkheid, capaciteiten en succes. Amsterdam: Swets \& Zeitlinger.

Hicks, L. E. (1970). Some properties of ipsative, normative, and forced-choice normative measures. Psychological Bulletin, 74(3), 167-184.

Hochberg, Y. (1988). A sharper Bonferroni procedure for multiple tests of significance. Biometrika, 75(4), 800-802.

Hoel, P. G. (1984). Introduction to mathematical statistics (5th ed.). New York, NY: Wiley \& Sons.

Hofstee, W. K. B. (1966). Secular trends in an adjective checklist. Educational and Psychological Measurement, 26(2), 363-367.

Hofstee, W. K. B. (1967). Method effects in absolute and comparative judgment. $\mathrm{PhD}$ thesis, Rijksuniversiteit Groningen, Groningen.

Hofstee, W. K. B. (1969). Method effects in judging the desirability of traits. Educational and Psychological Measurement, 29(3), 583-604.

Hofstee, W. K. B. (1970). Comparative versus absolute judgments of trait desirability. Educational and Psychological Measurement, 30(3), 639-646.

Hogan, T. P., Benjamin, A., \& Brezinski, K. L. (2000). Reliability methods: A note on the frequency of use of various types. Educational and Psychological Measurement, 60(4), 523-531.

Horst, P. \& Wright, C. E. (1959). The comparative reliability of two techniques of personality appraisal. Journal of Clinical Psychology, 15(4), 388-391.

Howe, E. S. (1960). Further comparison of two short-form derivatives of the Taylor Manifest Anxiety Scale. Psychological Reports, 6, 21-22.

Howe, E. S. (1964). A third comparison of two short-form derivatives of the Taylor MAS, using psychiatric patients. Psychological Reports, 14 (2), 497-498.

Howe, E. S. \& Silverstein, A. B. (1960). Comparison of two short-form derivatives of the Taylor Manifest Anxiety Scale. Psychological Reports, 6, 9-10.

Jackson, D. J. \& Alwin, D. F. (1980). The factor analysis of ipsative measures. Sociological Methods \& Research, 9(2), 218-238.

Jackson, D. N. \& Minton, H. L. (1963). A forced-choice adjective preference scale for personality assessment. Psychological Reports, 12(2), 515-520.

Jackson, D. N., Neill, J. A., \& Bevan, A. R. (1973). An evaluation of forced-choice and true-false item formats in personality assessment. Journal of Research in Personality, $7(1), 21-30$. 
Jackson, D. N., Wroblewski, V. R., \& Ashton, M. C. (2000). The impact of faking on employment tests: Does forced choice offer a solution? Human Performance, 13(4), 371--388.

Johnson, C. E., Wood, R., \& Blinkhorn, S. F. (1988). Spuriouser and spuriouser: The use of ipsative personality tests. Journal of Occupational Psychology, 61(2), 153-162.

Jones, E. E. \& Sigall, H. (1971). The bogus pipeline: A new paradigm for measuring affect and attitude. Psychological Bulletin, 76(5), 349-364.

Jurgensen, C. E. (1944). Report on the "Classification Inventory," a personality test for industrial use. Journal of Applied Psychology, 28 (6), 445-460.

Karr, C. (1958). A comparison of EPPS scores obtained from the standard forcedchoice procedure and a rating-scale procedure $(\mathrm{PhD}$ thesis, University of Washington). Dissertation Abstracts, 19, 3382-3383. University Microfilms No. 59-01225.

Katz, M. (1962). Interpreting Kuder Preference Record scores: Ipsative or normative. Vocational Guidance Quarterly, 10, 96-100.

Knapp, R. R. (1964). An empirical investigation of the concurrent and observational validity of an ipsative versus a normative measure of six interpersonal values. Educational and Psychological Measurement, 24(1), 65-73.

Knapp, T. R. (1966). Interactive versus ipsative measurement of career interest. Personnel and Guidance Journal, 44(5), 482-486.

Kogan, W. S. \& Fordyce, W. E. (1962). The control of social desirability: A comparison of three different $\mathrm{Q}$ sorts and a check list, all composed of the same items. Journal of Consulting Psychology, 26(1), 26-30.

Kopelman, R. E., Rovenpor, J. L., \& Guan, M. (2003). The Study of Values: Construction of the fourth edition. Journal of Vocational Behavior, 62(2), 203-220.

Lamning, K. (1989). Detection of invalid response patterns on the California Psychological Inventory. Applied Psychological Measurement, 13(1), 45-56.

Lapointe, F.-J. \& Legendre, P. (1994). A classification of pure malt Scotch whiskies. Applied Statistics, 43(1), 237-257.

Lapointe, R. E. \& Auclair, G. A. (1961). The use of social desirability in forcedchoice methodology. American Psychologist, 16(7), 446.

Lentz, T. F. (1938). Acquiescence as a factor in the measurement of personality. Psychological Bulletin, 35(9), 659.

Lindell, M. K. \& Drexler, J. A., Jr. (1979). Issues in survey methods for measuring organizational change. Academy of Management Review, 4(1), 13-19.

Lindquist, E. F. (1953). Selecting appropriate score scales for tests: Discussion. In G. K. Bennett (Ed.), Proceedings of the 1952 invitational conference on testing problems (pp. 34-40). Princeton, NJ: Educational Testing Service.

Longstaff, H. P. \& Jurgensen, C. E. (1953). Fakability of the Jurgensen Classification Inventory. Journal of Applied Psychology, 37(2), 86-89.

Loo, R. (1999). Issues in factor-analyzing ipsative measures: The Learning Style 
Inventory (LSI-1985) example. Joumnal of Business and Psychology, 14(1). 149-154.

Lord, F. M. \& Novick, M. R. (1968). Statistical theories of mental test scores. Reading, MA: Addison-Wesley.

Lorge, I. (1937). Gen-like: Halo or reality. Psychological Bulletin, 34(8), 545-546.

Luteijn, F. \& Barelds, D. P. H. (2004). Groninger Intelligentie Test 2: Handleiding. Amsterdam: Harcourt Test Publishers.

Luteijn, F. \& Van der Ploeg, F. A. E. (1983). Groninger Intelligentie Test: Handleiding. Lisse: Swets \& Zeitlinger.

Mais, R. D. (1951). Fakability of the Classification Inventory scored for self confidence. Journal of Applied Psychology, 35(3), 172-174.

Marsh, H. W. \& Grayson, D. (1994). Multitrait-multimethod analysis. In T. Husén \& T. N. Postlethwaite (Eds.), International encyclopedia of education (2nd ed., Vol. 7, pp. 4000-4007). Oxford: Pergamon.

Martin, B. A., Bowen, C. C., \& Hunt, S. T. (2002). How effective are people at faking on personality questionnaires? Personality and Individual Differences, 32(2), 247-256.

Matthews, G. \& Oddy, K. (1995). Ipsative and normative scales in adjectival measurement of personality: Problems of bias and discrepancy. International Journal of Selection and Assessment, 5(3), 169-182.

McGuire, W. J. (1969). Suspiciousness of experimenter's intent. In R. Rosenthal \& R. L. Rosnow (Eds.), Artifact in behavioral research (pp. 13-57). New York, NY: Academic Press.

McNemar, Q. (1940). A critical examination of the University of Iowa studies of environmental influences upon the IQ. Psychological Bulletin, 37(2), 63-92.

Mellenbergh, G. J. (1996). Measurement precision in test score and item response models. Psychological Methods, 1(3), 293-299.

Mellenbergh, G. J. \& Thio, K. T. (1966). Een Nederlandse versie van de S.O.V. Nederlands Tijdschrift voor de Psychologie en haar Grensgebieden, 21 (10), 627-641.

Meng, X.-L., Rosenthal, R., \& Rubin, D. B. (1992). Comparing correlated correlation coefficients. Psychological Bulletin, 111(1), 172-175.

Merenda, P. F. \& Clarke, W. V. (1963). Forced-choice vs free-response in personality assessment. Psychological Reports, 13(1), 159-169.

Merritt, S. L. \& Marshall, J. C. (1984a). Reliability and construct validity of alternate forms of the CLS Inventory. Advances in Nursing Science, 7(1), $78-85$.

Merritt, S. L. \& Marshall, J. C. (1984b). Reliability and construct validity of ipsative and normative forms of the Learning Style Inventory. Educational and Psychological Measurement, 44(2), 463-472.

Messick, S. (1960). Dimensions of social desirability. Journal of Consulting Psychology, 24(4), 279-287.

Messick, S. \& Jackson, D. N. (1961). Desirability scale values and dispersions for MMPI items. Psychological Reports, 8, 409-414. 
Mosteller, F. \& Youtz, C. (1990). Quantifying probabilistic expressions. Statistical Science, 5(1), 2-34.

Murray, H. A. (1938). Explorations in personality: A clinical and experimental study of fifty men of college age. New York, NY: Oxford University Press.

Nederhof, A. J. (1985). Methods of coping with social desirability bias: A review. European Journal of Social Psychology, 15(3), 263-280.

Newkirk, G. F., Brogden, H. E., \& Loeffler, J. C. (1950). The prediction of officer potential of ROTC cadets. American Psychologist, 5(7), 360.

Norman, W. T. (1963). Personality measurement, faking, and detection: An assessment method for use in personnel selection. Journal of Applied Psychology, 47(4), 225-241.

Norman, W. T. (1967). On estimating psychological relationships: Social desirability and self-report. Psychological Bulletin, 67(4), 273-293.

Oort, F. J. (1993). Theory of violators: Assessing unidimensionality of psychological measures. In R. Steyer, K. F. Wender, \& K. F. Widaman (Eds.), 7th European Meeting of the Psychometric Society (pp. 377-381). Trier, Germany: Gustav Fisher Verlag.

Oosterveld, P. (1996). Questionnaire design methods. $\mathrm{PhD}$ thesis, University of Amsterdam, Amsterdam.

Orvik, J. M. (1972). Social desirability for the individual, his group, and society. Multivariate Behavioral Research, 7(1), 3-32.

Paulhus, D. L. (1981). Control of social desirability in personality inventories: Principal-factor deletion. Journal of Research in Personality, 15(3), 383388.

Paulhus, D. L. (1984). Two-component models of socially desirable responding. Journal of Personality and Social Psychology, 46(3), 598-609.

Paulhus, D. L. (1991). Measurement and control of response bias. In J. P. Robinson, P. R. Shaver, \& L. S. Wrightsman (Eds.), Measures of personality and social psychological attitudes. Measures of social psychological attitudes, vol. 1 (pp. 17-59). San Diego, CA, US: Academic Press, Inc.

Perry, D. K. (1955). Forced-choice vs. L-I-D response items in vocational interest measurement. Journal of Applied Psychology, 39(4), 256-262.

Preston, C. C. \& Colman, A. M. (2000). Optimal number of response categories in rating scales: Reliability, validity, discriminating power, and respondent preferences. Acta Psychologica, 104 (1), 1-15.

Radcliffe, J. A. (1963). Some properties of ipsative score matrices and their relevance for some current interest tests. Australian Journal of Psychology, 15(1), 1-11.

Raghunathan, T. E., Rosenthal, R., \& Rubin, D. B. (1996). Comparing correlated but nonoverlapping correlations. Psychological Methods, 1(2), 178-183.

Rorer, L. G. (1965). The great response-style myth. Psychological Bulletin, 63(3), 129-156.

Rosen, E. (1956). Self-appraisal, personal desirability, and perceived social de- 
sirability of personality traits. Journal of Abnormal and Social Psychology. $52(2), 151-158$.

Rosen, E. \& Mink, S. H. (1961). Desirability of personality traits as perceived by prisoners. Journal of Clinical Psychology, 17(2), 147-151.

Rosenberg, M. (1965). Society and the adolescent self-image. Princeton, NJ: Princeton University Press.

Ross, R. T. (1934). Optimum orders for the presentation of pairs in the method of paired comparisons. Journal of Educational Psychology, 25(5), 375-382.

Rundquist, E. A. (1950). Response sets: A note on consistency in taking extreme positions. Educational and Psychological Measurement, 10, 97-99.

Saville, P. \& Willson, E. (1991). The reliability and validity of normative and ipsative approaches in the measurement of personality. Journal of Occupational Psychology, 64, 219-238.

Scott, W. A. (1963). Social desirability and individual conceptions of the desirable. Journal of Abnormal and Social Psychology, 67(6), 574-585.

Scott, W. A. (1968). Comparative validities of forced-choice and single-stimulus tests. Psychological Bulletin, 70(4), 231-244.

Shipley, W. C., Gray, F. E., \& Newbert, N. (1946). The Personal Inventory -- its derivation and validation. Journal of Clinical Psychology, 2(4), 318-322.

Siegel, S. (1956). Nonparametric statistics for the behavioral sciences. New York, NY: McGraw-Hill.

Sisson, E. D. (1948). Forced choice - the new army rating. Personnel Psychology, $1,365-381$.

Spranger, E. (1928). Types of men: The psychology and ethics of personality. Halle: Max Niemeyer Verlag.

Sprangers, M. (1988). Response shift and the retrospective pretest: On the usefulness of retrospective pretest-posttest designs in detecting training related response shifts. $\mathrm{PhD}$ thesis, University of Amsterdam, Amsterdam.

Staff, Personnel Research Section, AGO. (1946). The forced choice technique and rating scales. American Psychologist, 1(7), 267.

Stanush, P. L. (1997). Factors that influence the susceptibility of self-report inventories to distortion: A meta-analytic investigation ( $\mathrm{PhD}$ thesis, Texas A\&M University). Dissertation Abstracts International, Section B: The Sciences and Engineering, 58(4-B), 2167. University Microfilms No. AAM97-29278.

Stephenson, W. (1952). Some observations on Q technique. Psychological Bulletin, 49(5), 483-498.

Stern, W. (1911). Die differentielle Psychologie in ihren methodischen Grundlagen. Leipzig: Johann Ambrosius Barth.

Stevens, S. S. (1946). On the theory of scales of measurement. Science, 103(2684), $677-680$.

Stevens, S. S. (1951). Mathematics, measurement, and psychophysics. In S. S. Stevens (Ed.), Handbook of experimental psychology (pp. 1-49). New York, NY: John Wiley \& Sons.

Suppes, P. \& Zinnes, J. L. (1963). Basic measurement theory. In R. D. Luce, 
R. R. Bush, \& E. Galanter (Eds.), Handbook of mathematical psychology (pp. 1-76). New York, NY: John Wiley and Sons.

Tamir, P. \& Lunetta, V. N. (1977). A comparison of ipsative and normative procedures in the study of cognitive preferences. Journal of Educational Research, 71(2), 86-93.

Taylor, E. K. \& Wherry, R. J. (1951). A study of leniency in two rating systems. Personnel Psychology, 4, 39-47.

Taylor, J. B. (1959). Social desirability and MMPI performance: The individual case. Journal of Consulting Psychology, 23(6), 514-517.

Ten Berge, J. M. F. (1999). A legitimate case of component analysis of ipsative measures, and partialling the mean as an alternative to ipsatization. Multivariate Behavioral Research, 34(1), 89-102.

Thorndike, R. L. (1942). Regression fallacies in the matched groups experiment. Psychometrika, 7(2), 85-102.

Tjoa, A. S. H. (1973). De Edwards Personal Preference Schedule (EPPS), sociale wenselijkheid, gedwongen keuze en een Nederlandse EPPS versie. $\mathrm{PhD}$ thesis, Universiteit van Amsterdam, Amsterdam.

Tucker, L. R. (1953). Selecting appropriate score scales for tests: Scales minimizing the importance of reference groups. In G. K. Bennett (Ed.), Proceedings of the 1952 invitational conference on testing problems (pp. 22-28). Princeton, NJ: Educational Testing Service.

Van den Brink, W. P. \& Koele, P. (2000). Statistiek, deel I: Datareductie (revised ed.). Amsterdam: Boom.

Van den Brink, W. P. \& Koele, P. (2002). Statistiek, deel III: Toepassingen (revised ed.). Amsterdam: Boom.

Van den Brink, W. P. \& Van Schaik, M. (1995). Verbale onzekerheidsuitdrukkingen met een welomschreven numerieke betekenis. Nederlands Tijdschrift voor de Psychologie, 50, 34-35.

Van der Ark, L. A. (1999). Contributions to latent budget analysis: A tool for the analysis of compositional data. $\mathrm{PhD}$ thesis, Leiden University, Leiden.

Van der Linden, W. J. (1994). Decision theory in educational testing. In T. Husén \& T. N. Postlethwaite (Eds.), The international encyclopedia of education (2nd ed., pp. 1416-1421). Oxford: Pergamon.

Van Geffen, L. (1980). Commentaar: Maak werk van de keuze van tests. De Psycholoog, 15(8), 468-469.

Villanova, P., Bernardin, H. J., Johnson, D. L., \& Dahmus, S. A. (1994). The validity of a measure of job compatibility in the prediction of job performance and turnover of motion picture theater personnel. Personnel Psychology, 47(1), 73-90.

Von Neumann, J. \& Morgenstern, O. (1947). Theory of games and economic behavior (2nd ed.). Princeton: Princeton University Press.

Vorst, H. C. M. (2005). Personal communication. November 17, 2005.

Vorst, H. C. M. \& Bermond, B. (2001). Validity and reliability of the Bermond- 
Vorst Alexithymia Questionnaire. Personality and Individual Differences, $30(3), 413-434$.

Walsh, J. A. (1990). Comment on social desirability. American Psychologist, $45(2), 289-290$.

Warner, S. L. (1965). Randomized responses: A survey technique for eliminating evasive answer bias. Journal of the American Statistical Association, 60, 63-69.

Waters, L. K. (1965). A note on the "fakability" of forced-choice scales. Personnel Psychology, 18(2), 187-191.

Wherry, R. J. (1938). Orders for the presentation of pairs in the method of paired comparisons. Journal of Experimental Psychology: General, 23(6), 651-660.

Wicherts, J. M. (2002). Meetequivalentie tussen penEpapier-en computerafname van vragenlijsten: Alexithymie, sociale wenselijkheid en angst. Masters thesis, University of Amsterdam.

Widaman, K. F. (1985). Hierarchically nested covariance structure models for multitrait-multimethod data. Applied Psychological Measurement, 9(1), 126.

Wiegersma, S. (1959). Belangstellingsonderzoek bij de differentiatie na de lagere school. PhD thesis, University of Amsterdam, Amsterdam.

Wiggins, N. (1966). Individual viewpoints of social desirability. Psychological Bulletin, 66(2), 68-77.

Wolff-Albers, A. D. \& Mellenbergh, G. J. (1970). A. V.L. Waardentest. Groningen: Wolters-Noordhoff NV.

Wright, C. E. (1961). A factor dimension comparison of normative and ipsative measurements. Educational and Psychological Measurement, 21(2), 433444.

Zavala, A. (1965). Development of the forced-choice rating scale technique. Psychological Bulletin, 63(2), 117-124.

Zuckerman, J. V. (1952). Interest item response arrangement as it affects discrimination between professional groups. Journal of Applied Psychology, 36(2), 79-85.

Zuckerman, J. V. (1953). A note on "interest item response arrangement". Journal of Applied Psychology, 37(2), 94-95. 